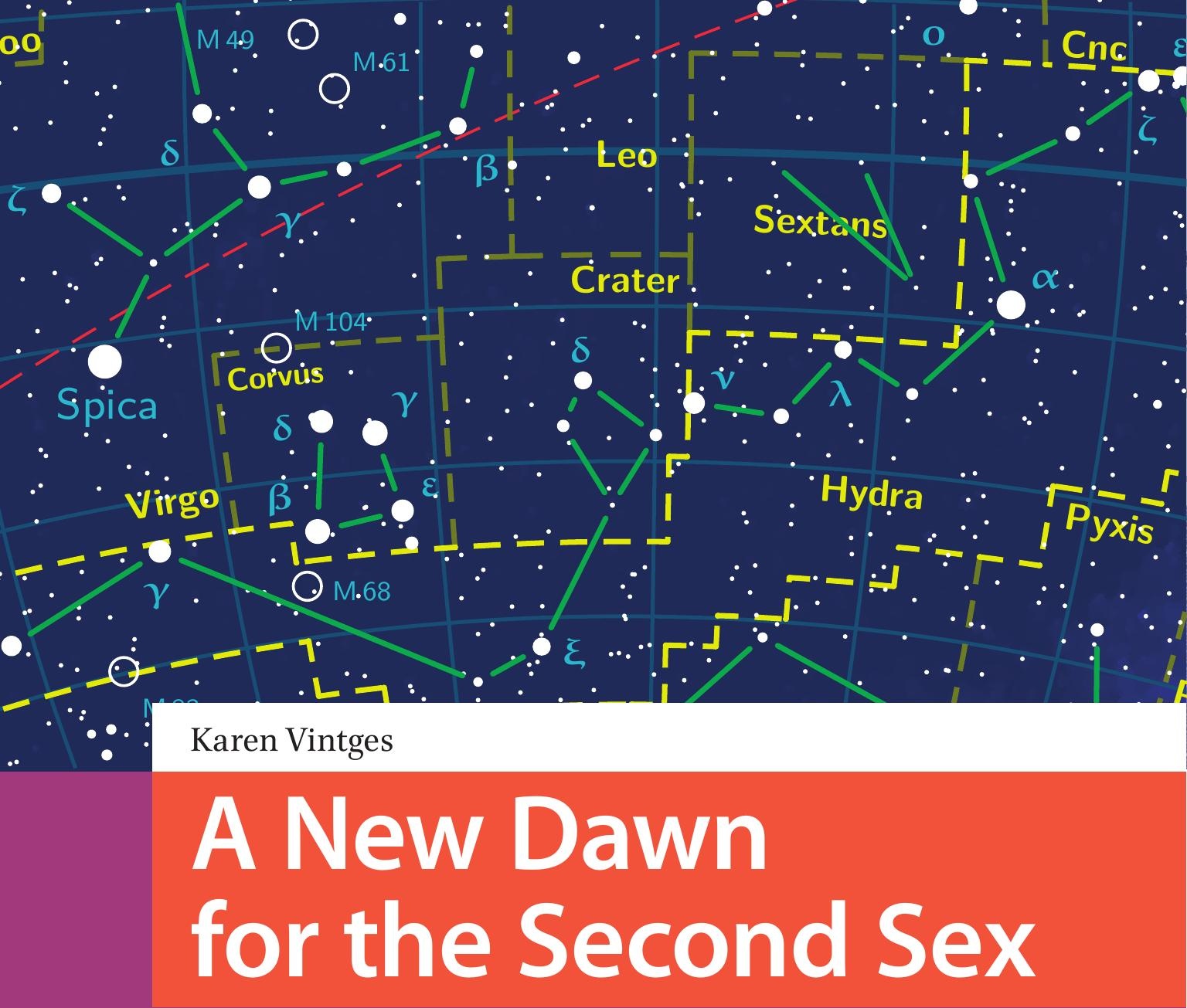

Women's Freedom Practices in World Perspective 
A New Dawn for the Second Sex 



\section{A New Dawn for the Second Sex}

Women's Freedom Practices in World Perspective

Karen Vintges 
Cover illustration: Hydra Constellation Map; courtesy of Torsten Bronger

Cover design: Coördesign, Leiden

Lay-out: Crius Group, Hulshout

Amsterdam University Press English-language titles are distributed in the US and Canada by the University of Chicago Press.

$\begin{array}{ll}\text { ISBN } & 978 \text { 90 } 89646026 \\ \text { E-ISBN } & 9789048522279 \text { (pdf) } \\ \text { DOI } & 10.5117 / 9789089646026 \\ \text { NUR } & 740\end{array}$

(c) Karen Vintges / Amsterdam University Press B.V., Amsterdam 2017

All rights reserved. Without limiting the rights under copyright reserved above, no part of this book may be reproduced, stored in or introduced into a retrieval system, or transmitted, in any form or by any means (electronic, mechanical, photocopying, recording or otherwise) without the written permission of both the copyright owner and the author of the book.

Every effort has been made to obtain permission to use all copyrighted illustrations reproduced in this book. Nonetheless, whosoever believes to have rights to this material is advised to contact the publisher. 
To Vera 
'I think that the ethico-political choice we have to make every day is to determine which is the main danger' - Michel Foucault

'The Gods have their twilight, the heroes are forgotten; but though mythology has been a passing phase in man's mental history, the epic lives on' - Susanne Langer 


\section{Contents}

$\begin{array}{ll}\text { Acknowledgements } & 9\end{array}$

Introduction 11

1 Women's Freedom Practices 21

2 Women's Freedom Practices in World Perspective 59

3 Muslim Women's Freedom Practices 95

4 The Battle of Myths $\quad 129$

5 Feminism in a New Key $\quad 165$

$\begin{array}{ll}\text { Bibliography } & 175\end{array}$

$\begin{array}{lr}\text { Index } & 191\end{array}$

\section{List of Illustrations}

Anna Maria van Schurman: Self-Portrait (1640) 55

Emma Goldman (c. 1910) $\quad 57$

$\begin{array}{ll}\text { Betzy Akersloot-Berg: Shipwreck (1893) } & 79\end{array}$

$\begin{array}{ll}\text { Pandita Ramabai Sarasvati (1858-1922) } & 79\end{array}$

Poster 'Raw Deal' (2013) 124

Forged-Iron Cooperative, Morocco (2008) 127

$\begin{array}{ll}\text { Lady Foucault (2011) } & 135\end{array}$

FKA Twigs live in Paradiso, Amsterdam (2015) 162 



\section{Acknowledgements}

Time is scarce in academia. All my gratitude goes to the Netherlands Organisation for Scientific Research (NWO) for funding the research project 'Women and Islam: New Perspectives 2008-2013', as part of the broader NWO Research Program 'Cultural Dynamics'. Participants in the research project are co-applicant Marjo Buitelaar, Moroccan partners and $\mathrm{PhD}$ supervisors Moha Ennaji and Fatima Sadiqi, PhD supervisors Ruud Peters and Hetty Zock, and PhD students Fatima Ballah and Aziza Ouguir. I thank all of them, for sharing their knowledge, experience, and friendship with me.

I especially thank my students at the University of Amsterdam for sharing with me their insights, critical comments, and fun, and my colleagues at the University of Amsterdam for their scholarly advice and support; in particular, Huub van Baar, Roosmarijn Bakker, Maarten Coolen, Anja van Heelsum, Marie-Louise Janssen, Victor Kal, Mariwan Kanie, Annelies Kleinherenbrink, Annelies Moors, Federica Russo, Matthé Scholten, Bert van der Schoot, Gerard Wiegers, and Tamar de Waal. I also thank my colleagues in the Philosophy and Public Affairs group of the Department of Philosophy: Robin Celikates, Gijs van Donselaar, Yolande Jansen, Thomas Nys, and Beate Rössler.

I am indebted to many other colleagues; in particular, Janet Abbey, Asma Barlas, Edien Bartels, Marriëtte van Beek, Souad Eddouada, Sandra Harding, Lynne Huffer, Willy Jansen, Norah Karrouche, Ziba Mir-Hosseini, Elizabeth Shakman Hurd, Hans Radder, Siep Stuurman, Dianna Taylor, and Merieme Yafout, and especially to my Beauvoir colleagues Margaret Simons and Nancy Bauer for support and inspiration.

Many thanks as well to Al Nisa, in particular, Ceylan Weber and Leyla Çakir; the Moroccan Women's Association Netherlands, in particular Ikram Chiddi; Project Zina/De Balie, in particular, Elly Ludenhoff; NIMARinstitute, especially Jan Hoogland and Cynthia Plette; and Hivos, especially Ireen Dubel.

Of many other important people, I mention here: Agaath Homminga, Tineke de Jong, Eloe Kingma, Hotze Mulder, Benjamin Rous, Lenny Vos, and Marijke de Wit - for their professional support; Khadija El Mourabet and Rajae el Mouhandiz - Rajae especially for sharing her music in a documentary on our research project 'Moroccan Women Today: New Perspectives'; Torsten Bronger for allowing me to use his hydra constellation map for the book cover; Marjan Brouwer of Franeker Museum Martena for providing me with a copy of the self-portrait of Anna Maria van Schurman; Elsje de 
Ruijter of Museum Tromp's Huys at Vlieland for providing a copy of the painting by Betzy Akersloot-Berg; and Joseph Guillermo for allowing me to use the figure of 'Lady Foucault.'

I thank the students of the 'feminist-alcoholic-collective' for teaching me about feminism again - especially Heidi Dorudi for sharing her knowledge of Iran, Harriet Bergman for teaching assistance, Nathalie Janssen for technical and enthusiastic support, and Jolien Spigt for sharing her feminist media sites. My thanks as well to Ton Dekker for lucid feedback and English expressions; Jeannette Bloem for pondering over metaphors; Maryn Wilkinson for guiding me through feminist media studies; Nuria Andreu for inspiration and fun in planning and producing the documentary Moroccan Women Today: New Perspectives; the boards of the IAPh and the Society for Women in Philosophy.NL; Platform H.NU and colleagues and students united in the Dutch new university movement for reclaiming our universities as places of inspiration.

Finally, my special gratitude goes to the University of Amsterdam, for allowing me a sabbatical semester, and to Ineke van der Burg, Annemie Halsema, Yolande Jansen, Michiel Leezenberg, Veronica Vasterling, and my publisher Saskia Gieling, for astute comments on chapters of the manuscript. All mistakes in the final text are mine.

Portions of Chapters 1 and 2 are based on: Vintges 2004a, 2005, 2007, 2011, 2012, and Vintges forthcoming. Chapter 3 synthesizes the results of the project 'Women and Islam: New Perspectives'. Part of Chapter 4 is based on Vintges 2013. 


\section{Introduction}

In her study The Second Sex, published in French in 1949, Simone de Beauvoir brings to light the second-class status of women in history. According to her, women were always ruled by men and exclusively defined in their relation to them. She concludes, however, that things for women will turn out for the better thanks to their access to contraception, work, and education. 'The free woman is just being born,' she announces, thus picturing women as subjects on the move (Beauvoir 2010: 767).

Today, women all over the world are climbing the social, educational, and economic ladder. They are entering influential positions on all continents, as presidents and political leaders, managers, scholars, and teachers, and undertake risky ocean voyages and mountain expeditions. It has become obvious: women can do anything. A new dawn seems to have broken for them. As mainstream opinion holds, it is only a matter of time for women's liberation to be completed.

However, over the last couple of years, some of my female students at the University of Amsterdam started to counter this view, telling me that the situation for women 'is far worse than you think it is.' And, by way of another example from my own experience as a Western, white, university teacher (and here I follow one of philosophy's methods of starting from the bottom up, from one's own experience): why are there only six women among the 40 students enrolled on the Research Master's program, while $5^{\circ}$ per cent of the students in my - predominantly white - department are women? Of the - again, mainly white - full professors in the Netherlands, only 17 per cent are women. In the areas of economics and politics, inequality between men and women in positions of power is standard, as is the case in other countries in the West, a part of the world that is commonly believed to have achieved the goals of feminism. Could it be that, after all, women's brains are less fit to participate in the upper ranks of these areas, as some scientists claim today? Or are women still discriminated against, albeit in subtler and less obvious ways? Or could it be that women are unwilling to step out of their 'comfort zone'? And yet another possibility: are women perhaps resisting the prevailing models of successful personhood?

Male dominance in the domains and ranks of society where crucial decisions and big money are at stake endures the world over. Power asymmetries between men and women still manifest themselves in many other ways. The number of women living in poverty is disproportionate to the number of men, and women earn less than men at all levels. Sexual violence 
against women and children continues everywhere, and has taken on new, extreme forms such as a global trafficking in women from poor to wealthier countries, 'jihadists' forcing captured women into sex slavery and 'lover boys' luring and blackmailing underage girls into prostitution through social media.

In The Second Sex, Beauvoir aims to grasp the hidden currents of her time, discussing and integrating social developments and scientific results in a synthesizing view - as is the task of social philosophy. She concludes that 'patriarchy' (literally, the rule of the father) will not come to an end by legal or economic changes alone, but that 'institutions, customs, public opinion and the whole social context,' have to change for men and women to become equal. Until these new economic, moral, social, cultural, and other consequences take place, 'the new woman cannot appear' (777). Summing up all of these consequences, Beauvoir implies that 'patriarchy' has many dimensions. From her argument, we can distill the image of patriarchy as a many-headed monster, with a legal 'head', next to a moral, economic, institutional, and social one, each representing practices that should be replaced by other social practices. Only then will women's positions definitely change; only then will women no longer be 'torn between the past and the present' (777). The image of patriarchy as a many-headed monster not only captures the multi-faceted character of patriarchal patterns, it conveys, too, that different 'heads' of the monster can dominate in different settings, requiring different strategies of attack. ${ }^{1}$ Women's experiences with patriarchy's - often ugly - faces differ through time and place, demanding a variety of strategies.

The image also allows us to question the standard view in the West that feminism is no longer necessary, except as an export product to rescue women from 'other cultures'. Contra this standard view, is 'patriarchy'

1 Yvonne Benschop and Marieke van den Brink (2012) use the metaphor of a seven-headed dragon to characterize the multifaceted gender inequality practices that exist in Dutch academia. In their analysis of women's discrimination in several disciplines, they conclude that different gender inequality practices are salient in each context, requiring a variety of gender equality measures. No one-size-fits-all- approach will do: 'there are simply too many heads on the dragon, and each requires a specific attack' (89). Informal scouting practices in the medical sciences for professorships need to be countered by a more open way of recruitment. In the humanities, 'the exclusionary effect of masculine information and support systems affects women candidates in all phases of the appointment process,' tendencies that should be countered by strategic alliances between women candidates and men in decision-making positions (Benschop and Van den Brink 2012: 87). In the natural sciences, selection processes ultimately question and measure women's qualities against a masculine standard. An effective measure here is the inclusion of female members of appointment committees (88). 
perhaps like a waterbed, when pushed down in one place, rising in another? Or returning to our image of the monster, does patriarchy rear new 'heads' when one is cut off? When its legal head is slayed, does it perhaps grow others, in different domains? In this sense, are we dealing with a hydra?

As Greek mythology tells us, the divine hero Heracles had to perform twelve labours in order to save himself, the second labour being the killing of the so-called Lernaean hydra. This serpent-like monster had many heads, one of them immortal. Heracles first smashed off all other heads, with the help of his nephew Iolaus, who burnt the wounds with a torch thus preventing the growth of new heads. Heracles then lifted the monster in the air, bashed off the last immortal head and buried it. After its defeat, the goddess Hera placed the hydra amongst the stars, turning it into a constellation (cf. the book cover). From the myth of the hydra we may ask ourselves whether patriarchy, too, has an 'immortal' head. Could it be that it yet has to be slayed and that, until then, it will continue to grow new heads? The story of the hydra suggests that defeating the monster is only possible in a joining of forces. Can 'feminism' be re-articulated again as such a joint project?

Currently, 'feminism' is an essentially contested concept. Women from the Middle East, Asia, Africa, and Latin America, have developed strong movements for women's empowerment and rights. To many, however, 'feminism' is an integral part of the (formal and informal) imperialist strategies of the West and, in that sense, is synonymous with Western colonialism. African-American women, in a similar vein, have criticized 'feminism' for representing the prism of privileged white women, who are part of the problem instead of the solution. For these reasons, many postcolonial thinkers keep their distance from the political language of feminism.

However, the Moroccan women I have met in recent years taught me this political language again. From our cooperation in a research project, I learned that postcolonial thinkers are sometimes too critical in throwing away the categories and ideas that feminism is based on. Many Muslim women use the phrases 'women's issues' or 'gender justice', instead of 'feminism'; but 'patriarchy', 'women's oppression', and 'women's rights' are concepts that women from all backgrounds in Morocco use, including women from Islamist organizations. Rather than doing away with feminism, I take from their - multiple - voices the necessity of 'decolonizing feminism', i.e. of its critical reformulation in world perspective (cf. Connell 2009; Rhouni 2010).

In yet another sense, such a reformulation seems necessary. The standard view of feminism in the West holds that everything is already settled, but 
for some minor issues. One of these issues is that girls and women do not equally participate in the labour market, allegedly due to some remaining obstacles and to women and girls not being angry and eager enough to compete for jobs, let alone for long-hours careers. State and market organizations try to remove these obstacles and stimulate women to seek full-time employment. Without questioning the current division of paid labour and care work, women are supposed to enter the job market on male terms under the banner of the values of feminism.

My worries about this type of state-and market-feminism only increased when, some time ago, I was invited by a group of Dutch female professionals to join a brainstorm meeting on how to raise a new 'feminist movement' in the Netherlands. Among them were a few parliamentarians, a highranking police officer, and a trade union leader, all of whom sympathetically exchanged their experiences of being lonely at the top'. I remember a conversation on the road to Rotterdam with one of these professionals, who, by that time, was an employee of a prestigious management consulting firm. Why had I not understood a word she said? And why did I leave the meeting without any of the enthusiasm I had originally felt? I did write an introduction to the first magazine of the new movement, on how feminism today was more practical than ideological, but the title of the new movement made it clear to me why I had felt uncomfortable: it was called 'Women Inc.'

What had puzzled me was was the idea of a new feminist movement being an enterprise. ${ }^{2}$ Women Inc.'s activities and aims are mainly about enhancing women's 'employability' in the labour market. Women from all cultural backgrounds (Inc. meaning not only incorporated, but also inclusive) are mobilized through, among other things, festivals with a range of events, such as lingerie shows, workshops for kick boxing or pole dancing, and panels on topics such as health and money. Partly subsidized by the state, Women Inc. is an organization that exemplifies the rise of state- and market-feminisms that use the channels and mechanisms offered by the market to promote gender equality (cf. Kantola and Squires 2012). How should we evaluate these current feminisms? Has 'feminism' been confiscated as a political term to the extent that its meanings range from

2 Women Inc. today has over 16 employees who function as program makers, project leaders and coordinators. It is financed by the Ministry of Education, Culture and Science, local governments, organizations and foundations. It has worked for the Ministry of Education, Culture and Science, The Ministry of Internal Affairs, Delta Lloyd, ABN AMRO bank, Hurkmans Consultancy, Microsoft, and several other companies, as well as several local governmental institutions. 
'the invasion of other countries' to 'shopping, pole-dancing, even eating chocolate' (Power 2009: 12, 27)?

Maybe it is no coincidence that, in recent years, interest in the work of Beauvoir has grown. ${ }^{3}$ Her 8oo-page study The Second Sex generally counts as the founding text - or 'exemplar' - of contemporary feminism (cf. Vintges 1998). Are people perhaps interested once more in the ideas and ideals of 'original' feminism? Should we return to its initial meanings and reclaim the notion versus its current confiscations? But what does it stand for, and how do we distinguish it from its current mainstream versions? The present study aims to answer these questions as well as to articulate some inspiring guideposts for change (cf. Taylor 2004).

In order to push the critical perspective offered by Beauvoir's theoretical work, some concepts from the work of Michel Foucault will be introduced in this study. His mid- and final works provide important clues to update Beauvoir's stances on who women are today -an issue that Foucault himself did not address, but which is the main theme of the present study. Especially his final work offers some concepts that enable us to revitalize Beauvoir's notions of politics and ethics, allowing for a critical reformulation of feminism in world perspective.

\section{Outline}

Building on the theories of Foucault and Beauvoir, the present study is anchored in current academic debates as well as in the original vocabulary of contemporary feminism (cf. Vintges 1998). The first chapter discusses both Beauvoir's and Foucault's critiques on current 'neoliberal' models of self and society, and distills from their work a theoretical toolset that fits a culturally plural, global feminist perspective. The chapter argues that Foucault's final work on ethics exhibits some striking similarities with Beauvoir's perspectives as developed in her essay The Ethics of Ambiguity (1948), which allow us to synthesize (the best elements of) their approaches in a concept of 'freedom practices'. The latter concept will be defined in terms of five core characteristics in order to specify it as an analytical tool. From this approach women's 'freedom practices' i.e. their critically creative ethical life projects, become visible, several of which will be sketched at the end of the chapter. 
Chapter 2 discusses the culturally plural character of the concept of freedom practices as distilled from the works of Foucault and Beauvoir. It argues that the concept comprises a culturally plural notion of an embedded ethical self that surpasses notions of moral autonomy. The concept, moreover, is culturally plural in yet another sense, in that it comprises cultural repertoires in addition to verbal ones. Building on the concepts of Susanne Langer (1960), women's freedom practices are articulated as comprising several 'keys', especially the 'presentational forms' of rite, art, and myth, alongside verbal language. From its culturally plural character, the concept of freedom practices in principle allows for a critical reformulation of feminism in world perspective. Against dominant readings of Beauvoir's exemplary text, The Second Sex, I will argue that this work supports a critical reformulation of today's mainstream feminism. Re-reading The Second Sex through the lens of Beauvoir's The Ethics of Ambiguity, the work's culturally plural perspective comes to the fore. Moreover, many of The Second Sex's analytical concepts turn out to be still relevant in the light of new theoretical, scientific findings and current social and political developments. The work also gives us a clue to specify what is the 'immortal' head of the patriarchal hydra today. The chapter ends by sketching some examples of women's freedom practices in world perspective.

Chapters 3 and 4 elaborate concrete examples of women's freedom practices that oppose the different faces of the hydra's 'immortal' head, in various 'keys'. Chapter 3 discusses examples of Muslim women's agencies and freedom practices, both past and present, in the domain of religion, in a synthesis of the research project 'Women and Islam: New Perspectives'. The chapter draws on the work of its participants, especially on the dissertation of Aziza Ouguir that examines the legendary stories on the lives of Muslim women saints in Morocco's past (Ouguir 2013); on Fatima Sadiqi's and Moha Ennaji's work on Moroccan feminism; and on Marjo Buitelaar's research on Dutch Moroccan women's life stories. It also presents the work of Muslim women scholars who have uncovered the Qur'an's gender egalitarian message. Finally, the chapter discusses some of the conditions of Muslim women's lives in the West as well as a few examples of cross-cultural feminist media strategies.

Chapter 4 presents several freedom practices of women and girls that oppose patriarchy's 'immortal' head in the West. As a social philosopher, trained to elucidate social patterns in 'the multiplicity of forms', it took me some time to specify patriarchy's dominant faces in this context. Moroccan 
colleague Fatima Sadiqi handed me an important clue telling me that 'while we as women in the Arab world are oppressed via space, you Western women are oppressed through the image' (Sadiqi 2013). Another part of the answer was handed to me by Beauvoir's chapter on myths in The Second Sex, the studies of British feminists Angela McRobbie (2004) and Rosalind Gill (2008) and by Camille Paglia's study Sexual Personae (1990). I will specify the contours of patriarchy's immortal head in the West in a discussion of current Hollywood films, especially The Twilight Saga, four books and five films that in recent years created a 'global hype' (Bucciferro 2013).

A concluding chapter evaluates the extent to which we are witnessing a new dawn for women and the extent to which Beauvoir's study The Second Sex is still relevant to our times and deserves a new dawn as well. Contra mainstream feminism in its colonial, state, and market versions, a 'feminism in a new key' will be articulated, consisting of women's culturally plural freedom practices, each hunting the hydra in their own contexts and 'keys' - with mutual support.

The reader who is primarily interested in the thematic content of this study should skip the following section on its methodological backgrounds.

\section{Method}

Postcolonial authors rightly argue that Western philosophy should revise its concepts and perspectives in the context of our globalized world. Foucault hinted at this as well, when he said: 'European thought finds itself at a turning point. This turning point, on an historical scale, is nothing other than the end of imperialism. The crisis of Western thought is identical to the end of imperialism' (Foucault 1999: 113). He added that there is not yet a philosopher 'who marks out this period. For it is the end of the era of Western philosophy. Thus, if philosophy of the future exists, it must be born outside of Europe, or equally born in consequence of meetings and impacts between Europe and non-Europe' (113).

In my view, Foucault can be counted as a philosopher who developed some critical notions for a philosophy of the future. Using ancient Greek ethics, i.e. a pre-modern era, as a stepping stone, he came up with a new concept of freedom in contrast with the dominant Western ones of individual autonomy and authenticity. I take his concept of 'practices of freedom' as a serious contribution to the postcolonial project of developing concepts that account for diversity and different cultural settings. As a consequence, 
new political and normative perspectives emerge, with some remarkable similarities to Beauvoir's ideas, updating her views in a timely manner.

But what about Beauvoir's 'grand theory' of patriarchy from a Foucauldian approach? Foucault was opposed to 'total' theories of society. To him, history and society are too complex to be covered by one 'totalizing approach' (Foucault 2003: 6). Societies consist of various and dynamic patterns of power one Logic cannot account for. All-encompassing theories, moreover, have inhibiting effects, putting brakes on discontinuous, particular, and local critiques.

Rather than covering the development of societies via one central concept, as grand theories do, Foucault argues for a variety of analytical tools to capture concrete patterns of power in history. At the background of his methodological concern is what William Walters (2012) calls Foucault's 'patchwork' conception of society (Walters 2012: 78). Foucault's analyses of dominant power practices (for instance, current 'neoliberal governmental' ones - see Chapter 1) should never be taken as a new grand theory of society and socio-cultural change, as Huub van Baar (2011) and Stephen Collier (2009) argue. Walters (2012) interestingly introduces the concept of 'polytemporality' in this respect. We should 'grasp the contemporary as a rather polytemporal state of affairs [...], a time combining multiple political techniques and styles of government, not all of which cohere or answer to a single logic of development' (Walters 2012: 10, cf. 40).

Dominant patterns of power thus exist in combination with others from different times and from different descent, contradicting or overlapping each other, or converging into new assemblages. 'Genealogical' research should track and trace these power patterns by 'studying upwards' and finding out what their nodal points are - decisive for who we are today. However, I would like to draw attention to the fact that, according to Foucault, grand theories do make sense. After discussing 'the inhibiting effect specific to totalitarian theories,' he adds: '(n)ot that all-encompassing and global theories haven't, in fairly constant fashion, provided - and don't continue to provide - tools that can be used at the local level; Marxism and psychoanalysis are living proof that they can' (Foucault 2003: 6). In the words of Foucault, analytical work 'cannot proceed without an ongoing conceptualization,' but this conceptualization 'implies critical thought - a constant checking' (Foucault 2000: 327, quoted in Walters 2012: 42).

A 'genealogical' approach can take in grand theories, since strong patterns need strong theories, but it discloses these patterns in their entanglement with other power practices. Total theories have 'provided tools that can be used at the local level only when, and this is the real point, the theoretical 
unity of their discourse is so to speak, suspended, or at least cut up, ripped up, torn to shreds, turned inside out, displaced, caricatured, dramatized, theatricalized, and so on' (Foucault 2003: 6). Beauvoir's grand theory of patriarchy, which involves a single logic of development of human history, should equally be torn and cut up, and be re-articulated as a set of analytical tools that allow us to study patterns of patriarchal power in their current various configurations, in 'a constant checking.' To paraphrase Laura Nader (2008), we should study upwards, and downwards, and sideways simultaneously - an approach that can be re-interpreted as well as an intersectional one (cf. Harris 2015). ${ }^{5}$

Finally, from Foucault's analysis of the entanglement of science and normalizing power practices, we can learn that it does not take long for scientific results to be adopted in government policies and procedures. In the process of trying to get funding for a research project employing Muslim women's own perspectives, I received an email of a Dutch-Moroccan woman activist asking me what the heck I was thinking. Muslim women in the Netherlands are very suspicious of questionnaires and other top down survey research, and rightly so. As Foucault formulated it, 'visibility is a trap' (Foucault 1979: 200). Science reports classify people and are often used to intervene in their lives in controlling, social engineering ways (cf. Spivak 1988).

Foucault's analysis of the entanglement of power and knowledge, however, did not stop him from doing concrete research, nor from developing theoretical concepts and toolsets. His work aims to uncover what he calls 'subjugated knowledges': types of knowledge that are disqualified as insufficiently elaborated, non-scientific and naive. At stake are knowledges from below' that deserve to be revealed by using the tools of scholarship (Foucault 2003: 7). What makes critique possible at all is exactly 'the reappearance of what people know at a local level, of these disqualified knowledges' (8). In a similar vein, the present study aims to uncover women's and girls' subjugated knowledges, which deserve to be revealed instead of disqualified and marginalized, as repertoires of critique and creative transformation of dominant models of self and society.

Walters (2012) discusses Foucault's approach to scientific research in terms of map making, referring to Foucault's own ironic description of himself as a cartographer (Walters 2012:141). He adds that 'there is nothing innocent about cartography' since maps 'erase as much as they reveal' (142). As Ronald Giere (2006) argues, cultural background, conventions of map

5 Nader (1969) launched the concept of 'studying up' for doing fieldwork among the powerful rather than the powerless. I therefore use the term 'studying upwards.' 
making, and the designation and specification of what features are mapped, all determine 'a perspective from which the region is mapped' (Giere 2006: 75). ${ }^{6}$ However, we can and should discuss our maps in order to make better ones. This is what academics do, in reference to the world and to other theories, i.e. earlier map making. And this is what demarcates academic work from other social power practices or language games, such as literature, poetry, religion or spirituality. If there were a definition of academic work at all, I would prefer it to be: the art of accountable map making.

6 While Giere (2006) mainly refers to scientific 'models' in terms of representational maps, other authors apply Giere's scientifc perspectivism to scientific theory as such. With thanks to Hans Radder. 


\section{$1 \quad$ Women's Freedom Practices}

Simone de Beauvoir (1908-1986) is the author of an extensive oeuvre. Apart from The Second Sex, a series of autobiographies, a play, some philosophical articles and reviews, and a voluminous study on the position of old people throughout history, she wrote philosophical novels, a genre that gave her the opportunity to express her ideas about human existence in a non-academic form. In most of her novels she outlines, in indirect ways, her philosophical concept of an ethical self in contrast to other models of personhood - as is the scheme of Les belles images.

Laurence, the central character in the novel Les belles images - published in French in 1966 - is an advertising manager immersed in a world of 'pretty pictures.' We meet Laurence as she broods over a slogan to sell wooden panels, going through recent psychological surveys and questionnaires that once more show that people want 'novelty, but with no risk' (Beauvoir 1968a:36). Laurence knew her job: 'I am not selling wooden panels: I am selling security, success and a touch of poetry into the bargain' (20). In addition to being a career woman with developed market skills, she is successful in her personal life as well, with an affluent architect husband, two daughters, a lover on demand, and a family house in the country. All seems to be well: '(e)verything was clear, fresh, perfect: the blue water in the swimming pool, the opulent sound of the tennis-balls, the sharp white rock of the peaks, the rounded clouds in the smooth sky, the smell of the pines' (19). But cracks begin to show.

\section{Super Woman and Organization Man}

'Every morning when she opened her shutters Laurence gazed at a splendid glossy photograph' (19). Being an advertising specialist, 'she knew too much about how a set was put together - it fell to pieces under her eyes' (91). Laurence increasingly feels like the king who turned everything he touched into gold: '(e)verything she touched turned into a picture' (18), including her daughter Catherine.

Laurence had always been a pretty picture herself, a 'faultless child, an accomplished adolescent, a perfect young woman,' 'so clean-cut, so fresh, so perfect' (19). But Catherine suddenly starts to ask difficult questions, about why people are poor and why there is war in the world, and she cries at night in her sleep. Pressed by family members, Laurence arranges for her 
daughter to see a psychologist. Catherine is advised to break contact with a new girlfriend, who worries too much about 'sad things' in the world (67). Laurence, against the will of her family, ignores the expert advice. Raised as socially unaware, she wants a different life for her daughter.

According to Mario Vargas Llosa, Les belles images contains a critique of people's alienation in modern, consumerist society. The work describes the depersonalization of human beings and their subtle transformation into robots (cf. Vargas Llosa 1996: 56-57). To Irène Pagès (1975), Les belles images deals with an attitude of absence and a flight from everyday existence (Pagès 1975: 133). However, the main characters in the novel, rather than coming across as depersonalized robots or absent minded people, present as individuals who are highly invested in their own daily lives. Les belles images shows us a deep modification of the modern subject, rather than the end of man. It shows us a new - increasingly global - model of personhood: the subject of a society of (risk) management, who is a risk-averse executive in work and life, focused on status and success and, above all, security.

In her novel, Beauvoir sketches the Americanized way of life of the Parisian upper class in the 196os. She does so along the lines of William Whyte's 1956 bestseller The Organization Man, to which she repeatedly refers in her autobiography. ${ }^{1}$ According to Whyte, the American way of life in the 195 os had become a life under the protection of organizational planning. As corporations increasingly bureaucratized, in their pursuit of success, security, and safety, these norms spilled over into American society at large. At stake is a collective organization of the American population by planned thought and calculative action with the help of the social sciences. Whyte analyses the science-based social engineering of people's life and work, and focuses especially on 'the personal impact that organization life has had on the individuals within it' (Whyte 1956:4).

According to him, modern society's bureaucratization, as analysed by Max Weber, has most poignantly affected the United States (cf. 5), since it went together with a new ideology, holding that the ends of organization and morality coincide and that science-based techniques can lead to a finite, achievable harmony (cf. 8). The Organization Man has internalized this ideology. As 'the man of success', he is actively participating in, and endorsing, a corporate society that he instead should resist. Look at the growth of business administration courses at universities, Whyte concludes with horror; look at the new suburbia, these dormitories where Organization

1 Authors of the Foucauldian 'governmentality school' discussed later in this Chapter as well refer to Whyte's famous study The Organziation Man published in1956 (cf. Miller and Rose 2008: 119). 
Man lives. And see the growth of personality testing. Pointing out how psychological experts are involved in the making of organization man, Whyte aptly concludes his book with an appendix entitled 'How to cheat on personality tests.'

Beauvoir claims that in her travel account America Day by Day (1999), published in French in 1948, she had already reached similar conclusions on the American way of life: 'no one, as far as I know, was talking about the organization man yet; but that was whom I described in my reports' (Beauvoir 1968b:132-133). She specifies that she was struck by how even very young boys and girls employed only the abstract measure of money (cf. 133). Whyte's study shows that America has become 'essentially a consumer society [...] measuring value by success' $(385)$ - with people living in suburbs where space, air, light and order prevail, and where the world is one big 'kitchen garden' (439).

In her novel Les belles images, we also encounter Organization Man, who measures his worth in terms of status, success, and safety. Laurence's father and her husband - who calls himself a 'feminist' - are convinced that technical organization will change all societies for the better: the 'gap between the capitalist and socialist countries will soon be done away with' (Beauvoir 1968a: 11). The world will form a single entity and men will no longer suffer: 'thanks to synthetic proteins, birth control, automation, and atomic energy it was reasonable to think that by about 1990 the civilization of abundance and leisure would be in existence' (61).

The main female characters, Laurence and her mother, 'design' their lives by organizing and safeguarding their consumption patterns, status, and success. Guaranteeing themselves a marital status is a necessary ingredient to their safety, since - as Laurence's mother expresses it, '(s)ocially a woman without a man counts for nothing' (119), a woman without a man is 'a half-failure, a kind of derelict' (120). Laurence needs her family around her as a 'cocoon,' alongside her career and luxurious life-style, and is keen 'to prevent anything breaking in upon this security' (38). The female characters in the novel represent the 'woman of success,' i.e. Organization Woman.

2 To the sociologist Max Weber mentioned by Whyte, bureaucracy was a necessary element of modern society. Weber famously concluded that: 'once it is fully established, bureaucracy is among those social structures which are the hardest to destroy' (Weber 1968: 987). In contrast, Whyte optimistically argues that if 'organization has been made by man; it can be changed by man' (Whyte 1956:14). A new balance between individual and organization is needed. To Whyte, we need to know 'how to cooperate with The Organization but, more than ever, so do we need to know how to resist it' (13). Whyte concludes that education is central to the problem (cf. 447) and that a revitalizing of the humanities is decisive (cf. 106-107, 109). 
In Beauvoir's posthumously published novella Misunderstanding in Moscou (2011), probably dating as well from 1966 (cf. Keefe 2011), we come across another example of the Organization Woman. As one of the characters in the novel expresses it:

She's the "super woman" type (femme totale). [...] There are a lot like that in Paris. They have some sort of career, they claim to dress well, to engage in sports, look after their house perfectly, bring up their children very well. They want to prove to themselves that they can be successful at all levels. And, in fact, they spread themselves too thinly, they succeed in nothing (Beauvoir 2011: 226).

The Super Woman type also appears in Beauvoir's novel The Woman Destroyed (1971), published in French in 1967. These women claim to 'succeed on every level. And they don't really care deeply about anything at all' (Beauvoir 1971: 19).

In Les belles images, Super Woman's way of life, with her focus on personal success and safety in all domains of life, is contrasted by Beauvoir with another way of life that is about friendship and a concern for others. The selfregarding lifestyle of Super Woman Laurence is contrasted with the voice of her former teacher, who told her '(s)ay what you think' (Beauvoir 1968a: 31); '[f] orm your own opinion' (37); and: '(i)t will depend upon us whether these deaths [of the past wars] were useless or not' (22). Laurence finally decides that, rather than enclosing her daughter in a world of beautiful pictures, she should allow her to experience the real world and get involved with other people. She concludes: '(n)ot Catherine. I shan't let what has been done to me be done to her. What have they made of me? This woman who loves no one.' Her daughter won't be deprived of her girlfriend, and is not going to see the psychologist any more. She maybe then 'will get herself out of it. Out of what? Out of this night. Of ignorance, of uncaring' (152).

For a better understanding of the contours of this more 'caring' way of life, we must turn to Beauvoir's essays on ethics, especially to The Ethics of Ambiguity (1948).

\section{An Ethics of Ambiguity}

Together with the existentialist philosopher Jean-Paul Sartre, Beauvoir always opposed abstract morality: both view moral maxims or dogmas as false universalities. In her essay The Ethics of Ambiguity (1948), published 
in French under the title Pour une morale de l'ambiguïté (1947), Beauvoir explains why she believes this is the case, and how, instead, we should conceive of ethics as always radically situated.

She starts her essay by pointing out 'the ambiguity' of our human condition: as human beings we are a 'thinking reed.'3 We experience ourselves as consciousness, but also as a body, 'a thing crushed by the dark weight of other things' (Beauvoir 1948: 7). For this dualist approach she refers to Sartre's study Being and Nothingness (2001), published in French in 1943 (cf. 10-12). In this work, Sartre argues that, in contrast with 'immanent beings' or things in the world, human consciousness is always at a distance of being. It acts, so to speak, as a spotlight that discloses 'being', 'transcending' it instead of coinciding with it. Since human consciousness involves this distance by definition, it is devoid of any content or 'being'. We are, therefore, free by definition, or as Sartre has it, we are 'ontologically' free, but we experience this as emptiness and 'lack' of being. To compensate for this lack we seek the recognition of others of ourselves as 'being' a consciousness. But, according to Sartre, this is impossible, since our perception of our fellow humans turns them into things as well, or - vice versa - we turn into a thing under their gaze. There will always be enmity and struggle between consciousnesses, according to Sartre, about who looks and who is looked at: the first remains a - lonely - consciousness, the second becomes a bodily thing in the world, not only for the other but for himself as well, since he petrifies under the gaze of the other.

After a brief introduction to Sartre's mind-body dualism in Being and Nothingness, Beauvoir's essay sets off in another direction. While many philosophies have tried to hide the 'tragic ambiguity' from which we suffer (7), we have to accept it, and precisely by doing so we can surpass it. If we assume our ambiguity by an ethical 'conversion' (13), we accept our freedom: instead of 'wanting to be,' we are 'wanting to disclose being' (12). We then exactly coincide with who we are. Wanting to disclose being, we experience ourselves as 'the positive existence of a lack' (57, cf. 13; cf. Langer 2003: 94). We take upon us that we have to disclose the world in concrete projects, and realize our existence as presence in the world, in the shape of an 'engaged freedom' (Beauvoir 1948: 10). The ethical conversion involves that we turn into a situated, incarnated - embodied - existence, experiencing emotions like pride, joy, and passion, but also 
desire, hate, love, and friendship, in close contact with the world and our fellow men. ${ }^{4}$

Beauvoir, then, in reference to the philosopher Hegel, examines how our freedom is related to the freedom of others. We find a justification of our own existence 'only in the existence of other men' (72): 'each one depends upon others' (82). The ethical 'conversion' of willing freedom therefore implies willing the freedom of others: ' $(\mathrm{t}) \mathrm{o}$ will oneself free is also to will others free,' which 'points out to each person concrete action to be achieved' (73). Beauvoir thus takes on Hegelian notions of the interdependent and dialogical character of human existence, and articulates these, moreover, in terms of our embodied existence in the world. ${ }^{5}$ To her, living as an embodied and situated ethical self is a preferred, higher phase above pure consciousness. Freedom is not something we have, but is only realized in an ethical project: 'to will oneself moral and to will oneself free are one and the same decision' (25). Willing oneself free is to 'effect the transition from nature to morality by establishing a genuine freedom on the original upsurge of our existence' (25). As she formulated it elsewhere: '( $t$ )rue freedom comes about only through a positive project' (Beauvoir 1999: 333).

However, living ethically, as a 'positive' existence in the world, does not mean that our ambiguity is totally left behind. Our existence 'still remains a negativity in the positive affirmation of itself. [...] The failure is not surpassed, but assumed' (Beauvoir 1948: 13). The ethical conversion should be compared with 'taking a trip,' rather than with 'escaping from prison.' In the first case, our conscious dimension, which separates us from others, is 'present in its surpassing' insofar as it is accepted; in the latter case, it is left behind. Hegel confused these two movements in 'the ambiguous term "aufheben"' (84); a Hegelian optimism does not recognize that we always remain finite concrete realities. ${ }^{6}$

4 Her speaking in terms of man as a 'positive existence' in the world clearly departs from Sartre's theory. But even more she departs from his original philosophy in valuing emotions as ways to connect with others, while to Sartre experiencing emotions is a matter of self-deceit. For an explanation of their different outlooks in this respect, see Vintges (1996).

5 Beauvoir mentions Hegel many times in her essay. She adds: 'I remember having experienced a great feeling of calm on reading Hegel in the impersonal framework of the Bibliothèque Nationale in August 1940. But once I got into the street again, into my life, out of the system, beneath a real sky, the system was no longer of any use to me: what it had offered me, under a show of the infinite, was the consolations of death; and I again wanted to live in the midst of living men' (Beauvoir 1948: 158). In her war diary she as well goes into her reading of Hegel's works in the Bibliothèque Nationale, from July 1940 onwards (cf. Altman 2007).

6 The singularity and finiteness of our existence follows not from our bodily existence per se since our situatedness as a lived body can be collectivist as well and only singular in the sense 
Through ethical conversion, mutual recognition and even connectedness between people, in the shape of love and friendship, are possible. They will, however, never be final since, 'one can not imagine any reconciliation of transcendences: they do not have the indifferent docility of a pure abstraction; they are concrete and concretely compete with others for being. The world which they reveal is a battle-field where there is no neutral ground and which cannot be divided up into parcels' (118). Out of 'the irreducible character of ambiguity' (9), which involves a remaining separation between people, the 'plane of hell, of struggle, will never be eliminated' (119). People will always want to subordinate others to compensate for their own 'lack' of being. There will always be enmity and 'evil will' - elements that are difficult to account for 'in Kantian ethics, which is at the origin of all ethics of autonomy,' out of its focus on man's rational will (33).

Since separation and struggle between people shall never be finally overcome, an ethical conversion has to be practiced time and again: 'ethical freedom' (24) 'requires a constant tension' and a 'permanent choice' (26). Such an ethics 'experienced in the truth of life' is to be preferred, however, above Hegel's consolation of an 'abstract evasion,' and any abstract humanism that claims to speak on behalf of mankind (159). 'Universal, absolute man exists nowhere' (112), there is but 'the individual reality of our projects and ourselves' (106). Beauvoir's 'realist' position involves a permanent dimension of power and conflict between people and groups of people, to be overcome again and again by concrete ethical effort.

The 'assertion of our finiteness' (158) implies that abstract moral theories do not make sense since, in the end, we can never speak for other people. Moral maxims or dogmas hide the fact that we are all concretely situated and that our choices often affect others in negative ways. Kant conceives of 'the human person insofar as it transcends its empirical embodiment and chooses to be universal' (17). However, 'it is not impersonal universal man who is the source of values, but the plurality of concrete, particular men projecting themselves toward their ends on the basis of situations whose particularity is as radical and as irreducible as subjectivity itself' (17-18). As soon as 'one introduces the presence of the finite individual in the world' (121), one faces concrete and difficult problems, for which ethics 'does not furnish recipes' (134). Instead of applying abstract and universal moral maxims 'there must be a trial and decision in each case' (134), as if

of expressing its momentous collective situatedness. Our finiteness and singularity follow particularly from the other side of our ambiguous condition; namely, our conscious dimension that to Beauvoir always involves our own situated rather than universal perspective. 
we are dealing with a work of art. This does not mean 'that we are likening action to a work of art,' but 'in any case human transcendence must cope with the same problem: it has to found itself' (130).

Beauvoir's 'ethics of ambiguity' essentially argues for 'ethics irreducible indeterminacy' (Langer 2003: 90). Time and again her essay underlines the ambiguous, contingent character of any ethical decision. There can be no 'previous justifications which might be drawn from the civilization, the age, and the culture'; 'the good of an individual or a group of individuals requires that it be taken as an absolute end of our action; but we are not authorized to decide upon this end a priori' (Beauvoir 1948:142). Instead of a 'total truth,' there are but 'necessarily partial truths which every human engagement discloses' (68). When people speak about 'Nation, Empire, Union, Economy, etc.' we should consider which concrete individuals are involved, and which genuine human interests are at stake (145). An ethics of ambiguity recognizes that all actions 'must be legitimized concretely' (148). In each case, we try to establish what is the main danger, so to speak, being aware of the fact that 'all authority is violence' and that '(n)o one governs innocently' (108).

Beauvoir counterposes her notion of a lived, contingent ethics especially to the maxims of Kant, criticizing his abstract morality for not addressing the real substantive problems of daily life. ${ }^{7}$ Her approach in this respect comes close to Hegel's view. In an open attack on Kant, Hegel, in his Philosophy of Right, argues that Kant's abstract universalism is insensitive to the particular context of problems that need to be solved. Kant's morality is all about a pure Sollen, comprising moral standards that are more about ethical purity than about real life. Instead, to Hegel, ethical life (Sittlichkeit) is grounded in concrete forms of existence. ${ }^{8}$

Beauvoir likewise grounds ethics in real social life. We even find her arguing in Hegelian terms that our social conditions can doom us to a passive existence, keeping us in 'a state of servitude and ignorance' as is 'the situation of women in many civilizations' (37) (cf. Chapter 2). ${ }^{9}$ But while she, like Hegel, grounds ethics in social forms of life, contra Hegel, they are radically plural. At stake to her are the forms of life of different communities and of different individuals within them: 'the Arabian fellah

7 She equally does so in The Second Sex (cf. Beauvoir 2010: 650).

8 With thanks to Maarten Coolen.

9 Beauvoir in this respect refers to the situation of black slaves and of 'Mohammedan woman enclosed in a harem' (Beauvoir 1948: 38 ), as well as to 'the situation of women in many civilizations' (37). In The Second Sex she expanded this to the situation of all women throughout time and place (cf. Chapter 2). 
is oppressed by both the sheiks and the French and English administration. [...] The interests of the French proletariat are not the same as those of the natives in the colonies' (89). During the Second World War, black leaders in the United States, like Richard Wright, refused 'to drop their own claims for the sake of the general interest.' Ethico-political choices are socially situated, and '(f)or each one it also depends upon his individual situation' within these social contexts (89).

However, an ethical attitude requires that we are not blinded by the goals that we set up for ourselves (cf. 89), but that, through our own struggle, we aim to serve 'the liberation of all' (112). Since 'each is bound to all' (112), the cause which we serve 'must not lock itself up' (89-90). In our 'surpassing toward others,' each one exists as a 'separate existence engaged in his own projects. So much so that the terms "useful to Man," and "useful to this man," do not overlap' (112). But to abolish all suppression 'each one must carry on his struggle in connection with that of the other and by integrating it into the general pattern' (89). Our situated ethical projects need to connect to a general perspective.

The ethical self that emerges from Beauvoir's ethics of ambiguity is socially situated, embodied, and engaged in concrete ethical projects in the world. To Beauvoir, 'man's project toward freedom is embodied for him in definite acts of behavior' (78). In her novel The Mandarins (2005), published in French in 1954, she introduces the concept 'art of living' (art de vivre), to indicate the personal ethical way of life of one of the novel's main characters (Beauvoir 2005: 180, 182). The term 'art of living' refers to a critically creative ethical life project that is developed and grounded in real social life (Beauvoir 1948: 159; cf. Vintges 1996: 81). It is this ethical way of life that Beauvoir posits as an alternative to the model of personhood of Organization Man and Super Woman, as depicted in Les belles images.

Later in the chapter we will discuss some remarkable parallels between Beauvoir's notion of a lived ethics and the concepts of ethics that Foucault developed in his final work. To understand his approach, however, we must first examine his critique of modern societies and especially his concept of the neoliberal, 'entrepeneurial' self.

\section{The Entepreneurial Self}

Who are we today, what kind of subjects have we become? Foucault, throughout his work, aims to answer this question, in order to open up possibilities for change. Tracking and tracing practices of power in Western 
history that have constructed men's subjectivities through the ages, he especially focuses on power practices that are entangled with the social and human sciences. According to him, these sciences play a major role in the various ways power is exercised in Western modern societies, ranging from disciplinary techniques to neoliberal ones - the latter spreading rapidly today across the globe. Foucault's analyses offer us some relevant insights into who we are today and especially who women are today.

In his early works (1960-1969), among others The Order of Things (1970), published in French in 1966, and The Archeology of Knowledge (1972), published in French in 1969, Foucault, in a discussion of the history of the human sciences, criticized the concept of Man as a free, 'original' subject, i.e. as the origin or source of sense, meaning, and knowledge. Consequently, he is often referred to as a structuralist, but, in fact, his approach is more historical. To him, the figure of Man as an original subject is a historical product, a temporary effect of history that will be erased like a face drawn in sand at the edge of the sea, as the famous last lines of The Order of Things state. New forms of subjectivity will emerge: subjectivities to Foucault are historical products that change over time.

In his mid-work (1970-1976), among others Discipline and Punish (1979), published in French in 1975, and The Will to Knowledge (2006), published in French in 1976, Foucault again brings up the human sciences, but now he focuses on their entanglement with social practices of power that shape our subjectivities. This approach allowed him to conceive of a new type of power techniques, which made him one of the most cited authors in the social sciences.

In the two books mentioned, he introduces the concepts of 'discipline', 'surveillance', and 'normalization' to indicate a type of power that emerged and proliferated with the rise of the human sciences. From Foucault's perspective, the latter encompass what now are called social and life sciences: at stake are sciences such as psychiatry, biology, medicine, and economics and, later, psychoanalysis, psychology, sociology, ethnology, pedagogy, and criminology. These sciences, in all their practical dimensions - such as buildings, therapy rooms, intake procedures, exams, and tests - are entangled with a type of power that classifies and categorizes people, and resocializes or treats them when they are deemed abnormal. This normalizing type of power that also trains the bodies and behaviour of 'normal' people, and surveys them on an individual as well as a collective level.

The sciences set out the Norm for these 'normalizing' and 'disciplining' practices: they produce the standards of 'normal' and 'abnormal' behaviour. By detailed control and sanctions, 'normal individuals', the normal child, woman, man, are produced as concrete realities, and the same counts for 'the 
abnormal' who likewise are specified and categorized, trained and treated. ${ }^{10}$ Disciplining and normalizing power practices consist of fine-tuned power techniques - i.e. a 'microphysics' of power - such as the parcellation of groups of people into individual bodies, ${ }^{11}$ and the organizing of individual bodily behaviour by applying timetables, training exercises, examination, hierarchical observation and techniques of 'continuous registration, perpetual assessment and classification' (Foucault 1979: 220).

Since roughly 1800 , these power techniques have spread throughout Western societies, among others in armies, workplaces, and in penal, medical, welfare, and educational institutions. Foucault's main example is the modern prison, where these science-based techniques from minute to minute mould the bodies of the individual criminal. But, as the last lines of the chapter Discipline state, 'prisons resemble factories, schools, barracks, hospitals, which all resemble prisons' (228).

However, there is resistance in diffuse, spontaneous, and localized forms. In addition to a docile body that internalizes disciplinary power techniques, Foucault in his mid-works points to a direct bodily resistance against techniques of surveillance and normalization. From 1978 onwards, however, he puts forward some new concepts that involve people's agency, rather than unmediated bodily responses..$^{12}$ In his lectures at the Collège de France, he talks about the state, arguing - in line with his earlier analyses - that we should conceive of it as a set of techniques, rather than an institute. Speaking about the state from such a perspective is a matter of scale: at stake are techniques of managing the whole social body, i.e. the techniques of governing a population (cf. Foucault 2008: 186).

Foucault introduces the term 'governmentality' to indicate these governing techniques. A general problematic of governing emerged since the sixteenth century, in relation to the family, a household, a convent, a people

10 By classifying who is normal and abnormal, disciplinary practices at the same time 'produce' abnormal people, i.e. the 'perverse,' the sick, the criminal, the madman, the abnormal child - each of them categorized in many subdivisions. By fine-tuning the categorizing of 'abnormalities' - cf. the emergence of the new spectrum of autism disorders - normal man is increasingly defined as well.

11 This happens among others through architectural planning - as is exemplified by Jeremy Bentham's Panopticon. Foucault discusses his architectural design of this model prison as a metaphor throughout for disciplinary power. Bentham's design consisted of cells in a circular structure, with a watchtower in the middle. The cells are illuminated, with windows on both sides, so as to completely overview the behavior of its inmate. For an excellent introduction to Foucault's mid-work see C.G. Prado (2000).

12 'Agency' as a concept standard refers to persons having some room to manoeuvre within social structures, or to intervene in and alter their surroundings. 
(Foucault 2007a: $87 \mathrm{ff}$.). At stake is the correct way of managing individuals, goods, and wealth - a type of power that can be characterized as 'a conduct of conducts' (Foucault 2000:341; cf. 2008: 186). From the eighteenth century onwards, a process of 'governmentalization of the state' took place. Through the development of forms of knowledge such as statistics and political economy, and the installing of police institutions and practices, a management of the population as a whole became possible. The final end of government, since then, is 'not just to govern, but to improve the condition of the population, to increase its wealth, its longevity, and its health' (Foucault 2007a: 105).

In the last chapter of The Will to Knowledge (Foucault 2006), he already conceptualized the management of the population in the shape of a biopolitics'. At stake is the management of the 'species body', i.e. of biological processes: 'births and mortality, the level of health, life expectancy and longevity, with all the conditions that can cause these to vary' (Foucault 2006: 139). But as William Walters (2012) clarifies, to Foucault the concept of biopolitics 'still offered only a very partial reflection on the nature of the modern state' (Walters 2012: 16). The concept of 'governmentality' covers the state's regulation of the population through a much broader set of management techniques, next to biopolitical ones. According to Foucault, the microphysical disciplining of individual behaviour remains important as well, since managing a population means managing it 'in depth, in all its fine points and details' (Foucault 2007a: 107). But 'governmentality' has become the dominant model of the modern state, a complex form of power 'that has the population as its target, political economy as its major form of knowledge, and apparatuses of security as its essential technical instrument' (108).

In subsequent lectures, Foucault focuses on liberalism and neoliberalism as two distinct 'governmental' regimes (Foucault 2008). Often these two forms of government are identified in terms of a minimal(ist) state and a maximum freedom of the market - based on the presumption that the mechanisms of the market economy will create prosperity and social order. Foucault instead characterizes them as political regimes that manage the population in extensive ways, and that construct rather than respect a free market.

Liberalism, from the eighteenth century onwards, had to organize the economy as a field where there can be no sovereign or state power (cf. Foucault 2008: 283). By way of concrete political measures and government techniques it established a freedom of the market, of property rights, of rights of discussion and 'possible freedom of expression and so on,' in this 
way producing 'free' buyers and sellers (63). The arousal and production of freedom was paired with a management of danger, i.e. the implementation of strategies of security that had to guarantee the freedom of economic processes (cf. 65). Liberalism as a governmental regime thus organized security and freedom, among others by installing penal practices, assurance policies and biopolitics, and by applying techniques of disciplining and normalizing such as mass surveillance and the training of individual bodies. It thus created a 'subject of rights' that is simultaneously a subject of extensive control (cf. 67).

Neoliberalism, according to Foucault, likewise comprises an extensive set of governmental techniques, installing market competition, organizing societal security and producing a specific type of subjectivity. Foucault especially discusses the American type of neoliberalism ${ }^{13}$ - introduced by economists from the Chicago School like Milton Friedman, Friedrich von Hayek, and Gary Becker - that started to spread in the United States after the war. To these authors, market competition or the model of the enterprise, was a formative power of society as well (cf. 148). They conceived of a 'society made up of enterprise-units' (225), in other words of a 'general regulation of society by the market' (145). The model of American neoliberalism turned into 'a whole way of being and thinking.' Foucault concludes that it became 'a method of thought, a grid of economic and sociological analysis' (218) as well as 'a general style of thought, analysis and imagination' (219) - as Whyte already noted in his study Organization Man (1956).

To Foucault, the most characteristic feature of American neoliberalism is the production of the homo oeconomicus (economic man) as 'entrepreneur of himself' (Foucault 2008: 226). While homo oeconomicus used to be a partner of exchange, the new homo oeconomicus is a calculative agent, 'being for himself his own capital, being for himself his own producer, being for himself the source of (his) earnings' (226). The modern subject today is supposed to be a homo oeconomicus all over, a rational actor who calculates costs and benefits, and organizes his or her whole life accordingly, thus being 'someone who is eminently governable' (270).

Foucault goes at length into the emergence of this new neoliberal subject. He first discusses how, since the second half of the twentieth century,

13 Foucault discusses two forms of neoliberalism, i.e. German Ordo-liberalism (after the journal 'Ordo') developing in the 1930s, and the American type of neoliberalism of 'the Chicago school of Economics', developing since the 1950s. While German Ordo-liberalism concentrates on social policies which enhance the market economy as such, for instance by installing favourable tax conditions for people to start enterprises, the Chicago school redefines the social sphere as a form of the economic domain (cf. Foucault 2008). 
economics is 'no longer the analysis of the historical logic of processes; it is the analysis of the internal rationality, the strategic programming of individuals' activity' (223). The object of economic analysis shifted from 'processes of capital, of investment, of the machine, of the product, and so on' into 'the way in which individuals allocate [...] scarce means to alternative ends' (222). Economists used to conceive of labour in abstract terms, but new scientific approaches focus on the labourer as an active person, who acts on the basis of cost benefit calculations. The labourer is seen as possessing a certain capital - his abilities, his skills, his health - that he invests to generate a stream of earnings (cf. 224). This 'human capital' is made up of acquired elements, through education, good parenting, and cultural stimuli, and of innate, hereditary elements, such as good genes, that inevitably will become a topic of interventions and investment as well. The labouring subject is managed by all kinds of techniques to optimize his human capital, for instance by actively seeking skills or opportunities.

Homo oeconomicus' conduct, involving an optimal allocation of scarce resources to alternative ends, became generalized to every form of behaviour. Every purposeful conduct was interpreted - and governed - as conduct that employs limited means to alternative ends (cf. 268-269). Since homo oeconomicus is calculating and planning his or her optimal satisfaction and success in the world (cf. 226-229), it is someone 'who responds systematically to systematic modifications artificially introduced into the environment' (270). Homo oeconomicus, as someone who accepts reality appears 'precisely as someone manageable': '(b)ehavioural techniques' can be implemented to govern and activate the neoliberal entrepreneurial self (270).

Neoliberalism, far from being a laissez faire politics, according to Foucault, comes down to an active and extensive restructuring of self and society. Thomas Lemke (2001) summarizes that, to Foucault, neoliberalism is not just an ideological rhetoric or a political-economic reality, but, above all, 'a political project that endeavours to create a social reality that it suggests already exists' (Lemke 2001: 203). Neoliberalism involves that '(g)overnment itself becomes a sort of enterprise whose task it is to universalize competition and invent market-shaped systems of action for individuals, groups and institutions' (197).

The sciences play a major role in the construction of the modern, entrepreneurial self, as providers of expert knowledge. Foucault especially shows how we are governed, individually and collectively, by 'the gray sciences, the minor professions, the accountants and insurers, the managers and psychologists [...] Every practice for the conduct of conduct involves authorities, aspirations, programmatic thinking, the invention 
of redeployment of techniques and technologies.' The conduct of our day-to-day conduct, 'in our homes, workplaces, schools, and hospitals, in our towns, regions, and nations, and by our national and transnational governing bodies,' is based on 'expert' knowledge and advice that, for a large part, characterize who we are under neoliberal governmental regimes (Rose et al. 2006: 101).

Neoliberalism in the Foucauldian sense is more than the latest version of capitalism, and cannot be tackled by a purely anti-capitalist struggle. Marxism comprises too blunt a set of tools to analyse the specificity of current neoliberal regimes, which cannot be addressed 'in terms of the metastructures of labour and capital' (McRobbie 2011b: 180). The conduct of people is more intensely governed than ever, via their own investments and endeavours to run themselves as an enterprise. Neoliberal man, according to Foucault, is indirectly manipulated and activated by incentives - in other words, is governed by 'carrot and stick' (Guus Dix 2014).

Examples of such incentives in my own environment as a university teacher involve competitions for 'the best teacher of the year'; regular appeals to follow time-management or library-skills courses and to improve one's valorisation skills; cutting down research time for those who do not 'produce' enough; invitations to innovate one's digital learning environment, and a constant bombardment of self-assessment forms. These management techniques sit side by side with overtly disciplinary ones, such as an excessive and 'transparent' monitoring of one's teaching and research activities. ${ }^{14}$

Foucault's analysis of neoliberal self and society has been elaborated in 'governmentality studies' by authors Nikolas Rose, Peter Miller, Mitchell Dean, Thomas Lemke and Mariana Valverde, among others. They mostly focus on neoliberal governmentality, i.e. on the spreading of enterprise regimes all over society and on current techniques of 'governing the soul' (cf. Rose 1990). Governmentality authors show how these techniques typically work 'at a distance' (Miller and Rose 2008: 16), by installing capacities for self-control in 'autonomous individuals' (cf. Lemke 2001: 201). To analyse the specific ways in which their 'free choice' is managed, they interestingly take on board another concept that Foucault developed in his later work, namely the concept of self-techniques.

14 For an extensive overview of these kinds of micro-management in Academia, see Gill (2009) and Gill and Ngaire Donaghue (2016). Even cameras turn out to be in ample use across university buildings and terrains. When some ICT students at my university hacked the university's mail data base to send out a protest letter against their department's reorganization, they were tracked down a few days later on the basis of camera footage, and suspended. The students sued the university and won. 
In 1980, two years after he launched the concept of 'governmentality', Foucault argues that, in all societies, we find

techniques which permit individuals to perform, by their own means, a certain number of operations on their own bodies, on their own souls, on their own thoughts, on their own conduct, and this in such a way that they transform themselves, modify themselves, and reach a certain state of perfection, of happiness, of purity, of supernatural power, and so on (Foucault 2007b: 154).

He adds that governing people is all about 'a subtle integration of coerciontechnologies and self-technologies' (155) and elsewehere characterizes current Western society as 'a tricky combination in the same political structures of individualization techniques, and of totalization procedures' (Foucault 2000: 332). People's agency is at stake where it concerns the 'processes through which the self is constructed or modified by himself' (Foucault 2007b: 154). But the tricky part is that their agency is created and determined by coercive techniques. In the words of Kevin Thompson (2003), we only deal with a 'minimal freedom,' since people's options are 'defined precisely by the structuring work of governance' (Thompson 2003: 122).

It is this type of 'minimal freedom' that is analysed in current governmentality studies, which focus on the indirect way neoliberalism 'conducts' people's 'conduct', namely through offering them self-techniques. By way of these self-techniques, people act as entrepreneurial selves, i.e. as managers and designers of their own lives, choosing their behaviour, lifestyle, and opinions. In empirical studies, Miller and Rose (2008) demonstrate how authorities of various types 'shape, normalize and instrumentalize the conduct, thought, decisions and aspirations of others in order to achieve the objectives they consider desirable' (Miller and Rose 2008: 32). Advertising techniques, for instance, link the desires of individuals to the productive machine, in such a way that consumers become 'active agents in their own consumption patterns' (140), shaping 'a style of life through participation in the world of goods' (141).

Authors of the governmentality school thus focus on the link between selftechniques and top down social engineering. Exemplary to their approach is the argument that 'the language of individual freedom, personal choice and self-fulfillment came to underpin programmes of government' (48), and that '(p)ersonal autonomy is not the antithesis of political power, but a key term in its exercise' (54). In that sense, governmentality studies, in the words of 
Walters (2012), suffer from 'panopticitis,' while '[o]ur time is perhaps more open and plural than some would have us suppose' (Walters 2012: 81).

From a postcolonial perspective, Aihwa Ong (2006), Van Baar (2011), and Walters (2012) identify neoliberal governmental techniques as a set of power techniques next to, and in entanglement with, other power techniques. They focus on the spreading of neoliberal governmental techniques today across the globe, in Eastern Europe, Latin America, China, and East Asia, especially, where 'technocrats embrace business agenda's and legitimize ideals of human talent and self-enterprise' (Ong 2006: 12). Ong shows how governments all over the world have 'fragmented the national territory and the population in the interest of economic development,' (77), by creating areas of neglect and marginalization on the one hand, and areas of open markets on the other hand, where people are turned into world citizens with marketable skills.

Van Baar (2011) analyses how neoliberal governmentality is introduced in Eastern European policies, exploring the 'hybrid assemblages' of power technologies, and 'the continuities with past socioeconomic and cultural formations' (Van Baar 2011: 166-167). Neoliberal 'activation' techniques are imposed on the Roma, such as radical cuts in social benefits and awards for those who actively seek work, develop skills, or participate in public work programs. Neoliberal power techniques thus 'responsibilize' the members of this heavily discriminated and marginalized group to their deprived situation. Van Baar shows that, with the scarcity of jobs, the results of such activation policies have been that one per cent of the Roma has found work, while all others are living in extreme poverty, with no basic housing, jobs, or human rights.

Since neoliberalism in world perspective is but one set of power practices and techniques next to, and entangled with, others, Van Baar and Walters adopt Foucault's concepts of neoliberalism as a toolset, instead of as an all-encompassing theory. From their perspective, and in line with Foucault's aversion to totalizing theories and his own patchwork approach of societies (cf. the Introduction), neoliberalism in Western contexts also emerges as a dominant set of power patterns - in hybrid entanglement with other hierarchical power patterns - rather than an all-encompassing system.

Foucault explicitly pointed to the persistence of disciplinary power techniques and of sovereign - juridical - power: 'we should not see things as the replacement of a society of sovereignty by a society of discipline, and then of a society of discipline by a society, say, of government. In fact, we have a triangle: sovereignty, discipline, and governmental management, which has population as it main target and apparatuses of security as its essential mechanism' (Foucault 2007a: 107-108). This perspective allows for 
an analysis of possible tensions and struggles between multiple layers and kinds of power techniques present in societies.

Neoliberal governmental power techniques, i.e. the proliferation of the model of the enterprise over society, can be countered, for instance, by a rights-based discourse that - as part of the sovereign state - may overrule neoliberal tendencies. An example is the furious reaction of the Dutch population in recent years against the secret filming of patients in the emergency centre at a main hospital, with a view to it being sold to a commercial television station. The juridical discourse on 'privacy' turned against this exploitation: the board of the hospital had to resign and the television programme was cancelled. Similarly, when the Dutch bank ING announced a plan to sell its client data, public opinion forced them to back off and to apologize for not 'sticking to their core business' and guaranteeing the privacy of their clients. Other layers of society as well may counter neoliberal tendencies, such as communitarian traditions. An example is the boycott some time ago by the Dutch population of a new commercial television station (TALPA), which had obtained the rights to broadcast summaries of the soccer matches in the Dutch League and did so interrupted by commercial breaks. TALPA went bankrupt, countered as it was by a communitarian trend that resisted the commodification of what was considered to be a Dutch common good. ${ }^{15}$

But other counter practices than those mentioned above can be detected as well. In the words of Walters (2012), instead of overvaluing neoliberalism, we should be keen on discerning 'other ways of governing and contesting governance, however minor they might be' (Walters 2012: 42). According to Walters, the concept of governmentality in principle allows for more mobile ways of seeing the world (cf. 53 ff.). However, its main definition ('the conduct of conducts'), in my view, urged Foucault to develop some new concepts. From 1980 onwards, he points to another kind of power practices involving other types of self-techniques, uncoupled from techniques of coercion.

\section{Practices of Freedom}

In his final works after 1980, Foucault focuses on specific kinds of ethical techniques of the self, as they are found - in exemplary ways - in Western antiquity. As Frédéric Gros (2005) notes, the only salvation in Foucault's

15 However, FOX now has obtained the rights, and will undoubtedly commodify the broadcasting of the Dutch soccer competition again in the near future. 
early and mid-works beyond a disciplined identity was madness, crime, or literature (cf. Gros 2005: 513). But from 1980 onwards, Foucault discusses certain ethical techniques of the self to defy coercive regimes. He did so 'not to abandon politics, but complicating the study of governmentalities through the exploration of the care of the self' (512-513). However, as Colin Gordon contends, the full implications of Foucault's ethics for current governmentality studies are not yet understood (Donzelot and Gordon 2008: 53).

To date, Foucault's work on ethics is undertheorized in social and political theory, since it supposedly proposes a lifestyle politics without any meso and macro political aims. But what Foucault actually provides is another concept of politics, contra top down political programs and social engineering: a bottom up way of practicing politics that not only involves micro-aims, but meso- and macro-aims as well.

In two books, The Use of Pleasure (Foucault 1986a) and The Care of the Self (Foucault 1986b), both published in French in 1984, in interviews, and especially in his 1981-1982 lecture series The Hermeneutics of the Subject (Foucault 2005a), Foucault draws attention to what he calls 'prescriptive texts' in Greek and Roman antiquity that offer tools for ethical self-improvement. At stake are 'texts whose main object, whatever their form (speech, dialogue, treatise, collection of precepts, etc.) is to suggest rules of conduct. [...] These texts thus served as functional devices that would enable individuals to question their own conduct, to watch over and give shape to it, and shape themselves as ethical subjects' (Foucault 1986a: 12-13).

Crucial to Foucault is the difference between what he calls 'ethicsoriented moralities' and 'code-oriented moralities' (30). Today, we only think of ethics in terms of moral codes or moral rules that we should apply. But in antiquity, ethics mainly consists of vocabularies that are intended as guides for the concrete shaping of one's personal existence. These vocabularies constitute a relationship of the self to the self; they envision 'intentional and voluntary actions by which men not only set themselves rules of conduct, but also seek to transform themselves, to change themselves in their singular being, and to make their life into an oeuvre that carries certain aesthetic values and meets certain stylistic criteria' (10-11).

All moral systems, Foucault says, require an ethical self-formation, an ethical work on the self, since people are to become the type of agents that can act in accodance with the moral rules of the system (cf. Foucault 1997c: 263). Every 'self-formation as an "ethical subject"' (Foucault 1986a: 28) has four aspects, which we can coin as the answers to the questions what, why, how, and to what purpose: What is the material that should be worked 
over in the ethical self-practices, i.e. 'the ethical substance'? Why should this work on the self be done, on behalf of what or which instance, i.e. what is 'the mode of subjection'? How should this work be done, i.e. what is the 'self-forming activity' or 'ascesis'? And, finally, to what purpose should it be done, i.e. what is the 'telos'? (cf. Foucault 1986a, 1997c; Vintges 1996). While ethical self-formation is inherent to every moral system, the type of moral agency at stake varies with the relationship between, and the content of, these four aspects.

The space of this dimension of ethical self-formation varies as well. It is only limited when moral codes dominate the moral system. But it can also take the upper hand. The latter is the case in Western antiquity, according to Foucault. All the emphasis was on developing a personal ethos. The vocabularies that offered the self-techniques for one's ethical self-formation were relatively independent from social and legal institutions and from moral rules (cf. Foucault 1997c: 255). Ancient ethics was not 'a unified, coherent, authoritarian moral system' (Foucault 1986a: 21). Instead, it was a matter of self-stylization, through the practicing of self-techniques ('ascesis'), rather than of prohibitions (cf. 23). One cannot find 'any normalization in, for instance, the Stoic ethics' (Foucault 1997c: 254). Ethical self-formation was practiced 'in the midst of many separate groups' which 'proposed - more than they imposed' different styles of behaviour, 'each having its specific character or "shape"' (Foucault 1986a: 21).

To indicate the relatively independent status of ancient ethical 'selfpractices' (with moral codes or rules only functioning in the background), Foucault develops the concepts 'care of the self', 'ethos', 'aesthetics of existence', and 'practice of freedom' (for the latter cf. Foucault 1997d). A freedom to create oneself was offered through vocabularies that provided the tools and techniques to acquire an 'ethos', i.e. a personal ethical way of life. At stake was an ethical self-creation in contrast to an ethical selfformation that is determined and limited by the moral codes of a moral system. Still, in ethics-oriented moralities, codes are not unimportant, 'but they revolve around a rather small number of rather simple principles' (Foucault 1986a:32) The main emphasis in ethics-oriented moralities is not placed on the code or 'the instances of authority that enforce the code' (29), to which the ethical subject 'must submit at the risk of committing offenses that make him liable to punishment' (29-30). Instead, the accent is placed on the relationship with the self and on the exercises and self-techniques that enable one to develop an ethos (cf. 30).

Ethical self-techniques are, for instance, the practicing of bodily self-tests (can I stop eating for some time?), writing exercises (such as the keeping of 
notebooks, 'hypomnemata', to record insights and ideas to guide one's future actions), meditation, reflection, and dialogue with oneself and others. By practicing ethical self-techniques, one strives to acquire a personal ethos, which is 'a mode of being for the subject, along with a certain way of acting, a way visible to others' (Foucault 1997d: 286). Ancient ethics thus concerned one's whole way of life, as Foucault's colleague at the Collège de France, classicist Pierre Hadot, already had pointed out. ${ }^{16}$

Acquiring an ethos in ancient Greece is also 'a way of caring for others.' It enables one to be a good politician, citizen, and friend, and to occupy one's 'rightful position in the city, the community, or interpersonal relationships' (Foucault 1997d: 287). Foucault specifies that human relations preferably consist of dynamic power relations. Often, we are faced with a situation of domination, however, when 'an individual or social group succeeds in blocking a field of power relations, immobilizing them and preventing any reversibility of movement by economic, political, or military means' (283). Acquiring an ethos through a care of the self is about trying to play the games of power with 'as little domination as possible' (298).

Gros (2005) notes that the care of the self, rather than isolating us from the world, 'enables us to situate ourselves within it correctly. [...] The subject discovered in the care of the self is quite the opposite of an isolated individual: he is a citizen of the world. The care of the self is therefore a regulative principle of activity, of our relationship to the world and to others' (Gros 2005: 538). Instead of a solipsism, narcissism, or aestheticism, we deal with an ethico-political attitude: at stake is one's acting in the world.

Foucault, moreover, suggests that inherent to ethical practices of freedom is a critique of domination. According to him, ancient philosophy 'calls into question domination at every level and in every form in which it exists, whether political, economic, sexual, institutional, or what have you. To a certain extent, this critical function of philosophy derives from the Socratic injunction "Take care of yourself"' (Foucault 1997d: 300-301). In practicing an ethical care of the self we affirm the principle of ethical self-creation, since, as Thompson (2003) aptly notes: 'the activity of constitution is its own norm' (Thompson 2003: 124). Ethical care of the self in that sense can be said to be 'critically creative' in itself (Taylor 2004: 266).

16 Arnold Davidson (1990) argues that in order to fully understand Foucault's final work, one must take into account that it is guided or framed in terms of Hadot's approach of ancient philosophy as spiritual exercises or ascesis (cf. Davidson 1990, 1994). Davidson clarifies that Foucault was a careful reader of Hadot's major essay on ancient spiritual exercises, originally published in 1977 and reprinted as the first chapter of his Philosophy as a Way ofLife (Hadot 1995). 
The care of the self also implies a relationship with others insofar as an ethos is never invented by the individual himself, but concerns models that one finds in one's culture and are proposed and suggested by one's culture, society, and 'social group' (cf. Foucault 1997d: 291). In The Hermeneutics of the Subject (Foucault 2005a), Foucault repeatedly states that 'the care of the self always takes shape within definite and distinct networks or groups,' involving

relationships that vary according to the different groups, milieus and cases [...] If you like, you cannot take care of the self in the realm and form of the universal. The care of the self cannot appear, and, above all, cannot be practiced simply by virtue of being human as such, just by belonging to the human community, although this membership is very important. It can only be practiced within the group, and within the group in its distinctive character (117).

Speaking of these groups, in The Hermeneutics of the Subject, Foucault not only refers to ancient philosophical schools, but also to some religious groups such as the Therapeutae (Foucault 2005a: 91, 114, 116). Membership of such communities, that offer self-techniques for a critically creative care of the self, is necessary, since people need others, preferably friends and tutors, to create a personal ethos. Gros (2005) summarizes that 'practices of the self are neither individual nor communal: they are relational and transversal [crosswise KV]' (Gros 2005: 545). Group membership enables the creation of a personal ethos, and the fabrics of such groups are the ethical life projects of their members.

When asked whether the care of the self in the classical sense should be updated, Foucault answers: 'Absolutely,' quickly adding that in modern times this will, of course, lead to something new (Foucault 1997d: 294, cf. 295). Ancient ethics developed from the fourth century BCE till the first and second centuries CE, from an elitist practice into a care of the self that appeals to a more general public. But it was always linked 'to a virile society, to dissymmetry, exclusion,' with slaves and women as the excluded others (Foucault 1997c: 258). Instead, 'couldn't everyone's life become a work of art?' (261).

According to his colleagues at the Collège de France, Hadot and Paul Veyne, Foucault's final work is his 'tacit attempt to offer contemporary mankind a model of life' (Hadot 1995: 208). In the words of Veyne (1993):

Greek ethics is quite dead and Foucault judged it as undesirable as it would be impossible to resuscitate this ethics; but he considered one if its elements, namely, the idea of a work of the self on the self, to be capable 
of reacquiring a contemporary meaning, in the manner of those pagan temple columns that one occasionally sees reutilized in more recent structures (Veyne 1993: 7, quoted in Davidson 1994: 67).

Foucault was especially interested in the 'relatively independent' status of the ancient practices of the self, which to him formed an alternative to the self-techniques of modern man that are linked to coercive power regimes. What fascinated him is the idea 'that ethics can be a very strong structure of existence, without any relation with the juridical per se, with an authoritarian system, with a disciplinary structure' (Foucault 1997c: 26o; emphasis added). Foucault repeatedly highlights the relatively independent status of ancient ethical self-practices, for instance when he states that in the Greek and Roman civilizations 'such practices of the self were much more important and especially more autonomous than they were later, after they were taken over to a certain extent by religious, pedagogical, medical, or psychiatric institutions' (Foucault 1997d: 282; emphasis added). Elsewehere he argues that the ancient "'arts of existence," these "techniques of the self," no doubt lost some of their importance and autonomy when they were assimilated into the exercise of priestly power in early Christianity, and later, into educative, medical, and psychological types of practices' (Foucault 1986a: 11; emphasis added). He adds that codes of behaviour and forms of subjectivation 'can never be entirely dissociated, though they may develop in relative independence from one another' (29; emphasis added). Important is 'the distinction between the code elements of a morality and the elements of ascesis' and 'their relative autonomy' (31; emphasis added). The classical care of the self, however, 'disappeared, that is, was integrated and lost a large part of its autonomy' (Foucault 1997c: 278; emphasis added).

Foucault at some point suggests that the 'growth of capabilities' of modern humankind can be disentangled from the dominant power regime (cf. Foucault 1997e: 317) and turned into ethical self-practices. Cressida Heyes (2007) elaborates on this suggestion, in a superb chapter on dieting entitled 'Foucault goes Weight Watchers'. Heyes analyses the tricky ways in which current weight-loss dieting programs install 'self-techniques' that, in fact, are integrated with a coercive regime of micro-management. Commenting on the Weight Watchers meetings she concludes: 'I have never been in an another adult milieu where discipline was applied to such tiny behaviors, and deviance greeted with such serious and inflexible responses from the staff' (Heyes 2007: 74). However, approaching dieting as a set of 'self-techniques', allows to conceive of their enabling effects as well, Heyes argues. She recalls the 'paradox' that Foucault hinted at, namely that 
normalizing disciplinary practices also enable new skills and capacities 'that may exceed the framing of the original activity' (67). The self-techniques used in the Weight Watchers program, such as the keeping of notebooks (compare the use of 'hypomnemata' in Greek ethics), 'have a resonance and potential that could exceed the regime of normalization that generated them' (79). Drawing on Foucault's ethics, Heyes mentions the possibility that dieting's enabling aspects may lead people to a care of the self (cf. 87). Heyes gives us an idea of how the use of self-techniques in a constraining context may spill over into the developing of ethical practices of freedom. ${ }^{17}$

In a similar vein, Thompson (2003) examines Foucault's strategic perspective, arguing that the minimal freedom of the neoliberally governmentalized agent can be transformed into practices of freedom. This happens not by rejecting present techniques of the self, but by changing their goals and key features, placing them in service of the aims of an ethical care of the self (cf. Thompson 2003: 131).

Gros (2005), in my view, most adequately captures Foucault's strategic perspectives by highlighting the collective dimension of the concept of practices of freedom. While community and individual today are produced, regulated, and dominated by the modern State as 'complementary opposites' (Gros 2005: 544), we should move beyond this opposition. Foucault counterposed "what he calls "modes of life," "choices of existence," styles of life," and "cultural forms" to both the demands of community and individual rights together' (544).

Moving beyond the opposition between individual and community is not only Foucault's critical alternative to current neoliberal models of self and society, but at the same time a strategy to realize this alternative, as is clear from his articles on the gay movement. In one of these articles, he explicitly proposes to concieve of the movement's politics in terms of an 'art of life' (Foucault 1997a: 163). He moreover adds that decisive social changes have taken place by way of bottom up, critical socio-political movements such as the gay movement. In the 196os and 7os, they invented new ways of life and changed 'our mentality, our attitudes, and the attitudes and mentality of other people - people who do not belong to these movements. And that is something very important and positive. I repeat, it is not the normal and old political organizations that have led to this examination' (173).

Elsewhere he writes that '( $r$ )ecent liberation movements suffer from the fact that they cannot find any principle on which to base the elaboration of a new ethics. They need an ethics, but they cannot find any other ethics 
than an ethics founded on so-called scientific knowledge of what the self is, what desire is, what the unconscious is, and so on' (Foucault 1997c: 255-256). The 'art of life' to Foucault is an answer to this dilemma. Transforming self and society preferably takes place through collective practices of freedom that explicitly criticize forms of domination while at the same time creating ethical alternatives for self and society on micro- meso- and macro-levels (cf. Thompson 2003: 131; Vintges 2004a: 293). ${ }^{18}$

Foucault in his final lectures points to some practices in Western antiquity that were particularly critical in character. In his discussion of the notion of 'parrhesia' - literally meaning 'fearless speech' - he points to the way this was elaborated by the Cynics into a whole ethos (cf. Foucault 2001, 2005a, 2011). As he explains, parrhesia has more meanings in antiquity, namely criticizing oneself and one's friends, among others. But Foucault is mostly interested in parrhesia as the fearless speech of the powerless to those in power, which involves serious risk-taking, as was practiced by the Cynics in particular. Foucault explains that the 'right' parrhesiast in antiquity, the one who is believed a truth-teller, is he who says what he knows to be true: his way of life and words are in harmony; in other words, his bios is in sync with his logos. Such a 'harmonious accord' (Foucault 2001: 136, 90) of one's deeds and one's words is exemplified by Socrates, but also by a farmer in Euripides' play Orestes, who has the courage to express controversial political opinions, and who is respected as a parrhesiast since he is 'a man of blameless principle and integrity' (69). Overall, 'the manner in which a person lived was a touchstone of his relation to truth' (117).

Elsewhere, Foucault again suggests that critique preferably is an attitude, or a lived practice, in which bios and logos are linked and one's acts and speech activities accord. ${ }^{19}$ An outspoken critical, socio-political

18 Foucault argues that practices of liberation can be necessary but that they need to be linked to practices of freedom. A colonized people has to liberate itself from its colonizers, but also needs practices of freedom to define 'admissible and acceptable forms of existence or political society. This is why I emphasize practices of freedom over processes of liberation; again, the latter indeed have their place, but they do not seem to me to be capable by themselves of defining all the practical forms of freedom' (Foucault 1997c: 283).

19 The parrhesiastic attitude according to Foucault is at 'the roots of what we could call the "critical tradition in the West"'; he specifies his research on parrhesia as 'a genealogy of the critical attitude in Western philosophy' (Foucault 2001: 170-171). Rather than as the triumph of pure Reason, Western Enlightenment according to him should be interpreted as the re-emergence of a critical attitude of testing limits and as such should be conceived of as an ethos instead of an analytics of truth (cf. Foucault 1997d). Foucault rereads Kant's famous treatise 'What is Enlightenment?' through this lens, arguing that Kant's question already involves an acceptance of the fact that we deal here with an event in time, and not with pure Reason. 
movement in that sense entails such an accord as well; that is to say, it practices what it preaches. If the gay movement has to offer a critically creative 'art of life', it preferably consists of a set of critically creative ethical life projects.

Foucault's notion of fearless speech indirectly addresses the fact that assemblages of neoliberal and disciplinary micro-management in Western societies install a lot of fear in people, demanding courage to counter them. From my experience as an academic in a corporatized university, practicing parrhesiastic critique on an individual basis is exhausting, especially with the rise of a bully culture in neoliberal academia (cf. Zabrodska et al. 2011). A collective, outspokenly critical practice of freedom, as developed by students and staff at the University of Amsterdam in early spring 2015, is far more energizing and effective (cf. Gray 2015). From Foucault's main interest in politics as bottom up, collective practices of freedom, comprising micro-, meso- and macro-aims, I take that parrhesiastic practices preferably take place in the context and shape of such socio-political movements.

Foucault's notion of either explicitly critical (what he calls parrhesiastic), or implicitly critical practices of freedom, involve a new concept of homo politicus, something Wendy Brown (2015) does not notice when she complains about the lack of a homo politicus in Foucault's work. While Brown advocates a return of the homo politicus in its sovereign classical shape, in terms of the original subject of Western political philosophy, Foucault posits a different concept of homo politicus, one that is embedded in and produced by collective practices of freedom, which allow him or her to im- or explicitly counter coercive frames while moving beyond them.

Summing up, we can distinguish five basic positions in Foucault's work that people can occupy in power constellations. The first two we coined as (1) the docile body; and (2) direct bodily resistance - both with no room for people's agency. Since 1978, however, Foucault introduces various concepts of human agency. Neoliberal man as theorized by Foucault is an agent who manoeuvres within the constraints of his neoliberal surroundings, and whose position we may coin - in the terms of Thompson (2003) - as (3) neoliberal 'minimal freedom'. Discussing people's ethical self-formation within code-oriented moral systems, which equally gives them some room to manoeuvre, Foucault points out a kind of agency that we can label as (4) moral minimal freedom. Finally, in Foucault's works since 1980, there is a notion of (5) free agency - as constructed in relatively independent practices offreedom. While most governmentality studies focus on (3), i.e. on people's agency in the sense of a neoliberally constrained 'minimal freedom', 
they do not incorporate (5), i.e. people's free agency as constructed in relatively independent practices of freedom. They sometimes mention Foucault's notion of self-care, but without noticing the possible dynamics the concept allows for. ${ }^{20}$ The concept of practices of freedom, however, not only involves a strategic perspective, but can be used in analytical ways as well. Self-techniques can be transformed and overdetermined in such a way that we deal with ethical practices of freedom, rather than with self-techniques that are linked to coercion, as will be illustrated in following chapters.

\section{Freedom Practices: Five Core Characteristics}

Foucault's and Beauvoir's works on ethics show some remarkable parallels that allow us to finally synthesize their approaches in a concept of ethical 'freedom practices', i.e. distinct sets of critically creative ethical life projects, coined in terms of the following five core characteristics. A first similarity is that both authors conceive of freedom in terms of an ethical practice, and not as an attribute or quality of human beings per se. To Beauvoir, 'true freedom' involves the creation of an ethical life project, in a concern for the well being of others. To Foucault, freedom comprises creating an ethical life project that involves 'a way of caring for others' (Foucault 1997d:287). Paraphrasing Beauvoir's formulation 'One is not born, but rather becomes, woman' (Beauvoir 2010: 293), we can conclude that to both authors one is not born, but rather becomes free, by developing a personal ethos, i.e. by developing a personal ethical life project in a concern for others.

A second similar component is that developing a personal ethical life project to both authors concerns one's visble behaviour and acting in the world, rather than inner life - being, in that sense, ethico-political in character.

Thirdly, to both, an ethical life project inherently involves a critique of any domination. To Beauvoir 'willing ourselves free' entails willing others free, and involves a concrete commitment to those who are denied a personal ethical life project. To Foucault, practicing a personal ethos in

20 Lemke (2001) argues that neoliberalism is a political rationality that 'tries to render the social domain economic and to link a reduction in (welfare) state services and security systems to the increasing call for "personal responsibility" and "self-care"' (Lemke 2001: 203). Self-care here is directly linked to neoliberalism (see also Miller and Rose 2008: 7). 
explicitly critical, parrhesiastic ways, or in implicitly critical ways, opposes any domination, since the activity is its own norm. Their normative perspective can be articulated in terms of 'access for all' to a personal ethical life project.

Fourth, to both, developing an ethical life project is not a matter of applying rules or laws but of creation. To Foucault, the relatively independent status of ethical self-practices means that one's actions cannot be distilled from moral codes or dogmas, but are a matter of stylization and invention, as is clear from his use of the terms 'art of life', 'aesthetics of existence', and 'arts of existence'. Beauvoir argued for the creative aspect of any ethical decision from the perspective of our situatedness as finite beings in the world, and she, too, spoke of ethics in terms of an 'art of living'. To both authors, ethics involves inventing our behaviour and weighing our solutions, instead of obeying rules, or deciding upon ends a priori. To both, in the words of Foucault, 'the ethico-political choice we have to make every day is to determine which is the main danger' (Foucault 1997c: 256).

Fifth, both authors ground any ethics in social contexts. In The Ethics of Ambiguity, Beauvoir situates ethics as the concrete projects of groups of individuals and of individuals within them. She argues, moreover, that social conditions can deny people access to a personal ethical life project, which is the basic - Hegelian - premise of The Second Sex as well (cf. Chapter 2). Foucault more concretely refers to specific collective settings that are necessary for people to be able to acquire an ethos. At stake are groups and networks that operate relatively independent from moral codes and that offer people self-techniques to create a personal ethical life project. Our concept of freedom practices refers as well to this collective level, i.e. to identifiable and distinct relatively independent ethical communities, groups or networks offering self-techniques, and models for creating a concrete ethical way of life. But it also covers the personal level, i.e. the creation of a personal ethos in such a context. The term 'freedom practices' thus refers to both the collective and the individual level as two sides of the same coin, and can be used to indicate the creation of a personal ethos within such communities, groups, or networks, as well as these collective settings themselves - the fabric of which are the ethical ways of life developed by their members.

From the above, I propose to coin a concept of 'freedom practices' in terms of the following five core characteristics. At stake are distinct sets of critically creative ethical life projects that involve:1) the development of a personal ethical life project in a concern for others; 2) consisting of one's visible behaviour and acting in the world; 3 ) implicit or explicit critique of 
any domination; 4) creation; 5) relatively independent ethical communities, groups, or movements offering self-techniques and models.

In an analogy with causal overdetermination - meaning that a social phenomenon or practice is the effect of multiple causes at once, one of which alone is not enough to account for the effect - I propose that a freedom practice is at stake as an effect of multifactorialism, i.e. of overdetermination by the five different factors, or five core characteristics specified above.

Where do the parallels between Foucault's and Beauvoir's concepts of ethics in terms of distinct sets of critically creative ethical life projects come from? Their respective theoretical backgrounds, i.e. poststructuralism and existentialism, do differ substantially. But to both intellectual movements power is an inherent dimension of social relations. Both share a critique on abstract moralism and abstract humanism, and specifically on Hegelian and Marxist notions of a final reconciliation between people. As we have seen, Beauvoir recommends looking at which concrete individuals are at stake behind abstract ideas, since there is only the multiplicity of life forms and projects, instead of one single ethical community. From his Nietzschean orientation, Foucault considers power as permeating the whole of society and knowledge, as do postmodern - i.e. neo-Nietzschean - thinkers. To existentialists and postmodernists alike, universal values and dogmas involve (a will to) power of concrete individuals or social groups. To both Beauvoir and Foucault, abstract universal morality is to be surpassed by a concept of ethics as radically situated embodied life projects that partake in power relations, being power practices themselves.

Furthermore, we should take seriously that Foucault explicitly distanced himself from postmodernism. Both Beauvoir and Foucault share an existential ethical perspective, arguing for a personal, ethical self-creation, rather than a deconstruction of the self. ${ }^{21}$

Moreover, both counterpose their notion of a radically situated ethical life project to collectivist ideals and programs. Foucault integrated the idea of a personal ethical life project in his final work, convinced as he was that there is no way we can return to totalitarian models of Hegelian-Marxist signature. Beauvoir, in The Ethics of Ambiguity (1948), criticized Hegel

21 Foucault, in this respect, refers to nineteenth-century poet Charles Baudelaire's vision of 'modern man' as the man 'who tries to invent himself' (312). He adds, though, that Baudelaire unfortunately did not imagine that this ascetic elaboration of the self has 'any place in society itself or in the body politic' and is not limited to the domain of art as such (312). Beauvoir, in a similar vein, criticizes Oscar Wilde and surrealist writer Anaïs Nin for their 'aestheticism,' i.e. for making the beauty of their own lives their main focus as an art work in itself (cf. Beauvoir 1988: 165, 170; cf. Vintges 2001). 
for his collectivist conception of man, and explicitly targeted a Marxist politics that subordinated the individual to collectivity (cf. Beauvoir 1948: $18 \mathrm{ff}$.). But Foucault and Beauvoir not only criticize a stifling collectivism or communitarianism, they also keep their distance from an unencumbered individualism. To them, a personal ethical life project takes shape within a specific collective setting, instead of being its counterpoint. They point to collective and personal dimensions as two sides of the same coin - as do postcolonial authors like Audre Lorde (1984). The latter, in a similar vein, conceives of a 'community in difference' that balances individual and collective dimensions - expressing a vision of community that is 'shared by a number of black women scholars' (Havis 2014: 247; Lorde 1984: 111). ${ }^{22}$

Beauvoir and Foucault also share a certain distrust in academic philosophy. According to Hadot (1995), academic philosophy increasingly narrows itself into abstract reasoning; moreover, it risks losing its independence and turning into state ideology. In the words of Schopenhauer, university philosophy as a 'state-financed philosophy' aims 'to give students opinions which are the liking of the minister who hands out the Chairs' (cf. Hadot 1995: 271). In contrast, ancient ethics was relatively autonomous from moral codes, and engaged one's whole mode of being in a practice of freedom. Hadot contends that remainders of this concept of philosophy as a way of life are present in the works of Descartes, Spinoza, Nietzsche, Schopenhauer, Hegel, Marx, and Husserl, and, last but not least, in 'the movement of thought inaugurated by Heidegger and carried on by existentialism (that) seeks - in theory and in principle - to engage man's freedom and action in the philosophical process' (272). Both Beauvoir and Foucault can be grouped under this tradition. They counterpose their concept of ethics as a way of life to certain academic strands of philosophy that, according to them, come down to an empty, timeless reasoning.

Besides these parallels between Beauvoir's existential-ethical perspective and Foucault's final work, some crucial differences remain. Most important is Foucault's critique of the free, 'original' subject of existentialism. While Beauvoir in The Ethics of Ambiguity does situate the ethical self in social contexts, Foucault does so in more specific ways, pointing to certain relatively independent, identifiable networks and groups that offer the tools and models necessary for people to freely create and cultivate a personal ethical life project. Foucault's final, more radical, socio-historical approach 
is an indispensable 'update' of Beauvoir's ethics, transforming it into a timely philosophy. ${ }^{23}$

Whereas Beauvoir recognizes that social conditions may deny people access to a personal ethical life project, she does not specify these in terms of access to concrete ethical vocabularies. People kept in a state of servitude and ignorance should seize the opportunity 'once there appears a possibility of liberation' (Beauvoir 1948: 37). At some points in her essay, her emphasis on 'willing freedom' leads her to a moralism, which she later admitted and regretted. From Foucault's more concrete, historicizing approach we take that people can develop critically creative ethical life projects only within relatively independent ethical communities, groups or movements offering self-techniques and models - i.e. our fifth core characteristic of a freedom practice - that, like other discourses, emerge over time and cannot simply be made to happen.

As discussed in previous sections, Beauvoir and Foucault launch their concept of the critically creative ethical life project within collective settings as a counterpoint not only to abstract humanist and collectivist doctrines, but also to the current neoliberal models of Super Woman and Organization Man and the Entrepreneurial Self. But to what extent do their concepts of ethical self-creation differ from these models? Do the latter not involve similar projects of self-stylization and self-creation?

Comparing the ethical self involved in a freedom practice with the models of the neoliberal self, we can first conclude that the notion of an ethical life project involves a concern for the well-being of others, while the model of personhood of the neoliberal self is focused on personal success and safety. Developing a critically creative ethical life project moreover demands 'slow, sustained, and arduous work,' as Arnold Davidson notes (Davidson 2005: xxviii), instead of some quick and 'Easy steps to Accessing More Happiness and Boosting Your Success.' Furthermore, it concerns our acting in the world, rather than finding the truth of one's inner self, as is standard in current training programs of self-improvement designed by 'experts'. Next, it implicitly or explicitly opposes domination, instead of accommodating hierarchical and competitive frames, with dividing lines between winners and losers. And lastly, it is concretely situated within a distinct social group, community, or movement, while the neoliberal self is supposed to be autonomous and to independently choose his or her own way of life. 
While, thus far, only freedom practices of men have come to the fore, we can finally ask whether the concept is of any use to analyse women's positions in past and present. Is the concept of 'freedom practices' applicable to women as it is to men? And: is it not inherently Western? In Chapter 2, I will elaborate on the concept's culturally plural character, especially on its cross-cultural model of the ethical self as well as its plural 'keys'. Here, I will focus on the existence of women's freedom practices from the main theoretical perspective articulated thus far, i.e. as developed within philosophical schools and circles.

\section{Women's Freedom Practices: Some Examples}

In view of Foucault's claim that ethical practices of freedom in antiquity were only meant for free men, where do women and girls come into the picture? As we have seen, Foucault explicitly criticized the hierarchical, male character of antiquity's ethics. When discussing how 'Greek ethics were linked to a purely virile society with slaves, in which the women were underdogs' (Foucault 1997c: 256), he adds: '(a)ll that is quite disgusting!' (258). Moreover, when he points to remainders of the 'care of the self' tradition in Christianity (Foucault 1989: 451), and in a string of religious groups in the Middle Ages and the Renaissance (e.g. Foucault 1997c: 278, cf. Chapter 2), he never refers to women either. Hadot (1995) likewise only mentions men, in ancient times and thereafter, as practitioners of philosophy as a way of life.

In Chapter 2, I will argue that many women in history developed freedom practices in ways that Hadot and Foucault never conceived of. But, already from their concepts of philosophy as a way oflife, we find women engaged in such practices. Since ancient times, women have been members of relatively independent philosophical schools and circles that offered self-techniques to develop an ethical life trajectory. They created a personal ethical life project that challenged the dominant gender patterns of their time. In what follows, I mention only some women who became famous role models. However, they stand for many others who developed a critically creative ethical life project within the context of such circles, but who never made it into history books. ${ }^{24}$

24 Historical research today shows the existence of women philosophers from ancient time onwards. In what follows I especially make use of Carolien Ceton et al. (2012), a volume comprising 65 entries on women philosophers throughout times and cultures, composed by a range of scholars. 
Examples of women philosophers in Western antiquity are Hipparchia (c. 300 BCE) - member of the Cynic school of philosophy - and Leontion and Hypatia. Leontion (c. 300 BCE), commonly described as a hetaera, was a member of the Epicurean philosophical school that had slaves and women among its pupils. The members of this school, founded by the philosopher Epicurus, lived in a community a few miles outside the centre of Athens, away from the hectic life of the city. They bought a garden near their home, the famous Garden of Epicurus, where they together practiced the hedonist Epicurean lifestyle of friendship and pleasure. The Epicureans strived for tranquility of the soul and bodily health. Death to them is a natural phenomenon, nothing to be afraid of. We should, moreover, only strive for the fulfilling of simple natural desires, and abstain from unnecessary ones like ambition, wealth and power: man needs little to be happy and free. Leontion's works are lost, but she is praised for her sharp writing style - and especially for her treatise against the reputed leader of the Peripatetic school, Aristotle's successor, Theophrastus. Leontion thus carved her own path as a woman within the context of the Epicurean school, endorsing its values of cultivating friendship, philosophical contemplation, and living in harmony with nature.

Hypatia of Alexandria (355-415 CE), a skilled philosopher, mathematician, and astronomer, was a member of the Neoplatonist movement. This was a group of scholars, pupils, and friends that practiced an ascetic ethical lifestyle, marked by the study of theology, mathematics, astronomy, and oriented to higher forms of goodness and harmony. Some fragments and themes of Hypatia's work are known, such as her ideas on friendship. As the first female head of the Alexandrian Platonic school, she developed and passed on her own philosophical way of life to her students. ${ }^{25}$

Dutch seventeenth-century philosopher Anna Maria van Schurman (1607-1678) created a personal ethical life project as a woman within the context of philosophical as well as religious circles. ${ }^{26}$ Born in a wealthy Reformed family, and educated in the fine arts and literature, she became a very accomplished scholar, artist, and linguist, fluent not only in European languages, but also in Hebrew, Chaldean (Throat), Aramaic, Ethiopian, Arabic and Syriac, Latin and Greek. ${ }^{27}$ She was the first woman in the Netherlands permitted to attend a university - seated behind a wooden

25 Cf. the film Agora (2009) on Hypatia's life and work.

26 The following is based on Jeannette Bloem (2004) and (2012).

27 Museum Martena in Franeker, the Netherlands, shows some of her artistic work and her collection of insects, as well as diaries and correspondence, and the self-portrait inserted in the text. 
partition so the other students could not see her. Van Schurman wrote several public treatises, including a dissertation on the suitability of the female mind for scholarship and literature (1641), in which she argues that women who have the means to do so can, and should be allowed to study. She travelled widely, corresponded with prominent male philosophers of her time, including Descartes, and became something of a celebrity, due to her erudition.

Later in life she joined the religious community of preacher Jean de Labadie. When he was dismissed from the Reformed Church for his 'heretical' views, and founded his own house church in Amsterdam, Van Schurman made a radical decision. She sold her house and part of her library and joined his community, a choice that caused great commotion among her friends, admirers, and theologians, not least because she lived as a single woman under one roof with men. The attack on her reputation resulted in Van Schurman writing the Eucleria - published in 1673 in Latin, in 1684 in Dutch - in which she justifies her new way of life.

Van Schurman had always carved her own path as a Christian woman, and refused to be guided by others, hence her joining the Labadist community is often seen as a betrayal. This pietist movement, however, similarly refused to be guided by church institutions. Van Schurman's membership of this community, moreover, allowed her to share her life with like-minded peers on a daily basis, inspired as she was by the prototype of the first Christian communities.

Rather than as a betrayal, her life qualifies as a freedom practice, as an effect of multifactorialism, i.e. its being overdetermined by the five different factors specified earlier. She: (1) developed a personal ethical life project; (2) expressed in actions in the world such as attending university, publishing, corresponding; (3) in an explicit critique of the stereotype of the silent and humble Christian woman; (4) creating and inventing a way of life as a woman that challenged the dominant gender patterns of her time; (5) within philosophical circles, and later, within a relatively independent, religious community, both offering her self-techniques and models for a personal ethical self-creation.

Eightteenth-century philosophers Belle van Zuylen, Mary Wollstonecraft, and Caroline Schlegel, to name but a few, all belonged to philosophical circles that resisted traditional dogmas and conventions. Within these contexts, they consciously created their own personal ethical life project, in an explicit critique of the traditional roles for women. Their ethical ways of life comprise alternative models for self and society that challenge the dominant gender patterns of their time. 
Anna Maria van Schurman: Self-Portrait (1640)

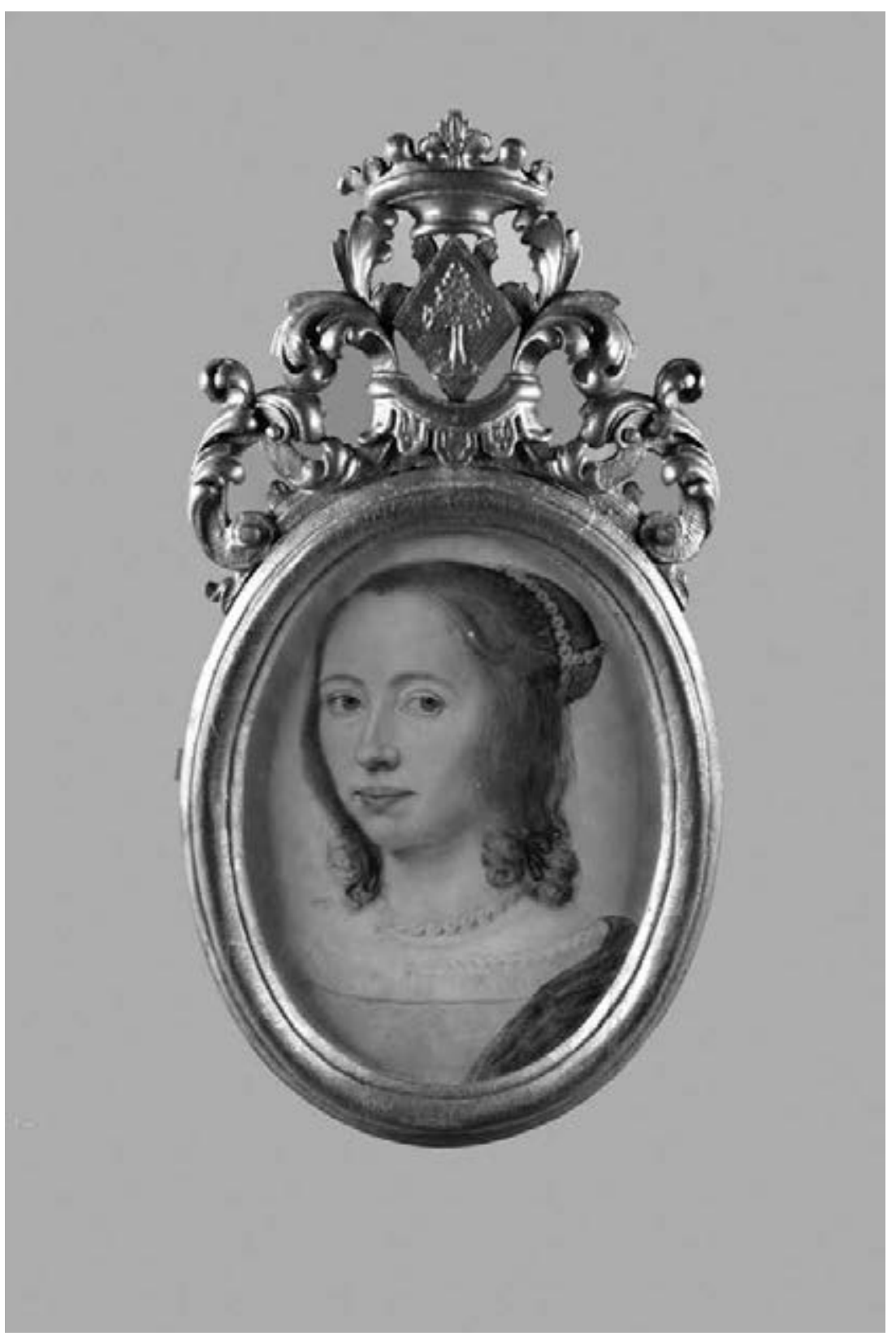

Copy provided by Museum Martena, Franeker 
The life of Anna Julia Cooper (1858-1964), who is generally considered the first black feminist, similarly comprises alternative models for self and society in relation to dominant patterns of race and gender. Cooper was an American scholar who participated in circles of abolitionist intellectuals. ${ }^{28}$ In her book A Voice from the South: By a Woman from the South (1892), she advocated the rights of African American women and girls to higher education. She created her own ethical life trajectory, by acting in the world, lecturing and publishing widely on racial and gender equality and setting up black communities and cultural organizations, in a challenge to the prevailing ideas about black women.

Russian born activist Emma Goldman (1869-1940), who participated in the international anarchist movement, likewise lived' her political philosophy. ${ }^{29}$ While Goldman initially sympathized with the Russian revolution, after a few years she became one of its sharpest critics. She also changed her initially positive attitude towards political violence. As an activist, she created a lifestyle that combined an anarchist political 'spirit' with passion, commitment, creativity, and courage. Goldman's personal ethical life project, comprising her actions in the world, can be seen as political philosophy in action. As such, it contains a set of cultural alternatives for self and society, on micro-, meso-, and macro level, such as the necessity of improving the social condition and rights of workers, of access for women to birth control, of new forms of direct democracy, and of resistance against patriottism and war, militarism, and nationalism. Emma Goldman (E.G.) made her life into 'an example' (Ferguson 2011: 283).

Simone de Beauvoir, within the philosophical 'school' of existentialism, not only conceived of ethics as a freedom practice, but created a personal ethical life project along these lines as well. She cultivated a personal life trajectory as a woman intellectual, against the conventions of her time, by carefully stylizing her acting in the world, in concrete commitments against sexism, colonialism, and racism, within the collective setting of an existentialist circle of friends that she often called her 'family'. Although she did not elaborate a concept of ethical self-techniques, and merely spoke of the necessity of permanent ethical effort, her autobiographies give us an account of the concrete self-techniques that she and other existentialists developed, such as the establishing of daily routines of work and leisure, living in hotel rooms, and eating in restaurants. Other self-techniques that she developed include undertaking long walking trips on her own 


\section{Emma Goldman (c. 1910)}

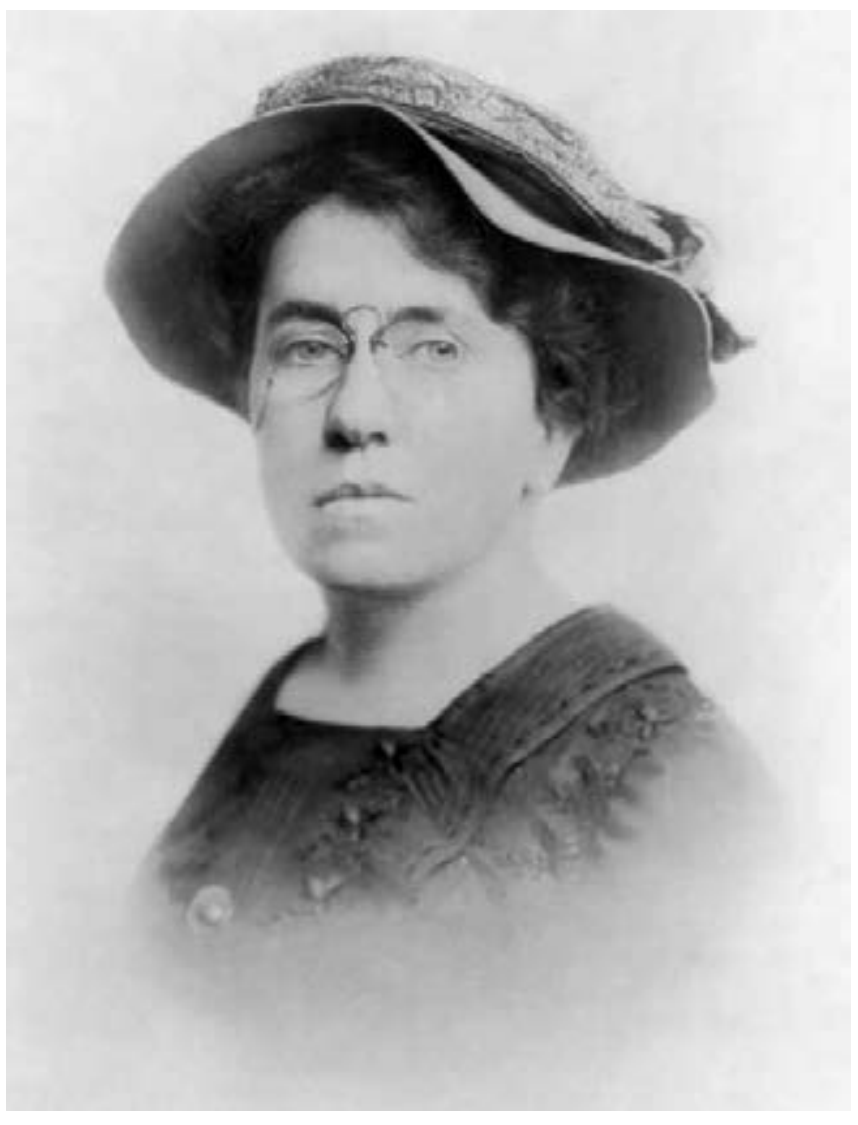

Photographer: Takuma Kajiwara

Retrieved from: https://commons.wikimedia.org/wiki/File:Emma_Goldman_unrestored.jpg

(cf. Hesp 2015), and the writing of five autobiographies, which can be seen as 'hypomnemata', i.e. writing exercises to create herself as the ethical subject she aspired to be (cf. Vintges 2004b, 1996).

In her introduction to The Second Sex, Beauvoir positions herself as living in a time of transition, when women, for the first time in history, could develop a critically creative ethical life project. In the next chapter, we will see that many women in past and present did so, in ways that neither Beauvoir, nor Foucault have imagined. 



\section{$2 \quad$ Women's Freedom Practices in World Perspective}

Is the concept of freedom practices Western-centric in character? Or does it involve a culturally plural notion that is present throughout cultures, and that, as such, allows for a critical reformulation of feminism in world perspective? 'Feminism' is often criticized for being inherently white and Western - a critique that largely corresponds with mainstream feminism's claims that women in the West are the liberated, autonomous subjects that women from 'other cultures' are yet to become. Chandra Talpade Mohanty (1991) and Lila Abu-Lughod $(1986,2002)$ famously criticized Western feminists for a priori victimizing non-Western women, instead of approaching them as agents. Sawitri Saharso (2000), in a similar vein, argued that Western feminists should take different models of self into account, rather than imposing a Western view, in informal and formal, even violent ways. According to Saba Mahmood (2008), 'feminism' today 'runs the risk of becoming more of a handmaiden of empire' (Mahmood 2008: 82). Referring to the American invasion of Muslim countries to bring freedom and democracy, especially to their female inhabitants, she concludes that we face a 'collusion of empire and feminism in this historical moment' (84, cf. 89).

Mahmood (2012) specifies what is intrinsically wrong with Western feminism's model of the self; namely, its reliance on a conception of autonomized agency and its refusal 'to grant legitimacy to any other form of subjectivity or criticality' (Mahmood 2012: xii). Feminism's model of the autonomous self, moreover, is paired to a 'normative secularism', i.e. the assumption that only in a secular society can people be free and liberated autonomous persons (Mahmood 2008: 82). The concept of freedom 'as an individual capacity to act autonomously in accord with one's own desires and interests,' wrongly presupposes 'a necessary antagonism between the individual and the social' (Mahmood 2007: 148). According to Mahmood, this concept of 'freedom is normative to feminism as it is to liberalism'; she therefore, not surprisingly, keeps her distance from any 'feminism' (Mahmood 2005: 10).

Eléonore Lépinard (2011) concludes that the value of autonomy is 'a site of feminist divisions,' and the reason why we face a serious 'crisis of the feminist subject' (Lépinard 2011: 217). While Lépinard argues that a reformulation of the concept of autonomy is 'an urgent task to pursue for feminist theory' (217), it seems necessary to replace it by another, culturally 
plural concept. Before we assess the merit of the concept of ethical 'freedom practices' (i.e. critically creative ethical life projects developed within distinct communities) in this regard, we must first take a brief look at some of the philosophical debates about the concept of autonomy. ${ }^{1}$

\section{Surpassing autonomy}

Autonomy (literally: giving oneself one's own law) is one of the main principles of Western liberal philosophy. It can be traced back to the ideas of seventeenth-century thinkerJohn Locke, especially to his idea that individuals have basic human rights that the state should respect and protect. Arguably, more important are the ideas of the eighteenth-century - Western Enlightenment - philosopher Kant, who held that people should lead self-authorizing, self-determining, and self-governing lives. To Kant, acting autonomously meant to act in accordance with reason's requirements, i.e. in accordance with maxims or rules that can simultaneously be willed as universal laws.

Mainstream Western feminism is based on the idea (l) of women's autonomy. Liberal feminist philosophers like Susan Moller Okin and Martha Nussbaum argue for a global implementation of this idea (l). Okin (1999) criticizes multiculturalism and claims that feminism essentially should be based on Western liberalism's 'fundamentals', such as the principle of autonomy (Okin 1999: 24). According to her, discriminatory practices against women are inherent to all cultures, whereas the norm of gender equality 'is at least formally endorsed by liberal states' (8). Nussbaum (2000) argues that personal autonomy is part of 'the good life,' and belongs to the principles a global feminism should be based on.

To these and other liberal thinkers, autonomy, in line with the ideas of philosopher Kant, involves the capacity to rationally choose one's own way of life. To Kant, being rational meant following substantive moral standards, on the basis of independent deliberation. ${ }^{2}$ Kantians today often argue in more procedural, i.e. content-neutral ways, holding that independent deliberation is important for autonomy, no matter what the outcome, moral or not. Decisive is whether one acts according to one's own will. Beate Rössler (2002) synthesizes the two approaches, arguing that what is important is that a 'rich' reflection takes place on 'the practical question,'

1 The philosophical literature on autonomy is complex and extensive. I only discuss some issues that I consider relevant to the debate on feminism in world perspective.

2 'Autonomy of the will is the property the will has of being a law unto itself' (Kant 1948: 108). 
i.e. the moral question of how one wants to live one's life and who one wants to be, a reflection that is not only rational but can be informed by emotions as well. What is crucial is 'that a person, to be autonomous, asks herself this practical question in the proper, that is, independent, way' (Rössler 2002: 144). Autonomy should be taken as a normative principle, rather than an ontological one. Persons should be able and be allowed to live in a 'self-chosen way,' leading a 'self-determined life' $(147,150){ }^{3}$

Some prominent 'second wave' feminist scholars have attacked the concept of autonomy as independent moral decision-making for being inherently masculine (cf.Jaggar 1983) and for wrongly presuming an atomistic conception of the self (cf. Young 1990). Seyla Benhabib (1987) traces this model of the self back to philosopher Thomas Hobbes' proposal to think of men as 'mushrooms', emerging from the earth and coming to full maturity without any kind of engagement with each other (Benhabib 1987: 84). Other authors have characterized the model of the autonomous self as a 'Teflon subject' to which nothing sticks (White 2000:4), or as 'disembedded, 'punctual,' or 'disengaged' self (Taylor 1989:159 ff.). All these concepts critically target the liberal notion of the person as 'inner citadel' (cf. Christman 1988), capable of independent decision-making and self-control, as if the person is extension-less and not constrained by established custom (cf. Van Leeuwen and Vintges 2010: 654).

In response to these critiques, Catriona Mackenzie and Natalie Stoljar (2000) elaborated the concept of 'relational autonomy'. The notion aims to cover the variety of ways in which people's identities are shaped within social relationships; namely, 'by a complex of intersecting social determinants, such as race, class, gender, and ethnicity' (Mackenzie and Stoljar 2000:4). ${ }^{4}$ By taking these social dimensions into account, the authors aim to rehabilitate the concept of autonomy for feminist theory, 'disentangling it from suspect ideals of radical independence and self-reliance' (Westlund 2009: 26).

Rössler (2002) points out the problematic side of the concept of 'relational autonomy.' If relationality is to be seen as inherent to the concept of autonomy itself, it is legitimate to wonder whether we are dealing with autonomy at all. That is to say, it 'is precisely the distinction between a relational and a nonrelational concept of autonomy that allows a person the possibility of extricating herself from relationships' (Rössler 2002: 149). Of course, a Kantian notion of moral freedom or personal autonomy is situated in a social

3 With thanks to Matthé Scholten.

4 An extensive debate has ensued on the heuristics of the concept of relational autonomy. Again, I selectively discuss some issues only, in the light of the debate on feminism in world perspective. 
world where subjects have to 'orient themselves more or less autonomously in their social relations. But this is, strictly speaking, a chronological dependency: moral freedom has to keep its priority over existing social contexts and institutions since otherwise it would not be what it is supposed to be: individual freedom' (Rössler 2013: 17). Mackenzie (2014) seems to endorse Rössler's argument for the external character of relationality when she argues for an improvement of women's social conditions that should enable them to be self-authorizing, self-determining and self-governing agents. Be it that the person is always socially embedded, Mackenzie's perspective thus, in a normative respect, covers the Kantian liberal one.

Lisa Schwartzman (2006) explicitly challenges the liberal feminist approach. She criticizes liberal theory's abstract, 'ideal theoretical' method - as propagated by, for instance, liberal feminists Onara O'Neill and Nussbaum - for not dealing with our actual, non-ideal, social world.Schwartzman especially criticizes liberal theory for its individualist methodology, i.e. its individualist approaches of society, from which social relations of power - such as women's oppression by men - cannot come to the fore. Elizabeth Anderson (2009) counters Schwartzman's critique by arguing that liberal theory is not 'group blind' at all. She points to Montesquieu's and Mill's critiques of women's oppression, arguing that liberalism has long been interested in oppressive social practices defined on group lines' (Anderson 2009: 139). Endorsing a normative individualism does not necessarily imply a methodological or ontological individualism. Anderson concludes that liberalism is entirely consistent with the methods Schwartzman advances (131).

In these philosophical debates, Western feminists tend to agree not so much on an ontological individualism, but rather on a normative individualism, i.e. on a normative Kantian ideal of independent individual choice and decision making. Anderson's reply to Schwartzman illustrates how liberal theory is currently able to incorporate any critique. John Dryzek et al. (2006) contend that liberalism will become more conscious of its own historical contingency, however, and that new alternatives to liberalism will gain strength in future years, among others from postcolonial and feminist signature (Dryzek et al. 2006: 24-26). The work of anthropologist Mahmood is a case in point.

\section{Ethical Self-Formation in Religious Contexts}

Mahmood's critique on Western feminism's too narrow models of self and society is based on her study of a grassroots women's piety movement in Cairo (Mahmood 2005). The women participating in this Islamist movement, 
instead of being the oppressed creatures that Western feminists hold them to be, are religious agents who practice an ethical 'self-cultivation' that engages their entire way of life (Mahmood 2005: 158). Liberal feminists with their 'conceptions of the subject, autonomous reason, and objectivity, through which the pietists are understood to be lacking in faculties of criticism and reason' (Mahmood 2012: xii) cannot imagine that Muslim women strive for completely different values; namely, a pious instead of a free, autonomous life.

For an alternative concept of human agency, in her study, Mahmood turns to Foucault's final work. His ethics approach is 'particularly helpful for conceptualizing agency' since it allows us to conceive of its multiple forms (Mahmood 2005: 29). Authors like Daisy Dwyer (1978), Abu-Lughod (1986), and Janice Boddy (1989) have already approached Arab and Muslim women as active agents. However, their studies remain grounded in a binary framework of agency as either consolidating or resisting norms - and the same counts, in a general sense, for Judith Butler's concept of agency (cf. Mahmood 2005: 20 ff.). Instead, Foucault's final approach allows for a conception of the variety of ways in which norms are 'performed, inhabited and experienced' (22).

Mahmood especially refers to Foucault's four axes of ethical self-formation (cf. 32), distinguished by him in terms of ethical substance, mode of subjection, means, and telos and reformulated by us in terms of the answers to the questions: what, why, how, and to what purpose (cf. Chapter 1). This analytical toolset allows for a conception of multiple forms of moral agency, to be specified in terms of the concepts and models that cover the four aspects of ethical self-formation.

As discussed earlier, Foucault argued that the dimension of ethical selfformation is present in all moral systems. He also added that 'techniques of the self' 'can be found in all cultures in different forms' (Foucault 1997c: 277). Mahmood's study builds on Foucault's approach and demonstrates that it allows for an analysis of the moral agency of the Muslim women of the Egyptian piety movement. Foucault's notion of ethical self-formation conceptualizes 'the work bodily practices perform in crafting a subject' (Mahmood 2005: 122), i.e. the techniques of 'self-fashioning' (Mahmood 2001: 223). The concept of ethical self-formation captures how piety in Islam must become an embodied habit by simultaneous exercise of the body, the emotions, and reason, through the practicing of self-techniques. As such, it involves a situated and integrated notion of the self that a Western notion of autonomy does not cover.

Mahmood specifies the moral agency of the women of the grassroots piety movement in Cairo in terms of Foucault's four axes, concluding that 
the ethical substance of their moral agency are the movements of the body; its mode of subjection the divine plan for human life - embodied in the Qur'an; its telos to approximate the exemplary model of the pious self of the Prophet and his Companions; and its self-techniques the 'ritual practices, styles of comporting oneself, dress and so on,' that establish a coordination between outer conduct and inner states, i.e. one's intentions, movements of desire and thought (Mahmood 2005: 31).

According to Mahmood, the Muslim women of the Egyptian piety movement practice their ethical self-formation without questioning the dominant rules of gender segregation and their own subordinate status as women. But though she wants to stay away from 'the binary terms of resistance and subordination' (Mahmood 2005: 15) and from a concept of freedom, her own study more than once addresses the question whether or not the Egyptian women's mosque movement can be said to have latent liberatory potentials' (5). Repeatedly, Mahmood discusses whether the movement not only challenges Western secular-liberal models of the self - as is central to the movement's self-understanding - but male authority in Islam as well, which is not claimed by the movement itself (cf. 175). The movement is 'altering the historically male-centered character of mosques as well as Islamic pedagogy' (2, cf. 15) to the effect that it is 'undermining the authority of dominant norms, institutions, and structures' (174-175, cf. 34, 89, 175, 179). Foucault's notion of ethical practices of freedom seems to resonate at the background of Mahmood's study. However, Mahmood only takes on board Foucault's concept of ethical self-formation within 'code-oriented' moral systems. She convincingly demonstrates that this concept is culturally plural in character. Her work is exemplary in this respect and has inspired many others (e.g. Bracke 2007; Longman 2007). But is Foucault's concept of practices of freedom - and by extension our concept of 'freedom practices' - equally applicable in non-Western perspective?

\section{Freedom Practices: A Culturally Plural Concept}

Is the concept of freedom practices Eurocentric or culturally plural in character? Since the concept especially capitalizes on Foucault's notion of ethical practices of freedom, to answer this question we must first examine his concepts - among others his occasional use of the term 'spirituality', in reference to Hadot's approach of ancient philosophy as a way of life (cf. Chapter 1). 
According to Hadot (1995), ancient philosophy consists of 'spiritual exercises' that require effort and training and that aim for the stylization of one's whole way of life. It is therefore necessary, Hadot argues, to use the term 'spiritual',

because none of the other adjectives we could use - "psychic," "moral," "ethical," "intellectual," "of thought," "of the soul" - covers all the aspects of the reality we want to describe [...] the word "thought" does not indicate clearly enough that imagination and sensibility play a very important role in these exercises (Hadot 1995: 81-82).

In his final work, Foucault uses the concept 'spirituality' in a similar vein (cf. Vintges 2011). He states:

By spirituality I mean - but I'm not sure this definition can hold for very long - the subject's attainment of a certain mode of being and the transformation that the subject must carry out on itself to attain this mode of being. I believe that spirituality and philosophy were identical or nearly identical in ancient spirituality (Foucault 1997d: 294).

According to Foucault, this spiritual self-transformation took place in ancient times within "scattered centers" whose origins were in different philosophical or religious movements' (Foucault 1986a: 21). ${ }^{5}$ Jeremy Carrette (2000) criticizes Foucault's concept of spirituality for 'expunging' any metaphysical reference (Carrette 2000: 114, cf. 180). But to Foucault, 'spirituality' does not cover religion as such, as Carrette presumes, but when used in the context of religion, refers to an ethical care for the self; in other words, to practices of freedom in religious contexts.

The concept of spirituality in this sense returns in Foucault's comments on the 1978 Iranian Revolution, which he, like many others at that time,

5 Foucault (2005a) distinguishes between two major poles: 'on one side a more popular, religious, cultic and theoretically unpolished pole; and, at the other end, care of the soul, care of the self, practices of the self, which are more individual, personal and cultivated' (Foucault 2005a: 115). But, as he argues, the practice of the self was nevertheless important in the latter kind of groups as well. He states: 'I certainly do not mean that there is this distinction between popular and crude versus learned, cultivated and friendly, things were much more complicated' (115). To show 'the complexity and variety of all these institutional dimensions of the care of the self, there is another example: this is the famous group of the Therapeutae' (116). This religious community combined religious rituals and practices, with 'care for the soul' by searching for knowledge, meditation, reading, apprenticeship and so on (cf. 117, 127). 
considered primarily as an anti-imperialist revolution (cf. Honig 2008). Arguing that people were 'spiritually' involved, he meant that, to them, their whole way of life was at stake. In a similar vein, he spoke of a 'political spirituality,' opposing Truth regimes and producing something new (Foucault 2005b: 209). He also talks about Shi'ism as a form of Islam that differentiates between 'mere external obedience to the code' and 'the profound spiritual life.' In revolutionary Iran, identification with the Islamic tradition combined with 'the renewal of spiritual experiences,' i.e. people's 'desire to renew their entire existence' (Foucault 2005c: 255). ${ }^{6}$

Elsewhere, Foucault discusses the presence of practices of freedom in religious contexts in more explicit terms. As discussed briefly in the previous chapter, in this respect he pointed to some religious groups in ancient times as well as to certain religious groups during the Middle Ages and the Renaissance. The latter resist pastoral power and

claim the right to make their own statuses for themselves. According to these groups, the individual should take care of his own salvation independently of the ecclesiastical institution and of the ecclesiastical pastorate. We can see, therefore, a reappearance, up to a certain point, not of the culture of the self, which had never disappeared, but a reaffirmation of its autonomy (Foucault 1997c: 278). ${ }^{7}$

Discussing the status of ascetic practices within Christianity, he states that 'with the religion of the text, the idea of God's will and the principle of obedience, morality took much more the form of a code of rules. Only certain ascetic practices of Christianity were more closely linked to the exercise of a personal liberty' (Foucault 1989: 451). While the Church stressed the principle of 'a morality whose precepts were compulsory and whose scope was universal,' this did not rule out 'the existence of ascetic movements having their own aspirations' (Foucault 1986a: 21). In sum, '(e)thics-oriented moralities [...] have been very important in Christianity, functioning alongside the "code-oriented" moralities' (30).

6 Janet Afary and Kevin Anderson (2005) criticize Foucault's stances concerning the Iranian revolution in 978 . Foucault, however, explicitly criticized the violence that marked the postrevolutionary power struggle in Iran, distancing himself from its outcome. In newspaper articles published in April and May 1979 he supported the rights of the individual against the 'bloody government of a fundamentalist clergy' (Foucault 2005d: 265).

7 Notice once again that it is the relative independence of ethical self-practices that interests him - cf. Chapter 1. 
Foucault's conceptualizing of practices of freedom that involve a personal creative ethical self-formation in the context of Christianity and Islam can be extended to other religious contexts as well. As Inoue Tatsuo (1999) states, Chinese culture and philosophy are too rich and complex 'to be presumed ignorant of the value of individuality' (Tatsuo 1999: 51). Especially the seventeenth-century Neo-Confucian movement has a tendency to emphasize 'the worth of individual self-development and the importance of an independent, critical, and creative attitude toward the Confucian texts and their authoritative exegeses' (51). This critical tendency competes with an authoritarian tendency that originated from Confucianism, but it has been present all along, cultivating a 'critical spirit toward political power and the courage to resist persecution' (51). In Buddhism, a 'spiritual individuality' (52) exists 'perhaps even more vividly' (51) and the same counts for the Islamic mystical tradition of Sufism (52).

Foucault, during his visit to Japan in 1978, showed a great interest in the practice of Zen Buddhism. He took lessons and afterwards said to his teacher: 'I'd like to ask you just one question. It's about the universality of Zen. Is it possible to separate the practice of Zen from the totality of the religion and the practice of Buddhism?' (Foucault 1999: 113). He also remarks that whereas Zen and Christian mysticism cannot be compared, the techniques of Christian spirituality and that of Zen are comparable. Foucault's question and remark show his interest in non-Western, ethicalspiritual self-techniques during these years.

As discussed earlier, Foucault was convinced that Western philosophy must change its concepts and turn into a philosophy that is worldwide in its vision (cf. Foucault 1999: 113, cf. the Introduction). His own concept of practices of freedom qualifies as a cross-cultural concept in that it refers to rich traditions throughout cultures, and implies a notion of an integrated ethical self, engaged in techniques and practices of ethical self-creation, in an implicit or explicit critique of constraining models of self and society.

Beauvoir presented the concept of a personal, critically creative ethical life project as a counterpoint to constraining neoliberal models of the self. For her, a lived ethics has many faces, situated as it is in social contexts that are radically plural. As we have seen, in The Ethics of Ambiguity, Beauvoir criticizes the Kantian concept of moral autonomy, which holds that a person's ethical choice is achieved 'in the intelligible world by a purely rational will,' requiring that the human person 'transcends its empirical embodiment and chooses to be universal' (Beauvoir 1948: 33, 17). To her, however, rather than being universal, the ethical self is socially embedded within distinct communities and is an interdependent, embodied self. The culturally plural 
character of our concept of freedom practices is also rooted in Beauvoir's culturally plural notion of the ethical self. Although, throughout her work, she criticized dogma-oriented religious systems that oppressed women on behalf of rigid doctrines, her perspective, i.e. that the ethical life project is always radically situated, is open, in principle, to an ethics-oriented kind of religiosity that involves personal ethical-spiritual life projects developed within communities, in the shape of a freedom practice.

During her stay in the US, in 1947, she was invited by her friend Richard Wright to attend several Harlem church services. In America Day by Day (1999) she notes how black religion is a source of inspiration to black people that may be used for their submission - since black people's religion is 'exploited as a distraction' - but also as a source of black subversion (Beauvoir 1999: 57). The sermons of the pastors of the many churches in Harlem have immediate social resonance and help black people become conscious of their problems because they allude to the burning issues of justice and happiness. This is why many black intellectuals display a certain goodwill to the Church, even as they deplore its submissive attitude' $\left(275^{-276)}\right.$. She concludes that the cultural sources of the black community are taken on in a critically creative way by its leaders, in an inventive politics (cf. Simons 2002: 282-283; Van Leeuwen and Vintges 2010: 657).

Next to its culturally plural notion of the ethical self, the concept of freedom practices involves a cultural pluralism in yet another sense; namely, in its comprising other 'modes of thought' alongside strictly verbal ones. At several points in his work, Foucault discusses non-verbal modes of thought; for instance, when he argues that ' $(t)$ hought does exist, both beyond and before systems and edifices of discourse. It is something that is often hidden but always drives everyday behaviors. There is always a little thought occurring even in the most stupid institutions; there is always thought even in silent habits' (Foucault 2000: 456). As we have seen, like Hadot (1995), he conceives of ancient philosophy's bodily practices, rituals, and habits as comprising thought and knowledge (cf. McLaren 2002). Moreover, motivated by his critique on modern science's normalizing dimensions, Foucault explicitly argues for a philosophy that studies and revalues people's 'subjugated knowledges,' i.e. 'historical contents' and types of knowledge that have been disqualified as non-conceptual, and as 'below the required level of erudition or scientificity' (Foucault 2003: 7 , cf. the Introduction).

In reference to Foucault's concepts of 'art of living' and 'subjugated knowledges', Havis (2014) discusses the ways some black women use ancestral narratives, folk-wisdom, music, and other cultural repositories to redefine 'individual and group identity' in non-static ways. To Havis, their use of these 
cultural repertoires comprises philosophical ideas and a certain philosophical praxis that academic philosophy can learn from (Havis 2014: 239, 249).

Langer (1960) explicitly argues for academic philosophy to build on other modes of thought alongside verbal ones, and develops a set of concepts to conceive of some important 'non-verbal' modes of thought. She especially points to religious rite, art, and myth, which together she defines as 'presentational' modes of thought, since they are characterized by a 'simultaneous, integral presentation' of ideas (Langer 1960: 79). Rite, myth, and art do present thought in 'forms', i.e. an arrangement of elements, among others in visual forms 'grasped in one act of vision' (75). Their 'presentational,' non-verbal, 'forms' address perception, intuition, insight and imagination in a direct way and have an emotive import. Yet, they are the bearer of ideas, showing these holistically and simultaneously - instead of stating them in a linear way as verbal language does. Their 'forms' express a certain proportion of parts, a structure in the sense of a relational order, and thus articulate a certain pattern. As such, they comprise ideas and in that sense, to Langer, not only science, but rite, art, and myth 'are intellectual activities' (Langer 1960: Preface). A 'philosophy in a new key' should recognize the 'presentational' realms as modes of thought in their own right (71).

The term myth, to Langer, refers to a specific, secular genre of narratives. Other than religion, mythology does not originate in 'religious feeling,' but in fantasy and specifically in its primary form, the dream (139). Myth is a 'dream-narrative' (144), made of 'dream-material' (139). Mythical tales are 'the great dreams of mankind' (159). Fairy tales, too, are made of dream material, namely 'image and fantasy.' Both the fairy tale and myth have 'symbols for father and son, maiden and wife and mother, possession and passion, birth and death' (144). But myth, other than fairy tales, expresses the cosmic setting of mankind and its relation to nature (cf. 146); as such, it comprises 'mystic' truth (cf. 142). While fairy tales are a form of wishful thinking and allow people to cope with actual experiences, myths, whether literally believed or not, are for understanding actual experiences. Myth's typical themes are tragic, its characters are often supernatural, and its purpose is more difficult and serious. At its best, myth entails a 'recognition of natural conflicts, of human desire frustrated by non-human powers, hostile oppression, or contrary desires' (143).

According to Langer, the heyday of myth is over, but its ways of thinking live on today, side by side with philosophy and science (cf. 165). We have to recognize that 'emotional attitudes that have long centered on a myth are not easily broken; the vital ideas embodied in it cannot be repudiated because someone discovers that the myth does not constitute a fact' (164). 
In sum, ' $(t)$ he Gods have their twilight, the heroes are forgotten' (165), but myth's vital meanings, and 'moral orientation' (143) live on in 'the mode of art' (165), such as music, painting, architecture, poetry, dance, and drama.

To Langer, myth represents the primitive phase of man's metaphysical thinking (cf. 163). Academic philosophy today risks losing its relevance and vitality if it denies its roots and debunks all 'presentational' modes of thought as irrelevant to intellectual progress. A 'philosophy in a new key' finds timely 'new conceptual forms' (cf. 238-239) in the presentational realm that it can articulate and build on.

Langer's elaboration of various non-verbal modes of thought allows for an articulation of ethical freedom practices comprising several other 'keys' in addition to verbal language. Foucault already pointed to the practicing of rite, and of bodily exercises in a broader sense, as an integral part of ethical freedom practices. His approach can be enriched by applying Langer's concept of the 'presentational' keys of art and myth, alongside rite: ethical freedom practices from this perspective comprise several 'keys' in combination with verbal modes of thought - comprising, among others, religious, artistic, and mythical 'forms'.

Freedom practices in the 'forms' of art are present in jazz scenes, as is argued in 'jazz studies', but also in blues- and hip hop scenes. But many more art styles, shared by - male and female - dancers, actors, musicians, painters, and others, comprise a distinct set of critically creative ethical life projects, embodied in a 'presentational' mode. An example more related to myths, concerns the performance of Asian martial arts, which have their roots in pre-history and are rich with mythical figures and stories. According to former Dutch Kendo champion/teacher and academic philosopher Henk Oosterling, these martial skills involve a physical spirituality, comparable to the ethical bodily self-techniques that Foucault focused on. Oosterling inspired Rotterdam primary schools in underprivileged neighbourhoods to include martial arts lessons in their curriculum as well as gardening, cooking, and philosophy in an eco-social program that has become a shared educational freedom practice (cf. Oosterling 2015).

We can conclude that because the concept of freedom practices involves a set of culturally plural 'keys' and also relies on a cross-cultural notion of an ethical self, it is culturally plural in character. As such, the concept of freedom practices covers a treasury of identifiable sets of critically creative ethical life projects, through time and space, which conform to our five core characteristics. The present study only focuses on (a variety of) women's freedom practices in past and present, especially in light of the debate on feminism in world perspective. A first conclusion can be that, because of 
its culturally plural character, the concept of freedom practices allows for a critical reformulation of feminism in world perspective; namely, in terms of a set of critically creative movements that in several 'keys' struggle for women's access to an ethical freedom practice, i.e. a personal ethical way of life within their distinct communities. A feminism in world perspective that strives for access for all women to a 'freedom practice', practices what it preaches and consists of a set of freedom practices itself, i.e. collectives that offer self-techniques, and that develop new ethical ways of life and models for self and society, in critically creative ways, and in various 'keys'.

\section{Re-reading The Second Sex in World Perspective}

Whereas the concept of freedom practices, with its culturally plural character, in principle, allows for a critical reformulation of feminism in world perspective, does the classic text of feminism, i.e. Beauvoir's study The Second Sex, support such a critical and culturally plural reformulation? While Beauvoir's The Ethics of Ambiguity (1948) - contra a Kantian notion of moral 'autonomy' - presented a radically situated and integrated notion of an ethical self, do we find a similar notion in her study The Second Sex? Or does The Second Sex, the work that we classified as the 'exemplar' of contemporary feminism, propagate a Western-centric concept of individual freedom? In what follows, I will examine the work's normative perspective.

According to many, Beauvoir merely applied Sartre's concepts of human consciousness as 'transcendence' and ontological freedom in The Second Sex. Thus, The Second Sex is criticized for taking a male perspective, privileging male activities over traditional female roles. ${ }^{9}$ According to Mackenzie (1998), Beauvoir favours a model of autonomous subjectivity to be associated with masculinity, and denies bodily dimensions (Mackenzie 1998: 150). Eva Lundgren-Gothlin (1996) argues that Beauvoir imported the androcentric perspective of the Hegelian-Marxist tradition, privileging work as productive activity above caregiving tasks - to mention but a few examples of critique from this direction. However, re-reading Beauvoir's study through the lens of The Ethics of Ambiguity, published

8 Cf. Vintges (2004a). Foucauldian feminists Margaret Mclaren, Ladelle Mcwhorter, and Dianna Taylor, from whose works I draw heavily, in similar ways propose to conceive of feminism in terms of practices of freedom (cf. McLaren 2002; Taylor 2004; Taylor and Vintges 2004; McWhorter 2013).

9 For an overview of these critiques from the time of The Second Sex's publication see Jo-Ann Pilardi (1993). 
two years before The Second Sex, clarifies the work's actual normative perspective.

In the Introduction to the work, Beauvoir immediately states that her 'ethical background' (Beauvoir 2010: 16) is 'existentialist morality' (17). She clarifies that rather than trying to conceal one's principles, it is better to state them from the start: "then it would not be necessary to specify on each page the meaning given to the words "superior," "inferior," "better," "worse," "progress," "regression," and so on' (16). Instead of referring to the public good, general interest, or personal happiness, an existential ethical perspective involves that '(e)very subject posits itself as a transcendence concretely, through projects; it accomplishes its freedom only by perpetual surpassing toward other freedoms' (17). Here, Beauvoir hints to the normative perspective she developed in The Ethics of Ambiguity; namely, to an existence as an engaged freedom, involved in ethical projects in the world and living in interdependence with others. Later, in The Second Sex, she refers to her ethical theory more explicitly, as will be discussed below. To understand the work's normative perspective more fully, however, we first have to examine the work's main thesis; namely, that societies have always been patriarchal, based as they were on male authority and women's subordination.

According to Beauvoir, whatever a society considered the most important activities were the prerogatives of adult males. In subsequent chapters, she discusses how biology, psychoanalysis, and historical materialism each have explained this fundamental asymmetry between the sexes in reductionist ways, i.e. on the basis of nature, sexual desire, and the economy, respectively. In contrast, woman's 'total situation' should be studied, instead of reducing her secondary position to one single cause. ${ }^{10}$

To Beauvoir, the power asymmetry between the sexes is the outcome of a combination of factors, as will become clear after a brief detour through the work of Hegel. In The Ethics of Ambiguity, we saw her arguing in line with Hegel that human freedom is interdependent, since we find a justification of our own existence 'only in the existence of other men' (Beauvoir 1948: 72). But in The Second Sex she explicitly refers to Hegel's ideas on the necessity of recognition, as explained in his 'master-slave' or 'lord-bondsman' metaphor (Hegel 1977: 104-119). Hegel started from the premise that human consciousness 'exists only in being acknowledged' (111). It needs another consciousness to affirm the truth, or objectivity, of its own existence. Therefore, when two

10 In line with philosopher Edmund Husserl's articulation of the task of philosophy, she aims to elucidate the whole phenomenon, i.e. women's total situation, in contrast to scientific approaches that are necessarily reductionist in character (cf. Vintges 1996). 
consciousnesses meet, a struggle for life and death emerges: each seeks to utilize the other one for its own purposes; namely, to be recognized as an independent or pure consciousness. The one who has the courage to struggle till the end becomes the master, because, by ultimately risking his life, he demonstrates that he is not attached to life but pure consciousness instead.

The one who surrenders fails in finally staking his life and becomes the slave. As the outcome of this struggle we have 'a pure self-consciousness, and a consciousness which is not purely for itself, but for another.' The former is the master, the other is the slave, who is a 'consciousness in the form of thinghood,' still bound to Nature. The master 'is the independent consciousness whose essential nature is to be for itself; the other is the dependent consciousness whose essential nature is simply to live or to be for another' (115). The latter is an inferior, dependent consciousness, instead of an 'essential being.' But he is constitutive for the master's existence. The superior consciousness needs the other, inferior consciousness 'in order thereby to become certain of itself as the essential being' (111).

However, the slave realizes himself in labour, gaining a measure of independence. He finally beats the master in a life-and-death struggle, which, to Hegel, is essential for the slave's rising to self-certainty. According to him, the individual 'who has not risked his life may well be recognized as a person, but he has not attained the truth of this recognition as an independent self-consciousness' (114). To Hegel, in a higher phase of human history, reconciliation and mutual respect between human consciousnesses is achieved. Not only the slave, but the master, too, is finally free, since, only then, can he be fully recognized, by a free subject like himself. According to Hegel, the master-slave relationship - often referred to in terms of (the mechanism of) 'Othering,' i.e. degrading others into an inferior consciousness bound to thinghood - is a phase in history that is overcome when consciousnesses mutually recognize one another.

It is Hegel's master-slave dynamics, rather than Sartrean theory, that is the basic schedule of The Second Sex. Instead of applying Sartre's ontological concept of freedom, as is presumed by, among others, Mackenzie (1998) and Gail Linsenbard (1999), ${ }^{11}$ Beauvoir, following Hegel, points out how women have been kept in a state of servitude and ignorance that denied them access to a personal ethical life project. According to her, men have been the masters in history who made women into the Other, i.e. men's

11 Many authors argue that Beauvoir's philosophical framework in The Second Sex differs substantially from Sartre's (cf. Sonia Kruks 1990; Eva Lundgren-Gothlin 1996 [1991]; Vintges 1996 [1992]); Debra Bergoffen 1997; Sarah Heinämaa 1999; Margaret Simons 1999; Bauer 2001. 
slave or 'vassal'. Women have shared their experience of being revealed to themselves as 'an inferior caste' with other Others, like proletarians, or blacks. But while the latter have revolted, positing themselves as subjects, women, as a group, remained the absolute Other (cf. Beauvoir 2010: 322; cf. Gines 2010: 43). They were never able, as a group, to invert the power dynamic, switch roles, and become masters themselves.

One of the reasons is that women have always been more 'enslaved to the species' than men (Beauvoir 2010: 277). As robust as women may have been in prehistoric times, 'the burdens of reproduction represented for them a severe handicap in the fight against a hostile world' (74). Through their frequent pregnancies, women could not participate in the activities of men, who, by hunting and fighting, willingly risked their lives, proving themselves to be the sovereign consciousness that does not coincide with life. Men thus could claim their superior status, and women consented since they recognize men's superiority in putting their lives at stake in the activities of war and hunting. It was the combination of these two factors; namely, men's biological privilege in combination with the mechanism of Othering, which led to the 'triumph of patriarchy' (88). History has shown that 'men have always held all the concrete powers; from patriarchy's earliest times they have deemed it useful to keep woman in a state of dependence; their codes were set up against her; she was thus concretely established as the Other. This condition served males' economic interests; but it also suited their ontological and moral ambitions' (163).

To consolidate women's consent with their secondary role, women have been conditioned to fulfil their role as men's Other, which is the meaning of Beauvoir's famous line 'One is not born, but rather becomes, woman' (293). 'Myths' of Woman moreover have been invented by men to justify the hierarchical relationship between the two sexes. Through these Myths, patriarchal society 'imposed its laws and customs on individuals in an imagistic and sensible way; it is in a mythical form that the group imperative insinuated itself into each consciousness' (281). In the great collective Myths of mankind, men appear as mind, spirit, and consciousness, and women as inferior consciousness bound to thinghood, Nature, and Flesh. Women have never created their own Myths, but experience themselves through men's eyes: they 'still dream through men's dreams' (166).

In the second part of her study, Beauvoir discusses that only a limited range of roles is available for a woman, because she is 'exclusively defined in her relation to man' (166). These roles are wife, mother, prostitute, mystic, and 'amoureuse'. In subsequent chapters, Beauvoir presents these roles from women's own perspectives, i.e. as lived experiences. 
She concludes the work by arguing that we have arrived at a new moment in history, now that women have access to contraceptives as well as to paid jobs and education. According to her, the 'convergence of these two factors participation in production and freedom from reproductive slavery - explains the evolution of woman's condition' (142). With these new developments, the master-vassal relationship between men and women can be overcome.

In line with The Ethics of Ambiguity, she concludes that reconciliation and mutual recognition between the sexes will never ultimately be reached, but that they require permanent ethical effort. A definite reconciliation between the sexes is impossible due to a remaining dimension of power and enmity between people, which will always lead to conflicts between dualities (cf. 10). But conflicts between the sexes can and need to be overcome time and again, 'by the free recognition of each individual in the other, each one positing both itself and the other as object and as subject in a reciprocal movement' (163).

Men and women in history have projected that part of their ambiguity that they rejected onto each other: 'instead of living the ambiguity of their condition, each one tries to make the other accept the abjection of this condition and reserves the honour of it for one's self,' thus 'projecting onto their partner the part of themselves they repudiate' (Beauvoir 2010: 779). Men have lived their conscious dimension and women their bodily one, and women often consented with their position as - bodily - Other in order to avoid 'the anguish and stress of authentically assumed existence' (10). Instead, men and women should assume both sides of their ambiguous human condition, i.e. their conscious and bodily dimension, and live as an embodied existence in the world. In fact, 'man is, like woman, a flesh, thus a passivity, the plaything of his hormones and the species, uneasy prey to his desire; [...] each of them lives the strange ambiguity of existence made body in his or her own way' (779). If both men and women 'assumed it with lucid modesty, as the correlate of authentic pride, they would recognise each other as peers and live the erotic drama in harmony' (779). Only as embodied consciousness can they meet each other, as singular persons. Only then will love and friendship between them involve the uniqueness of the beloved, instead of mutual projections.

But friendship and generosity [...] are not easy virtues [...]; it demands that man surpass himself at each instant. Put into other words, man attains an authentically moral attitude when he renounces being in order to assume his existence; through this conversion he also renounces all possession, because possession is a way of searching for being; but the conversion by which he attains true wisdom is never finished, it has to be made ceaselessly, it demands constant effort (163-164). 
The Second Sex's normative perspective involves that both men and women must assume their fundamental ambiguity in order to attain 'an authentically moral attitude' (164). In other words, they should turn into embodied ethical selves, and only then can they meet in friendship and love. While to Hegel achieving a fully realized self-consciousness is the ultimate end, to Beauvoir turning into - and recognizing each other as - an embodied, incarnated consciousness is decisive. ${ }^{12}$ If the work emphasizes what have been 'male' activities in history, i.e. the dimension of 'transcendence', it is to argue that women should (be able to) fully assume this side of their ambiguous human condition as well.

To Beauvoir, men in history also have led one-dimensional lives: they too should assume both sides of their human condition. From our re-reading of The Second Sex through the lens of Beauvoir's own ethics, the normative perspective of The Second Sex emerges. Rather than arguing for women's assimilation to dominant male identities, the work argues for both men and women to turn into embodied ethical selves, and for thorough societal changes. The cross-cultural, embodied, and situated notion of the ethical self of The Ethics of Ambiguity turns out to be the normative premise of feminism's exemplary text, The Second Sex, as well. But do the work's analytical, explanatory approaches still hold in the light of recent scientific results and current social developments?

\section{Re-writing The Second Sex in World Perspective}

Beauvoir's claim that men have oppressed women throughout history has been criticized as too narrow to do justice to the variety of women's positions in time and place. Cultural anthropologists Peggy Sanday and Ruth Goodenough (1990) argue that we must move beyond The Second Sex in order to address the variability and contradictions in male-female

\footnotetext{
12 While I read The Second Sex through the lens of Beauvoir's essay The Ethics of Ambiguity, Bauer (2001) comes to a similar conclusion, on different grounds. She especially refutes the argument of Lundgren-Gothlin (1996) that The Second Sex is based on androcentric notions that echo a Hegelian / Marxist privileging of labour. Bauer, in contrast, argues that Beauvoir's philosophical position in The Second Sex amounts to a specific appropriation of Hegel's philosophy. While Hegel's normative perspective entails our mutual recognition as subjects, Beauvoir argues that conflict can be overcome by our mutual recognition as subjects and objects. Beauvoir reformulates 'the free recognition of each individual in the other' in terms of 'each one positing both itself and the other as object and as subject in a reciprocal movement' (cf. Bauer 2001: 186; Beauvoir 2010: 163; emphasis added).
} 
relations in past and present. Oyeronke Oyewumi (1997) criticizes Beauvoir for universalizing her own experiences as a woman in France, and shows that seniority, rather than gender, is fundamental for organizing society in Western Nigeria. ${ }^{13}$ According to Gines (2010), by drawing a parallel between women's oppression and racial oppression, Beauvoir fails to address the ways racial and gender oppression intersect, which 'results in the erasure of black women who experience both racial and gender oppression' (Gines 2010: 43).

The Second Sex's Hegelian schedule of men as master and women as absolute Other, hardly allows for any differences between women's positions, let alone for an approach that takes into account how class, racial, and ethnic oppression intersect with patriarchal oppression. Is The Second Sex heavily flawed in this respect? In what follows, I argue that the work is flawed as 'grand theory', but that it comprises an indispensible set of theoretical tools for current analyses.

The Hegelian mechanism of Othering, which Beauvoir applies in her work as an all-encompassing theory, can be re-articulated as a still relevant tool to address typical patterns of power. This mechanism involves people seeking superiority and self-certainty by degrading others to an inferior status, as devalued and dehumanized 'Other', a position that is internalized by this 'Other' and that he or she can only overcome by defeating the master. Hegel's master-slave theory has been taken up by Marxists and interpreted through the prism of the class struggle in history by, among others, Alexandre Kojève in his famous 1930s seminars in Paris. Other - mainly French - thinkers have applied Hegel's mechanism of Othering in dimensions beyond the sphere of economy (cf. Descombes 1980). Sartre elaborated this perspective into an analysis of racial and colonial oppression - in, for example, his Anti-Semite and Jew (1995) and in his essays on colonialism (cf. Young 2006; Gordon 2008; Judaken 2008) - which inspired Frantz Fanon and Richard Wright, among others, to articulate anti-black racism and Western colonialism and their negative psychological impact on the oppressed in similar terms. In a similar vein, it was adopted by Beauvoir to articulate sexism and its negative impact on women.

The mechanism of 'Othering' is still confirmed today by social identity theorists. Sociological and social psychology studies of group behaviour show that people often identify in contrast to a - negatively discriminated - out group, or several out groups (cf. Reynolds and Turner 2010).

13 Oyeronke Oyewumi (1997) argues that instead of importing European concepts, African scholars should produce their own concepts. For a discussion see Bibi Bakare-Yusuf (2003). 
'Psychological oppression,' and 'Misrecognition' are concepts that today are used in feminist, multicultural and postcolonial studies to indicate that the mechanism of Othering saddles its victims with a 'crippling self-hatred' (cf. Taylor 1994: 26), as empirical research amply confirms (e.g. Bartky 199o; Prilleltensky and Gonick 1996). While to Hegel the mechanism of Othering was rooted in the quest for (self-) certainty of human consciousness, ${ }^{14}$ this mechanism can also be interpreted in line with 'Nietzsche's hypothesis' in terms of man's fundamental 'will to power, and of power being a 'warlike clash between forces' (Foucault 2003: 16). ${ }^{15}$

By applying the mechanism of 'Othering' to the relations between the sexes, Beauvoir disclosed a set of patriarchal power patterns that is deeply ingrained in human history. The Second Sex's purpose was to lay bare these patterns in their multiple, i.e. cultural, societal, political, economic, mythical, and psychic dimensions. Disclosing this set of strong power patterns was the major task Beauvoir set herself in The Second Sex. Due to her focus on these patterns, she rather carelessly dealt with the fact that in her more empirical chapter on history, women pop up as agents on almost every page, in their roles as peasants, workers, and artists. Since her theme was patriarchal power in all its ramifications, she did not address women's agency in theoretical terms.

She did not conceive of women's limited kinds of moral agency, which we have characterized in terms of a minimal freedom; nor did she have a place for women's critically creative ethical life projects or 'freedom practices'. Beauvoir only mentions some examples of women who escaped the stereotypical role of men's Other, but she hardly addresses them in their own right. When she complains that women never confronted the world and the universe in the way the genius painter Vincent van Gogh did, she overlooks figures like nineteenth-century Dutch-Norwegian paintress Betzy Akersloot-Berg, who used to sail on fisher ships and rescue boats, securing herself on deck to observe sea storms (Bell 2000: 52); and artist Frida Kahlo, whose self-portraits, like van Gogh's, are radically brutal.

Women's agencies are the topic of many studies today (cf. for instance Ahmed 1992 for women's agencies in Islamic history; Duby and Perrot 1992-1994 for idem in Western history). The present study, on a very

14 Beauvoir later rejected her Hegelian approach as an 'idealistic and a priori struggle of consciences,' adding that she should have based her study of woman as Other on economic 'facts of supply and demand' (Beauvoir 1968b: 202).

15 'Above all, a living thing wants to discharge its strength - life itself is will to power (Nietzsche 2007: 15). 


\section{Betzy Akersloot-Berg: Shipwreck (1893)}

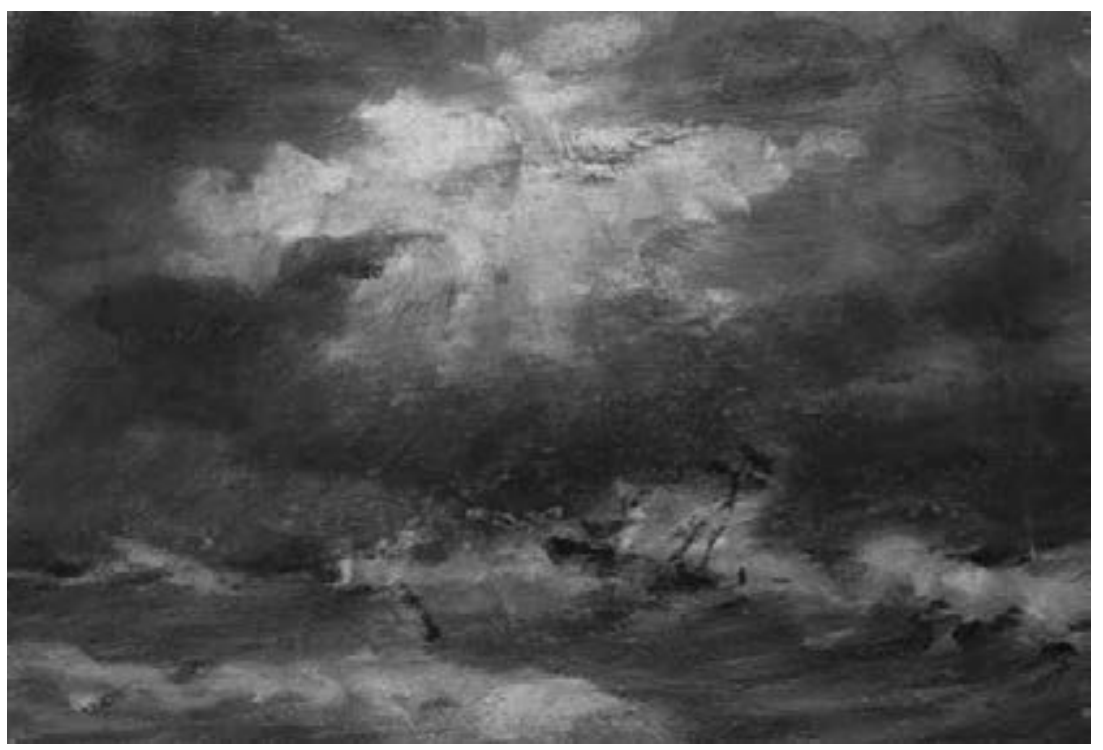

Copy provided by Museum Tromp's Huys, Vlieland

\section{Pandita Ramabai Sarasvati (1858-1922)}

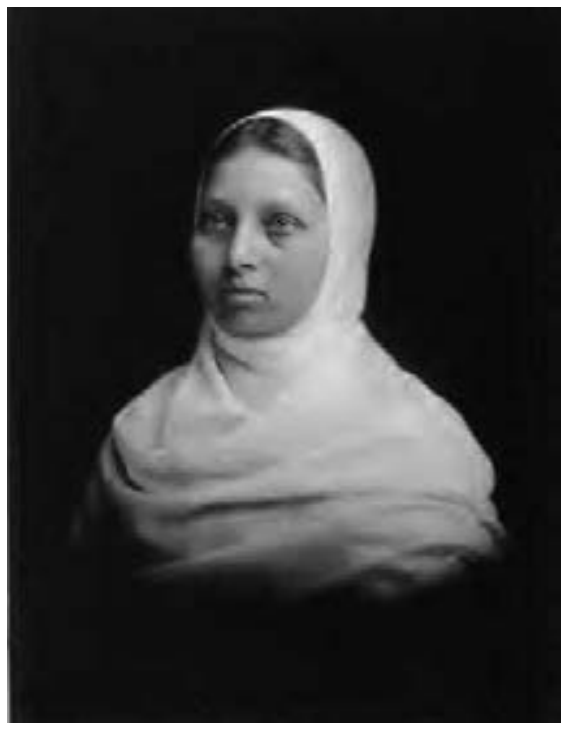

Retrieved from: https://archive.org/details/highcastehinduwo00ramaiala, The high-caste Hindu woman by Ramabai Sarasvati, Pandita, 1858-1922 Philadelphia: [Press of the J.B. Rodgers printing co.] 1887 
modest scale, aims to contribute to these projects, by examining examples of women's moral agencies and freedom practices throughout cultures. However, in studying upwards, downwards, and sideways (cf. the Introduction), Beauvoir's gendered 'mechanism of Othering' is still relevant as an analytical tool that covers strong and dominant patterns.

Does the second part of Beauvoir's explanation of women's typically subordinated status in history - namely, that in prehistory they were more 'enslaved to the species' than men - still hold in the light of current anthropological research? Anthropological surveys show that hunting and gathering societies, typical of the past, are mostly patrilocal, probably due to the importance of men in hunting and war, while women's roles were as gatherers (Ortner 1974; Ember 1978). But feminist anthropologists have demonstrated that complementarity between the sexes, rather than hierarchical relations, also occur in hunting and gathering societies; for instance, in Minangkabau and Hopi societies (cf. Schlegel 1977; Sanday 1990). They have showed, too, that the degree to which women's work as gatherers substantially contributed to subsistence varies, and that foraging, not hunting, was the principle economic strategy throughout most of human evolutionary history (cf. Slocum 1975). Based on research among pastoral, shepherd societies, Philip Carl Salzman (1999) likewise argues that a universal gender inequality in prehistory cannot be assumed. ${ }^{16}$

Recent anthropological research confirms that bi-locality, instead of patrilocal residence, exists as well, dependent on geographic contexts. ${ }^{17}$ As many authors contend, drawing inferences from studies on current hunting and gatherers societies about the Paleolithic Era remains a matter of plausible conjecture. But Beauvoir's too general assumption of women's lower social status in prehistory, due to their procreative role, is refuted by research that shows, not so much the existence of matriarchal societies in

16 Beauvoir refers to the work of Lévi-Strauss, especially to his thesis The Elementary Structures of Kinship (1969), published in French in 1949. In a footnote to the Introduction of The Second Sex, she thanks him 'for sharing the proofs of his thesis, that I drew on heavily' (Beauvoir 2010: 7). Lévi-Strauss, in a comparison of human cultures, claims that society is founded on the prohibition of incest that involves the necessary exchange of women between (tribes of) men. As Beauvoir summarizes in a review of his work, 'the incest prohibition represents the very moment of the passage from nature to culture' (Beauvoir 2015a: 59). She distils from his analysis that societies in the past were always dominated by men, quoting from his work: "Political authority, or simply social authority, always belongs to men" [...] For men, the counterpart - or the other - who is also the same, with whom reciprocal relationships are established, is always another male individual' (Beauvoir 2010: 82).

17 Bi-local residence refers to the couple's living alternately with the wife's group as well as with the husband's group (the latter comprising 'patri-locality'). 
the sense of a rule by women over men, but patterns of 'complementary equality' between them. ${ }^{18}$ While Beauvoir's model of women as the second sex is 'probably relevant to a good many societies, there is less and less reason to suppose that it is applicable everywhere' (Gottlieb 1990: 130). Studying upwards, downwards, and sideways turns out to be necessary here as well. Beauvoir's schedule again emerges as a relevant analytical toolset that covers typical, dominant gender patterns, rather than as an adequate total theory.

Does The Second Sex comprise other explanatory and analytical tools that are still relevant today, in view of new scientific insights and of the political, economic, and social (under)currents of our time? I will selectively discuss some developments that I consider relevant. ${ }^{19}$

New neuroscience research has claimed that male and female brains are essentially different - due to an XY foetus being flooded with testosterone during pregnancy and an XX foetus not being flooded with testosterone during pregnancy, respectively (cf. Baron-Cohen 2003; Bao and Swaab 2011). On the basis of this research, it is argued that the brains of men are systematizing and the brains of women are empathizing. Yet, other scholars have criticized and refuted the claims. Not only are hormones not the major determining factor for foetal brain behaviour, brains are not the major determining factor for cognition, behaviour, and interests. Causality goes both ways in that hormone levels impact mental states and, vice versa, behaviour and mental states impact brains. The brain is a plastic organ (cf. Eliot 2009; Jordan-Young 2010; Vasterling 2013; Kleinherenbrink 2014). Beauvoir's rebuttal of monist biological explanations, i.e. her argument that women's behaviour is the outcome of their total situation, apparently still holds today.

Her historicizing and de-essentializing approach of psychoanalysis in The Second Sex similarly is also still relevant. To Freud, the development of human life is based on sexuality alone. All human behaviour is driven by unconscious desires that are structured by universal 'laws', as symbolized in the myth of Oedipus. Instead, Beauvoir argues, sexual desires should be seen as an integrated part of one's total personality, developed in social contexts. Freud's thesis of woman's inferiority complex, due to her lack of a penis, then emerges in a totally different light. Freudian psychoanalysis adequately grasps that society today is male, with male sexual organ embodying 'all

18 With thanks to Willy Jansen.

19 For in depth discussions of Beauvoir's integration in The Second Sex of the results of several scientific disciplines of her time, see Galster (2004). 
the privileges of virility' (cf. Beauvoir 2010: 769). But Freud proposes this descriptive schema in terms of universal laws (cf. 6o). According to him, the girl, due to her feeling inferior in relation to man, will always be

faced with the alternative of either maintaining her autonomy, becoming virilised [...] or else finding happy self-fulfilment in amorous submission, a solution facilitated by the love she felt for her sovereign father; it is he whom she is looking for in her lover or husband, and her sexual love is mingled with her desire to be dominated. Maternity will be her reward, restoring to her a new kind of autonomy (Beauvoir 2010: 55).

Beauvoir refutes Feud's 'laws' by arguing that, from an existential point of view, which takes into account woman's total situation, the girl is not so much 'torn between "viriloid" and "feminine" tendencies,' but instead hesitates 'between the role of object, of Other that is proposed to her and her claim for freedom; thus it is possible to agree on certain points: in particular when we consider the paths of inauthentic flight offered to women. But we do not give them the same Freudian or Adlerian signification' (61-62). Sexuality does play a considerable role in human life, but 'the body and sexuality are concrete expressions of existence,' of which sexuality is but one, albeit important, aspect. Moreover, it 'must not be taken as an irreducible given,' (56) but as influenced by 'social forms' (57). The meanings of the 'castration complex' and the 'Oedipus complex' will be 'profoundly modified,' in a society where the mother would enjoy the same lasting prestige as the father and assumes equal material and moral responsibility for the couple. The girl would no longer turn to passivity, and the boy would not have a superiority complex 'if it were not instilled in him' (778).

Confirmation of Beauvoir's thesis that Freud's 'laws' of sexual desire in fact are linked to patriarchy as a historical phase of mankind, can be taken from the changing of myths in current societies, involving some - not insignificant - shifts in women's and girls' dreams and desires (cf. Chapter 4). They can be taken as well from the emergence of alternatives to the Oedipus myth, for instance as developed by Butler in Antigone's Claim (Butler 2000). As Annemie Halsema (2015) argues, Butler's alternative reading of the myth of Antigone - namely, as showing the socially contingent character of kinship instead of simply representing family bloodlines - covers multiple forms of kinship other than the nuclear family system (cf. Butler 2000: 6).

In The Second Sex, Beauvoir also criticized Marxism for its monistic approach, examining in particular Engels' claim that economic equality will end women's oppression. According to Beauvoir, modifying women's 
economic situation will not be enough: 'this factor has been and remains the primordial factor of her development, but until it brings about the moral, social and cultural consequences it heralds and requires, the new woman cannot appear; as of now, these consequences have been realised nowhere: in the USSR no more than in France or the United States' (Beauvoir 2010: 777).

While Marxists argue that a socialist mode of production has never fully been established, due to the absence of a world revolution, Beauvoir's thesis that economic equality is not enough to change women's secondary status is proven in indirect ways; namely, by current neoliberal developments that recruit women for paid work on a scale never witnessed before. Neoliberal economies are not built on a gendered division of labour. They do not need women to perform traditionally feminine activities - since domestic and caring work can be outsourced and purchased on the market - and they recruit women like men in the production process (cf. Oksala 2013:42). Not constrained by nation states and without their social protection, neoliberal economies even show a growing interest in women as a reliable global work force (cf. Eisenstein 2009). Gender and development programs of neoliberal signature even privilege women as the preferred economic agent, since, in a commitment to their family, they regularly save and repay, and urge others to do so as well (cf. Batliwala 2007; Cornwall et al. 2008).

Women's growing participation in the labour market goes together with an increasing 'feminization' of labour. Their entrance has facilitated the decrease of good and steady jobs, and the rapid growth of flexibly paid work and increasing levels of exploitation. ${ }^{20}$ Men and women in the current global economy are working in precarious, low income jobs with flexible and even 'on call' working schedules. Many have more than one job, in order to earn a minimum income for their families, and many work in so called 'global factories' and sweatshops, under conditions of low pay, unsafe workplaces and long hours. Men and women today are equally exploited within the neoliberal system on a global scale (cf. Young 2000: 95).

But women still have a disadvantaged position because they are (perceived as) a woman. At all levels, women earn less than men, a phenomenon that is known as the 'gender pay gap'. Women workers despite working more hours than men - earn only ten per cent of the world's income (cf. Moghadam 2005). Moreover, they experience that the

20 For a discussion of the current feminist debates on the different stages and dimensions of this process see, among others, Oksala (2013) and Fraser (2009). 
perceived quality of their work is lower than that of their male counterparts. Recent studies show that unconscious and conscious preference for males, because of the power they traditionally symbolize, is still in place. Women still have to work two or three times harder than men just to be considered okay. ${ }^{21}$

Given the double burden of work and care-taking, women all over the world confirm cutting down on sleeping hours to get everything done. Women of privileged classes and groups hire others - mostly women - to do their housework. But women of all classes, especially those with young children, are often exhausted - due to their double, and even triple, shifts - something they hide from the world and from each other. ${ }^{22}$ The old 'sexual contract' that relegated women to care-taking tasks in the domestic sphere (cf. Pateman 1988) turns out to be quite resilient. ${ }^{23}$

Furthermore, women are still overrepresented among the poor, and largely absent from the power structures that rule us. The ranks of society where crucial decisions are made and large sums of money are involved, remain predominantly male and difficult for women to enter. ${ }^{24}$ Sexual violence against women and girls moreover continues worldwide, ${ }^{25}$ and

21 A study from North Carolina State University shows that instructors of online courses were given much higher evaluations when students were told that their instructors were men. The instructor was given a 4.35 rating out of 5 when the students were told he was male, whereas the same instructor got a 3.5 rating when the students were told she was female. This proves that men get higher satisfaction rates from their students simply because they are male. A similar kind of research shows that when gamers on the internet are told that they have lost from a woman their reactions are debunking, in contrast to when they suppose to have lost from a man. Women writers, academics, journalists, politicians, all experience - and rightly so, as scientific research confirms - that their contributions are less noticed or taken seriously. As a senior female UN official said at a recent symposium: 'my male colleagues always listened politely, but then the meeting went on just as if I did not speak at all.'

22 With the cutting down in the West of social and medical service provision for the elderly, and the propagation of informal care, mainly women prove to fill in these tasks again, often in combination with a working life. In the Netherlands today one out of three working women is a so called 'informal carer.'

23 The term 'sexual contract' was introduced by Pateman (1988), to argue that the 'social contract' as a contract among only the male heads of the family, was paired to the relegation of women to the domestic sphere.

24 Cf. the implicit gender bias tests of Harvard University: https://www.projectimplicit.net/ about.html (last accessed, 21 September 2016).

25 For a recent report from the United Nations see http://www.un.org/en/women/endviolence/ situation.shtml (last accessed, 21 September 2016).

Recent research shows that in the Netherlands one in nine women have been raped, and that half of all women aged 22-24 years have encountered involuntary sex - against one in five men in the same age group. 
today takes new forms such as a rise in the trafficking of women and children on a global scale for the purpose of sexual exploitation. ${ }^{26}$ Though the extent to which - mainly - female sex workers are exploited, for instance in the Amsterdam red light district, is not transparent, the new globalized, mafia-conditions of the sex industry are insufficiently taken into account when local feminists and liberals focus - in juridical terms - on the rights of the 'happy hooker'. Similarly, when Amnesty International claims that prostitution should be legal, studying upwards, downwards, and sideways seems to be more appropriate, so as to establish what 'the main danger' is for the sex workers involved. ${ }^{27}$

In the Middle East and Africa, new 'jihadist' movements have emerged that exchange girls and women as sex slaves. Cyber stalking as a new way of intimidating girls and women (the majority of cyber stalkers being men) and the amount and accessibility of sexually abusive imagery via the internet, including child pornography, increase on a daily basis (cf. Akdeniz 2008). Rape of women and girls is used in conflict areas all over the world as a weapon of war to destroy individuals, families, and communities and the fabric of society as such, but also affects many others, such as single women refugees who have to survive in asylum centres as well as girls on American college campuses. Popular media in the West, such as advertisements, women's magazines, television programmes, music videos, games, and mainstream film, increasingly portray women as synonymous with sex, in stereotypical objectifying ways, but also in new ways, i.e. as sexual agents who are always 'up for it' (cf. Gill 2008; cf. Chapter 4).

In spite of Beauvoir's claim that patriarchal power patterns will be surpassed in a new age, they turn out to be more resilient than she, and

26 Amnesty International estimates that worldwide over 2.4 million people are victims of human trafficking, mostly women and children: http://www.amnesty.nl/mensenhandel-enmensensmokkel (last accessed, 21 September 2016). According to the International Labour Organisation (ILO), in 2007 more than 12.3 million people worldwide were victims of forced labour, many of whom were women that ended up in the sex industry. For the year 2013, it is estimated that between 1,500 to 3,00o people - mostly women - are victims of human trafficking in the Netherlands, ending up in prostitution and the sex industry. Regarding the Amsterdam red light district, estimated numbers of forced prostitution vary enormously, ranging from seven to 90 per cent, with local police officers estimating more than 50 per cent. A reliable website is for example http://sekswerkerfgoed.nl/mensenhandel-neemt-toe-vooral-door-delegalisering-van-prostitutie-waar-of-niet-waar/ (last accessed, 21 September 2016). For the report of the Dutch National Rapporteur on human trafficking see http://www.nationaalrapporteur. $\mathrm{nl}$ (last accessed, 21 September 2016). For a discussion of the range in estimated numbers see http://behindtheredlightdistrict.blogspot.nl/2015/o1/what-do-rapports-say-about-forced.html. (last accessed, 21 September 2016).

27 With thanks to Janja Rakus. 
many with her, presumed. When pushed down in one place, like a waterbed mattress, they rise up in a new place. From Beauvoir's argument that social changes should take place at all levels, we distilled the image of patriarchy as a many-headed monster with a legal 'head', next to a moral one, economic, institutional, social, and public one - to name the aspects she mentions each of which should be slayed (cf. Beauvoir 2010: 777; cf. the Introduction). From the newly emerged faces of patriarchy discussed above, we can indeed conclude that we are dealing with a dominant set of power patterns in the shape of a hydra, the mythical multi-headed monster that grows new heads when one is cut off. Patriarchal patterns, persistent as they are, turn out to grow ever new 'heads'.

But what then is the 'immortal', most resilient head of the hydra today, that has to be slayed for the monster to disappear into the sky? And is it a similar one everywhere? Could it be that women all over the world share a common enemy after all? Beauvoir's The Second Sex gives us a clue to answering these questions. While we found that biology, economy, and psychoanalysis fall short as sufficient explanations for the persisting power hierarchy between men and women, I take from Beauvoir's work that the dominant Myths of Woman comprise the hydra's most resilient head today. ${ }^{28}$ In light of her lengthy Chapter on Myths - at 120 pages, almost a book in itself - the first chapter that she wrote, did Beauvoir suspect herself that this was the most resilient head of the hydra after all?

In the chapter she argues that men have created the Myth of the 'Eternel Feminine' (Beauvoir: 2010: 275), which insinuates its laws and customs in an 'imagistic and sensible way' in each consciousness (281). The Myth of Woman, which invariably is about woman as the absolute Other and specifically as Flesh and Nature, is a 'masculine dream' (165) that affects everyone by way of 'religions, traditions, language, tales, songs and film' (281). Women also 'dream through men's dreams'; they have 'neither religion nor poetry that belongs to them alone' (166) To Beauvoir, 'Myth' thus involves dreams, poetry, religion, and mythical tales as well as an 'imagistic' way of presentation. Her concept of Myth largely covers the three 'presentational' realms of Langer (1960), i.e. rite, art, and the genre of mythical secular tales. In her chapter, she states that, today, the Myth of Woman 'still exists in the hearts of all men' (Beauvoir 2010: 166). At the

28 We, of course, have no full evidence and can only hint to how things work, but this is not unusual in social theory and research, nor is it in natural science. We seldom have full or complete evidence in terms of a full known mechanism, yet can hint to how things work in useful ways. With thanks to Federica Russo. 
end of The Second Sex she concludes that the 'conflict will last as long as men and women do not recognise each other as peers, that is, as long as femininity is perpetuated as such' (771).

But Myth is 'situated beyond the given' and 'endowed with an absolute truth,' and, as such, 'escapes any act of consciousness' (Beauvoir 2010: 275, 277). Myth cannot be managed or made, nor made to disappear. Yet, the dominant Myths of 'femininity' as Nature, according to Beauvoir, will 'be phased out one day' (166), when women will be recognized as full human beings, and will no longer be the absolute Other. The supposed 'Eternel Feminine' is fixed and unique, and divides humanity into two categories, whereas in reality there is only 'the dispersed, contingent and multiple existence of women' (275). The Myth of Woman, as a representation of the world from men's point of view, is a 'false objectivity' (282), which 'they confound with the absolute truth' (166), but which is bound to fade way.

At certain points in her work, Beauvoir hints at the possible emergence of new myths; for instance, when she states: ' $(t)$ hat for woman it is man who is sexed and carnal is a truth that has never been proclaimed because there is no one to proclaim it' (166). Elsewhere, she concludes that, today, 'little by little,' 'a new form of eroticism seems to be coming about: perhaps it will produce new myths' (283). Her suggestion that Myths will change, rather than being replaced by adequate insight or knowledge, approaches Langer's claim of the continuity of the non-verbal modes of thought of rite, art, and myth (cf. Langer 196o). The perspective that the 'presentational forms' of rite, art, and myth will continue to sit side by side with verbal, argumentative language and scientific knowledge, involves that stereotypical Myths of femininity can only be defeated by replacing them with new 'forms'.

While the dominant Myths of Woman entail the dreams and beliefs of men, do we find new 'forms' emerging in the presentational realms of rite, art, and mythical tales, which comprise women's dreams and beliefs? Are women involved in freedom practices in these domains, critically creating new 'forms'? And, if so, do they not risk recycling stereotypical Myths of femininity and practice a conservative kind of 'identity politics'?

\section{Women's Freedom Practices in World Perspective}

The concept of 'identity politics' has been used since the 198 os to indicate the strategies of movements, such as second wave feminism, black civil rights in the US, gay and lesbian liberation, and the American Indian movements, 
who claim their particular identities in explicit political ways (cf. Heyes 2002). ${ }^{29}$ Sonia Kruks (2001) defines 'identity politics' as the demands of groups of people for their recognition on the very grounds on which it previously was denied: 'it is qua women, qua blacks, qua lesbians that groups demand recognition. [...] what is demanded is respect for oneself as different' (Kruks 2001: 85, quoted in Heyes 2002). Marginalized or oppressed social groups, like women, blacks, gays, and indigenous peoples, not only fight their discrimination, but demand and develop social change on behalf of their identities. The identity claims of these groups have been contested from the outset and from various angles..$^{30}$ Identity politics is criticized for being, among other things: an essentialist conservatism, i.e. a defending of traditional identities and cultures instead of an openness to dialogue and change; as group coercion, i.e. the applying of internal restrictions to group members; as identification with the aggressor, i.e. a taking on of a negatively stereotyped identity instead of leaving it behind. In spite of all these criticisms, however, the substance of identity politics has not gone away, as Linda Alcoff (2006) aptly states.

For a critique of identity politics, postmodern and postcolonial thinkers often refer to Foucault's mid-work, which discusses fixed identities as effects of normalization and discipline. However, in his final work, Foucault addresses the issues of identity and identity politics in a positive way, albeit in different terms. As we have seen, care of the self implies a work on the self, but what is this self? In a discussion of Plato's text Alcibiades, Foucault argues that the notion of 'self' conveys the notion of identity. 'Departing from what ground shall I find my identity? Alcibiades becomes aware that this principle is the soul, not in the sense of a substance but as 'a principle of activity' (Foucault 1997b: 230). Identity thus involves one's acting in the world, rather than an inner essence or deep self. The self at stake in the care of the self is a self in action.

Rosi Braidotti and Rick Dolphijn (2015), in line with the work of philosopher Gilles Deleuze, also criticize notions of a pre-given self and argue for an art of life in terms of a nomadic impersonal life that 'does not respond to our names' (Braidotti and Dolphijn 2015: 26). While Foucault similarly

29 The label 'identity politics' usually refers to the strategies of these groups, although the substance of identity politics can be taken much broader, including forms of nationalism if we take nations as 'imagined political communities' in the terms of Benedict Anderson (1983).

30 Mainstream liberal theory opposes identity politics as obstructing the integration of minorities. Marxists rebut the relevance of cultural identification processes in favour of socio-economic ones; postmoderns criticize identity politics as a disciplining strategy of in- and excluding people, and postcolonials target its dealing with cultures as clear cut and fixed entities. 
does away with any pre-given self or original subject, and speaks of a self in action, his concept of an ethical art of life involves the creation of a personal ethical life project - within distinct groups or networks that emerge over time and that offer tools and models. A Foucauldian art of life is both more socially grounded and more personal than a Deleuzian kind of nomadic life.

As indicated in the previous chapter, Foucault not only pointed to certain philosophical schools and religious groups as identifiable freedom practices, but spoke of the gay movement in similar terms. In one of his articles on the gay movement, titled 'Sex, Power and The Politics of Identity' (Foucault 1997a), he argues that the gay movement rather needs an 'art of life than a science or scientific knowledge (or pseudoscientific knowledge) of what sexuality is' (Foucault 1997a: 163). What is important is 'the creation of new forms of life, relationships, friendships in society, art, culture, and so on through our sexual, ethical, and political choices. Not only do we have to defend ourselves, not only affirm ourselves, as an identity but as a creative force' (164). We do not know in advance 'which forms these creations would take. [...] Yet, I am sure that from the point of departure of our ethical choices, we can create something that will have a certain relationship to gayness' (164).

Foucault, while pointing to the relevance of the substance of identity politics, thus avoids some of its pitfalls and dangers. Creating new culture with a certain relation to 'gayness' replaces an essentialist concept of identity; ascribed group identities can be taken up in critically creative ways; and group coercion is avoided since creation takes place on the collective and individual level in transversal ways, the fabric of the movement in other words being the ethical life projects of its members. Foucault re-articulates identity politics in terms of an art of living, or practice of freedom that comprises 'political innovation, political creation, and political experimentation' (Foucault 1997a: 172).

In line with this approach, feminist 'identity politics' can be re-articulated in terms of a set of freedom practices ${ }^{31}$ that have a - certain - relationship

31 Marieke Borren (2013), in reference to Linda Zerelli (2005), also argues for a feminism in terms of 'a set of practices of freedom,' from the perspective of Hannah Arendt's concept of the political. Feminist freedom practices concern a political, non-identity based feminism. They consist of manifestations in the public sphere, not on the basis of 'a shared natural or essential collective identity [... ] but by common action in the service of a particular worldly issue or common end' (Borren 2013: 198). Borren's picture of 'playful-though-serious' feminist freedom practices, however, does not cover the steady work that freedom practices involve in our definition. Feminism as a set of freedom practices in a Foucauldian sense, moreover, include not only political struggles in the public sense, but also the critical creation of new ways of life and models for self and society. 
to 'womanness.' 'Feminist freedom practices' can be re-articulated as the explicitly critical, parrhesiastic version of women's freedom practices, which simultaneously create new modes of life in some relation to womanness. As argued in the previous chapter, the core characteristics of freedom practices, as distinct sets of critically creative ethical life projects are: 1 ) the development of a personal ethical life project out of concern for others 2) consisting of one's action in the world; 3 ) in an implicit or explicit critique of any domination; 4) by creation; 5) (within) relatively independent ethical communities, groups or movements. The term freedom practices thus refers to the personal and collective level as two sides of the same coin, i.e. to the creation of a personal ethical life project as well as to the collective setting that offers the models and tools to do so. Moreover, the concept of freedom practices turned out to be culturally plural as it comprises a cross-cultural notion of an ethical self, and a plural set of 'keys'.

Feminist, culturally plural freedom practices can now be more fully articulated, analogous to our five general characteristics, namely as: (ad 1) comprising women's personal ethical life projects in a concern for other women; (ad 2) consisting of actions in the world; (ad 3) that involve an explicit, political critique of practices that deny women access to a personal ethical life project; ( $\mathrm{ad} 4)$ by creating new ways of life or new 'forms' in a certain relationship to womanness; ( $\mathrm{ad} 5)$ within relatively autonomous groups, networks or movements, the fabric of which consists of (1).

Creating new ways of life, and new 'forms' in the sense of Langer (1960), in a 'certain relationship to womanness' does not presuppose 'an essential womanness,' to borrow a phrase from Elizabeth Spelman (1988:158). Maria Lugones and Spelman (1983), and Butler (1990), among others, have rightly argued that women do not possess a common nature and that womanness is inseparable from other aspects of one's identity, such as race and class. Intersectionality theory, as developed by, among others, Kimberlé Crenshaw (1991), puts the focus on women who are oppressed along gender, race, and class dividing lines simultaneously, aiming for a politics based on distinct group interests, rather than on the concept of universal woman. Any approach of women in abstract universal terms masks the privileged position of white upper-class women, who, for years, have dominated the feminist discourse (bell hooks 1984, cf. 25, 26; cf. Lutz et al. 2011).

Several feminist philosophers today advocate the restoration of universal woman as a realist category. Alcoff (2006) does so on the grounds that all women have a special position in regard to the reproduction of the species. However, with today's widespread access to contraception, and with, for instance, the increasing numbers of babies born as a result of gestational 
surrogate motherhood, and the possibilities of 'outsourcing' domestic (care) work, a division in two sexes along the lines of their reproductive functions is no longer obvious (which may explain the new focus on women's brains instead of their procreative functions, as discussed above).

Sally Haslanger (2000), rather than referring to women's reproductive functions, argues for a 'materialist feminism' that recognizes that males and females 'not only differ physically, but also systematically differ in their social positions' (Haslanger 2000: 38 ; cf. Mikkola 2013). Women's identities may be shaped in numerous ways, yet they have a feature in common that makes them women; namely, they are all socially positioned as subordinate to men, "marked" as a target for this treatment by observed or imagined bodily features presumed to be evidence of a female's biological role in reproduction' (39). Haslanger's approach involves 'total theory', which studies 'downwards' (cf. the Introduction), analyzing how ideologies implement 'schemes' and, thereby, reproduce women's subordinate status.

Bauer (2015) - in reference to Beauvoir's The Second Sex - argues that as long as women are socially constructed and made into women, real women do exist. In contrast to Haslanger, Bauer not only studies downwards but upwards as well. This means that she captures today's configurations of gender and power in some of their specific new shapes in the West (cf. Chapter 4). Haslanger and Bauer rightly claim that real women do exist as long as people are turned into, or perceived as, 'women'. However, the different heads and faces of the hydra in world perspective turn them into 'women' in multiple ways in multiple contexts. The dominant heads of the patriarchal hydra and the concrete shapes of its presentational head do differ throughout cultural frameworks - moreover, representing dominant power patterns rather than an all-encompassing system - to the effect that universal woman cannot exist in any realist or materialist sense. Studying upwards, downwards, and sideways simultaneously is necessary to uncover patriarchy's hybrid faces, which construct 'women' in concrete contexts.

Women's specific freedom practices do emerge from these concrete, hybrid contexts. When they invoke 'womanness' in their critical creation of alternative models for self and society, they do so out of a 'thrown affinity', to paraphrase Young (1990). $\cdot^{2}$ One identifies with a group in which one finds oneself thrown and, like ethnicity, gender is often felt as a core aspect of one's subjectivity, which one has affinity with. But invoking 'womanness' does not necessarily mean invoking a binary gender frame. Feminist freedom 
practices today happily sit side by side with others, such as queer freedom practices that aim to undermine a binary gender division (cf. Chapter 4).

The feminist freedom practices that have emerged in recent decades in the presentational realms of rite, art, and myth, critically create new 'forms', and new 'modes of thought' in a certain relationship to womanness, with women and girls being involved in grim fights, as will be clear from Chapters 3 and 4 . A 'feminism in a new key' takes on board these battles within the presentational realms, instead of debunking them as lower forms, or as a counterproductive identity politics (cf. Chapter 5 ). Feminist freedom practices, being the explicitly critical version of women's many - culturally plural - freedom practices, can tap from the latter as treasuries of ethical life forms and sources of inspiration. Some examples of women's freedom practices in the past that function as inspiring role models have already been discussed at the end of Chapter 1, from a Western-centric perspective. In what follows, a number of women's freedom practices are discussed in culturally plural contexts and 'forms'.

\section{Women's Freedom Practices in World Perspective: Some Examples}

The examples discussed below finally substantiate the claim that the concept of women's freedom practices - i.e. women's personal ethical life projects developed within relatively independent ethical communities - is culturally plural, and as such allows for a critical reformulation of feminism in world perspective, as movements sharing this perspective. The examples also show that women developed freedom practices in more 'keys' than verbal language. Chapter 1 - from the perspective of Foucault and Hadot - presented some examples of women's ethical freedom practices as developed within distinct, relatively independent, philosophical circles. But women in the past also participated in other relatively independent collectives, such as art movements and religious groups and circles, in the context of which they developed a personal ethos that implicitly challenged the dominant patriarchal patterns of their time.

Female Sufi mystics in Islamic history, for example, developed freedom practices within a religious movement, as is discussed in the next chapter. Women have done so in other religious contexts, for instance in the context of Taoism (cf. Despeux 200o). In the context of Catholicism, the Christian mystic Hildegard von Bingen (1098-1179) founded an independent community of nuns, where together they created a lifestyle of singing, reading, studying theology, and training themselves in artistic and musical 
skills. The Northern European Beguine movement (thirteenth-sixteenth century) is another case of women changing religion's ritual 'forms'. This spiritual movement consisted of a variety of women, from all classes and backgrounds, who interpreted the bible in their own ways and lived together in communities, fixing their own order of living. One of them, the woman mystic Marguerite Porete (1250-1310), author of The Mirror of Simple Souls (dating from the 1290s) was condemned by the Catholic Church for being a heretic and burnt at the stake.

An example of a woman who developed a personal freedom practice within yet other religious circles, is Indian activist Pandita Ramabai (1858-1922). She was an expert in Sanskrit poetry, social reformer, and author of a famous book on the oppressed position of women in India, The High-Caste Hindu Woman (1888). ${ }^{33}$ Ramabai's father, who practiced the Brahmanic lifestyle, against the will of his family and community, educated not only his son, but also his wife and daughters in the 'sacred language' of Sanskrit, in which the classics of Hinduism are written. Every morning, as a child, Ramabai repeated her lessons with her mother and, by the age of twelve, she had memorized 18,00o verses of the ancient Hindu texts. She was also fluent in many languages, including Marathi, Kannada, and Hindi. The family traversed India for several years, earning a living by reciting the Hindu texts in public. At the age of 20, Ramabai was publicly honoured in Calcutta for her knowledge and given the title Pandita (learned woman).

The family's travels across India gave Ramabai experience in public speaking and an awareness of women's conditions throughout the country. Ramabai became a member of the Indian social reform movement, which sought to modernize the traditional caste system and the treatment of women in India. She particularly focused on the stigmatizing treatment of widows in her country, of which there were many due to the child-marriage system. When she became widowed herself at the age of 24 , she defied the conventions and continued travelling, lecturing, and publishing, thus earning a living for herself and her daughter. In 1881, she founded the first feminist organization in India, the 'Arya Mahila Sabha'. During a stay in England and the US, she raised money to found a safe community for Indian widows of all castes, where they could gain skills in carpentry weaving, printing, and gardening, so as to be able to earn a living.

In her quest for a personal ethical-spiritual life project, Ramabai turned to Christianity during her stay in England. Her conversion is often interpreted as a betrayal of her Indian identity and is a reason why she is 
obscured from official histories of Western India. Uma Chakravarti (1998) argues, however, that Ramabai's turn to Christianity should be interpreted as a protest against the Hindu patriarchs of the time. Ramabai continued to pursue her own spiritual path, refusing to accept the authorities of the Anglican Church. While living amidst the widows in the community that she had founded, she increasingly practiced the ascetic Brahmanic lifestyle of her father. By cultivating a personal ethical life project within religious contexts and by acting in the world, lecturing and travelling widely, raising a feminist movement and building a community for widows, in an explicit critique of women's oppression, by changing ritual 'forms' and creating a way of life that challenged the dominant gender patters of her time, her life counts as a remarkable freedom practice.

A woman's freedom practice comprising 'keys' of art, rite, and myth, is the ethical life project of Werewere Liking (1950-), born Eddy Nicole Njock in 1950 in Cameroon. Liking has published poetry and novels, among others Orphée-dafric (1981) and Elle sera de jaspe et de corail (1983), and moreover is a paintress, performer, filmmaker and choreographer. She leads an art colony in Abidjan, Ivory Coast, where street children are given the opportunity to develop as artists. ${ }^{34}$ Liking uses elements of African symbols, rites, and myths to articulate a new African identity and consciousness. Her life and work aim to contribute to a new vision of the African world, by re-articulating African identity in its diversity, creativity, and dynamism. ${ }^{35}$ Music, sound, rhythm, and metaphor, are prominent in her texts and especially in her theatre plays, which aim to be life-changing experiences for people. Liking argues for a commitment of both men and women to a better society, criticizing any idea of a battle between the sexes. Her ethical personal life project, and her cultural centre Village Ki-Yi, comprise a critically creative re-invention of the African cultural heritage in more 'keys' than verbal language.

Women in our time from all continents, such as Bing Xin, Maria Zambrano, Sophie Oluwole, and Gloria Anzaldúa, each of whom stands for many others, engage in freedom practices that create new ethical ways of life and models for self and society, and a new world. The next chapter discusses Muslim women's freedom practices in this respect.

34 The following is based on Christa Stevens (2012).

35 Liking's ideas link up with nineteenth century Pan-Africanism and the twentieth century movement of négritude, that hold that Africans across the continent and in the diaspora share the same cultural and philosophical values, anchored in the precolonial cultures of the continent. 


\section{$3 \quad$ Muslim Women's Freedom Practices ${ }^{1}$}

In January 2011, an unusual event unfolded in Cairo's Tahrir Square. An unexpected youth-driven revolution, backed by social media, took place and was broadcast live by Al Jazeera and witnessed all over the world. Egypt had followed Tunisia's December 2010 'Jasmine Revolution'. The uprisings spread to Algeria, Jordan, Yemen, Iraq, Morocco and many other countries in the region, causing major problems for their governments. ${ }^{2}$

Women were clearly present during these spontaneous uprisings in 2010-2011 in North Africa and the Middle East, commonly known as the 'Arab Spring'. They, too, used Facebook, blogs, and other social media tools to contribute to the political struggle (cf. Sadiqi 2012; Brouwer and Bartels 2014). Sadiqi (2016) argues that these revolutions, which called for karamah (dignity) and democracy, involved the rise of women as new actors in the region, a presence that has continued in the years after the revolutions, demonstrating 'women's feminist persistence in the face of cultural resistance and backlash' (Sadiqi 2016: 3). In spite of women's absence in spaces of authority after the Arab Spring, there is 'a lot of dynamism of women, in civil society. And on the net we have a very new breed of women feminists, women who are neither Islamists, neither secularists, they want a better life for themselves' (Sadiqi 2013). Women's roles before, during, and after the uprisings deserve to be highlighted more than is the case in recent analyses by Tariq Ramadan (2012) and Hamid Dabashi (2012), which are for the most part 'ungendered' (Sadiqi 2016: 2).

Muslim women's agency is even more overlooked in the heavily polarized debates that take place in the Euro-Atlantic region, especially since 9/11, about 'the nature of Islam'. The issue of 'women's oppression in Islam' is a critical topic in these debates. In Western Europe especially, many are convinced that Islamic culture and religion are extremely hostile to women. With the rise of the so-called Islamic State in Syria and Iraq, and with terrorist attacks in Brussel and Paris 'in the name of Allah', anti-Islam and anti-Muslim opposition have only increased in recent years in Western Europe. Marine Le Pen, political leader of the French 'Front National' wrote a letter to the New York Times (8 January 2015) claiming that 'the massive waves of immigration' have to be stopped, since the values of the French

1 The chapter is based on the research of the participants in the project 'Women and Islam: New Perspectives' (2008-2013) (cf. Acknowledgements).

2 In Libya, Bahrain, Syria, Kuwait, Sudan, Saudi Arabia, Mauritania, Oman, and Djibouti. 
Republic are at risk. According to her, 'the presence of Muslims in France is a danger to the country,' since 'culture has a major influence on the way immigrants relate to French society and its values, on issues such as the status of women and the separation of state and religious authority.' Le Pen, like other political leaders of anti-immigrant parties in Western Europe, routinely raises the issue of the status of women in Islam to underpin her political anti-immigration stances. French feminist philosopher Elisabeth Badinter also contrasts the status of Muslim women with the French republican values of laicism, which guarantee women the right to autonomously choose their own lives independent from their communities. Badinter, who supported the legal ban on the headscarf in French public schools in 2004, complained in a 2011 interview with Le Monde that 'apart from Marine Le Pen, nobody defends laicism' (Badinter 2011). ${ }^{3}$

French laicism is a political model that advocates the strict separation of Church and State. Essentially, it is a specific, radical secularist version of Western liberalism (cf. Jansen 2013: 233 ff.). ${ }^{4}$ However, Badinter's outlook largely corresponds to mainstream feminism's claim that only liberalism's 'fundamentals', i.e. its concepts of autonomy and a secular state, guarantee women's rights to live their lives as free persons (cf. Okin 1999:24; cf. Chapter 2).

As discussed in the previous chapter, many postcolonial thinkers also equate 'feminism' with the 'fundamentals' of Western liberalism. To them, feminism is inherently secular in character. However, new kinds of feminism have emerged in the Muslim world that are based on religious principles. Islamic and Muslim feminists contest 'patriarchy' and fight for 'women's empowerment', women's rights', and 'gender justice' within the realm of religion, in a religious vocabulary and within religious 'forms'. By re-interpreting the Qur'an and Islamic history from the perspective of modern Muslim women, they re-articulate beliefs and idea(l)s that matter deeply to Muslim women and men. Western mainstream feminists, from their focus on concepts of autonomy and secularism, overlook the 'forms' of religion - as well as those of other 'presentational' realms - as modes of thought in their own right (cf. Langer 1960). They mistakenly debunk religious 'forms' that 'present' ideas in ways other than linear language, underestimating their relevance as intellectual activities (cf. Chapter 2).

3 Badinter later said her remark was meant as irony.

4 The model of French laicism goes back to French Neo-Kantianism. While the liberal legal-political framework accommodates expressions of religion, French radical secularism in principle inhibits such an accommodation, though it in practice shows otherwise (cf. Jansen 2013: 233 ff.). 
The present chapter, written from the perspective of Langer - and in line with Foucault's discussion of certain religious strands in Christianity and Islam - articulates Muslim feminists' re-contextualizing of Islamic rituals and beliefs in terms of ethical freedom practices that comprise important new visions for self and society.

\section{Women's Freedom Practices in Islamic History}

As a world religion with a long history, Islam contains much diversity. Focusing on Muslim women's freedom practices, I specifically discuss the ethical-spiritual dimension of Islamic belief, i.e. the dimension of moral systems that fascinated Foucault in his final work.

Like all moral systems, Islam involves a dimension of ethical selfformation, which is necessary for people to become the ethical subject that can follow the moral codes of Islam. Verse 2:256 of the Qur'an explicates that there should be no compulsion in religion: the Qur'an's core teaching is loyalty only to Allah. Religion is a matter of one's personal relation to God, which, in principle, invites one to create a personal ethical life project. But the relationship between the codes of the religious system and the space for personal ethical self-formation varies in Islamic history.

The latter dimension manifests itself most clearly in the original traditions of Islamic mysticism, which are oriented to the ethical-spiritual message of Islam (cf. Ahmed 1992) and that have their 'roots in the ritual practices taught by the Koran' (Schimmel 1975: 24). One of these traditions is Sufism. Aziza Ouguir (2013) shows that this mystical tradition originally addressed men and women in similar ways. Sufi scholars of the past made no distinction between men and women, and made it explicit that both can reach the highest ranks in Sufism. Ouguir discusses, among others, the works of Ibn Arabi (twelfth century) and Ibn Taymiyya (fourteenth century), who explicitly approve women being religious leaders and performing sermons (Ouguir 2013: 47). ${ }^{5}$ Their works thus convey an intrinsic gender equality in the heart of Islam.

Ouguir discusses the many strands of Sufism that developed over time, orthodox as well as popular, and Sufism's basic principles, formulated by eleventh-century Persian religious scholar Al-Ghazali. The telos of ascetic exercises in Sufism was not death to the self, but life in God, i.e. a state in

5 This is all the more striking since Ibn Taymiyya is often invoked by extreme Sunni radicals, including Daesh, to back their archaic attitude towards women. 
which the mystic is endowed with Divine attributes. This telos necessitates cultivating and embodying a number of qualities, such as repentance, gratitude, patience, and love (38). By means of exercises, such as ritual prayer, Sufi mystics search to unite with God, without vanishing, but with the hope of manifesting God's virtues in their lives. Sufism thus is not only oriented to the spiritual life on the level of the mind, but also to the practicing of an embodied ethical-spiritual life way of life.

Until the twentieth century, Sufism was a moving force in the Middle East. Today, it continues to play an important part in the lives of many Muslims at a more personal level. Many believers read Sufi literature and visit graves of Sufi saints to cultivate their spirituality, often in a reaction to the formalist rule following required by the more conventional forms of Islam. Not well known to many Muslim believers, however, are the female spiritual Sufi leaders of the past.

Margaret Smith (1984) discusses how, in Sufism, the gender of the believers was seen as less important than their devotional exercise. The title of saint 'was bestowed upon women equally with men, and since Islam has no order of priesthood and no priest caste, there was nothing to prevent a woman from reaching the highest religious rank in the hierarchy of Muslim saints' (Smith 1984: 2). Biographies of Muslim saints are full of references to women saints as well. Female Sufi saints were so influential that Muslim theologians, who opposed the Sufi movement, explicitly denounced the veneration of these women (cf. 3).

A famous Sufi saint and mystic is Rabia al Adawiyya (c. 720-801). A former slave from Basra, a city in the South of Iraq, she developed herself into a spiritual and intellectual leader within the emerging Sufism movement. Fom the many legends on her life, dating from several periods, she presents as a woman who self-consciously carved her own path, in ways that many female Sufi's followed. She consistently rejected the many marriage proposals she received, with words such as: 'God can give me all you offer and even double it. It does not please me to be distracted from Him for a single moment. So farewell' (Smith 1984:11). Her own contribution to Sufism lies in her call to avoid being led by traditions or rules. To a male Sufi mystic that tried to surpass her in piety she said: 'You traversed [the desert] in ritual prayer, but I with personal supplication' (9). About another Sufi she said: '(Y)es, Sufyan would be a good man, if he did not love the Traditions,' (16) thus conveying that the most important thing is to achieve a personal relationship with God.

Discussing Rabia's contribution to Sufism, Smith argues that she made her life into 'her plainest teaching' on this subject' (59). A well-known story 
relates how Rabia walked the streets of Basra with a torch in one hand and a bucket of water in the other, while saying: 'I am going to light fire in Paradise and to pour water on to Hell so that both veils [...] may completely disappear [...] and the servants of God may see Him, without any object of hope or motive of fear. What if the hope of Paradise and the fear of Hell did not exist?' (99). According to her, one should love God in unselfish ways (cf. 98).

In the stories, Rabia never speaks about the equality of men and women explicitly, and it would be nonsense to call her a 'feminist', as Mariëtte van Beek (2002) rightly argues. However, as Ouguir (2013) contends, the legends about Rabia's life convey 'equality effects' and even 'egalitarian effects. ${ }^{6}$ Rabia's life did not fit the patriarchal patterns of her time; on the contrary, it broke these moulds. Moreover, the high-spiritedness with which Rabia put the men around her in their place - especially her defeat of Sufi leader Hasan al-Basri in 'contests' of mystical capacities and miracle-working - has 'egalitarian effects' as they convey a critique on the men around her for not taking women seriously. The same is true of her rejection of all marriage proposals, her taking up of the position of a female intellectual and spiritual leader, and her emphasis on everyone's personal relationship with God.

Muslim feminist scholar Ahmed points out that Rabia was 'neither wife, nor slave, nor under any male authority' (Ahmed 1989: 149). She argues that Rabia lived a life of self-definition, a path she largely forged for herself, and thus opened for other women. Sufism 'cherished and projected as ideal the example of a woman leader,' regarding women 'not as embodiments of biological urges but as creatures needing resourcefully and thoughtfully to balance, as Rabia does, spiritual, biological and social dimensions' (149).

From the legends on Rabia's life emerge the five core characteristics of a freedom practice. She developed a personal ethical life project as a female mystic; acting in the world, as a spiritual leader 'in free and open

6 According to Siep Stuurman (2004a), a history of equality can be written that focuses on 'equality-effects' in discourses and texts that express notions and thoughts of equality without necessarily using the term equality as such. Equality can be expressed in a rational Enlightenment discourse, but also in mythical or religious discourses. We can recognize 'affinities and parallels [...] Stories may suggest similarity and equality without any explicit reference to them' (Stuurman 2004a: 24-25). Stuurman adds that there is a difference between equality effects and egalitarian effects. He states: 'it is useful to distinguish between equality and egalitarianism. Egalitarianism denotes the conscious pursuit of some specific variety of equality, while discourses and concepts of equality refer to specific senses in which persons are deemed equal in particular respects. The relation between equality and egalitarianism is one of potentiality: concepts of equality are not necessary egalitarian. On the other hand, it is obvious that ideas of equality can easily spill over into egalitarian discourses' holding that when things are alike they should 'receive similar treatment' (26). (See also Stuurman 2004b and Stuurman forthcoming.) 
interchange with other men and women' (Ahmed 1989: 149); implicitly critiquing women's subordination; creating a way of life as a woman that challenged the dominant gender patterns of her time; within the context of an emerging Sufi movement that offered self-techniques and models.

Rabia's legendary life was, and still is, a source of inspiration to many Muslim women, particularly to Muslim feminists. Algerian/MoroccanDutch singer Rajae el Mouhandiz recalls a film on Rabia's life that fascinated her as a child. ${ }^{7}$ Watching the film over and over again turned her into a feminist. To her, Rabia was

the first feminist role model whom I could look up to. I could not relate to Snow White, Cinderella, Rapunzel or any other female fairytale figures and to be honest as a child I felt sorry for them, because they all needed to be rescued by men and chased worldly dreams. My Rabia instead was a self made woman, who overcame so much and who tasted from various female roles, but chose to be close to God and loyal to her own journey to self. She inspired me to not chase Cinderella dreams, but to leave my own mark on the world via the arts. ${ }^{8}$

Especially Rabia's transgressing of women's second-class status in society is an inspiring example for today's Muslim feminists (cf. Ahmed 1989; cf. Chapter 2). Ouguir (2013) also discusses Rabia's life from this perspective, in addition to the lives of other notorious female Sufi mystics, like Fatima of Nishapur and Fatima of Cordoba, who are described in oral stories and hagiographies as spiritual leaders in their own right. Ouguir in her study especially focuses on several legendary female saints of Moroccan background, whose lives similarly transgress patriarchal patterns. Sufi saints for a long time played important social and political roles in Morocco. ${ }^{9}$ From

7 Her mother many times showed her a videotape of this film, that was produced in 1963 in Egypt and that is well known in the Arab world. For the film see https:/www.youtube.com/ watch?v=atXLFQCwYHk (last accessed, 21 September 2016).

8 Rajae adds: 'I was raised by a single mother, who was orphaned at a young age and who was married at 15 and the second time at 17 , and who overcame loss, abuse, neglect and prejudice, but who sacrificed to give her children a better education in the Netherlands. She never remarried, but decided to stay close to God. I believe Rabia's story relates to my mother's pain and hopes and in the end also to mine' (personal communication, 22 October 2014.)

9 Sufism gradually moved away from the ascetic moralism of early practice towards an organization of charismatic personal domination. However, in Morocco 'there is some continuity instead of a sharp distinction between Moroccan orthodox and popular Sufism, given that in many instances the latter also involves an acceptance of the foundational texts, beliefs and practices of orthodox Islam' (Ouguir 2013: 266). 
the hagiographies of al-Tadili (thirteenth century) and al-Kattani (twentieth century), female Sufi saints emerge on an equal footing with male saints.

Ouguir specifically exposes the lives of Moroccan saints Azīza al-Saksawiyya (fourteenth century) and Khadija al-Tamgdushtiya (nineteenth century). She gathered oral stories and hagiographic material, which portray both women as social and political leaders. Oral stories on the life of Aziza al-Saksawiyya, for instance, present her as a beautiful Sufi girl who rejected many marriage proposals and who performed miracles while she worked as a shepherd in the mountains. After studying in Marrakech and Algeria, she returned as a famous Sufi and became the political leader of her tribe. Hagiographer Ibn Qunfudh (fourteenth century) similarly describes Aziza al-Saksawiyya as the head of her tribe, and as a remarkably gifted woman that lectured to 'the men and women, who were always around her' (Ibn Qunfudh 1965: 86; translation: Ouguir 2013: 117).

Ouguir discusses the lives of many other Moroccan female Sufi saints, who developed their piety inside or outside their homes, performed miracles, and in some cases roamed the streets in 'madness'. Female venerators who visit the shrines of female saints - sometimes camping there for days - ask their particular woman saint for her blessing. But saints not only function for them as some kind of 'psychiatrist,' in the words of Fatima Mernissi (1977), who help them to deal with the hardships of their daily lives (cf. Ouguir 2013: 135). The saints are role models to their female venerators, and sometimes a source of inspiration to those seeking orthodox education and to become active religious agents (cf. 135). Ouguir found that several murshidats (Moroccan women preachers) integrate women saints as role models in their sermons on women's rights, in addition to other role models such as the prophet's wife Khadija Khuwaylid, who, being a wealthy merchant, spent her riches on the poor.

From her interviews with female leaders and politicians of the Islamist associations al-'adl wa al-Iḥsān, al-'adala wa al-Tanmiyya, and muntadā al-Zahrā, and with Islamist activists of other Moroccan organizations, Ouguir found that, although they reject the veneration of saints, they also integrate Moroccan female saints in their discourses, as empowering role models that may inspire Muslim women to engage in activism, education, and learning. Berber Islamists even 'name their associations after the Berber women saints who belong to their Berber tribes and regions, such as Lalla Zaynab. Likewise, Arab Islamist activists choose names of Arab women saints who are buried in the urban and rural locations of Morocco, for their associations, schools, youth houses and other institutions, such as Khumaysa, Umm al-Banīn' (216). 
From her interviews with Moroccan female Islamist leaders and activists, Ouguir concludes that they are feminists fighting patriarchy just as secular feminists do. While many of them prefer to speak of men and women's 'equity' rather than equality - i.e. that men and women have equal value rather than being equal - this only relates to the private sphere, in which they, moreover, oppose any hierarchical relations between men and women. Zakia Salime (2005) similarly concludes in her study on Moroccan Islamist women's organizations that they seek political, social, and economic empowerment of women and equality with men.

Other studies show that Muslim women throughout time and space developed personal ethical life projects as poets, scholars, and spiritual or political leaders (cf. among others, Nadwī 2007). In reference to several of these exemplary women, and especially to Rabia al Adawiyya, Ahmed (1989) argues that there is no need for Muslim women to import concepts from the West, since 'the beliefs on which feminism rests are an endemic part of Islamic civilization (just as they are an endemic part of Western civilization before the development of the political idiom of democracy)' (Ahmed 1989:144).

\section{Islamic Feminisms}

Muslim women scholars turn in particular to the Qur'an to articulate the contours of an endemic Muslim women's movement. Mernissi, in The Veil and the Male Elite: A Feminist Interpretation of Women's Rights in Islam (1991), originally published in 1987, discussed that the Qur'an conveys a message of gender justice. Ahmed (1992), too, argues that the Quran's ethical Spirit conveys that men and women are equal in the eyes of God. This explains 'why Muslim women frequently insist, often inexplicable to non-Muslims, that Islam is not sexist. They hear and read in its sacred text, justly and legitimately a different message from that heard by the makers and enforcers of orthodox, androcentric Islam' (Ahmed 1992: 66).

Ahmed explores how the ethical-spiritual message of the Qur'an was neglected with the elaboration of androcentric laws that were encoded in the Abassid period, i.e. the dynasty of the caliphs (750-1250). This period was extremely patriarchal and sexist: women were literally seen and dealt with as sexual objects ( $88 \mathrm{ff}$.). Even then, Sufis and Quarmatians continued to privilege Islam's ethical teachings. Had the ethical voice of the Qur'an been more widely acknowledged, 'it would have significantly tempered the extreme androcentric bias of the law, and we might today have a far more humane and egalitarian law regarding women' (88). Ahmed argues 
for an endemic Muslim women's movement that turns the ethical gender egalitarian voice of Islam against its hierarchical side - while political Islamism, once it gains power, does the opposite (cf. 242).

Ahmed discusses the history of feminism in the Arab world, particularly the different strands of Egyptian women's movements. Quasim Amin's work The Liberation of Women (2000), published in Cairo in 1899, is generally seen as the beginning of Arab feminism. Amin's approach was Western liberal in orientation, including in its rejection of the veil, an issue that was also important to British colonial administrators. Ahmed relates how British consul general of Egypt, Lord Cromer, a self-proclaimed 'feminist', argued against Muslim women's degradation through practices of veiling and segregation, while at home in England he presided over the Men's League Opposing Women's Suffrage (153). She notes that, at the time, European feminists criticized the actions of such men in their own societies, but acquiesced in 'the discourse of colonial "feminism"' that aimed to rescue women 'from the religion and culture in which they had the misfortune to find themselves' (244).

A Westward-looking women's movement, led by Huda Shaarawi, emerged in Egypt in the first decades of the twentieth century. An alternative movement, however, emerged at the same time - led by Malak Hifni Nassef - and pursued reforms for women 'in a native idiom' (160). Though this movement was generally not recognized as a voice of feminism, Sharaawi and Nassef advocated the same causes, among others the necessity of fundamental reforms in family laws and the right of women to access higher education and public spaces - Nassef's movement formulating these reforms in terms internal to the indigenous culture (cf. $179 \mathrm{ff}$.). Ahmed concludes once more that Muslim women's movements that want to enable women 'to contribute to their societies in all domains' (248) can rely on beliefs that are an endemic part of Islamic civilization.

Several studies of Muslim women scholars discuss the gender egalitarian message of the Qur'anic text in detail, among others Amina Wadud (1999), and Asma Barlas (2002). Wadud is an American scholar of Islam, who herself wears the hijab. She famously led a mixed-gender prayer service in New York City as a female imam in March 2005, which, at the time, triggered a lot of controversy and death threats on the internet. Her gesture was heavily disputed among Muslim women as well, with many of them arguing that it was counterproductive and that time was not ripe for it yet. Ahmed, however, commented that the time would never be ripe for women to enter the male domain and praised Wadud's gesture. In May 2005, Wadud repeated her gesture during a two-day conference on 'Islamic feminism' in 
Amsterdam. The meetings were attended by a mixed audience, men and women of Muslim and non-Muslim backgrounds, with much press and security as it took place at the height of the controversy around Islam in the Netherlands, with anti-Islam populism at its peak. ${ }^{10}$ When Wadud opened the meeting with a prayer, the public was silent, aware that Wadud's actions were changing an Islamic ritual 'form' into a gender egalitarian direction.

In her study Qur'an and Woman (1999), Wadud aims to show 'the relevance of the Qur'an to the concerns of the modern woman' (Wadud 1999: 95). Her hermeneutic-interpretative approach to the Qur'an is based on the presumption that its universality and wisdom can only be implemented through continued interpretation (cf. 94). ${ }^{11}$ The meaning of the text has to be disclosed in constant conversations, to keep its Spirit alive. The Qur'an being the word of Allah revealed to the Prophet is a revelation in context, adapted to the language of the time that gave words their meaning. This necessitates us to distill the general principles of the text and translate these for other contexts. A literal reading of the text 'does not allow for many of today's realities. [...] Therefore, the Qur'an must eternally be reviewed with regard to human exchange and mutual responsibility between males and females' (73).

Wadud starts her exploration of the text by discussing the Qur'anic story on the origin of humankind that states that women and men are created from a single nafs (soul). Unlike the Bible story, in which Eve is created from Adam's rib, woman is not secondary to man, the pair is on an equal footing. The Qur'an literally says: 'all things we have created by pairs' (Q51: 49) (Wadud 1999: 21). ${ }^{12}$ Since only Allah is unpaired and unique, it follows that men who consider themselves superior to woman are trying to be like Allah, which is deeply mistaken. Moreover, in the Qur'an, unlike the Bible, it is not only woman who is the cause of evil: both man and woman eat from the forbidden tree (Q20: 115-121) (cf. Wadud 1999: 25).

10 Due to the political murders of Dutch politician Pim Fortuyn in 2002, and in 2004 of Dutch film maker Theo van Gogh - both openly expressing their aversion of Islamic culture and religion - outspoken anti-Islam polarization increased and led to a series of confrontations, clashes and violent incidents between 'autochthonous' and 'allochthonous' parts of the population - the latter mainly of Moroccan and Turkish descent - such as the setting fire to Islamic schools and mosques. 11 Wadud 's book was originally published in 1992 in Malaysia, and since then has been translated among others into Indonesian (1994) and Turkish (1997).

12 In line with Wadud (1999), I refer to Qur'anic quotations in general in the text in parentheses by a $Q$ followed by numbers with a colon between them: the first number referring to the Chapter and the numbers after the colon referring to the verse(s) (cf. Wadud 1999: 11). Literal quotations from the Qur'an as well are taken from Wadud's text (for the English translations of the Qur'an she used, see Wadud 1999: 11.) 
Wadud also explores the passages in the Qur'an that portray female characters; namely, the mother of Moses, Mary, and Bilqis the Queen of Sheba. She concludes that in the text women are never declassified as sinners per se, nor are they explicitly restricted to a limited set of roles, subordinate to men, where there is no room for spiritual growth. The Qur'anic text explicitly calls for women to be on an equal footing with men in order to fulfil all religious duties. Verse 33:35 of the Qur'an places woman on an absolute par with man in relation to their spiritual potential:

For Muslim men and Muslim women, for believing men and believing women, for devout men and devout women (i.e. who have qunut), for true men and true women, for men and women who are patient and constant, for men and women who humble themselves, for men and women who give in charity, for men and women who fast, for men and women who guard their chastity, and for men and women who engage much in Allah's praise - for them has Allah prepared forgiveness and great reward (Q33:35) (cf. Wadud 1999: 99).

The Qur'an moreover explicitly states that women, like men, are offered paradise and proximity to Allah: 'whoever does right, whether male or female, and is a believer, (all) such will enter the Garden' (Q40:39-40) (Wadud 1999: 48).

The verses that remain problematic for women, among others verse 4:34 in the fourth Chapter of the Qur'an, al-Nisā' (The Women), which advises men when women disobey to 'admonish them, banished them to beds apart, and scourge them,' are to be seen as remnants of the socio-historic context in which the Qur'an was revealed (Q4:34) (cf. Wadud 1999: 100-101). They are specific for the situation in the Arab world in the seventh century, but they demonstrate the intention of gradual reform, since they put constraints on what were the habits of men (95). In the words of Nazirah Zein Ed-Din (1982): 'If all these customs had been entirely abolished by God, several problems would have ensued [...], not many of His commandments would have been obeyed' (Zein Ed-Din 1982: 224, quoted in Wadud 1999: 82). Similarly, the Qur'an posits severe restrictions on slavery. While its immediate total abolition was not completely instituted by the end revelation, enough clear indications of the Qur'an's intentions are given in this regard (101). Slavery is no longer accepted in the Muslim world, and the unequal treatment of women should not be either, since it contradicts the essence of Islam (cf. 77). The 'continued change which the Qur'an put into motion was not meant to stop when the revelation was completed' (101). There has to be a 
'continual assessment of a current situation' in the light of this principle of gradual reform (89).

Wadud concludes that while some limitations exist in the text, 'such as when it specifically addresses the social situation in Arabia at the time of revelation' (95), the Qur'an's key assumptions and overall worldview are egalitarian in character. Men and women are treated in the Qur'an as individuals that, depending on their own piety, can merit paradise. The differences between men and women should not be obliterated, but no fixed gender roles can be distilled from these differences (cf. 102-103). Social justice requires for women to have 'full access to economic, intellectual and political participation,' and for men to 'value and therefore participate fully in home and child care.' Only then can 'a more balanced and fair society' come about (103).

Pakistani-American scholar Barlas, in her study 'Believing Women' in Islam: Unreading Patriarchal Interpretations of the Qur'an (2002), demonstrates the egalitarian and anti-patriarchal nature of the Qur'an's teachings on the basis of the methodology that the Qur'an itself proposes for its reading. ${ }^{13}$ At several points, the Qur'an says that it must be interpreted holistically. The Qur'an warns us not to break its text into parts (Q15: 91-93). Each concept must be read in the context of others so as to arrive at the intentions of God. We have to treat the Qur'an as a unity and read it for its best meanings so as to reach its foundational message. The text also encourages a contextual reading, instructing us to discover its true meaning by reflecting and making the best use of reason. It is unavoidable that we read the text from our own 'reading sensibilities shaped by existing ideas, debates, concerns, and anxieties.' Indeed, if we are to re-contextualize the text for new generations of Muslims, 'we must bring new insights to our reading. Interpreting the Qur'an in light of new insights is also legitimate inasmuch as Islam is not bound by space, time or context' (Barlas 2002: 25).

From the methodological principles of the Qur'an itself, Barlas concludes that not all readings can be accepted. Verse 4:34, for instance, should be interpreted as a restriction instead of a licence for men to beat their wives, as is clear from examining the historical context of its teaching. At a time 'when men did not need permission to abuse women [...] it could only have been a restriction in so far as the Qur'an made daraba the measure of last, not the first or even the second, resort' (188). Read holistically and for its best meaning, the Qur'an points towards the ending of violence against women,

13 Barlas (2002) has been translated into among others Bengali, Indonesian, Spanish, French, and Urdu. 
which is in line with 'the Qur'an's view of sexual equality and its teaching that marriages should be based in love, forgiveness and harmony' (189). ${ }^{14}$

While the studies of Barlas and Wadud explicitly criticize patriarchy and women's subordination to men, they avoid the term 'feminism', due to its Western connotations. Today, however, both Wadud and Barlas accept the term 'Islamic feminism' that was launched by scholars Mir-Hosseini and Margot Badran. ${ }^{15}$ Mir-Hosseini (2004) concluded that 'by the late 1980s, there were clear signs of the emergence of a new consciousness, a new way of thinking, a gender discourse that is "feminist" in its aspiration and demands, yet is "Islamic" in its language and sources of legitimacy' (Mir-Hosseini 2004: 3). For instance, the Iranian journal Zanan, in the early 199os, 'made no apologies' for using the term feminism (cf. Mir-Hosseini: 1999: 6). The term 'Islamic feminism' conveys that 'there is a theoretical concord between the egalitarian spirit of Islam and the feminist quest for justice and a just world' (Mir-Hosseini 2004: 4; cf. Mir-Hosseini et al. 2015).

Historian Margot Badran (2009) also launched the term 'Islamic feminism' in reference to Arabic women's movements, which from the 1990s onwards started to use the term feminism. The term 'Islamic feminism' is important since it eradicates binaries such as 'religious' and 'secular' and 'East' and 'West', and conveys that feminism is a phenomenon endemic to Islamic civilization as well (cf. Badran 2009: 245).

Muslim women's organizations that struggle for women's rights, gender equality, and 'gender justice' in Islam, on the basis of an egalitarian rereading of the Qur'an, exist today in Morocco, Iran, Egypt, Malaysia, and Indonesia as well as in Western countries. About the beginning of the Malaysian movement, 'Sisters in Islam', Zainah Anwar and Rose Ismail (2012) relate:

Women were telling us how they were suffering in silence: they had been taught that Islam demanded complete obedience to their husbands, even in instances when the men in question deserved no such consideration. Over and over they were told in religious lectures and sermons; in private gatherings; over radio and television; at mosques,

14 Other key studies concerning the gender egalitarian character of the Qur'anic text are Riffat Hassan (1987) and Azizah al-Hibri (2014).

15 Cf. Barlas (2016). Barlas and Wadud attended the conferences on 'Islamic feminism' that for several years took place in Barcelona, since 2005, with delegates from many countries. Cf. https://abdennurprado.wordpress.com/2005/10/27/presentation-on-islamic-feminism-firstinternational-congress-on-islamic-feminism-barcelona-27th-october-2005/ (last accessed, 21 September 2016). 
and in the courts that all men were superior to all women; that the evidence of two women equaled that of one man; that the husband had the incontrovertible right to beat his wife or to take a second wife; and that the only place for a disobedient wife in the hereafter was hell (Anwar and Ismail 2012: 63).

Focusing on polygamy and the popular belief that men had the right to beat their wives, they started studying the Qur'anic text. In reference to the work of Wadud and the Qur'anic verse 4:34, they state:

Those supporting the rights of men to this violence sought justification in the Qur'anic verse on nushüz, commonly interpreted as “disobedience." [...] [I]t was Amina's pioneering work which enabled us to argue that wife-beating was not a God-given right in Islam. She pointed out to us the context of revelation. [...] We also looked at the Hadith literature, which had no record of the Prophet Muhammad ever beating any of his wives or supporting any incident of domestic violence (66).

As for polygamy, it was a revelation to see that the second half of the verse on polygamy $\left(\mathrm{Q}_{4}: 3\right)$ in Arabic clarifies that if one fears not being able to deal justly with women, 'then marry only one' (Anwar and Ismail 2012: 66).

The organization Musawāh ('equality' in Arabic), founded by MirHosseini and Anwar as the global branch of 'Sisters in Islam', calls itself the international 'Islamic feminist' movement for equality and justice in the Muslim family (Musawāh 2010). While the concept 'Islamic feminism' has become accepted in wider circles, it is contested by many others: by Muslims, because of the Western connotation of the term 'feminism' and by secularists who consider Islamic feminism a contradiction in terms. From both sides, Muslim feminists' re-reading of the Qur'an is often debunked as a selective cherry-picking - overlooking the fact that any re-reading of old texts in modern contexts involves re-interpreting. Critics claim as well that it is not clear what Islamic feminism stands for and who is and who is not an Islamic feminist.

While Elizabeth Warnock Fernea (1998) defines an Islamic feminist as 'a woman with extraordinary survival skills who constructs a self according to the company she keeps and the place she lives' (Sciolino 1998), Isobel Coleman (2010), for instance, includes all kinds of projects to alleviate poverty, such as NGO development work, and other kinds of activisms that challenge overarching structural inequalities. Mir-Hosseini (2004) rightly warns that any clear-cut definition of Islamic feminism falls short, since the movement 
is diverse and evolving (Mir-Hosseini 2004: 3). However, in what follows, I will present some of its contours from the perspectives outlined at the beginning of the chapter, articulating Islamic feminism in terms of Muslim women's ethical freedom practices.

\section{Muslim Women's Feminist Freedom Practices}

Islamic feminism's contours can be characterized along the lines of the five core characteristics discussed in Chapter 2; namely: 1) personal ethical-spiritual life projects of believing Muslim women that share a concern for other Muslim women; 2) expressed in actions in the world; 3) explicitly critiquing practices that deny Muslim women access to a personal ethical life project within their communities; 4) creating new ethical ways of life, and 'forms' in a certain relationship to womanness; 5) (within) distinct, relatively autonomous, groups or movements, the fabric of which consists of (1).

Regarding the first characteristic, it is no coincidence that several Islamic feminist scholars explicitly give an account of their own ethical-spiritual life trajectory. Wadud, in Inside the Gender Jihad (2006), goes into her personal spiritual quest at length. Ahmed has gone extensively into her own life in A Border Passage (1999), as did Mernissi in her own autobiography (Mernissi 1994). Barlas (2008a) questions the concept of feminism in relation to her own ethical-spiritual trajectory.

Where it concerns the second and third characteristic, Islamic feminists organize and act in the world in an outspoken critique of those practices that prohibit Muslim women from developing a personal ethical life project within their communities. Some initial contours of the movement thus become clear. While to Miriam Cooke (2001), Islamic feminists are those who 'navigate' among and through 'multiple identifications' with the common purpose of calling for justice and freedom (Cooke 2001: xxviii), she includes secular feminist Nawal El Saadawi as well as Zaynab Al-Ghazali - founder of the Egyptian Muslim Women's Association. The latter marginalizes domesticity and embraces political activism for herself, while holding that all Muslim women should stick to the domestic sphere. Al-Ghazali's affirmation for women in that sense qualifies her as an Islamist activist, rather than an Islamic feminist.

Women of the so-called Turkish Turban movement - a political movement of women students who, from 1983 onwards, started to wear the headscarf in universities despite it being forbidden by the Turkish state - examined 
in the work of Nilüfer Göle (1996), similarly emerge as Islamist activists rather than Islamic feminists, since their protests did not question women's subordination to men (Göle 1996: 136). Islamic feminists, however, do so. They criticize traditionalist Muslims' claims that men were designed as mentally and physically superior to women, and that women were meant to perform care-taking tasks in the domestic sphere.

Merieme Yafout, a Moroccan scholar and activist who was affiliated to the Faith and Justice Association (adle wa al-Ihssan) argues:

[T] he crucial thing is having choice. Some women choose to reconcile the two, to be housewives, to be good mothers and wives, but also to be part of society, to work as professionals, to be part of organizations that campaign for women's rights, for human rights or on the political scene and so on. So they're choosing to be present in the public and the private world. So our criterion is choice. Are women acting in a way they have chosen or in a way that has been imposed on them?

Yafout adds: 'Islamic feminists try to reconcile the two, making their own choices so they may be happy in what they do, without forgetting the community, without the egotism that makes an individual only think of herself and forget the community' (Yafout 2013). Islamic feminism's normative perspective is the ideal of a personal ethical life project that balances individual and collective dimensions.

While criticizing oppressive practices such as polygamy and violence against women, Islamic feminists at the same time create new visions and models for self and society, in line with the fourth core characteristic. To Zeynep Jane Louise Kandur, affiliated to the Istanbul women's branch of the Turkish Justice and Development Party, (Adalet ve Kalkinma Partisi, AKP), women should be encouraged to work or engage in activities outside their homes. While the family is important, who takes on the tasks of care-giving is for people to decide themselves:

$[\mathrm{P}]$ eople always point to the mothers, they should be re-educated so as to be better parents. However, in my view, the fathers should be re-educated and retrained, today. The Prophet was a good father; he was shocked to hear a man saying that he never kissed his child. The Prophet also took care of his house himself. Men should learn to care and nurture, like him. ${ }^{16}$ 
Islamic feminists not only argue for women's access to full social participation, but also for the sharing of household duties and the raising of children between men and women.

Men also support their causes. Muslim feminists often differentiate themselves from Western feminists by arguing that they prefer to struggle together with men for their ideals and not against them: cooperation between the sexes is not only their final goal, but their strategy as well and love in the family is upheld as a strong value. But from the premise that '(u)ltimately, only Allah can judge personal actions' (Wadud 2006: 36), Wadud, as a Muslim feminist, also supports lesbian, transgender, and gay Muslims' efforts to build support groups to help them reconcile their sexual orientation and gender identity with the Islamic faith (cf. Siraj al-Haqq Kugle 2010: vii).

Finally, relating to the fifth core characteristic, Islamic feminist groups and networks together form a relatively independent movement. According to Mir-Hosseini (2010), the movement of Islamic feminism is the 'unwanted child' of political Islam, which actually 'politicized the whole issue of gender and Muslim women's rights.' Political Islam, which propagated a return to premodern interpretations of sharia, with generally restrictive laws concerning women, led to the emergence of Islamic feminism and 'critiqu[e] [of] Islamists for conflating Islam and the shariah with undistilled patriarchy and for claiming that patriarchal rule was divinely mandated' (Mir-Hosseini 2010).

Whereas to Mir-Hosseini Islamic feminism has its origins in political Islam, others argue that Islamic feminist movements are the unmediated effect of Western influences. According to Ong (2006), the Malaysian movement 'Sisters in Islam' is the by-product of neoliberalism 'as exception.' In line with the authors of the 'governmentality school' (cf. Chapter 1), she argues that neoliberalism governs 'through freedom,' and 'requires populations to be free, self-managing, and self-enterprising individuals' in different spheres of everyday life, such as health, education, bureaucracy, and the economy (14). Ong shows how neoliberal governmental techniques have become translated and operationalized in non-Western contexts, especially in East and Southeast Asia, where they are 'neoliberal exceptions - rather than the general characteristic of government (cf. Ong 2006: 3-4) ${ }^{17}$ The introduction in Malaysia of neoliberal techniques to manage (parts of) the population involves a subsidizing by the state of 'moderate Islam'. Ong claims that Malaysian Muslim feminism similarly is subsidized by the

17 Ong (2006) argues that overall a variety of overlapping sovereignties and labor regulations is at stake, contra the claim of Michael Hardt and Antonio Negri (2000) 'that economic globalization has produced a uniform global labor regime' (Ong 2006: 8). 
state to - 'at a distance' - regulate Muslim women's entry into the market economy (35).

Like other governmentality authors discussed in Chapter 1, Ong - in reference to Foucault's final work - takes ethical self-practices in neoliberal contexts as totally linked to state-governmental techniques. From this perspective, she concludes that the Malaysian 'Sisters in Islam' in many ways 'act as surrogates for the government, and its vision of a corporate Islamic culture that promotes self-discipline, capital accumulation, and loyalty to the state' (36). But while Ong (2006) takes the 'Sisters in Islam' movement as the child of a neoliberal regime, it would be more accurate to call it the unwanted child of this regime, to paraphrase Mir-Hosseini. 'Sisters in Islam' is harshly criticized by (neo)liberal groups who attack the movement for defending conservative traditions. But it is criticized as well by Malaysia's main Muslim organizations. Islamic feminism has crystallized into a relatively independent movement, in relation to both the traditional power centres of Islam and those of a globalizing neoliberalism.

Islamic feminists organize in networks and gather together in reading groups to study the Qur'an. In a debate with Muslim scholar Tariq Ramadan in June 2008, Barlas defended the right of modern Muslim women to discuss and interpret Islam among themselves, while Ramadan insisted that only the Ulema are entitled to Qur'anic interpretation.

Ahmed (1992) argues that Western culture is very influential on a global scale and that any attempt to reinstall a pure, original Islam fails since contexts have changed. However, as we have seen, she also points to endemic Islamic sources to contest injuries against women. Badran, Barlas, Mir-Hosseini, and Sadiqi, in a similar vein, consider Islamic and Muslim feminisms as building on local and religious sources, while engaging in interactive debates inside and outside the Islamic world. ${ }^{18}$ Women's organizations like 'Sisters in Islam' and Musawāh equally turn to the cultural heritage of the Islamic world itself as sources for an endemic Muslim women's movement.

As a relatively independent movement, Islamic feminism is critically creative in character, since it cannot just rely on dominant interpretations but must confront the Qur'anic text itself. But this does not mean that it creates new beliefs and idea(l)s without foundations. Far from being relativist in character, Islamic feminists' claims involve the disclosure of the true meaning of the Qur'anic text.

18 Sadiqi (2014) argues for an endemic Moroccan feminism that takes on board pre-Islamic Berber culture. 
In this respect, Raja Rhouni (2010) and Aysha Hidayatullah (2014) warn against a new 'foundationalism' that wants to restore the true meaning of the Qur'an. Rhouni (2010) prefers the approach of Islam scholars Mohammed Arkoun and Nasr Abu Zaid, who both aim to restore the historicity of foundational texts - without denying the sacred or transcendental dimension of the Qur'an - arguing that Islam's tradition of 'ijtihäd (independent reasoning) should be revitalized. Islamic feminists should recognize that the text involves divine as well as human communication, as such containing 'at least two competing voices regarding women, one egalitarian (ethical) and the other hierarchical (practical)' (Rhouni 2010: 35).

Similarly, Aysha Hidayatullah (2014) holds that 'the Qur'an itself must be held responsible for its sexist and harmful readings' (Hidayatullah 2014:136). Both authors argue that Islamic feminists should not deny this, but seek to dismantle Islamic androcentric assumptions, and take their movement as 'an open-ended project of construction, which intends to reactivate the dynamics of Islamic thought as critical thinking' (Rhouni 2010: 16).

While Islamic feminists disagree about the status of the text, involving divine or a combination of divine and human communication, they do agree on reading the text for its divine message, which points to social justice and gender equality. When Rhouni argues that gender equality is not a norm already established by Qur'anic discourse, but a 'horizon or trajectory pointed at by the Qur'an' (Rhouni 2010:16) this covers Wadud's and Barlas' approaches as well. Like Wadud, Barlas points to the context of Arab societies in the seventh century in her reading of verse 4:34, interpreting this verse as a restraining order against men who mistreated women generally. Both Barlas and Wadud emphasize the importance of a contextual reading. As Wadud contends,

[E]ach Islamic society must understand the principles intended by the particulars. These principles are eternal and can be applied in various social contexts. [...] However, the movement from the principles to particulars can only be done by the members of whatever particular context a principle is to be applied. Therefore, interpretation of the Qur'an can never be final (Wadud 1999: 10).

Barlas (2002), while pointing to certain limits that are present in the text, also argues for the openness of the Qur'anic text toward future (other) interpretations.

Barlas (2016), in response to Hidayatullah (2014) and Rhouni (2010), argues for a disclosure of the meanings of the Qur'anic text in hermeneutical 
ways. Every text has 'an excess of meanings and no interpretation can exhaust them all' and 'every text has multiple contexts and can always be recontextualized.' Scriptures 'encompass a horizon of ethical possibilities and uncovering those that can be realized in our times could be our vocation. This might well include deriving a theory of sexual equality from the Qur'an's teachings' (Barlas 2016: 114, 119). Rhouni and Hidayatullah do not take into account the hermeneutical point of view that bringing a new perspective to the process of interpretation involves a disclosure of the text's true meaning. In other words, they do not take into account the hermeneutical claim that perspectivism and truth are interrelated, instead of being each other's counterpoints. Islamic feminists claim to uncover the true meaning of the Qur'an from their perspectives as modern believing women. By re-interpreting the text themselves, they aim to reveal its key principles - without denying its contextual voice - and to demonstrate its relevance to the concerns of modern Muslim women and men.

\section{Muslim Women in Western Europe}

The movement of Islamic feminism is not well known in Western Europe either among Muslims, or among other parts of the population that mostly assume that Islam is inherently hostile to women. Especially the media recycle stereotypical images of Muslim women as victims of an oppressive culture, and of Islam as an inherently violent religion (for instance, by showing images of Muslim terrorists when speaking of Muslims in general) ${ }^{19}$ The 'issue' of the oppressed Muslim woman has especially gained attention in recent years through the media-hyping of some high-profile former Muslim female writers and politicians who have emigrated to the West, and who argue that Western secularism is the only road to women's emancipation. Notable examples include the French-Iranian writer Chahdortt Djavann, the Somali-born Dutch-American author Ayaan Hirsi Ali, and AmericanIranian author Azar Nafisi (cf. Mahmood 2008; Vintges 2005, 2012). The stereotypical 'image' of the oppressed Muslim woman also routinely turns up on the internet in Western Europe, where the bashing of Muslims goes to extreme lengths. ${ }^{20}$

19 On the recycling of stereotypical stories and images of Muslims and Islam on Dutch television, see Andrea Meuzelaar (2014).

20 Cf. The Eurobarometer on Discrimination, 2015. Cf. http://www.equineteurope.org/ Discrimination-in-the-EU-in-2015 (last accessed, 21 September 2016). 
The typical representation of Muslim women in the media as passive victims of an oppressive religion, stands out as one of the core concerns of Muslim women in the West. Sarah Bracke (2011) shows that Dutch Muslim women's reactions to these stereotypes range from criticizing women's emancipation to claiming the possibility of emancipation as pious women, to investing in a grassroots women's movement that informs women on their rights in a literal reading of the Qur'an. Likewise, Narzanin Massoumi (2015), in her study on a British grassroots movement against the War on Terror, shows that Muslim women activists counter the dominant narrative of the oppressed Muslim woman by focusing on the rights of women in a literal reading of the Qur'an (Massoumi 2015: $16 \mathrm{ff}$.). Instead of feeling oppressed by Islam, they feel oppressed by Western culture. ${ }^{21}$

Some of Massoumi's interviewees told her, 'Islamically you can't be a feminist, not if you really understand what it is behind Islam [...] (b)ut you don't need to be a feminist because Islam gives you everything you need as women. [...] I think it's a minority of people that describe themselves as Islamic feminists [...] In a way they do make me really angry' (17). Annoying to them is the hegemonic 'feminist rhetoric [...] (T)hat ideology in Britain. [...] You always have a feminist perspective and a feminist agenda' (18). One participant concludes, ' $\mathrm{t}$ ] he way that the media is presenting us now, maybe in the past it was more equal for us. But now, it's becoming worse' (Massoumi 2015: 19).

Regular Muslim women's organizations in Western Europe today organize social meetings, self-help groups, readings, workshops, and debates, to support Muslim women in their various roles, in society, and in the Muslim community. Facing a climate of Islamophobia, Muslim women in Western Europe mostly keep their distance from any 'feminism' and primarily identify as Muslims.

Sociological research shows how European Muslims are affected by an increasingly hostile social climate, experiencing, among other things, a different treatment by the police and discriminatory practices in relation to housing, employment, and education. ${ }^{22}$ To date, Western European countries are far from being 'decolonized' (cf. Van Reybrouck 2014). In the Netherlands, interethnic contact has decreased over the last fifteen years, especially between people from Moroccan or Turkish descent and

21 Muslim women involved in Dutch migrant women's organizations similarly respond in this way (cf. Roggeband 2010).

22 For an analysis of the climate of Islamophobia in The Netherlands, cf. Ineke van der Valk (2012). 
the so-called autochthonous population. ${ }^{23}$ Overall, the income position of non-Western migrants is a third lower than of Dutch natives. Unemployment of non-Western immigrants and their children is considerably higher than of 'autochtonous' Dutch, and this does not improve for the younger generation. Poverty is widespread, especially among the Moroccan community. ${ }^{24}$ Detailed analysis shows that migrants with the same characteristics as natives have less chances of finding (permanent) work, and this also counts for higher education graduates. Several recent studies show that 'an applicant's ethnic background plays a role in selection decisions' (Statistics Netherlands 2013: 198, 184). ${ }^{25}$

The government counters these negative developments with an equal rights discourse and by equally applying neoliberal 'activation' techniques to all parts of the population (cf. Chapter 1). Willem Schinkel and Friso van Houdt (2010) assess that the Netherlands is currently one of the most

23 Netherlands Institute for Social Research 2012a: 132. In 2013, the 'Turkish group comprises almost 400.000 persons, the Moroccan group roughly 370.00o' (Statistics Netherlands 2013: 192) 'In 2009 the total Dutch population was $16,405,399$ of which $13,189,983$ (80\%) were considered as autochthonous Dutch (note that anybody with one or two parents born abroad is not considered autochthonous). About 1 million inhabitants are of Muslim descent' (Anja van Heelsum 2008: 8). Almost all people of Turkish and Moroccan origin living in The Netherlands 'regard themselves as Muslim' (Netherlands Institute for Social Research 2012b: 179) and religious self-identification is almost as high in the second generation as in the first generation (185).

24 The difference in unemployment increased during the recent years of economic crisis, as a report of Statistics Netherlands (2013) shows. For migrant groups in the Netherlands unemployment, since 2008 has risen sharply, and in 2012 is more than three times as high as for the 'native Dutch population': 16 per cent of them are unemployed, compared with 5 per cent of native Dutch (183). Migrant youth unemployment - age 15-24 years - is high, approaching 30 percent, with Moroccans reaching 37 percent $(183,197)$. While almost half of young Dutch natives have flexible jobs instead of permanent ones, this is the case for two-thirds of migrant groups. In total, non-western migrants are six times more likely to be dependent on social assistance benefit than Dutch natives (i.e. 2 per cent), with 9 per cent of the Turkish group and 14 per cent of the Moroccan receiving social assistance benefit - many women and people aged over 45 years among them. One in five non-Western migrants, and one in four non-Western children live in a poor household; for the Dutch natives this concerns respectively 5 and 7 per cent (191). Fewer than half of Moroccan migrants aged between 15 and 65 are in paid work and 'youth unemployment is very high, especially among those who have left senior secondary vocational education without a basic qualification. Moroccans are also the group where unemployment has risen fastest in the Netherlands in recent years. Many members of the Moroccan group receive social assistance benefit and poverty is widespread' (193). However, there is also a growing group of women and men from Moroccan background who are doing well in terms of education and profession.

25 In the Netherlands in 2012, 46 per cent of non-Western women were in paid work, with 60 per cent of their male counterparts; for the 'Dutch natives' the figures are $63 \%$ and $76 \%$ respectively (Statistics Netherlands 2013: 187). Migrant women's participation in labour has increased during the last ten years. 
'neoliberalized' Western European countries and a forerunner in dismantling the welfare state and in the burial of multiculturalism (Schinkel and Van Houdt 2010: 697). The population is increasingly regulated as a set of 'entrepreneurial selves', i.e. as persons who have to manage themselves and who are responsible for their own success or failure (cf. Chapter 1). 'Activation' programs, such as courses to improve people's job application skills and enhance their 'employability', and radical cuts in social benefits for those who do not actively seek work or develop skills, are equally applied. Unemployment has become an individual failure, while migrants of all generations have no equal chances at all due to their discrimination on the job market. ${ }^{26}$ Christian Joppke (2007) characterizes the new Dutch integration policies in terms of a 'repressive liberalism' that increasingly marks Western European states, and that coerces migrants 'to release their self-producing and -regulating capacities, as an alternative to redistribution and public welfare [...] seeking to make people both self-sufficient and autonomous by illiberal means' (Joppke 2007: 16). ${ }^{27}$

The neoliberal approach of 'responsibilizing' people is extra disadvantageous for migrant groups (cf. Van Baar 2012) as is also clear from its effects in the school system and in healthcare. The current Dutch school system can be characterized as a tricky combination of disciplining and neoliberal governance: a neoliberal 'responsibilizing' approach of children is paired with an intense monitoring and a negative categorizing of all those who fall behind. ${ }^{28}$ From a very early age, children are trained and supposed to behave as an 'entrepreneurial self', with skills such as coordination, self- and time-management, and cost-benefit calculation (see Chapter 1). Those who are (construed as) failing to do so are often boys, and more often boys from migrant backgrounds. It is quite common in the Netherlands to signal a 'boys problem', due to a 'feminization' of education: it is said that the boys cannot identify with the almost all female staff in primary schools applying feminine values.

26 Schinkel and van Houdt (2010) distinguish between a 'repressive' and 'facilitating' neoliberal responsibilization, the first concerning the migrant population, the latter concerning the indigenous population. From the analyses presented in my earlier chapters on the constraining sides of neoliberal governmentality, I would rather speak in terms of different forms of coercive responsibilization of both groups (cf. Schinkel and Van Houdt 2010: 708).

27 Saskia Bonjour and Doutje Lettinga (2012) discuss important differences, however, between national models of migrant integration regarding Islamic headscarves and civic integration abroad policies.

28 A documentary that criticizes the Dutch school system in terms of feminization, in fact clearly shows the neo-liberal disciplining character of the school system; cf. 'De echte jongens film', http://www.uitzendinggemist.nl/afleveringen/1373349 (last accessed, 21 September 2016). 
However, the real problem is not so much the school's 'feminization', but rather its disciplining type of neoliberalization and boys rebelling more than girls against the system's compulsory aspects. The school system works as a funnel with two exits, one for the normal, and one for those who are construed as 'falling short' and who, at a very young age, are relegated to several kinds of lower-level education. Due to the system's individualizing, 'responsibilizing' approach, especially migrant children with illiterate parents have no hope of equal chances. They lack the parental support in planning and helping with their homework, and they do not have their assignments written for them - as often happens with children from a white, middle-class background.

Moreover, schools are increasingly segregated in the cities, which also affects the chances of migrant children in negative ways. Former 'comprehensive schools', which offered many levels of secondary education, are today split between educational institutions that offer artisan schooling and vocational training and more academic establishments, including the top level 'gymnasia' schools. The director of the only remaining comprehensive school in Amsterdam is regularly forced to confront board members, parents and staff wanting to 'uncouple' the several academic streams in her school from the rest. ${ }^{29}$ Another secondary school in Amsterdam recently turned its lower education department into an 'art class' so as to be able to refuse lower-class migrant youth from enrolling. Most students of the - almost all white - University of Amsterdam have no contacts, let alone friendships, with people from Muslim background. 'Non-white' students generally have a hard time in this university. For example, one Surinamese student reported that university security guards follow him whenever he enters a university building.

Some Dutch-Moroccan and -Turkish youth are able to compensate for their discrimination in the school system at early age by embarking on the 'long route,' moving step by step into higher education (Crul 2008)..$^{30}$ An 18-year-old Dutch-Moroccan boy nicknamed 'Dotty', who pays his grandmother rent for living with her, works till 4 am in the vegetable market and then goes to adult education 9 am because he is determined to work his way up the school system.

'(T)hey started out in lower vocational education, moved on to middle vocational education, then to higher vocational education and some continue into University [...] About half of the second generation Turkish youth in higher education took this long route' (Crul 2008: 7). 
While an increasing number of Muslim migrants' children - especially girls from Moroccan background ${ }^{31}$ - are entering higher education, a majority are still allocated to lower-level schools. In particular, Dutch-Moroccan boys are rebelling against the disciplinary aspects of the school system - with its selective funnel character - to the point that they drop out and follow the neoliberal message ${ }^{32}$ of seeking their own success, but they do so via criminal activities: 60 per cent of them have been in contact with the police as a result of the street culture they have developed. These habits usually end around the age of 22 , when they are supposed to start leading a 'normal' life and settle down (cf. Statistics Netherlands 2008). ${ }^{33}$ According to Frans Bovenkerk (2014), the criminality rates of Moroccan boys in the Netherlands are much higher than in other Western European countries, due to the boys' lack of a positive father figure; that is to say, many of their fathers have been receiving social welfare in the Netherlands since the $1980 \mathrm{~s}$ due to the economic crisis. But their behaviour seems more linked to the general Dutch 'boys problem', i.e. to the prevailing neoliberal 'grid' of the Dutch education system and the general style of thought and imagination (cf. Chapter 1).

A similar program of neoliberal responsibilization has taken over the healthcare system. It is now common to categorize people using 'health literacy' criteria, meaning their ability to obtain, understand, and apply information about health issues. To economize the expenditures of healthcare, people are increasingly supposed to monitor their own health, consult websites, decide whether to take tests or not and judge when it is appropriate to visit a doctor. Healthcare workers are now trained to cope with the 'health illiterate' - about 30 per cent of the population - mostly people who grew up without schooling, many of whom are from immigrant groups of less developed countries. ${ }^{34}$ Doctors are supposed to reinforce prevention and self-management among these groups in order to make the healthcare system more efficient and less expensive. With e-health on

31 Muslim girls who pursue further studies are under less possible pressure from their family, for instance to marry young. Reaching economic independence as well widens their possibilities.

32 With thanks to Fatima Ballah.

33 Cf. Jan Dirk de Jong (2007) for a field study on the street culture of Moroccan youth groups in Dutch cities.

34 With thanks to Marga Vintges, medical doctor and senior researcher at Pharos (Dutch center of expertise on health disparities). In spite of all neoliberal cuts and reorganizations, many doctors still try to provide a humane type of care. In 2015, 70 per cent of the 9,00o family doctors successfully boycotted the health insurance companies that forced them to sign contracts against their will (among others on the type of drugs to prescribe and on which specialists or labs to send their patients to). 
the rise, and the development of health apps for tablets and smart phones, people will be increasingly encouraged to monitor their own blood pressure, blood sugar level, and so on, making the gap between the 'health literate' and the 'health il-literate' even wider.

The 'health illiteracy' of the people at stake is only one of their many 'shortcomings' linked to their 'low-educated' status and resulting in their generally disadvantaged position in a society that increasingly organizes and promotes a specific type of personhood, i.e. the successful, self-regulating individual with marketable skills. Another example is the citizenship tests for new immigrants. To successfully prepare and pass the test, immigrants must undertake all kinds of complicated, expensive, and bureaucratic initiatives. Far from being neutral, this procedure already requires many skills, and ultimately excludes from citizenship "certain "weaker" groups in society, such as traumatized refugees, women in disadvantaged positions, the elderly, and people with no, or only a limited educational background, such as illiterates' (cf. Van Oers 2013). Immigrants are supposed to not only have knowledge of 'Dutch values', but to identify with them as well: a recent government report on integration demands that immigrants 'internalize' Dutch values, such as an inner acceptance of homosexuality (Ministry of Social Affairs and Employment 2013). This tendency can be analyzed in general terms as the culturalization of citizenship that is taking place all over Europe. Schinkel and van Houdt (2010) speak of a 'neoliberal communitarianism' in this regard: a formal citizenship, with the right to be different in cultural and moral respects, is increasingly being replaced by a cultural citizenship comprising (neo)liberal values and models of personhood (Schinkel and Van Houdt 2010: 704).

Especially the wearing of a headscarf raises a lot of hostility towards Muslim girls and women in Western Europe today. Not only the French are convinced that Muslim women should be rescued by law from the headscarf, which they see as a symbol of oppression, but across Western Europe there is much confusion about the 'issue', also among 'feminists'. ${ }^{35}$ In what follows, I briefly discuss the 'issue' from the theoretical perspectives developed in earlier chapters of this study, exploring women's various subject-positions (Cf. Chapters 1 and 2).

Mahmood (2005), in reference to Foucault's concept of ethical selfformation, explains how for orthodox Muslim women, wearing a veil is a

35 Scott (2007), John Bowen (2008), Elizabeth Shakman Hurd (2008), and Jansen (2013) give extensive overviews of the debate in France that led to its legal ban in public primary and secondary schools in 2004. 
ritual to perform in the context of their self-cultivation. Foucault's concept of ethical self-techniques captures the 'repeated bodily acts,' by which Muslim believers train their 'memory, desire and intellect to behave according to established standards of conduct' (214). From this approach the meaning of the veil can be identified as a 'ritual practice of performative behavior' (23).

As one of Mahmood's interviewees comments:

I used to think that even though shyness [al-hayā'] was required of us by God, if I acted shyly it would be hypocritical [nifāq] because I didn't actually feel it inside of me. Then one day, in reading verse 25 of the Chapter [al-Qaşaş] [“The Story"] I realized that shyness [al-hayā'] was among the good deeds [huwwa min al-a'mäl al-şaliha] and given my natural lack of shyness [al-hay $\left.\bar{a}^{\prime}\right]$, I had to make or create it first. I realized that making [şana'] it in yourself is not hypocrisy, and that eventually your inside learns to have $\left[a l-h a y \bar{a}^{\prime}\right]$ too (156).

Wearing the veil emerges as a ritual gesture and exercise: by wearing it, 'your inside learns to feel shy without the veil, and if you take it off, your entire being feels uncomfortable [mish rādī] about it' (157).

While to orthodox Muslim women the veil is one of Islam's basic rituals 'forms', others point out that veiling is not explicitly prescribed anywhere in the Qur'an. Barlas (2008b) argues: 'many Muslims think they are authentic Muslims if they are dressed in Saudi style. But the Quran at the universal level does not prescribe the dress code of a given society, but merely advocates general principles as sexual restraint and mutual respect' (Barlas 2008b). In the same vein, Ahmed (1992) points out that: 'Verse 24: 31-32 just instructs women to guard their private parts and throw a scarf over their bosoms' (Ahmed 1992: 55).

Muslim women wear all sorts of different clothes, and their headscarves vary as well, in shape and colour, thus comprising different 'forms', and as such different modes of thought (cf. Chapter 2; Moors 2013). When Joan Scott (2007) takes veiling as simply an expression of Muslim traditions (cf. Scott 2007: 181), she implies that the veil or headscarf is a fixed symbol of meaning, and overlooks the variety of meanings that veiling involves, due to women's different subject-positions in relation to this 'form', including their reworking it.

When the veil is imposed on women by law, as, for example, is the case in Iran - with women testing these laws by pushing their headscarves as far back as possible - and recently in the so-called Islamic state in the 
territory of Iraq and Syria - where women are heavily intimidated and punished if they do not cover themselves - women's agency obviously is extremely limited. Imposing the veil on women can happen as well in other collective settings. Jansen (2013) refers, in this regard, to French author Samira Belil, whose Dans l'enfer des tournantes (2003) is 'a moving account of her escape from a ghetto where women, particularly those dressed in a Western style and non-veiled, were assaulted on a daily basis' (Jansen 2013: 307). In such conditions of pressure and punishment, the meaning of the headscarf is overdetermined as compulsory decency and protection from / of male sexuality, i.e. as a practice of 'Othering' women as sexual beings (cf. Chapter 2).

Veiling in orthodox circles as discussed by Mahmood (2005), instead emerges as a self-technique or ritual practice in the context of Muslim women's self-cultivation in a code-oriented moral system (cf. Chapter 1). In different contexts, the meaning of the veil has yet other meanings. To many Muslim women in Morocco, as Ennaji and Sadiqi (2006) contend, wearing the veil allows for 'greater movement through public space, as veiled women have access to the public space while remaining symbolically in private space' (Sadiqi and Ennaji 2006: 92). In Western European contexts as well, Muslim women use the veil to increasingly transgress the public-private space dichotomy of Islamic traditions.

Buitelaar (2006) discusses the "life story ${ }^{\prime 36}$ of a Dutch-Moroccan female politician who attained a high position in the Dutch administration. While her identity as a Muslim woman is important to her, wearing a headscarf allows her to combine and organize her experiences of intersectionality. Fashioning the headscarf in new ways enables her to demonstrate to Dutch as well as Moroccan audiences 'that she participates in public spheres in the Netherlands without renouncing either her religion or femininity' (Buitelaar 2006: 272). ${ }^{37}$ But wearing a headscarf also involves an outspoken political critique. Representing herself as a 'Muslim girl with a headscarf, brains and a big mouth,' is her answer to the dominant image in Dutch society of the oppressed Muslim woman. But it is her answer, too, to an orthodox Islamic discourse that expects Muslim women

36 Buitelaar (2006) especially applies the concept of the 'dialogical self,' of Hubert Hermans (2001), referring to the person's use of a self-narrative to integrate its multiple I-positions, emotions and self-representations, that are given with the several groups and categories to which it belongs.

37 Other studies likewise show that Muslim women use the headscarf to reconcile multiple identities. E.g. Fadwa El-Guindi (1999), Willy Jansen (1998), Buitelaar (2014). 
and girls to be obedient, caring, and modest, and avoid the public sphere. She states:

[Y]ou can find me engaged in a debate with three men at 11 o'clock at night. Does that look like I'm being oppressed? Well no, actually it doesn't. I am the living proof - not only I, but all those girls are the living proof - that all those ideas we used to have in the past about women and headscarves were just a lot of nonsense. [...] What I do is challenge society. If you ask me, I am the ultimate challenge (265).

This woman's life-story shows how wearing a headscarf as a ritual 'form' is reworked by Muslim women today, in the shape of a self-technique in the context of a freedom practice. While she later stepped out of the political arena, she certainly challenges and changes tradition by living her life as a pious woman, working outside the home. Many other Muslim women do so, by working, and sometimes by being single and not married. Muslim women in Western Europe challenge patriarchal traditions by simply leading their lives, a fact that is overlooked by many, including many 'feminists'.

While Badinter often refers to Beauvoir as her 'spiritual mother', and claims that her views on the headscarf are totally 'dans la lignée de Beauvoir' (Long 2013; cf. Rodgers 1995), it can be questioned whether Beauvoir would agree, given her situational approach of ethics (cf. Vintges forthcoming).$^{38}$ In a concluding chapter, Beauvoir's solidarity with Algerian freedom fighter Djamila Boupacha will be discussed as an example of a cross-cultural feminist coalitional politics. The final section of this chapter, meanwhile, discusses some cross-cultural feminist media strategies.

\section{Cross-cultural Feminist Media Strategies: Some Examples}

Muslim women and girls in the West are very present on the internet, as they are in North Africa and the Middle East. In Western Europe, they are active across a variety of different social media platforms. They visit websites on religious issues, but also, for instance, sites on beautiful-hijabmuslim-fashion-trends. The Happy Muslim Videos, launched from the UK, Germany, the States, and Iran, with Muslim youth, boys and girls, dancing

$3^{8}$ Badinter routinely positions herself as Beauvoir's spiritual heir, among others during her lecturing tours across Western Europe. Long (2013), in addition to discussing Badinter's ideas in this respect, gives an extensive account of Badinter's active support of the headscarf ban. 


\section{Poster 'Raw Deal' (2013)}

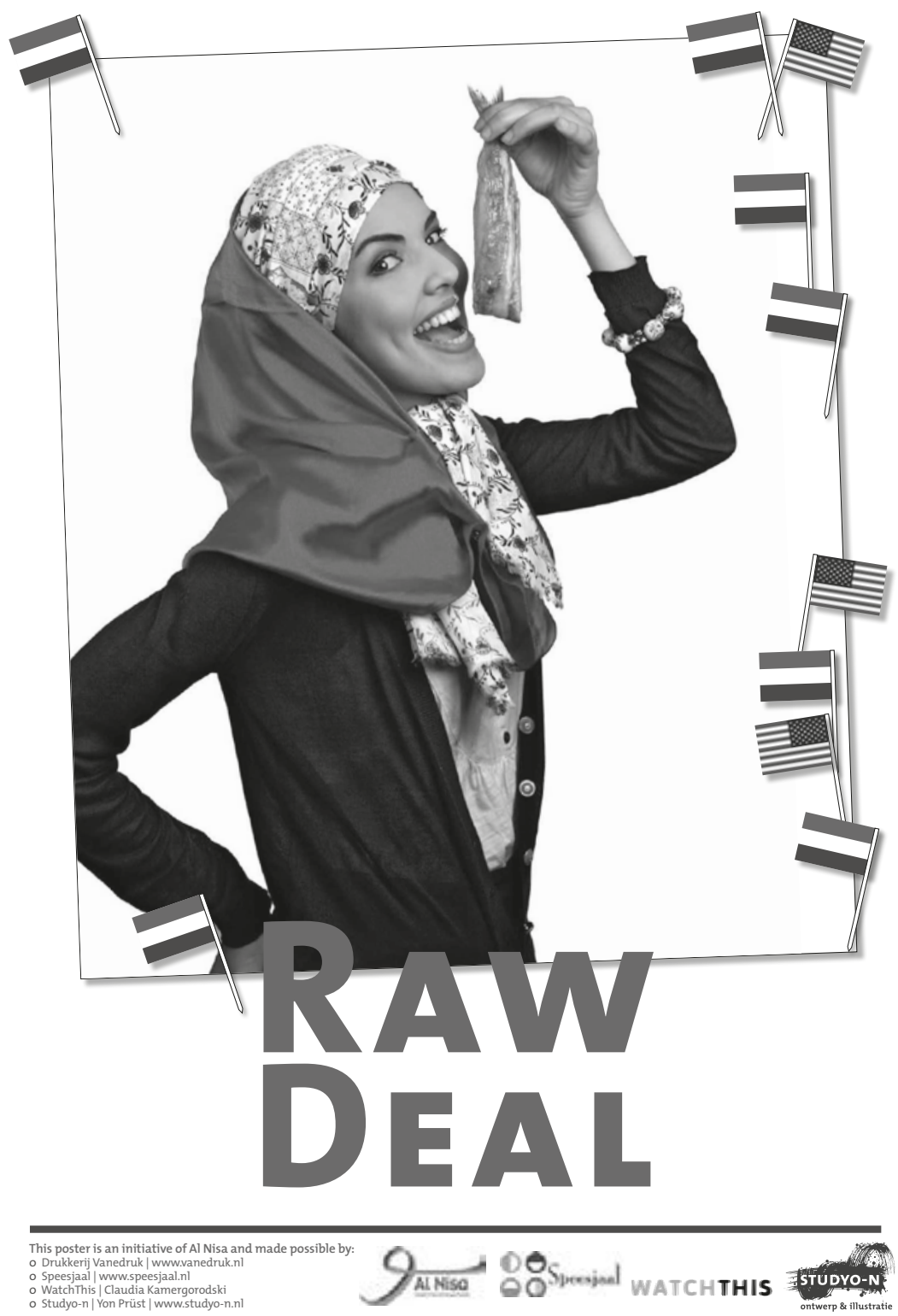

Al Nisa, Organization for Muslim Women in the Netherlands 
to Pharrell Williams' record Happy, were a success, with almost two million hits for the original British version alone..$^{39}$

In the Netherlands, in 2006, an Islamic Women's Manifest (IW/M) was released to the press, by Dutch Muslim feminist organization Al Nisa, publicly denouncing the wrongful image of Muslim women and raising awareness about the equality of Muslim men and women according to Islam (cf. Pektas-Weber 2007). ${ }^{40}$

In 2010, Al Nisa successfully launched a 'real Dutch' campaign, spreading posters via the internet with a view to replacing negative stereotypes of Muslim women. While anti-Islam populist politician Geert Wilders had targeted headscarves as 'head-rags' and had proposed imposing an annual tax for wearing them, his threat 'they are a raw deal for me' was ironically countered by a poster of a Muslim woman eating a raw herring, a ubiquitous Dutch habit. ${ }^{41}$

Cross-cultural feminist media strategies are important for changing the dominant Western media frame of the oppressed Muslim woman. Mir-Hosseini and British film maker Kim Longinotto together made two documentaries on women's strategies for coping with patriarchy in Iran, Divorce Iranian Style (1997) and Runaway (2008), broadcast widely at festivals and on Western television. ${ }^{42}$ In the same vein, was Dutch film maker Bregtje van der Haak's documentary Satellite Queens (2008), about the talkshow on Saudi satellite channel MBC, Kalam Nawaem - 'sweet' or 'soft talk' in English.

Featuring four hostesses from four different Middle Eastern countries, Kalam Nawaem purportedly reaches 45 million (male and female) viewers in 22 countries. Its four hostesses discuss lifestyle, cultural, and social issues, in a reinterpretation of Islamic heritage from a women's empowerment perspective. The four talkshow hostesses have reached celebrity status and function as role models to many. Their self-presentation in the documentary, however, is one of being average, believing Muslim women

39 For more versions: see https://www.youtube.com/results?search_query=happy+muslims+ For the Dutch version: https://www.youtube.com/watch?v=iotR7apCYxo, The Iranian version was forbidden and the dancers were prosecuted (last accessed, 21 September 2016) .

40 The action was inspired by the first International Congress on Islamic Feminism, in Barcelona, 27 October 2005.

41 The posters are downloadable so as to be spread in schools, offices and workplaces. The campaign was reported on in international Muslim newsletters; it was spread as well in Muslim groups in Germany (with German versions of the posters) and in New York in the English version represented here.

42 See https://www.youtube.com/watch?v=BBm8GqMNwXU and https://www.youtube.com/ watch?v=MbsVbyRGqL8 (last accessed, 21 September 2016). 
who fully participate in society, and who are self-conscious, modern, and beautiful. The documentary zooms in on the personal ethical life projects of these women, conveying egalitarian effects. As a consequence of the documentary, the talkshow was broadcast weekly on an Amsterdam television channel, the hostesses were regularly interviewed in Dutch newspapers and became celebrities in the Netherlands as well. ${ }^{43}$

Another example is the work of Spanish photographer and filmmaker Nuria Andreu, who gathered photographs from the photo albums of Muslim immigrant women in Belgium and the Netherlands to counter the lack of such images in archives and photographic institutes. In cooperation with the members of the intercultural research project 'Women and Islam: New Perspectives', she produced the documentary Moroccan Women Today: New Perspectives, which gives voice to a number of Moroccan women who develop new visions on their position in society (Andreu and Vintges 2013). More media strategies are necessary to change the dominant 'picture' of Muslim women in the West, considering the significant role the media play today, as will be discussed in the next chapter. 


\section{Forged-Iron Cooperative, Morocco (2008)}

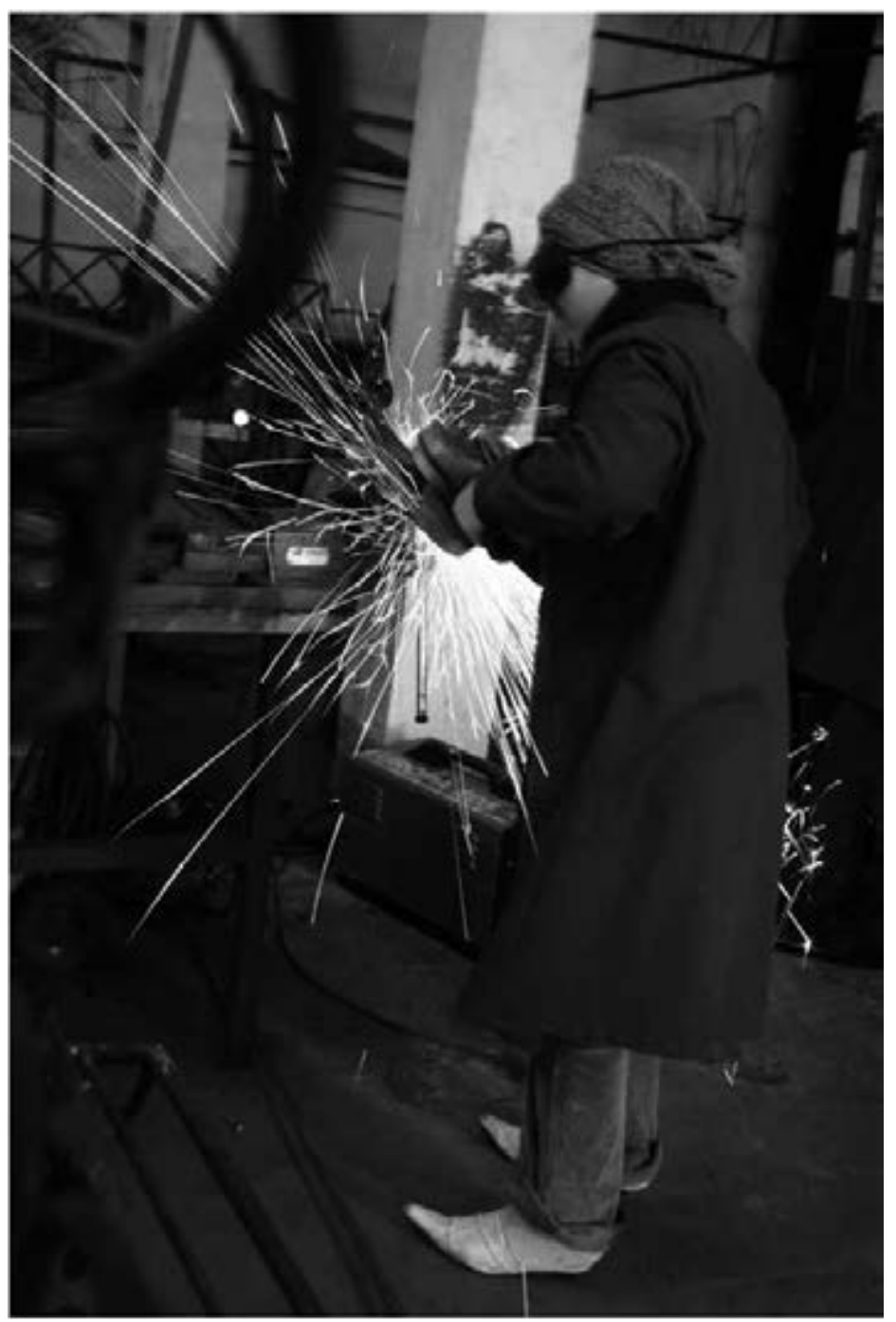

Photographer: Nuria Andreu

(c) Andreu, Núria. Forged Iron Cooperative. ARFEDEC (Association de Recherche pour le Development et la Cooperation). Tetouan, Maroc. 2008 



\section{The Battle of Myths}

Patriarchal power patterns turn out to be more resilient than Beauvoir presumed. But what is the 'bottleneck' today that keeps processes of change from definitely heading in egalitarian directions? In terms of our metaphor of a multi-headed monster, we argued that its 'immortal' head, which must still be defeated, is the 'presentational' realm of rite, art, and myth that conveys ideas not in a grammatical scheme of expression, but in the shape of 'forms', i.e. holistic 'pictures' or patterns that currently seem to be most resilient to change. Struggles within each of these realms are necessary in order to replace these dominant 'forms' that, in their arrangements of elements, or picturing of a 'relational order of things' (Langer 1960: 59), articulate a power asymmetry between the sexes.

The previous chapter discussed the multiple voices of the gender egalitarian movement of Muslim women. Muslim women today are involved in freedom practices in the religious realm that involve 'keys' of rite and verbal language, thus re-articulating beliefs and idea(l)s that matter deeply to Muslim women and men. But what is the dominant face of the hydra's 'presentational' head in the West today? And do we find women's freedom practices in this realm as well?

Discussing in particular popular culture, I will argue that media-hypes today fulfil the role of mythical tales, which, in the words of Langer (1960), are dream-narratives, made of dream-material, i.e. images and fantasies. According to her, '( $t$ )he Gods have their twilight, the heroes are forgotten; but though mythology has been a passing phase in man's mental history, the epic lives on, side by side with philosophy and science and all the higher forms of thought' (165). But while to Langer, the heyday of mythology is over, as its epic has passed into 'a new symbolic mode, the mode of art' (165), popular culture today suggests otherwise.

Art historian Camille Paglia, in her 70o-page study Sexual Personae (1990) - 'personae' meaning characters in a play or public setting - argues that the Hollywood stars of the 1930 r revived pagan myth. Western popular culture and especially Hollywood restored 'the pagan pantheon of physically perfect, openly sexual gods and goddesses' (Paglia 2013: 2). The creation of 'glamour' in early Hollywood had magical properties, since 'ordinary men and women were turned into divinities by the vast machinery of the star system' (3). In subsequent books, Paglia analyses other media 'celebrities' in similar terms, going into the 'sexual personae' of, among others, Elizabeth Taylor, Judy Garland, Princess Diana, Barbara Streisand, and Madonna - the latter 
being her favourite (Paglia 1992, 1994). Since popular culture - expressed in the popular media, such as advertisements, magazines, popular television, mainstream film, and internet - sidesteps politically correct feminists and other liberal censors, according to Paglia, it speaks the truth: popular media tell us what is, and not what should be.

Erving Goffman (1976), in a similar vein, assumes that popular culture tells us who we are. In his well-known study Gender Advertisements (1976), Goffman looks at the different representations of men and women in advertisements, pointing out that their apparent normality tells us something about ourselves: gender advertisements are to Goffman the most concentrated form of our contemporary 'gender codes'. ${ }^{1}$ While Goffman uses advertisements for a diagnosis of the time, specifically for a diagnosis of who men and women are, in a similar vein, I will use popular films for a gender diagnosis of the present. I specifically look at the five films of The Twilight Saga, which caused a 'hype' among girls and women, for a diagnosis of today's collective 'dream-narratives'. Do current Hollywoodhypes still only comprise men's fantasies, and do girls and women in that sense 'still dream through men's dreams' - in the words of Beauvoir? (Beauvoir 2010: 166).

Capitalizing on Paglia's approach - and partly on Beauvoir's, as we will see - I take current Hollywood-hypes as the new face of the mythical genre. From this perspective, the leading characters in the Twilight 'hype' can be discussed as mythical sexual personae, and the Twilight hype as one of the mythical tales of our time that through its 'visual forms' spread its ideas on a mass scale (cf. Chapter 2).

'Presentational forms' can be studied in a variety of ways, so Langer claims (cf. Langer 1960: Preface). While in her own view they are rooted in man's natural activity of symbolic transformation and ultimately in man's fantasy, to Lévi-Strauss myths are secular stories that are strongly structured in terms of the constitutive, essentially binary, structures of any society. As discussed, Beauvoir historicizes Lévi-Strauss' approach, suggesting that new myths will emerge, expressing new, non-hierarchical relationships between the sexes. Her approach in this respect comes close to a Foucauldian one, which takes all discourses, including mythical narratives, as crystallizing and developing over time, and this also includes ethical practices of freedom - re-articulated by us in terms of distinct sets of critically creative ethical life projects. Comprising new concepts and

1 'Gender codes' to him are ingrained cultural signals that make us position people in the categories male / female. 
models for self and society, in various 'keys', freedom practices equally emerge at a certain time and cannot be forced or simply be made to happen.

Do we find any slow movements at the mythical level of collective dream-narratives that take place under the radar, so to speak? Have freedom practices emerged in this realm, are women and girls involved in processes of change?

In search for an answer to these questions, I will first examine the current 'post-feminist' climate in the West and its new dominant model of womanhood, in the shape of a female sexual agent. Does she represent a new liberating moment, or is she the newest face of an old male projection, i.e. the newest version of the old myths of Woman? To answer to this question, I first explore the classic myths of Woman as analysed in the work of Beauvoir and Paglia. Next, I will focus on some mythical tales and sexual personae of our time, so as to answer the question whether the new female sexual agent of today is a recycling of old myths or a new liberating mythical figure. As argued above, I specifically examine the dream-narrative of the Twilight hype that moves masses of girls and women today. What story does it tell and which sexual personae does it present? Is Paglia right that the old myths of femininity will always pop up, or is Beauvoir right in her prediction that change will take place?

\section{Super Woman Revisited}

The concept of 'post-feminism' has a variety of meanings, ranging from a backlash to feminism, to an academic perspective of postmodern anti-foundationalism, to the pastness of feminism as such (cf. Gill and Scharff 2011:3), McRobbie (2004) articulates the concept in yet another sense; namely, in terms of a current entanglement of feminist and anti-feminist elements. Processes of liberalization today are intrinsically intertwined with neoconservative values. The popular Bridget Jones books and movies illustrate how feminism today is both taken into account while at the same time 'fiercely repudiated' (McRobbie 2004: 255). A desperate 30-year-old, sexually liberated Bridget, secretly dreams of a traditional wedding that would rescue her from her demanding working life as a single woman. While Bridget is totally aware that this is not how young women today are supposed to think, she - and the audience with her - escapes this censorious politics and freely enjoys that which is disapproved of: 'feminism is invoked in order that it is relegated to the past' (262). 
To more fully understand what is going on, McRobbie argues that we need Foucault's concept of neoliberal governmentality in the sense of a 'day-today' organizing of people's behaviour 'at a distance' (McRobbie 2011b: 180; cf. Chapter 1). Current neoliberal governmentality also involves a new gender logic or even a new 'sexual contract'. Women and girls are provided with sexual freedoms and with all kinds of opportunities for achievement in education and employment. But, as part of the same package, 'modes of patriarchal retrenchment have been digging in, as these conditions of freedom are tied to conditions of social conservatism, consumerism and hostility to feminism in any of its old or newer forms' (McRobbie 2011a: xi). The new sexual contract allows young women and girls to earn their own wages, provided that they prioritize consuming and spend their wages on fashion and beauty. It organizes their 'consumer-citizenship' (McRobbie 2008: 90), omitting 'any encouragement to a more active form of political participation' (McRobbie 2011b: 182).

French writers' collective Tiqqun, in Raw Materials for a Theory of the Young-Girl (2010), discusses the Young-Girl in similar terms. She symbolizes the total and sovereign consumer that is 'good for nothing but consuming; leisure or work, it makes no difference' (Tiqqun 2010: 2). The Young-Girl is someone who 'resembles her photo' (7), she does not love but only 'loves herself loving' (20). The new social organization of consumption and seduction has freed women and youth, the slaves of the past, only to meet the demands of mass consumption: it has 'freed them AS SLAVES' (2).

Beauvoir, in line with her critique on the neoliberal 'Organization Man', criticized the model of personhood of 'Super Woman' (femme totale), who aims to 'be successful at all levels' (Beauvoir 2011: 226; Chapter 1). In a similar vein, McRobbie (2015) introduces the notion of the perfect woman, i.e. the neoliberal woman or girl who is perfect in all realms of life. Facebook's board member Sheryl Sandberg, in her book Lean In (2013), advises women on how to succeed in business while having a family life. Anne Marie Slaughter, in a famous newspaper article entitled 'Why Women Still Can't Have It All' (2012), vice versa argues for women to reaffirm their commitment to their family while pursuing a career. Catherine Rottenberg (2013) concludes that both Sandberg's and Slaughter's approaches are phrased in the same neoliberal feminist language: both address women in competitive individualist terms, and encourage them to pursue career success, but also a succesful family life.

In the words of McRobbie (2015), being a Super Woman - 'having it all demands 'an inner-directed self-competitiveness' next to 'an outer-directed competition or antagonism towards other women' (McRobbie 2015: 14). 
The 'perfect' as a horizon of expectation involves an increase in levels of (self) competition, triggering economic growth, innovation, and a more entrepreneurial outlook, and pathologizing failure, since if one is not excellent one can only be, at best, mediocre. McRobbie signals a new 'competitive femininity' with 'older reprehensible features of traditional female culture being reactivated and having new life breathed into them' (McRobbie 2015: 9, cf. 7, 15). The 'neoliberal feminism' of today, which wants women to lean in, has done away with social critique and solidarity.

While McRobbie (2008) speaks of a new 'sexual contract' on neoliberal terms, Oksala (2013) argues that neoliberal governmentality no longer needs any 'sexual contract' due to its increasing commodification and marketization of domestic and care-work. It no longer needs 'feminine' subjects who surrender their self-interest to the well-being of their husbands and children: 'the self-interest of particular women can now be bought relatively easily with the subordination and exploitation of others' (Oksala 2013: 42). Women today, like men, increasingly function as egoistical subjects of interest, making choices on the basis of rational economic calculation. They not only want a happy home, but 'they too want money, power and success. They are atomic, autonomous subjects of interest, competing for the economic opportunities available' (39).

Ladelle Mcwhorter (2013) likewise concludes, albeit from another angle, that the sexual contract has lost its meaning, and that many women today live 'in a state of post-liberation' (Mcwhorter 2013: 71). However, the appearance of Super Woman as the perfect femme totale, shows that old heads of the patriarchal hydra are still alive and kicking, and are still vital to many women's lives. Neoliberalism might not necessarily be patriarchal in character, but it converges with older features of 'femininity', to paraphrase McRobbie, culminating in a new dominant model of womanhood.

Beauvoir already outlined this new figure of Super Woman, but today she has yet another face. British feminists Rosalind Gill, Angela McRobbie, and Christina Scharff, in reference to Foucault's concept of neoliberalism, have pointed to a new kind of sexualization of women and girls that is taking place in mainstream popular media - including social media.

Foucault's earlier concepts of disciplining and normalization have been extensively used in gender studies. Bartky (1988) analysed how women's bodies are disciplined into docility. They are trained to take less space than men's bodies; gesture, posture and movement and bodily comportment are restrained; dieting, smiling and make-up are a must and skin should be soft and smooth at all times. The bar of femininity is raised so high, and demands such radical technologies, that virtually every woman is destined to fail and consequently 
is subjected to shame (Bartky 1988: 71). Irene Diamond and Lee Quinby (1988), Jana Sawicki (1991), Lois McNay (1992) and Margaret A. McLaren (2002, 2004) similarly 'gendered' Foucault's theories on the disciplining of the body.

Building on Foucault's concept of neoliberalism, and on the work of authors of the 'governmentality school' (cf. Chapter 1), McRobbie (2004), Gill (2008), and Gill and Scharff (2011) analyse that what marks out the present, post-feminist, moment as distinctive is not only a dramatically increased intensity and extensiveness of the hostile surveillance of women's bodies and psyche, 'but even more fundamentally that notions of choice, agency and autonomy have become central to that regulatory project' (Gill 2008: 443). Television make-over shows, women's magazines, advertising campaigns, and billboards organize women's self-regulation 'at a distance', to act in accordance with the model of the new female sexual agent that they spread. Gill identifies this model that emerged in the media over the last decade as the new face of neoliberal woman, a new figure 'constructed to sell to women: a young, attractive, heterosexual woman who knowingly and deliberately plays with her sexual power and is always "up for" sex [...] an increasingly globalized figure who appears in different transnational sites in magazines like Cosmopolitan' (437).

Gill, in reference to Rose (1990), assesses the new female sexual agent that has emerged involves a neoliberal, postfeminist moment of 'governing the soul (cf. 443). Rather than a remoulding of the body, we face a remaking of women's subjectivity; women are no longer sexually objectified, they are sexually 'subjectified' (cf. 440). It is not just that women should look nice, or even that they are entirely judged on their looks. But more fundamentally 'a particular kind of beauty and sexiness has become a prerequisite for subjecthood itself (440). Women's autonomy, choice, and self-improvement today 'sit side-by-side with surveillance, discipline and the vilification of those who make the "wrong" "choices" (e.g. become too fat, too thin or have the audacity or bad judgment to grow older)' (442). Gill concludes that we deal with a remaking of female subjectivity, in terms of a 'compulsory (sexual) agency' (440).

In a similar vein, Bauer (2015), in a discussion of the current sexual hookup culture among American college students, speaks of women's sexual 'self-objectification'. She notices how her female students choose to spend their weekend evenings 'giving unreciprocated blow-jobs to drunken frat boys,' enjoying the sense of power it gives them (Bauer 2015:10). In reference to Beauvoir's argument in The Second Sex that women often consented with their role as bodily Other (Beauvoir 2010:10; cf. Chapter 2), Bauer argues that women should resist an 'allure to self-objectification.' Whereas Bauer points to the girls' behaviour in terms of their choices, from Gill's perspective their 
Lady Foucault (2011)

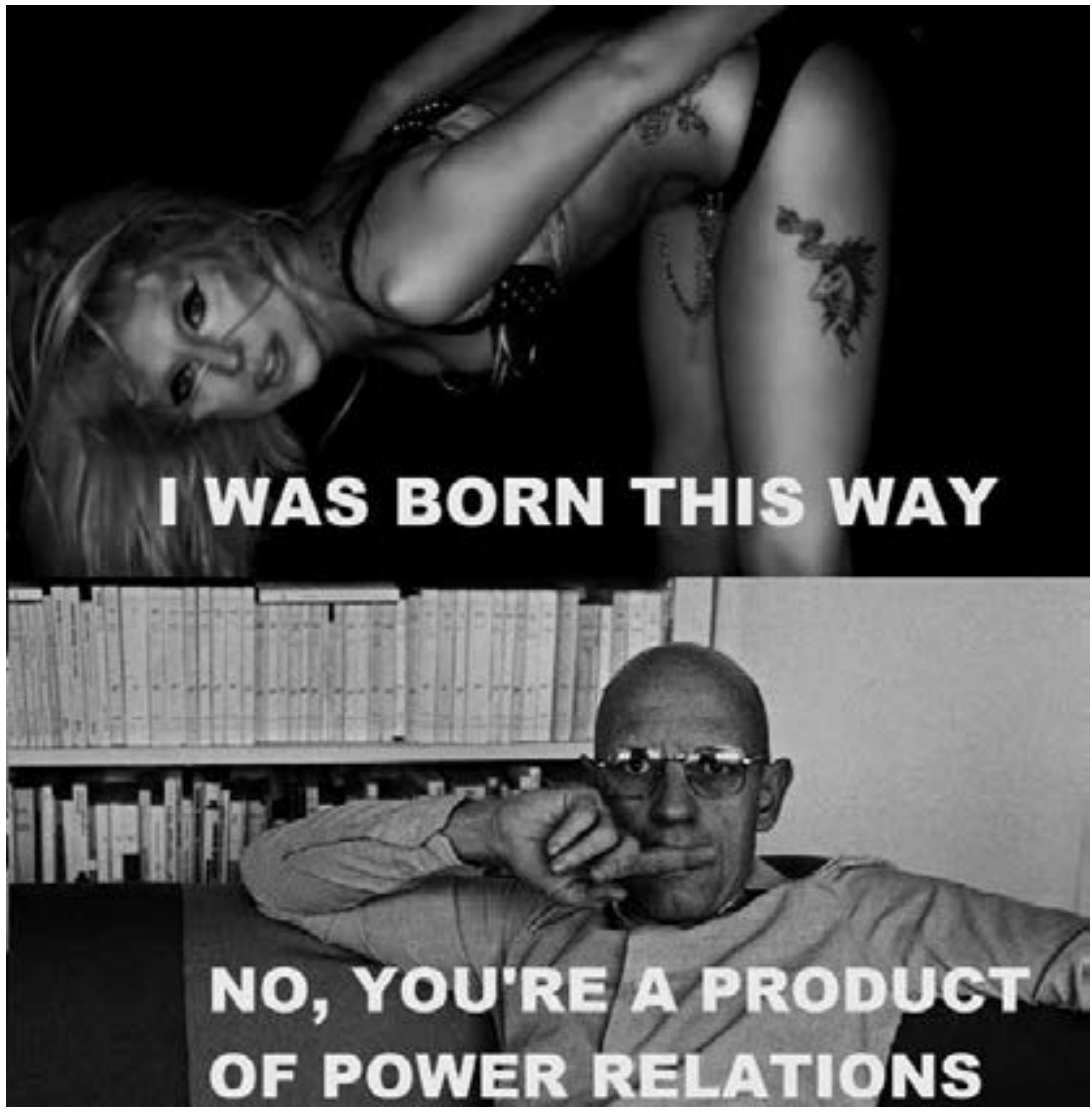

Author: Joseph Guillermo

behaviour emerges as a compulsory sexual agency, reflecting their 'sexual subjectification' in a post-feminist-neoliberal area.

Super Woman, who must be perfect and successful in all realms of life, today is supposed to be sexy as well. Girls and women, including women professionals like lawyers, CEOs and consultants, are advised to dress in sexy ways. A website with tips on 'how to not dress boring to work' advises 'all those sexy women who rule the world' to do so 'in bright lips, sky high heels and outfits that can go from 9 am to late dinner cocktails. The TIP is always in the posh fabulous heels.' ${ }^{2}$ If women and girls decide not to comply

2 http://thefashiontag.com/2014/05/05/7-office-wear-ideas-how-to-not-dress-boring-to-work/ (last accessed, 21 September 2016). 
with the new norm of sexiness, they run the risk of being neglected, or even fired. As blogger 'Abbeysbooks'- a pseudonym for feminist film critic Janet Abbey - comments: 'men today only see the signs that say hot: make-up; hair color bright of course; designer clothes; higher than high heels, so read hyper high stilettos; cleavage and well you get the idea I am sure. Scrub it all off and they think she is plain, not worth the attention' (Abbeysbooks n.d.).

The dominant image of sexiness that girls and women identify with, surely affects their own hopes and fears. Annemarie van Oosten (2015) shows that girls' posting of sexy selfies on social network sites influences their sexual behavior and sexual self-image. Jessica Ringrose (2011) equally shows how British fourteen-year-old girls' 'performing slut' on social media affects their identity in a negative way, involved as they are in a narrative of 'servicing the phallus' and 'non-reciprocal' pleasure (Ringrose 2011: 112).

While according to Gill and Scharff (2011) girls and women have to be sexy on penalty of not being noted at all, according to Paglia (2012), they are taking control of their capacity to inflame men with sexual desire, using it in a power play. As she expresses it in an interview in Playboy: '(t)he more a woman takes off her clothes, the more power she has' (Paglia 1995). Women today have finally understood their role: a new 'pro-sex, pro-art, pro-beauty feminism,' triumphs over the politically correct, oppressive kind of feminism of the 1970 s and 8os, as she had predicted all along (Paglia 2012). ${ }^{3}$

British sociologist Catherine Hakim (2011), in a similar vein, calls for women to use their 'erotic capital' in the bedroom and the boardroom. As Hakim argues, men's greater sexual desire leaves them frustrated, and women can take advantage of this in public as well as private life, bargaining for 'a better deal' (Hakim 2011: 8). According to Hakim, '(p)atriarchy has tried hard to $[. .$.$] control women's public dress and behaviour. As I see it, radical$ feminism has gone down a dead-end by adopting similar ideas that belittle women's allure. [...] Why not champion femininity rather than abolish it? Why does no one encourage women to exploit men whenever they can?' (3). Similarly, Dutch feminist magazine OPZIJ recommended its readers to use their erotic capital in the workplace, in a positive appraisal of Hakim's book Honey Money - in spite of its rather alarming title.

Whereas Hakim (2011) speaks in terms of women's 'erotic capital', does she perhaps - unintentionally - transmit that we need a Marxist analysis of how capitalist principles of profit and commodification have reached

3 Paglia adds that now that 'all careers have been opened to women,' feminism is only needed 'in Third World countries where women can be treated like chattel.' In what follows I only discuss her stances regarding women's positions in the West. 
women's bodies today? According to Power (2009), the capitalist labour market today demands that all people be an all-round self-seller, and especially impels women to include their bodies as part of the package and expose themselves. ${ }^{4}$ Is capitalist economy currently invading women's bodies?

As discussed earlier, McRobbie (2011b: 180) argues that Marxism's conceptual tools are too blunt to grasp the ways in which subjectivities, and especially those of women today, are restructured. Instead, a Foucauldian concept of neoliberalism, in terms of a 'conduct' of people's conduct 'at a distance', allows for a more specific analysis of how women and girls are activated to copy and embody the new female figure outlined above.

Foucault characterized the neoliberal homo oeconomicus as 'entrepreneur of himself,' being for himself his own capital, i.e. a source to produce earnings (cf. Foucault 2008: 226). He pointed out how, today, we are supposed to improve our human capital - our abilities, skills, health - which is made up of acquired elements, alongside hereditary ones. From this approach, and paraphrasing Hakim (2011), it can be argued that women today are stimulated and advised by all kinds of experts, to improve and invest in, their 'erotic capital', as part of their human capital and, furthermore, they are advised to make the most of it. Their erotic capital can be seen as made up of hereditary elements, such as good genes, as well as of acquired components. Women and girls today are activated to optimize the latter, by practicing self-techniques such as constant full-body exercise, cosmetic surgery, wearing porn-chic fashion, and enhancing their skills in the sexual realm. They are stimulated to, on the basis of their own cost benefit calculations, make the most of their erotic capital, to enhance their success in all domains of life. The new female figure that emerges is the woman who is an entrepreneur of her own erotic capital.

At stake is not a literal marketization of womanhood, but one being shaped and governed to conform to the model of the market. Neoliberalism's dissemination of market-shaped systems in the social field, and especially its generalization of the model of the entrepreneurial self to every form of behaviour, involve an optimizing management technique of governing the population. It has converged with older forms of femininity, and culminated in the emergence of a new form or myth of womanhood namely',

4 Power (2009) in this context refers to Alain Badiou's explanation of the hatred in the West against the veil: according to him, the French law on the hijab is a purely capitalist law, since it 'orders femininity to be exposed. In other words, having the female body circulate according to the market paradigm is obligatory' (Badiou 2004). 
of Super Woman, and Super Girl, who have to manage their erotic capital as part of their being perfect.

Laura Harvey and Gill (2011), in their discussion of the television show 'The Sex Inspectors', argue that a new female 'sexual entrepreneur' has emerged that cannot easily be judged in binary terms as either a liberated or a compulsory sexual agent. Others in the same volume similarly point to the complexity of women's and girls' negotiating of, and navigating between, sexual regulation and agency, some of them framing the new female sexual agency in a 'context of persistent coercion and inequality,' others deploying 'a more upbeat language of freedom and choice' (Gill and Scharff 2011: 9).

Does the new figure of the female sexual agent who manages her erotic capital, as part of her being perfect, involve a new liberating moment, or is she the new face of old constraining myths of femininity? For an answer to this question, we will first investigate the dominant myths of Woman as they were analyzed by Beauvoir (2010) and Paglia (1990).

\section{Myths of Woman}

As discussed earlier, Beauvoir's concept of Myths covers the 'presentational' realms in terms of Langer (1960); namely, ritual religion, art, and mythical tales. In what follows, I focus on Myths in the latter sense; that is to say - in Langer's terms - on mythical stories that comprise mankind's collective dreams and fantasies, dealing with themes of 'human desire frustrated by non-human powers, hostile oppression, or contrary desires' (Langer 160: 143; cf. Chapter 2). For her analysis of mankind's mythical tales, Beauvoir refers in The Second Sex to Lévi-Strauss' thesis that the incest taboo - i.e. the prohibition of marriage between close relatives - marks the transition from nature to culture. According to Lévi-Strauss, the incest taboo is constitutive of society since it involves 'exogamy', i.e. an exchange of women among men, which creates the kind of alliances that society consists of. Lévi-Strauss saw this basic asymmetry between the sexes as well reflected in the myths of mankind, which he took as the voices of our ancestors. In his study on myths, he analyses how they are always structured along binary oppositions, manifesting among others the rule of exogamy, which involves that 'between groups, women are exchanged like foodstuffs' (cf. Lévi-Strauss 1971: 49).

In line with Lévi-Strauss, Beauvoir argues that the mythical tales of mankind comprise a hierarchical relationship between men and women. But for the roots of this asymmetry she refers to the mechanism of Othering: man establishing woman as the negative of himself is, in her view, a phase 
to be overcome (cf. Chapter 2). She thus situates the myths of mankind in historical perspective; namely, as developed by patriarchal society 'for the end of self-justification' (Beauvoir 2010: 281). Beauvoir places Lévi-Strauss' findings in a broader, historicizing framework, arguing that patriarchal patterns will be surpassed in a new age. She states:

After studying the diverse forms of primitive society in depth, LéviStrauss could conclude: "The passage from the state of Nature to the state of Culture is defined by man's ability to think biological relations as systems of oppositions; duality, alternation, opposition [...] are not so much phenomena to explain as fundamental and immediate givens of social reality." These phenomena could not be understood if human reality were solely a Mitsein based on solidarity and friendship. On the contrary, they become clear if, following Hegel, a fundamental hostility to any other consciousness is found in consciousness itself; the subject posits itself only in opposition; it asserts itself as the essential and sets up the other as inessential, as the object (7).

While to Lévi-Strauss the status hierarchy between the sexes is constitutive for society, to Beauvoir it represents a historical, passing phase of mankind (cf. Rubin 1975 for another historicizing approach).

In her chapter, Beauvoir argues that the Myths of Woman seem to fluctuate and to be contradictory. However, their unity can be discerned as soon as we realize that Woman embodies Nature for men. Man's carnal contingence dooms him to death. Woman, who symbolizes nature and flesh, therefore inspires horror in man: 'the horror of his own carnal contingence that he projects on her' (171). But nature also involves giving life. Nature therefore 'inspires ambivalent feelings in man, as has been seen. He exploits it but it crushes him; he is born from and he dies in it; it is the source of his being and the kingdom he bends to his will' (167).

Nature, to man, is life and death, ally and enemy, chaos and supreme reality (cf. 167). And he views woman as 'akin to nature, she embodies it: animal, little vale of blood, rose in bloom, siren, curve of a hill, she gives humus, sap, tangible beauty and the world's soul to man' (270). Man longs for her, but fears her as well; he wants to subdue her, as an untamed animal. And as every desire, man's longing for woman involves 'consuming the desired object, entailing its destruction' (178). Woman to man is 'Delilah and Judith, Aspasia and Lucretia, Pandora and Athena, woman is both Eve and the Virgin Mary. She is an idol, a servant, source of life, power of darkness; she is the elementary silence of truth, she is artifice, gossip and lies; she is 
the medicine woman and witch; she is man's prey; she is his downfall, she is everything he is not and wants to have' (166).

Man not only wants to possess woman, he also wants to be validated by her for his strength, his beauty, his courage. 'She is one of the privileged prizes promised to heroes, adventurers and individualists. In ancient times, Perseus saved Andromeda, Orpheus went to rescue Eurydice from Hades and Troy fought to keep the beautiful Helen. Novels of chivalry recount barely any prowess other than delivering captive princesses' (206). But conquering is more fascinating than rescuing. ' $(\mathrm{I}) \mathrm{t}$ is far better to tame Penthesilea than to marry a consenting Cinderella': man's true victory is 'that woman freely recognise him as her destiny' (207). Apart from prey and prize, she is a sexual vamp as well. 'She is the mermaid whose songs dashed the sailors against the rocks; she is Circe, who turned her lovers into animals, the water sprite that attracted the fisherman to the depths of the pools' (188). The woman 'who freely exercises her charms - adventuress, vamp, femme fatale - remains a disquieting type' (213). The mythical tales of mankind, according to Beauvoir, express men's - contrary - desires. But women, like men, do identify with them, experiencing themselves through men's eyes: 'woman knows and chooses herself not as she exists for herself but [...] as men dream of her' (159).

Beauvoir also discusses the insinuation of myths of femininity in the shape of films (Beauvoir 2010: 281), and paintings (204). She especially discusses Hollywood films, with women in the role of femme fatale or vamp adventuress 'as the bad woman' (213), or as enfant terribles to be 'tamed by the healthy brutality of a lover or husband' (374). Films like Citizen Kane and The Razor's Edge show how men fantasize themselves as benefactor, liberator, or redeemer of women (cf. 207, 214). The female movie star typically is the 'most recent incarnation of the hetaera,' who flanked 'by her husband or serious male friend - rigorously required by Hollywood - [...] delivers Woman to the dreams of men who give her fortune and glory in exchange' (625). Female Hollywood stars are 'a passive object in the producer's hands' (591) whose bodies are no longer their own: 'the producer decides on their hair colour, weight, figure and type; teeth are pulled out to change the shape of a cheek. Diets, exercise, fittings, and make up are daily chores' (628).

Beauvoir not only includes films in her discussion of the dominant myths of Woman, she also points to a shift in the myth of Woman in her discussion of a new female film 'character' that was created by French rebel movie star Brigitte Bardot (Beauvoir 2015d). Beauvoir suggested in The Second Sex that new myths of eroticism will emerge (Beauvoir 2010: 283) that will display that 'man is also flesh for woman; and woman is other than a carnal object' 
and that the flesh for each person, in each situation 'takes on singular significations' (277). Similarly, in a 1950 article written for the American style magazine Flair, titled 'It's About Time Woman Puts a New Face on Love', she argues that a new type of 'equalitarian love' will arise (Beauvoir 2015b: 78).

According to her, in Roger Vadim's film And God Created Woman (1955), a new character of woman as 'erotic hoyden' emerges, in a replacement of the myth of woman as the magical and mysterious vamp (Beauvoir $2015 \mathrm{~d}$ : 116). While the attraction the magical vamp exercised 'was that of a passive thing' and men went to their doom when she cast a spell, 'Bardot does not cast spells; she is on the go.' When she strips her clothes off 'she is not unveiling a mystery. [...] She walks, she dances, she moves about. Bardot's eroticism is aggressive instead of magical.' In the game of love 'she is as much a hunter as she is a prey. The male is an object to her, just as she is to him' (119). The character that Bardot created thus surpasses the traditional Myth of woman, asserting that between woman and man there is 'mutual desire and pleasure' (119).

However, Vadim's movies remain abstract, Bardot never turns into a real human being. Vadim 'de-situates sexuality' (121): the world is absent in his films, which puts the spectator in the position of a voyeur. Vadim's films lack any erotic emotion. It is a good thing that he portrays sexuality in an honest way; but he is to be blamed, Beauvoir argues, 'for having gone so far as to dehumanize it.' The 'human factor' has already lost its importance in many spheres. Man today 'is regarded by politicians, brains-trusters, publicity agents, military men, and even educators, by the entire "organization world" as an object to be manipulated' (120-121; cf. Chapter 1). Vadim, in a similar vein, strips sexuality of its humanity. 'In real life, and usually in good novels and films, individuals are not defined only by their sexuality. Each has a history, and his or her eroticism is involved in a certain situation' (121). Vadim instead reduces the world, things, and bodies to their immediate presence.

Whereas Beauvoir recognizes 'the subversive feminist potential' of Bardot's character, she concludes that it ultimately involves a new embodiment of the old myth of the 'eternal feminine' (Boulé and Tidd 2012: 8). Tidd (2004) aptly summarizes that, to Beauvoir, Bardot 'challenges the consuming tyranny of the male gaze and ultimately loses' (Tidd 2004: 46).

Paglia, in her study Sexual Personae (1990), likewise deals with the mythical tales of mankind. She also discusses Hollywood films and movie stars from the perspective of myths, as discussed at the beginning of this chapter. Paglia was a great admirer of Beauvoir. She felt that the feminists who came after her were never capable of filling Beauvoir's shoes, or for that 
matter hers (Showalter 2001: 304, 305, 308; Paglia 2013: 9). Paglia discusses the mythical narratives of mankind in a similar way to Beauvoir. ${ }^{5}$ She, too, argues that, in myths, man is to woman as Culture is to Nature, rephrasing this opposition in terms of a contradiction between Apollonian and Dionysian - pagan or 'chthonian' [of the earth - KV] forces, respectively. Like Beauvoir, Paglia concludes that women live and imagine themselves through the fantasies of men, and never created their own dreams.

But unlike Beauvoir, Paglia accepts all this as a given. According to her, '(w)oman does not dream of transcendental or historical escape from natural cycle, since she is that cycle' (Paglia 1990: 10). The dominant myths on women are based on reality since women, because of their biology, embody the principle of fertility and thus are inevitably identified with nature. In contrast, men embody the Apollonian principle that has to restrain nature: '(m)en, bonding together, invented culture as a defense against female nature' (9). According to Paglia, women are not only assimilated to nature in myths and art, they ARE the nature that man seeks to master.

Nature pops up in yet another meaning in Paglia's work. Contra rosy feminist Rousseauist conceptions of nature, we must recognize that nature is 'no picnic' (5). We should adopt Sade's views rather than Rousseau's. Nature - and sex as nature in us humans - is all about aggression: Sade was right to consider sex a demonic force. Sex is 'a far darker power than feminism has admitted' (3). In an interview, Paglia clarifies what this means for women; namely that men 'do look at women as rapists,' adding that, as a lesbian, she can totally identify with them (Paglia 1995). We are dealing here with the reality of nature; in other words, with nature's laws, which are about violence and war, with women being men's prey.

To Paglia, moreover, nature is not only violence, it is also death, mud, and rot. It is the Dionysian realm of liquid nature, a miasmic swamp whose prototype is the still pond of the womb' (12). Nature 'is the dehumanizing brutality of biology and geology [...] the squalor and rot we must block from consciousness to retain our Apollonian integrity as persons. Western science and aesthetics are attempts to revise this horror into imaginatively palatable form' (6). Women suffer more from nature than men, since, as we have seen, they are nature, their body being a 'chthonian machine, indifferent to the spirit who inhabits it. Organically, it has one mission, pregnancy' (10). Nature is the enemy and woman is its necessary victim.

Admittedly, I have schematized Paglia's arguments to an extent, whereas in her work all of the above is presented in one package. Identifying her 
arguments more specifically, however -1) nature as female corporeality that men seek to master; 2) nature as violent relations of domination and submission, with women as men's prey; 3) nature as a substance of mud and rot of which women suffer more than men - allows us to compare them with Beauvoir's arguments in The Second Sex.

The violent dimension of sex, in line with Sade's view, is a common theme in their work. Like Paglia, Beauvoir wrote about the Marquis de Sade (Beauvoir 2012), but her conclusion is totally different. Beauvoir praises Sade, for his courage in showing the violent dimension of sex; but she pities him for his total emotional isolation. There is sadism, but sexual love is possible as well, when both partners accept their human condition and transform into an incarnated consciousness: a 'psycho-physiological unity.' In a state of 'emotional intoxication, existence is grasped in oneself and in the other as at once subjectivity and passivity. Through this ambiguous unity, the two partners merge: each is delivered from its self-presence and attains an immediate communication with the other' (Beauvoir 2012: 59-6o).

Sexual love thus involves 'an apprehension of the other person as consciousness through the flesh' (6o), and is an erotic encounter between unique embodied consciousnesses. Paglia instead only conceives of sex as violent relations and considers all talk of love-sex as outdated 'PC' (politically correct) feminism. Sex, as Sade has revealed, is a dark side of mankind, 'a dangerous sport,' and a combat in which especially women are in danger of being possessed and killed. Unlike PC-feminists, Paglia is not against date rape, pornography, and SM, since they are the reality of sex (cf. Paglia 1992).

There are similarities and differences with regard to Paglia's claim about Nature's substance as well. To Beauvoir, nature represents life, 'a warm spring, [...] rich in regenerating forces' (Beauvoir 2010: 168). But, as in Paglia, it is also 'the soft viscosity of carrion,' and the 'rotting of death' (169). They both share the thesis that, generally, women suffer more from nature's grip on them than men. Beauvoir, like Paglia, argues that woman 'is more enslaved to the species than the male is, her animality is more manifest.' But she immediately adds: 'in her as in him, the given is taken on by existence; she also belongs to the human realm. Assimilating her with Nature is simply a prejudice' (277). Society and culture can compensate women for their reproductive roles. Paglia comes remarkably close to Beauvoir's outlook in this respect when she states: 'nature's burden falls more heavily on one sex. With luck, this will not limit woman's achievement, that is, her action in male-created social space' (Paglia 1990: 9). Here, Paglia seems to argue that women can achieve individual self-realization in work and life. But she immediately returns to nature's laws, concluding that the more woman 
strives for individual self-realization, 'the fiercer will be her struggle with nature [...] And the more nature will punish her: do not dare to be free! for your body does not belong to you' (10).

Finally, Paglia's claim that women's bodies are represented as nature, which men want to master, is identical to Beauvoir's argument that, in myths, women are nature to men, who aim to tame, conquer, and even destroy women as part of nature. However, unlike Beauvoir, Paglia prefers to speak of 'reality based' myths: the identification of women with nature is based on the reality of nature's laws that 'limit eroticism, that is, our imaginative lives in sexual space' (9). Since woman is nature, our imaginations and dreams will never change. History has no chance. It is the character of women's bodies, as the immanent principle of fertility that makes the dichotomy of Man as Culture and Woman as Nature inescapable.

By contrast, Beauvoir sees nature and culture as intertwined and she posits that nature is always culturally embedded and shaped. To her, human beings are a 'becoming', and woman is a subject on the move. While Paglia refers to nature's laws, and cannot think in terms of any change at all, Beauvoir argues that women's access to contraceptives, education, and jobs will allow them to escape confining stereotypes and practices. Like Paglia, she is aware of an always remaining dimension of power struggle between the sexes, but to her it can be overcome given permanent effort (cf. Chapter 1).

Paglia's work can be classified as a 'politically realist' theory of gender: her work 'genders' the 'political realism' of authors like Quentin Skinner and others, who build on seventeenth-century philosopher Thomas Hobbes' concept of the state of nature as a state of war. In addition to Hobbes, Paglia refers to Sade and Nietzsche, conceiving of the relations between the sexes in terms of a state of nature, where women necessarily are men's prey (cf. Paglia 1990: 2). According to her, the popular media - uncensored as they are - prove her theory; namely, that the sexes are eternally at war. In film, popular music, and commercials, 'all the daemonic myths and sexual stereotypes' pop up again that movements like Christianity and feminism tried, in vain, to eradicate (26). Women should face reality and embrace their role. Feminism 'has betrayed women, alienated men and women, replaced dialogue with political correctness' in its attempt to 'inhibit sex' (cf. Paglia 1995). The stereotypical myths of woman as Nature will, however, pop up again the more we try to suppress them, since they are based on reality.

Returning to our discussion of the new figure of the female sexual agent as manager of her erotic capital, we can conclude from the above that to Paglia she recycles the traditional myth of woman as Nature, by finally accepting 
it. We have seen that, unlike Paglia, Beauvoir suggested that new myths, especially on erotic love, will emerge, and she cites the character created by film star Bardot in this regard. Her image of female sexual agency was liberating, in that it broke with the myths of woman as passive, mysterious Flesh. But it fell short where it remained an abstract figure. For a model of female sexual agency to really break the mould of the old myth of Woman, it has to involve a situated woman of flesh and blood, rather than an abstract - male-projection.

Is the post-feminist-neoliberal female sexual agent, in the shape of manager of her erotic capital, a new liberating figure from this perspective? While her agency breaks with the myth of Woman as Nature and passive Flesh, she remains an abstract projection. As discussed earlier, the popular media bombard women and girls with the stereotypes of female hotness and sexiness, stimulating them to embody these stereotypes, by choosing cosmetic treatments, including plastic surgery - even recommending the use of Botox to very young girls.

Linda Duits and Liesbet van Zoonen (2006) argue that girls should be taken seriously when they choose to wear porno-chic fashion. ${ }^{6}$ Girls' agencies should be taken into account, where it concerns the way they dress. What are girls saying with their garments?

Does a belly shirt mean fashion, sexual availability, pride in one's body, that it is incredibly hot outside, or sheer habit? Is girls' clothing a consistent language, or does its meaning change across space and time? For academic research, the consequences of such an approach are uncomplicated: in the tradition of feminist analysis, research should be aimed at giving girls a voice (Duits and Van Zoonen 2006: 115).

Gill (2007), however, argues that the authors' call to respect girls' 'autonomous' choices for porno-chic fashion, such as belly shirts and G-strings, remains trapped in a neoliberal discourse. It ignores the fact that girls' choices are taking place in conditions that are not of their own making; namely, in a context in which a particular kind of sexualized self-presentation 'has become a normative requirement for many young women in the West [...] 'Porn star' is no longer just a slogan on a T-shirt - it is a vital component of many young women's CVs, at a moment in which pole dancing classes are the biggest 'fitness' craze sweeping the UK and young women's magazines instruct on 'how to make love like a porn star' (Gill 2007: 72-73).

6 Girls' choices for wearing a headscarf are discussed by them in similar ways. Cf. Chapter 3 for further discussion of girls' choices regarding veiling. 
Gill's response puts the focus on girls' compulsory sexual agency in current post-feminist, neoliberal societies (cf. 74), but her approach implies a concept of postfeminist-neoliberalism as an all-encompassing System. While Gill rightly argues that an approach in terms of women's and girl's own choices is not enough, and that social conditions should be taken into account, Duits and Van Zoonen (2006) rightly imply that societies are more open and dynamic, and that one model does not fit all.

As discussed in previous chapters, rather than an overall System, neoliberalism comprises a set of dominant power patterns and techniques, alongside others, among which freedom practices, i.e. distinct sets of critically creative ethical life projects. While Foucault's mid-work positioned people as docile bodies, his later work conceptualizes how people can develop into free agents within the context of relatively independent cultural collectives, or into minimally free subjects in the context of moral systems, or a neoliberal frame that allows them some room to manoeuvre.

From this perspective, in what follows, I investigate whether other figures of female sexual agency have emerged within the realm of the popular media. Do we find women's freedom practices in this domain? Like Paglia, Beauvoir referred to films as the vehicles of mythical tales, our dreamnarratives in the sense of Langer (1960). In what follows, I look in particular at today's dream machine, Hollywood, and to other media's celebrities or sexual personae. As Laura Mulvey famously analysed, in traditional Hollywood films, girls and women either have to die or marry, an observation that resonates with Beauvoir's analysis that women in myths are typically tamed or destroyed (cf. Mulvey 1999). Do current Hollywood hypes suggest that the stereotypical myth of woman as Nature is immortal, as Paglia would have it? Or is Beauvoir right in suggesting that new myths on love will emerge and has a new female sexual agent emerged who truly breaks the mould?

\section{The Twilight Hype ${ }^{7}$}

As a social philosopher mostly interested in dominant social patterns and dreams, I focus on popular films rather than avant-garde ones, and especially on Hollywood-hypes. In what follows, I focus specifically on the five films of The Twilight Saga, in search of an answer to the question

7 Here, and in following sections, I insert authentic comments from the internet without always referring to name and place, since the sites they are drawn from are often obscure or no longer existent. I follow the spelling of the comments as I found them. 
of whether new myths on love and new female figures have emerged. The films, based on four novels by American author Stephenie Meyer - translated into 37 languages - caused a hype over the last decade, especially in 'the mediascape' of the internet. ${ }^{8}$ Not being a media scholar, or a trained feminist media critic, I focus on the Twilight 'hype' mainly for a diagnosis of the present, and especially of present collective dream-narratives.

The Twilight fan base, which at its peak in 2011 reached an estimated 26 million, mainly consists of girls, but also includes women of all ages. The hype around the films and the actors is often compared to Beatlemania, with screaming girls all over the world camping out days before the arrival of their stars. The Twilight fan base reaches across continents, ranging from the US to Brazil and Argentina, Kuwait, the Philippines, Japan, Australia, Korea, Chile, and from Eastern to Western Europe, spreading over about fifty countries. The fans use social media such as Twitter, Instagram, and Facebook, and internet sites. Discussions take place 24/7 among fans from several continents, who exchange, in addition to Twilight-related gossip and 'fan fiction', ${ }^{9}$ weather reports, news events, and the time of day or night in their respective countries.

Several academic studies have looked for an answer to the question of why so many girls and women worldwide are so obsessively involved - with titles such as Bringing Light to Twilight (2011), Twilight and Philosophy (2009), Bitten by Twilight (2010) and Seduced by Twilight (2011). As blogger Abbeysbooks aptly notes, the author of The Twilight Saga, Stephenie Meyer is in no way a great literary writer: 'she is an awful writer, it was by coincidence' - meaning that Meyer accidently hit on something big (Abbeysbooks n.d.). ${ }^{10}$ But what exactly did Meyer accidently create?

The four original novels, Twilight, New Moon, Eclipse, and Breaking Dawn are all about life and death, as illuminated by the title of a recently added publication, Life and Death: Twilight Re-imagined (2015), written on the occasion of the tenth anniversary of the series. In this last novel, Meyer has swapped the gender of all the main characters, in order to refute the dominant interpretation of the saga as a clichéd story of a 'damsel in distress'. A quick look at the storyline of the four novels makes clear where this interpretation comes from.

8 The term 'mediascape' was launched by Arjun Appadurai (1990) to describe a new global cultural economy that transgresses the boundaries of nation states.

9 The Fifty Shades of Grey book series by Erika Leonard James as well started as Twilight fan fiction, on the internet.

10 Her personal blog 'The Twilight Saga: Irruption into Simulation' (Abbeysbooks n.d.) comprises astute analyses of The Twilight Saga's sexual personae. 
Teenage girl Bella has moved to a new village to live with her father, and falls in love with a remarkably beautiful and gifted seventeen-year-old boy at her new high school. Having discovered that he is a vampire, she decides that 'it does not matter' and cannot live without him. Edward, the vampire boy, is, in fact, a 100+ year-old man, who excels in beauty and knowledge and, moreover, reads minds. He lusts for the girl's blood, which to him is like 'his personal brand of heroin,' but he remains faithful to the 'vegetarian' lifestyle that he and his family have adopted, feeding only on the blood of animals.

Worshipping the girl as his unique destiny and craving for her blood, he constantly fears he will kill her. While she struggles with her all 'too human hormones,' he puts the brake on their erotic encounters, for fear of killing her during lovemaking. The girl moreover is accident prone, falls, and hurts herself and 'attracts danger' mainly in the shape of attacks by non-vegetarian vampires. Edward and his family have to repeatedly protect and rescue her with the help of a pack of werewolves consisting of native American boys, one of them, named Jacob Black, being equally ardently in love with the girl. After her marriage to Edward, and the delivery within a few weeks of a half-man-half-vampire child, which kills her, her husband turns her, just in time, from a human into an immortal vampire. While vampires cannot procreate, Bella in the end has it all: baby, husband, and eternal happiness. Or does she?

From the above, it is clear that many elements of traditional mythical narratives are present, such as nature, death, desire, and semi-gods. ${ }^{11}$ Unlike more standard romance novels, The Twilight Saga thus entails themes that mythical dream-narratives are made of. According to Julia Pearlman (2010), The Twilight Saga is 'a revision of American mythology' (Pearlman 2010: 4): the narrative reconstructs conservative gender, class, and race relationships, and instructs the reader on 'how to be American' (14). Pearlman astutely analyses the racist subtext of the series, such as the fact that the girl Bella prefers the love of the white - superior - vampire man Edward, above the equally passionate love for her of Jacob, whose surname 'Black' is no coincidence.

But which model of love is preferred here, what do the millions of female fans of The Twilight Saga dream of? Is it the love of an overall superior figure,

11 Anthropologist William Bascom (1965) clarifies that mythical narratives, other than fairy tales, 'account for the origin of the world, of mankind, of death, or for characteristics of birds, animals, geographical features, and the phenomena of nature. They may recount the activities of the deities, their love affairs, their family relationships, their friendships and enmities, their victories and defeats' (Bascom 1965:4). In contrast to the genre of myth fairy tales and folk tales are stories that present existential dilemmas for us to identify with (cf. Bettelheim 1976). 
i.e. the love of the father, as Freud would have it? Is it the worshipping by werewolf and vampire of the girl Bella, out of a childish narcissism? Is it marriage, pregnancy, motherhood? Is Paglia right, and do the girls dream in terms of the eternal 'natural laws' that, according to her, lie at the basis of every myth? Is The Twilight Saga merely a new copy of stereotypical myths?

Paglia's laws of nature totally apply to the storyline: women are men's prey in violent sexuality and suffer more than men from nature as death. According to Paglia, 'In the day we are social creatures, but at night we descend to the dream world where nature reigns, where there is no law but sex, cruelty and metamorphosis' (Paglia 1990:4). The picture of sex as a demonic force totally applies to the Twilight story. The Twilight story featuring werewolves and vampires, symbolizes the nightly, animal world of sex and violence. Sex is even literally dangerous in the story since lovemaking would involve killing the girl. Paglia's picturing of nature as death and mud is also present insofar as pregnancy is a struggle for survival, the unborn vampire child destroying her as a human.

While in the typical Hollywood films woman has to be mastered by being tamed through marriage or killed - in terms of Mulvey (1999) - the Twilight story is not about the girl having to marry or die: she must do both.

Feminists have complained about the patriarchal storyline, arguing that Meyer, who at the time she wrote the books was a stay-at-home mum from a Mormon background, not surprisingly focused on early marriage and pregnancy as a girl's ultimate desire and destiny. Pearlman (2010) argues that the storyline involves an outspoken conservative backlash against feminism. Diane Negra (2009) specifies how numerous film scripts since the end of the 1990s entail four messages that together involve a feminist backlash. Firstly, they propound family values and the social fantasy of the hometown. It is safe and rewarding for a woman to go 'back home', away from the big city, and back to a task as care-taker. Secondly, time is frozen. There is no ageing. Thirdly, work is in line with women's essential femininity; female professional achievements are an expression of an unbalanced life. And fourthly, 'self-care' consists of a hyper-aestheticization of everyday life, a luxurious lifestyle consisting of an excessively celebrated elective domesticity and a self-stylization through cosmetic surgery, dieting, and exercising.

The storyline of The Twilight Saga fits Negra's four criteria perfectly. Heroine Bella has gone to the countryside, only to ultimately become part of an extended vampire family as a mother and wife. She will not age: as a vampire she will stay eternally young and super attractive. All the vampire women in the series are involved in domestic virtues, not aspiring to any 
professional training, but spending their time as spouses, with hobbies like fashion and house styling. The luxurious lifestyle of the vampire family is all about super cars, super houses, and super clothing, and Bella is given diamonds, phones as well as cars from her beloved vampire.

While, from this perspective, the Twilight story can be qualified as a conservative backlash against feminism, some feminist scholars have argued in contrast that its female first-person narrative allows girls and women to positively identify as sexual agents. The girl Bella pursues her own sexual desires and, in the end, has it all. Bonnie Mann (2009) concludes that since it is the male character that puts the brake on the erotic encounters, the story provides girls with a thus far missing narrative of 'male accountability' and 'female pleasure without penalty' (Mann 2009: 140). From The Twilight Saga's female first perspective, we experience the sexual world of a seventeen-year old girl, who can act out her desire since the male figure, for once, is the one who is accurate and sensitive. This allows girls and women the space to experience their own sexual feelings, instead of having to defend themselves constantly against male sexuality.

In this sense, the story can be seen as opening 'pockets of agency', to borrow a term from Maryn Wilkinson (2014; cf. Wilkinson 2014: 1). But, as Mann adds herself, there is a price to pay, since Bella dies in childbirth. Moreover, the storyline clearly conveys that it is the male figure that decides, in line with stereotypical patriarchal patterns. First marriage, then sex, and only then a vampire transformation. This is the right order as Bella herself ultimately admits. Early marriage is indeed the message, and early pregnancy is the happy outcome of it all. Women's sexual agency in the Twilight world appears to be totally in line with the static Myth of Woman described by Beauvoir and Paglia. Bella's agency remains firmly confined within the limits of patriarchal moral rules and, as such, can be qualified as a minimally free, limited agency. But, then, do the millions of girls and women who respond so emotionally to the Twilight world today, still live out their fantasies through men's dreams, to paraphrase Beauvoir?

\section{A New Face of Love}

By adding a fifth gender-swapped novel to the Twilight series, Meyer aims to prove that the Twilight story surpasses gender stereotypes and deals with 'the magic and obsession and frenzy of first love' (Meyer 2015: Foreword). But Meyer does not fully understand what she wrote, blogger Abbeysbooks 
argues (cf. Abbeysbooks 2013). ${ }^{12}$ According to her, The Twilight Saga in fact is a final retelling, in a modern variation, of the myth of Tristan and Isolde, which is about Courtly Love. The lady is courted and no consummation of love is allowed in the ritual:

Love was pure so to speak. This is Edward. [...] Twilight is perfectly named. It is the end of the Tristan and Isolde legend which ruled Western Civilization concerning all the rituals of love and marriage for 800 fucking years until the pill. As Nietzsche has said, "Only what is over can be fully understood." And that is what she has given us. The full understanding of Courtly Love in all its splendor, passion, death, courtship, engagement, marriage, and ritualistic behavior.

While the pill in the 1960 os put an end to the entire ritual, we are 'still struggling to put a new one in place and haven't succeeded yet. We are the FIRST culture in the history of the world that does not have a ritual for mating, betrothal, marriage.' Twilight is a re-introduction of the 'passion-myth' that goes back to the medieval Tristan and Isolde legend, about love that can only be satisfied by death. ${ }^{13}$ It comprises 'many inversions,' but it is 'a MYTH, not a story about healthy relationships in reality. It's a MYTH!' While The Twilight Saga is heavily criticized by many, she argues: 'All these addictive, healthy, destructive, etc. [labels] DON'T apply to the Symbolic Order where mythology is. Myth doesn't tell you how it should be, it tells you what is' (Abbeysbooks 2013).

In The Second Sex, Beauvoir describes the model of courtly love, born in the twelfth century in the Mediterranean south of France, as only a certain 'improvement in woman's lot' (Beauvoir 2010: 111). Courtly poets did exalt love and 'many codes of courtly love appear, [that encourage] young men to devote themselves to the service of ladies' (118). In this 'gallant tradition, woman is no longer an animal creature but rather an ethereal being, a breath, a radiance' (203). Yet, Beauvoir adds, woman remains the essential Other of man. 'While courtly love might ease woman's lot, it does not modify it substantially' (112). The role of woman is still passive, being the one who is conquered, loved, and worshipped. She remains an outsider to men's activities, and 'does not take part in their jousts and combats: her entire

12 The following quotes are taken from Abbeysbooks (2013).

13 Abbeysbooks (n.d.) refers in this respect to Denis de Rougemont's Love in the Western World (1956), which describes the passion-myth as rooted in the medieval Tristan and Isolde legend, resonating in twentieth century romance stories, popular music and films. 
situation predestines her to play this role of onlooker. The chevalier jousts in tournaments for his lady' (206).

This highly gendered model of courtly love is The Twilight Saga's original scheme, which explains why Meyer's gender-swapped fifth novel - not 'backed' as it is by the original myth of courtly love - does not 'work', to say the least. In the original storyline of the books, several tournaments with bloodthirsty creatures (werewolves, non-vegetarian vampires) have to be fought by the chivalrous lover, with the girl as onlooker and privileged prize. The courtesy of the lover who worships the unique lady-girl is without limits. Courtly love obviously differs from Sade's model of sex as violence and rape, which, according to Paglia, is the truth of sex. From this perspective, the Twilight hype among women and girls emerges as a desire for the old type of romantic love, and as an alternative to the sex dates and the compulsory sexual agency neoliberal society inflicts on them.

The Twilight story is about the uniqueness of the beloved, and about impossible and all the more passionate love - as is also suggested by the story's literary references to the classics Wuthering Heights, Romeo and Julia and Pride and Prejudice. As Abbeysbooks notes, Twilight's focus on the uniqueness of the beloved has 'a huge reverberating circuit of an impact. Girls who did not want to "put out" by the 3 rd date (you have to or he moves on and you are dateless) who wanted to wait for love/intimacy were given the courage to decide not to be meat in the market place. That's not insignificant. Twilight gave them that courage' (Abbeysbooks 2013).

But in addition to girls' and women's - implicit - critique of a compulsory sexual agency, might there be another explanation for the Twilight hype? To understand it more fully, the five Twilight films must be considered. The director and scriptwriter of the first film were women, as, of course, are the author of the original books and main actress Kristen Stewart. Have these women perhaps created a new - more egalitarian - face of love, in a way Beauvoir was hinting at?

While Meyer suggested 'hotness' in her books, the Bella character in most of the films is the opposite of a (post-feminist-neoliberal) sexy agent. She looks nerdy in green and brown coloured sweaters and pants. Especially in the first film, by director Catherine Hardwicke, the camera identifies with the Bella character: she is the one who looks, instead of being looked-at herself (cf. Edwards 2009). This female gaze clearly departs from the dominant Hollywood film that privileges the male gaze. Mulvey's famous article 'Visual Pleasure and Narrative Cinema' (Mulvey 1999), originally published in 1973, argued that cinema by its nature, steeped as it is in the act of seeing, satisfies a primordial wish for 'scopophilia', i.e. 
the pleasurable looking at an object for sexual stimulation. But it also has a narcissistic dimension in that we identify ourselves with the image on screen. The film screen functions as a mirror in which we see ourselves and, as such, touches the primary level of self-identification of the very young child in front of the mirror, as described by Jacques Lacan. Both narcissistic identification and scopophilia explain why people invest their libido in movie stars. ${ }^{14}$

Cinema involves, in fact, a triple act of seeing, in that characters look at each other, the camera looks at them, and the audience looks through the camera's eye (cf. Edwards 2009: 28). Traditionally, in Hollywood films, the woman is the visual object of desire, since the triple act of seeing is male, i.e. the male character looks at the female character, the camera identifying with his perspective, and the audience with the camera. But in Twilight, the typical visual object of desire is Edward, 'thus the implicit male authority of the gaze in fetishizing an image as sexual stimulant is claimed by Bella, and by extension her empathizing audience' (29). While the 'triple gaze' shifts in other scenes to the female character, the power shifts back and forth between male and female characters, 'between pursuer and pursued,' (30) and 'the obsessive pleasure in looking is shared between the characters, the camera and the audience' (32). The pockets of female agency in the storyline thus are enhanced in the Twilight film, allowing for an interpretation of the story in the direction of an egalitarian model of love.

Yet other, 'extra-textual' factors are relevant for an interpretation of the films in this direction, especially the 'sexual persona' of main actress Kristen Stewart. Raised by a feminist mother, she calls herself a feminist as well and, on the whole, is not the pleasing female star that Hollywood is used to. She swears in public, and flips off the constantly harassing paparazzi. She does not smile constantly and swaps high heels for Converse on and off the red carpet. The fact that she does not make the most of her erotic capital, i.e. she refuses to always provide visual pleasure to men, generates a lot of hostility towards her. As Stewart comments, '(i)f a woman isn't happy and un-opinionated and long-haired and pretty, then she's weird and ugly. I just don't get it. ${ }^{\prime \prime}$

14 The mechanisms of people's libido investment in movie stars have been further analysed in psychoanalytical film studies. From a Foucauldian perspective, Lacanian psychoanalysis can be re-articulated as comprising a useful toolset for analysing major patterns, suspending its all-encompassing claims (cf. Foucault 2003: 6; cf. the Introduction). Contra the Lacanian approach, Hall (1973) famously emphasized the active role of the audience in interpreting 'texts'. 15 Quotes are taken from the official webpage of the actress, imdb.com/name/nmo829576/bio (last accessed, 21 September 2016). 
As a method actor, Stewart blends her personal experiences with the role of Bella, creating a 'visual form' that allows for a reading of Bella as a female sexual agent - all the more since, in interviews, Stewart emphasizes the free sexual agency of the character. Yet another important, 'extra-textual' factor is the alleged off-screen affair of the two main actors. Whether it was a real relationship or a PR-orchestrated one is of no importance, since we are dealing with their public 'personae' and perceived relationship. Both actress Kristen Stewart and actor Robert Pattinson - referred to by fans as 'Robsten' - presented themselves as artists who are passionate about their jobs. They supported each other's careers and never confirmed an off-screen relationship. However, the perceived affair also contributed to a feminist subtext in the films. From this blending of the love couple in the movies with the supposed real life couple, who allegedly shared love and work on equal footing, in combination with the female first-person narrative and camera perspective, 'a new face of love' appeared. The new myth of love that emerged, by accident, due to the several factors mentioned, is that women's self-realization in work can go together with romantic love. ${ }^{16}$ Actress Stewart, who is passionately identified with by girls all over the world, is - according to her official webpage - totally involved in her work. She states, 'as an actor your life is so wrapped up in your job. It's not normal. People's jobs don't affect their whole lives. Mine is why I love my life.' She is not only into acting, but also aspires to become a film director. And yet, this feminist actress seemed to be loved by the 'sexiest man of the planet', British actor Pattinson.

It was especially this Robsten Saga that made people invest their libido in the films. As one of the directors said, they saw real love unfolding on screen. And as one blogger commented: '[they] became friends and fell in love and somehow the whole damn world fell right along with them.'

\section{The Battle of Myths}

The fact that people invested their libido in the couple not only explains the obsessive love of the fans, but also the intense hatred of anti-fans who call themselves 'Nonstens' - who were over-invested in the couple

\footnotetext{
16 Beauvoir's own ethical life project involved a personal attempt to put up a new face on love: her life long relationship with her friend Jean Paul Sartre, in the shape of a 'contract' involving 'necessary' love next to other 'contingent' ones, has been an inspiring model to others. But this new face on love had its negative sides, especially for women who were often the sad ones left behind by adulterous men. Beauvoir's relationship to Sartre is often discussed in these terms, but in fact it was more complex (cf. Vintges 1996).
} 
themselves. ${ }^{17}$ Others routinely debunked the films as girl stuff, loathing Twilight and especially Stewart in overtly sexist ways. Most of the hatred against the actress came, however, from the female fans of male actor Pattinson. Right from the beginning of the media frenzy, Stewart was targeted by traditional female fans of the actor, who wished for their heartthrob Pattinson a woman with domestic values, like themselves. They expressed their anger that Stewart refused to take second place and kept pursuing her own career.

A fear of identity loss seems to play a major role in their extreme disgust and hatred towards the persona Stewart. Neither sexiness, nor domestic virtues proved to be decisive for a woman or girl to be loved by the most wanted man on earth. The old Myth of Woman was trumped by an egalitarian model of love that involved equal self-realization in projects in the world, rather than women's 'being-for-men' (Beauvoir 2010: 159).

The hatred against Stewart reached a new peak in July 2012, when a so-called 'cheating scandal' hit the internet. Fifty photos were published of 'best paid Hollywood actress of the year 2011,' a twenty-two-year old Kristen Stewart, 'caught' by paparazzi in a 'make-out' session with a forty-one-yearold married father of two children - the director of a film in which Stewart played a major role, which was supposed to be followed up by a sequel. The pictures, published online by the gossip site US Weekly, show the two hugging (described in the press as 'steamy lovemaking') in the middle of the road, plus somewhere inside a car.

Stewart, at that time, was allegedly in a three-year relationship with Pattinson. During the years of filming the Twilight series, both young actors - Stewart was 17 when filming began, Pattinson was 21 - were hunted by the media to the point that they had to hide out and sometimes adopt military-style strategy to escape paparazzi and harassing fans. With the upcoming premiere of the final Twilight film, many wondered how the two actors would survive increasing hysteria, which seemed to heighten to a point where their lives were in danger and they could even be killed by a crazy fan or anti-fan, as Stewart herself formulated it.

'Nowadays it's harder because everyone is on Facebook and everyone knows where you are all the time, and everyone's Twittering. I'm going to die because somebody is going to say where I am and somebody is going to kill me. Someone's going to twitter my location and it's going to be, like, BOOM!'

17 For an analysis of the phenomenon of the anti-fan see among others http://journal.transformativeworks.org/index.php/twc/article/view/247/253 (last accessed, 21 September 2016). 
With the 'cheating pictures' published a few months before the final premiere, the heat around the two actors reached a new peak. While the fans initially claimed that the photos were fabricated, what really finished them were the alleged public apologies of Stewart and the director two days later, Stewart's saying:

I'm deeply sorry for the hurt and embarrassment I've caused to those close to me and everyone this has affected. This momentary indiscretion has jeopardized the most important thing in my life, the person I love and respect the most, Rob. I love him, I love him, I'm so sorry' (People, 25 July 2012).

Stewart's supposed apology for 'momentary indiscretion' made the infidelity into a real deal. All the more astonishing to many fans was her so-called statement, since the actors had always refused to talk to the press about their private lives, and certainly never turned to a tabloid like People before.

For about two weeks, people reacted in shock. Twilight fans worldwide were heartbroken, and shared their grief. ${ }^{18}$ Lizzy on 7 August posted:

'i am very very very sorry for them. i cant keep my feelings. i love them. i love. and i am very sorry and tired.'

Fan sites closed down, with declarations such as

'Thank you and Goodbye. These past days have been very difficult but I believe I'm coping just fine. What to say, how to say it? This is not going to be easy' (fan site Robstenation, 3 August).

Many other fans reacted in excessive ways in the media. Girls who had totally identified with Stewart cried and even spoke of suicide.

'Robsessed' fans - infatuated with the male actor, obviously sided with him, and reacted furiously against Stewart. For example, Twihardern17 posted:

'HOW DARE SHE CHEAT ON HIM!!!!!!!! I WILL NEVER FORGIVE HER. SHE JUST

LOST LIKE A MILLON FANS!!! SHE IS DEAD TO ME NOW.'

18 The quotes that follow are from the internet sites Hollywood Life and Gossip Cop, the fan sites Robstendreams and Robsessedpattinson, and Robstenation, and from the website of the journals Daily Mail and Huffington Post. I copy the spelling used. 
Funnyface 1064 posts:

BOTTOMLINE KRISTEN IS A LIAR!!!!! CHEATER!!!!!!! HOMEWRECKER!!!!!!!!!'

Stewart's fans were devastated. B_dogo1 on August 7, comments:

'What she did was wrong, but people are being way to mean about it. Kristen was like a role model to me, she still is I just see her in a different way.'

Pati2002 posts:

'Kristen if at all $\mathrm{u}$ read this, just know that some of us are still with $\mathrm{u}$ in each and every bad situation u r in, love you kristen.'

For many days the gossip press repeated itself, recycling stories of an ugly break up between Stewart and Pattinson, involving fighting about their dogs, plants, and homes. Explanations included that she had become bored with the relationship, or that she wanted to move beyond the Twilight personage of the cute teenager Bella, who she symbolized for so many years. Others suspected the director of serious sexual harassment.

A few voices, especially 'Twilighter' who claimed to be a lawyer, and sites like 'Justiceforkristen', and later 'MyHappyRKWorld' stuck to their suspicions about the so-called scandal, analysing the pictures as photoshopped and even staged. After one week the tabloids moved on and only 'fillers' were published, such as advice by therapists or gossip publicists as well as wild speculations concerning Stewart, with headlines such as 'Inside her Betrayal' and 'How Many Other Men?'

On national television, comedian Will Ferrell called Stewart a 'trampire' (The Conan show, 4 August). ${ }^{19}$ T-shirts with the text immediately hit the market, with other text options as well such as: 'FUCK Kristen Stewart', 'I wanna take a dump on Kristen Stewart', and 'Robert Pattinson deserves better'. Stewart was supposedly dropped from the planned sequel by Universal studios for being 'damaged goods', and because '[n]o one wants to cast the emotionally unstable slut that America hates.'

Donald Trump, who at that time was considering running for the presidency, warned Pattinson in a tweet not to take back Kristen Stewart. Trump writes: 'She cheated on him like a dog \& will do it again - just watch. He can do much better!' 
'Cuckolded' Pattinson, when appearing on the Daily Show on American television was advised by host Jon Stewart to 'kick her to the curb,' to which he added:

'when you are young and break-up, it feels like the world is ending but this is the first time I have actually seen the world react that way. It's insanity!' (Daily Show, 14 August).

Meanwhile, many fan-girls, via social media, fan sites, and YouTube, had started to defend their heroine, posting videos and selfies under labels like 'Stay Strong Kristen', Robsten is Unbroken', and 'We Believe in Kristen'. ${ }^{20}$ They launched a campaign to 'Hide The Lies', sampling visual proof of their hiding of the tabloid US Weekly in shops all over the world behind the dog food and other places, a type of global action unique thus far. ${ }^{21}$ Many girls clearly were not willing to let go of Stewart as their role model.

Other internet commenters started to get seriously worried about the public lynching of Stewart - characterized by some as a witch hunt or a stoning to death - that necessitated a permanent safeguarding of the actress, by official and informal bodyguards, the latter comprising a group of lesbian women friends. ${ }^{22}$ As one blogger commented:

'They will probably harm her physically or attempt to [...] I hope no one actually kills her. With the hate and judgment that's going around. I wouldn't be surprised.'

And another:

'This is insane. The psycho James Holmes who massacred people in Aurora isn't even getting $1 \%$ of the hate directed at Kristen.'

And yet another:

'Rob is not just an ordinary guy [...] He is the sexiest man in the world, he is a fenomen, he is the most loved one on the planet - what kind of

20 See for instance https://www.youtube.com/watch? $v=c_{5}$ UMy6YzfpE (last accessed, 21 September 2016).

21 Their site operationhideusweekly.tumblr is no longer operative. For an impression see: https://www.youtube.com/watch?v=njtB-YMzJA8 (last accessed, 21 September 2016).

22 See for instance https://www.youtube.com/watch?v=UqGi4DiHhho (last accessed, 21 September 2016). 
reaction cheating on him might cause? Robsten was the most beautiful couple of the decade, now Kristen is the most hated slut of the decade.'

People also noticed the unfairness of the incredible amount of public hate for Stewart compared to the milder critiques about the movie director. Especially men were taking up the task of defending Stewart against the hatred. US feminists at the time were not taking notice of the attacks on the actress, since it was 'too far out from the real world. ${ }^{23}$

When, after a few months, pictures showed the two actors together again and when they engaged in a common press tour for the last Twilight film, the hype about whether or not they were a couple reignited. As blogger 'Christopher Dark' commented: 'this kind of response is unprecedented. Perhaps ancient monarchs of old engendered this kind of response. Royalty is one thing. They were the movers and guiders of life then. But so much love for two actors is inexplicable to me and yet here I am among the second group. Bewildered but hopeful.'

Many other fans, however, were disappointed about the renewed 'relationship'. Nicola comments:

'Rob is such a dissappointment still being with the cheater. [...] Then obviously he is as fake and as much of a fame ho and has as much love for drama as the skank [...]. And for all his millions he will be using a used Vagina and the whole world knows about it.'

Deepika writes:

'he is a pussy whipped lap dog, doormat wussiness is definitely not an attaractive trait in a man. he is such a joke of a man.'

But while the actor is merely debunked as a pussy, the actress is openly threatened and harassed as being 'a cheater, a liar, a cretin, a loser.' Today, people are still not willing to let go: the cheating issue is brought up time and again.

Beauvoir, in her chapter on Myths, concludes that man's failings

are often lightly dismissed; even if he disobeys community laws, the man continues to belong to it, he is merely an enfant terrible, not a profound threat to the collective order. If, on the other hand, the woman deviates from society, she returns to Nature and the devil, she triggers 
uncontrollable and evil forces within the group. Fear has always been mixed with the blame for licentious behaviour. If the husband cannot keep his wife virtuous, he shares her fault; his misfortune is, in society's eyes, a dishonour. [...] And the community will take it upon itself to punish the guilty woman in his place: because she offended the group as a whole and not only her husband (Beauvoir 2010: 213).

Stewart apparently has 'offended' society. According to some, the 'cheating affair' allowed her to get out of the character of the decent Twilight girl. However, the affair evoked the projection on her persona of the other side of the dominant Myths of Woman, i.e. being death and the devil. From the above, we can analyse the clashes on the internet, spilling over into the regular media, as a battle between two competing myths of love, which like many internet wars has ugly faces. The old Myths of Woman are taking revenge on the new egalitarian face of love, i.e. the Robsten Saga that a substantial part of the fan base had identified with. The new myth of egalitarian erotic love that had 'happened' as a result of the above-mentioned factors - and maybe myths overall 'happen' in such ways - is not so much about female sexual pleasure without penalty (cf. Mann 2009: 140), but rather about female ambition without sexual penalty. This new dream-narrative for girls, with hindsight, has to be unmasked as the egotistic project of Stewart, being 'a hateful, vile little backstabber.'

Today, the Twilight fans that 'read' The Twilight c.q. Robsten Saga as a new dream-narrative of egalitarian romantic love, have moved on to the HBO series Outlander - the female counterpart to the archaic masculine series Game of Thrones - with the female first-person narrative of a female sexual agent in the role of a time-travelling medical doctor. Kristen Stewart, in the meantime, continues working and successfully survives the violence of the old Myths of Woman that still try to crush her. She challenges and replaces the dominant Myths of Woman at the heart of Hollywood's dream machine, with a feminist freedom practice shared with others. And certainly, overcoming millennia old Myths - to paraphrase Paglia - is 'no picnic', Hollywood being not only still predominantly white but male as well. ${ }^{24}$

24 The nomination of an all-white group of actors for the Oscar 2016 is an indication for what today is called 'the unbearable whiteness of Hollywood.' For an overview of the male character of this film industry, by the New York Film Academy, among others on the typical ways women are portrayed in most films (including absurd and ridiculous straw feminist characters), and the lack of female directors, see http://www.nyfa.edu/film-school-blog/gender-inequality-in-film (last accessed, 21 September 2016). In the wake of the Twilight hype, a contest for female directors was organized by 'Women in Film,' with among others actresses Stewart and Kate Winslet as 
A similarly 'dangerous' domain of myth production is the male dominated gaming industry, with its stereotypically sexist video games, in which female characters are either absent or represented in passive, often hypersexualized ways. Anita Sarkeesian, Brianna Wu, and Zoe Quinn, among others, are engaged in feminist freedom practices in this domain. Fighting the sexism of games and installing new egalitarian 'visual forms', they have been heavily harassed and even received death threats. An anonymous hate campaign, 'Gamergate', organized against them via online fora such as Reddit, became ugly to the point where all three women had to go into hiding. As a result of her experiences, Wu considers the internet an increasingly unsafe place, where women and girls who speak out against sexism are routinely and seriously intimidated. Recent protests against the typical sexist representations of female characters in comic books and magazines have also caused much controversy.

Female singers, performers, and dancers who are hyped as 'sexual personae' in the media trigger a lot of hatred, and controversy too. Feminist women today read Miley Cyrus's hyper-sexy performances - in combination with her postings on Instagram - as a freedom practice that critically creates a new sexual persona, subverting the traditional gender binary. Equally, male performers such as Stromae function as inspiring gender fluid new sexual personae. Kristen Stewart, who in recent years defies any labels - by refusing to 'tell all' and preferring to live in 'the grey zone' - likewise is a role model to many.

Singer and dancer FKA Twigs, born Tahliah Debrett Barnett has also been heavily criticized, in sexist and racist terms, for her porno-chic performance style. FKA-Twigs refuses however to conform to standard norms of heterosexual beauty, often wearing a nose ring and dressing up in unexpected ways. She produces and controls her own video clips and performances, takes the lead in her group of dancers, and speaks in a voice that is outspokenly anti-racist and implicitly feminist. Her style is overdetermined as a freedom practice conform our five core characteristics - expressing new 'forms' that break the moulds of submissive femininity through the performance of dance and music, within a circle of friends, in a shared artistic practice, comprising various 'keys'. ${ }^{25}$

members of the judging panel, for directing five spin-off films focusing on different characters from the story, to be released via social media.

25 Feminist 'total' disapprovals of cosmetic surgery as well should be reconsidered from this perspective. Other than Kathy Davis (1995; 2003), Heyes (2007) outlines cosmetic surgery and dieting as disciplining and normalizing techniques per se, and recommends for women to turn to yoga and other practices that counter 'the mental anguish and dis-ease caused by corporeal 
FKA Twigs live in Paradiso, Amsterdam (2015)

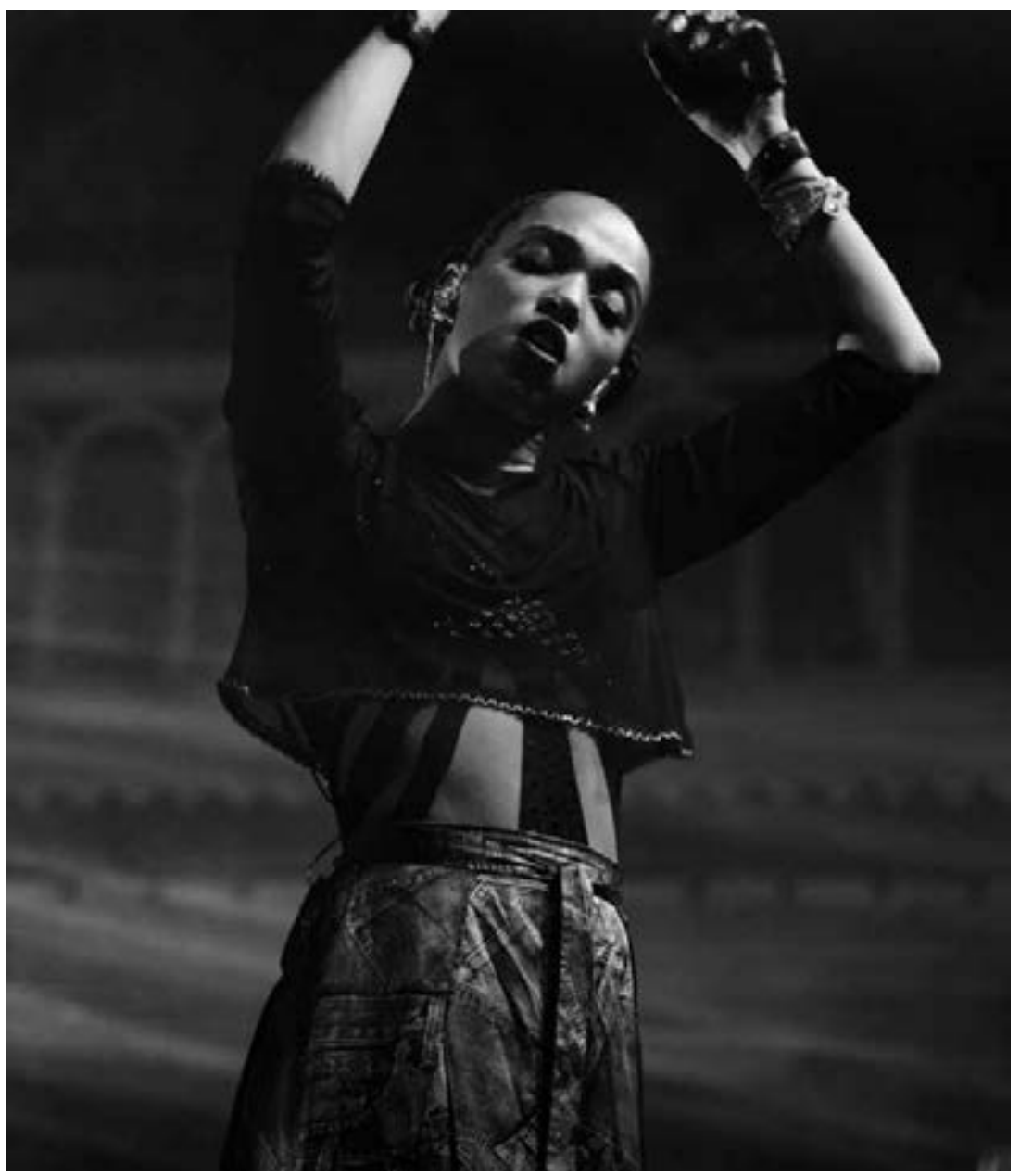

Photographer: Bobo Boom

Retrieved from: https://www.flickr.com/photos/fotnmc/16549707049/

normalization' (Heyes 2007: 121), so as to move us into freedom without ever dieting again (cf. 129). But cosmetic surgery as well can be a self-technique in the context of an ethical life project, involving a freedom practice, as was dieting in ancient Greece according to Foucault (cf. Foucault 1986a). 'Beauty' as such can be overdetermined as a self-technique in the context of a freedom practice, as is illustrated by Muslim women who use beauty in the context of their ethical life projects challenging patriarchy (cf. Chapter 3$)$. 
From the examples discussed above, we can conclude that new 'figures' of female sexual agency are emerging that comprise women's singular personalities, created in critically creative, slow, and arduous work within the mythical realm of the popular media, in a grim fight with its dominant 'visual forms'. While the dominant figure of the female sexual agent spread by the popular media comprises stereotypical behaviour and characteristics of female sexiness, as analysed by Gill and others, a new female sexual agent has appeared that breaks the mould of the old Myths of Woman: a female 'sexual persona' who walks, dances, and moves, to paraphrase Beauvoir, and that is involved in work and in concrete activities in the world.

In that sense, post-feminist-neoliberal models of woman- and girlhood are to be conceived of as dominant models of personhood, rather than exclusive ones. New kinds of female sexual agency that emerge today in the context of collective freedom practices in the mythical domain of popular culture, prove Duits and Van Zoonen (2006) right in arguing for an open and critical eye for the various relationships of women and girls to porno-chic fashion. A bottom up approach of 'studying upwards' is necessary. Many girls and women, however, are unaware of the ways the popular media manipulate their own choices to be sexy 'at a distance'. Many lack the vocabulary or tools to distinguish more liberating 'forms' of female sexual agency from schematic sexist ones. The truly new figures of female sexual agency that are emerging today in freedom practices within the mythical domain, may, and already do, inspire and encourage them to resist the sexist 'visual forms' and expert advice of the popular media that we are bombarded with on a daily basis. ${ }^{26}$ 



\section{$5 \quad$ Feminism in a New Key}

We live in a 'period of transition,' Beauvoir concluded in 1949. Abstract rights are 'far from wholly granted to women,' and, moreover, they 'have never been sufficient to guarantee woman a concrete hold on the world: 'there is not yet real equality today between the two sexes' (Beauvoir 2010: 155).

Today, we are still living this period of transition. Important breakthroughs have been reached by and for women in law, politics, and economics, in the West and elsewhere. Slow but steady movements are taking place under the radar in gender egalitarian directions in the Islamic world - where women, on the basis of a strict domestic-public dichotomy, are treated as essentially domestic beings (Ennaji and Sadiqi 2006); and similarly, in other places in the world, where women increasingly accede the public sphere and fight, often together with men, to improve their position in the 'private' sphere. But every where the powers that be are still predominantly male. A millennia old status hierarchy between men and women persists everywhere and the patriarchal patterns described by Beauvoir are apparently more resilient than she, and many with her, suspected. Langer (1960) stated that the human mind is 'a slippery customer; if one door is closed to it, it finds, or even breaks, another entrance to the world. If one symbolism is inadequate, it seizes another' (Langer 1960: 69-70). In a similar vein, we concluded that patriarchy is making new entrances and, like a hydra, grows new heads when others are cut off. Beauvoir's study The Second Sex comprises a still indispensable toolset for analysing the multiple dimensions of these patterns today, in their old and new shapes across continents.

While some men in the West complain that women have gained the upper hand and that they are the ones that are being crushed, it is neoliberalism that invalidates them, as was signalled by Beauvoir for the US. If 'the American male is crushed,' she wrote, it is by the Organization, and not by the female - since the American woman still 'remains a dependent and relative being' (Beauvoir 1999: 133). Beauvoir explicitly criticized 'Organization Society' and its models of Organization Man and Super Woman, which Foucault conceptualized in terms of an American type of 'neoliberal governmentality' and a neoliberal model of the 'entrepreneurial self'. Her critique of these models of self and society is more relevant than ever, since they are spreading across the globe - universalizing competition and 'market-shaped systems of action for individuals, groups and institutions' (Lemke 2001: 197) - under the banners of freedom, 'feminism' and democracy, equally crushing men and women. 
Contra these individualist, competitive models, Beauvoir's original feminism favours a model of an ethical self that, out of concern for fellow human beings, develops a personal ethical life project within a collective setting, rather than being its counterpoint - a perspective that we, with the help of the final Foucault's concepts, coined in terms of a concept of ethical 'freedom practices'. The concept balances personal and communitarian dimensions as two sides of the same coin: a personal ethical life project is developed within a collective setting, the fabric of which is the personal ethical life projects of its members. The concept of freedom practices thus refers to distinct sets of critically creative ethical life projects. Surpassing notions of autonomy, the concept captures women's struggles all over the world for women's access to a personal ethical life project within their respective communities. The concept also allows for a critical reformulation of feminism in terms of a freedom practice itself; more precisely, in terms of an assemblage of identifiable, distinct sets of critically creative ethical life projects.

While the ancient myth of the Lernean hydra holds that the monster's 'immortal head' had to be finally slayed, in The Second Sex Beauvoir suggests that the 'Myths' of Woman as Nature comprise patriarchy's most resilient head today. Her concept of 'Myths' covers the three so-called presentational realms in terms of Langer (1960); namely, rite, art, and mythical secular tales. Their dominant 'forms' today still 'picture' the old status hierarchy between the sexes, rather than conveying that 'the real relation is one of reciprocity' (Beauvoir 2010: 275). Changing the dominant 'forms' in these domains is necessary, as happens today by women engaged in critically creative freedom practices in these realms.

Muslim women are moving the domain of rite, pushing limits in the Islamic world as well as in their communities elsewhere (cf. Chapter 3 ); Islamic feminists re-articulate and re-contextualize Islamic idea(l)s in critically creative freedom practices, im- or explicitly critiquing the old status hierarchy between the sexes, developing new ritual 'forms' and new visions for their societies.

Mythical tales, or collective 'dream narratives', in the shape of popular media hypes turn out to be patriarchy's most resilient head in the West today. Hollywood hypes especially fulfil the role of mythical tales, and still recycle the old Myths of Woman as Nature. Movie stars, and other media hyped performers, revive the ancient 'pagan pantheon of physically perfect, openly sexual gods and goddesses' (Paglia 2013:2). As 'sexual personae' they still embody the stereotypical Myths of femininity. The dominant visual 'forms' of the popular media are often identified as 'merely' superficial 
(or 'super-structural'), but they are the bearers of ideas that 'insinuate' themselves 'in each consciousness' (cf. Beauvoir 2010: 281). As long as they still convey a 'picture' of Womanhood and of sexual love based on the Myths of Woman as Nature, the penalty on female ambition continues - since male partners are supposed to be women's superiors. As long as girls and women still dream through men's dreams, that is, many will hesitate to leave their 'comfort zone'.

But other women and girls today do engage in critically creative freedom practices in this realm, in fierce battles moving the dominant mythical 'forms' of the game industry the film industry, and the showbiz industry with its 'sexual personae' of media hyped performers. They are changing the dominant 'forms' of Woman as man's Other, shifting these in the direction of reciprocal relationships between men and women, or even of gender fluidity. Many other studies show how women all over the world in the domain of art move the dominant gender-images, as for instance the punk rock protest group Pussy Riot does in Russia today, in an equally grim fight (cf. Braidotti and Dolphijn 2015).

Rite, art, and mythical tales comprising 'modes of thought' in their own right, are the producers of 'new conceptual forms' that, Langer argues, a 'Philosophy in a New Key' should build on (Langer 1960: Preface, 71, 238). A 'feminism in a new key', in a similar vein, builds on women's freedom practices that critically create 'new conceptual forms' in the realm of rite, art, and myth. It recognizes that argumentative discourses are not sufficient, let alone decisive today, and that crucial battles take place in these 'presentational' realms.

Whereas to Paglia the stereotypical Myths of Woman as Nature are truly immortal, they turn out to lose their monopoly today. The hydra is on its way to the sky, turning into a constellation (cf. the cover), in a new dawn for the second sex. While the dominant 'forms' of mythical tales, art, and rite, insinuate the Myths of Woman in essentially material, social ways, they themselves prove to change under the influence of societal changes.

A feminism in a new key not only recognizes more 'keys' than verbal argumentative language alone. It also recognizes that the plurality of faces and heads of the hydra demand for a plurality of strategies. It also recognizes the new heads of the hydra that pop up today, in the shape of a 'compulsory sexual agency' for women and girls in the Western world, a masculinist political revival in different parts of the world, the new opportunities offered by the internet for sexual abuse, and the rise of transnational networks of trafficking in women and children. New international 'jihadist' movements operating 'in the name of Allah', comprising a mixture of modern 
technology and extreme machismo, also prove that patriarchy is a hydra in fact. While they according to Charlotte Wiedemann (2014), represent a 'last gasp of archaic masculinity,' they actually illustrate - as do the other phenomena mentioned - that patriarchy as a hydra grows new heads. Even when the monster will be projected in the sky, scattered fragments will always fall back to the earth, trying to rear new ugly heads. Out of a will to power in Nietzschean sense - or a striving for self-certainty in Hegelian terms - people will always try to dominate others and sexual violence and oppression is but one of its many manifestations. Women's explicitly critical freedom practices, in plural 'keys', will always be necessary, by those who are able or willing to engage in them. Others will simply live their lives as a freedom practice in an implicit critique of any gender domination.

Finally, an existential ethical perspective as such, as present in Beauvoir's work as well as in Foucault's final work, elucidates the new alliances that emerge today between groups of people throughout cultures. They share an orientation to an existential type of ethics, namely an ethics that is developed and lived by persons within their own communities - in an implicit or explicit critique of an abstract morality that is forced upon people. As such, they are open to a more general perspective. In the words of Beauvoir, 'the assertion' of 'particular solidarities' need not 'contradict the will for universal solidarity,' since as a 'finite undertaking' they are also 'open to the totality of men' (Beauvoir 1948:144). As she phrases it: '(i)t is fitting that the black fight for the black, ${ }^{1}$ the Jew for the Jew, the proletarian for the proletarian, and the Spaniard in Spain.' However, 'each one must carry on his struggle in connection with that of the other and by integrating it into the general pattern' (cf. Beauvoir 1948: 89).

Ethical 'freedom practices' in particular, as distinct sets of critically creative ethical life projects that invent new ethical ways oflife, and new models for self and society, are bound to each other by sharing an existential ethical perspective. The various sets of women's freedom practices, in a plurality of 'keys' and contexts, likewise connect out of their sharing this perspective, and their goal of women's access to a personal ethical life project within their communities. A feminism in a new key in world perspective, comprises all kinds of culturally plural support between women's various freedom practices, as is, for instance, illustrated by the cross-cultural feminist media strategies that emerged over the past years (cf. Chapter 3). An example related to politics in the stricter sense is the coalition that developed over the past years in Morocco between secular and Islamic feminists in a campaign for 
the reform of the family law (cf. Ennaji, Sadiqi, and Vintges 2016). Sadiqi (2006) concludes that this 'unique combination of activism by secular and religious women' greatly contributed to the coming about of the new family law in 2004, which involves real progress for women in Morocco. ${ }^{2}$

Moroccan scholar Yafout comments:

It's true that the view from the outside is that the two feminisms in Morocco still see each other as enemies. But when you use the word enemy, politics comes into play: in Morocco it's politics that does not want the various strands of Moroccan life to unite. There is always a politics that wants to divide and rule and that contributes to confrontations. But seen from another, more positive point of view, the two feminism learn a lot from each other (Yafout 2013; cf. Yafout 2015).

The coalitions between religious and secular feminists in Morocco, involve new perspectives not only for future developments in Morocco but also in a wider sense.

An earlier example of such a coalitional politics is Beauvoir's defence of Muslim women during the Algerian war of independence (1954-1962). Beauvoir sided with the Algerian National Liberation Front (FLN), which directed the war for Algeria's independence against French colonialism - a struggle that, to her, was comparable to the struggle of the resistance movement against Nazism during the Second World War. In her autobiography, Beauvoir expresses her outrage and shame about the French army's systemic use of torture against the population in Algeria, and about the daily hostility towards the population of 200,000 Algerian Muslims living in France (Beauvoir 1968b: passim). As Julien Murphy (1995) comments, 'Beauvoir understood her situation in light of anti-Muslim racism. By the time her thoughts were drawn to the Algerian war, she had visited America, felt her whiteness in Harlem, and seen American apartheid, which she spoke out against in America Day by Day. She was appalled by the widespread chauvinism and the depth of racism in France' (Murphy 1995: 289). She urgently wished to do something and focused on the position of women in the Algerian war, especially on the disparate treatment of female prisoners who were routinely raped by paratroopers and soldiers (cf. 270-271).

2 Sadiqi (2006) summarizes that the law 'mandates full equality between men and women as "head of household," full authority for state courts in matters of divorce, creation of special family courts, and the possibility of maternal custody in the event of divorce.' For further discussion of the substantial reforms that took place, see: Souad Eddouada (2008). 
Beauvoir acted on behalf of, among others, Jacqueline Guerroudj-Netter, her former student in Rouen, who was sentenced to death for her involvement in the Algerian independence struggle. ${ }^{3}$ Invited by lawyer Gisèle Halimi, she contributed to the defence of Algerian Muslim woman Djamila Boupacha, who was an active member of the FLN. Boupacha was accused of having planted a bomb at the center of Algiers, an action that she after several weeks of imprisonment and torture confessed, but afterwards denied. Beauvoir, in defence of Boupacha, wrote a polemic article in Le Monde in June 1960, formed a political action committee, and contributed to a book compiled by Halimi on behalf of Boupacha's case.

Beauvoir never met Boupacha in person, but, as Murphy states, together with Halimi, they formed a successful alliance, all three being 'middle-class and French educated, but of different religious backgrounds, Christian, Jewish, and Muslim respectively' (274). They educated the men of France about the significance of rape and succeeded in postponing Boupacha's trial, until she was released from prison in 1962 under the Evian treaty. Presiding over the Djamila Boupacha committee, Beauvoir in a 'transnational feminist gesture,' demanded attention to the 'gendered violence' by the French military against women, i.e. the use of rape as a weapon of war (Khanna 2008: 90, 81). ${ }^{4}$

When Boupacha was released from prison and was taken against her will to Algeria by the FLN, Halimi asked Beauvoir to again speak up for Boupacha. Beauvoir refused, however, arguing that as a French intellectual she had no right to intervene in the movement's decisions. In her memoirs, Halimi expresses her disappointment about Beauvoir, who, according to her, acted as an 'entomologist' rather than a sister-in-arms.

Kruks (2012), however, argues that Beauvoir was always keenly aware of her privileged situation as a white, middle-class person, and struggled with the dilemma of how to act on behalf of oppressed others without reaffirming her own privilege, or being selfish and hypocritical. She did not try 'to immerse herself in the lived experience of Algerians,' but, aware of her privileged status, she learned to deploy it as a basis for effective, public, political

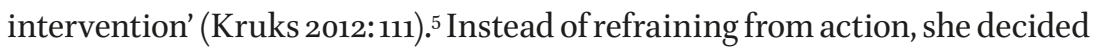

3 Her daughter Djamila Amrane - who was also sentenced to death for her FLN-activism published a study on the role of women in the Algerian war (Amrane 1991).

4 Cf. the Telefilm Pour Djamila, by Caroline Huppert (2014).

5 Mary Caputi (2006), in a discussion of Halimi's critique on Beauvoir, argues that Beauvoir's actions demonstrated sensitivity to oppression, as well as a conviction that she had to intervene on behalf of those struggling against injustice (Caputi 2006:121). Beauvoir primarily wished for a recognition of Boupacha's suffering. She did not meet Boupacha since 'what was needed was not more knowledge of her situation but a response to it' (123). 
to take responsibility for her own 'identity' (103; cf. Harding 1991: 290), by making Boupacha visible as a concrete person to the French public: her interventions in Boupacha's cause were directed to her own countrymen. ${ }^{6}$

To Lugones and Spelman (1983), a non-imperialist feminism requires friendship, instead of ready-made theories to frame women's lives. Only from within friendship can a mutual understanding and dialogue take place that does not reduce women to an abstract category, but rather can lead to 'joint theory-making' (Lugones and Spelman 1983: 581). The same often applies to joint practices, as is clear from the examples of cross-cultural feminist media strategies discussed in the previous chapter. From my own cooperation and discussions with orthodox believing women from different backgrounds, mutual understanding and sympathy for each other can overcome boundaries of national and ethnic descent in ways that rational discourse cannot. However, support is possible as well on other grounds, as is illustrated by Beauvoir's actions.

During the Khomeini revolution in Iran, Beauvoir, in March 1979, delivered a speech at a press conference in Paris, on the eve of a trip to Iran by an international women's delegation, in response to calls for help from a large number of Iranian women to international feminists. In her speech, Beauvoir summarized that the first task of the women's delegation was to acquire information concerning the struggle of Iranian women, communicating that information, and supporting their struggle. She concluded: 'I repeat that this matter is essentially an effort of gathering information, an information gathering mission in order to put ourselves in contact with Iranian women, in order to know their demands and the ways in which they plan to struggle' (Beauvoir 2015e: 269). She emphasized the need to support Iranian women from their point of view, instead of imposing a Western feminist perspective.

While feminism in world perspective consists of a set of distinct freedom practices, to Beauvoir they share the task of 'the transformation of society along with the transformation of women's place in it' (Schwarzer 1984:116). According to her, 'the successes of some few privileged women neither compensate for nor excuse the systematic degrading of the collective level' (Beauvoir 2010:154). For women's social and political status to really change, according to her, we need societies that accept responsibility for the raising of children and that provide conditions like free childcare, parental leave,

6 Beauvoir was disappointed about the situation of women in Algeria, after the independence. She states: 'Fanon thought they would become emancipated after the Algerian war. On the contrary, they have been crushed' (Moorehead 1974: 32; quoted in Murphy 1995: 203). 
equal chances, and equal pay (cf. 776-777). At several points in The Second Sex, Beauvoir hints at the necessity for societies to move in a socialist direction in order to provide these conditions. ${ }^{7}$ But she immediately adds that this has to be a new kind of socialism (cf. 68). State-socialist regimes have never done what they promised: modifying women's economic situation is not enough. Instead, for a real transformation '(e)verything would change - ideologies, myths, relationships between spouses and within each person, between parents and children and between everyone and society' (Beauvoir 2015c: 94).

Today, many women still get fired as soon as they get pregnant - meaning that their temporary contracts of employment 'unfortunately cannot be renewed'. Women moreover do most of the unpaid domestic and care work. Social security and social organization of care work are important causes for feminism; not because all women are care-takers per se, but because they are most at risk of being reduced to their caring role as soon as they have children. Today, arguments for a society that accepts its responsibility for care work are more important than ever, in view of the excessive and competitive working conditions of the pitiless rat-race that is the world market, and in view of the current neoliberal dismantling of the welfare state in the West.

To push and elaborate Beauvoir's argument in The Second Sex in this respect, I turn to Foucault's concept of a new kind of social security. Foucault criticized socialism for offering no alternative to the statist kind of governmentality that controls and manages the whole social body. While Daniel Zamora and Michael Behrent (2016) argue that he turned to neoliberalism as an alternative for stifling governmental regimes, Foucault, in fact, conceived of neoliberalism in similar terms - namely, as a coercive governmental regime that, in indirect ways, manipulates people with behavioural techniques into acting as a competitive entrepreneurial self in all domains of life (cf. Chapter 2).

Dean (2014) more adequately captures Foucault's trajectory, arguing that Foucault looked 'into the liberal and neoliberal political repertoire to find ways of renovating social democratic or socialist politics and escaping its perceived fatal statism' (Dean 2014: 437). ${ }^{8}$

7 She later specified that a socialist development is a necessary but not sufficient condition for the achievement of gender equality, and emphasized the importance of an independent women's movement (cf. Schwarzer 1984).

8 As is also clear from Foucault's desire to write a book on the art of government and socialist politics (cf. 437; cf. Foucault 2008: 100 n. 53). 
Foucault, in a 1983 interview on the social security system in France (Foucault 1988), talks about the problems of the current social security system as having the 'perverse effects' of an 'increasing rigidity of certain mechanisms' and a 'growth of dependence' arising from people's integration in the social security system itself (Foucault 1988:160, 162). As an alternative, he hints at a synthesis of people's 'lifestyles' and the functioning of social security, so as to attain the aim of 'optimal social security combined with maximum independence' (165). But this involves us undertaking a 'process of decentralization' and 'transform[ing] the field of social institutions into a vast experimental field [...] to get the desired change' (165; cf. Dean 2014: 437). Synthesizing social security schemes with people's (sets of) personal ethical ways of life, or 'freedom practices', is the perspective that Beauvoir also hints at when she argues for a new kind of 'democratic socialism where classes would be abolished but not individuals' (Beauvoir 2010: 69).

Today, a plurality of, often trans-local, grassroots movements, as social laboratories are creating alternatives to dominant neoliberal models of self and society. Countless cooperatives and community-based organizations are to be found across continents 'that cover every aspect of modern life', from food sovereignty i.e. local food production and consumption, fair trade, and global water justice to health care, housing, caring for the environment, north-south trade relationships, non-violent dispute resolution, helping immigrants and refugees, education' (Tully 2009:25). For these 'cooperative citizens,' the ethical norm is 'being the change,' and to them 'means and ends are one and the same' (25). Cooperative citizens, do not wait for governments or for a world revolution, but bring new alternatives into being here and now, 'step by ethical step', linking words and deeds, in line with Foucault's preferred concept of critique and political action (cf. 24; cf. Chapter 2).

Feminists partake in many of these movements, but also have their own relatively independent freedom practices that develop practical ethical alternatives for self and society. ${ }^{9}$ Feminists, from their own perspectives, contribute to astute analyses of current global power configurations (for an

9 While globalized, state and market 'feminisms' activate and skill women to become an entrepreneurial self, integrated into neoliberal capitalism, they may attribute to the destroying of indigenous life forms and economies. Feminism in a new key as a set of culturally plural freedom practices may contribute to the development of alternative, solidarity economies, based on cooperation, equality and sustainability. Within neoliberal market systems once established, openings can be found as well, in that, as Foucault suggested, the 'growth of capabilities' of people can be disentangled from dominant power regimes, authoritarian systems and disciplinary structures (cf. Foucault 1997e: 317; 1997c: 260), and 'exceed the framing of the original activity' (cf. Heyes 2007: 67). 
excellent example see Cornwall et al. 2008), and to achieving new societal and economic alternatives that synthesize collective and personal ethical dimensions. A feminism in a new key draws from women's multiple freedom practices, but also from feminisms of the past, re-interpreting them as critically creative freedom practices that comprise new ethical models for selves and societies, and for the world - without taking on board their essentialist claims. ${ }^{10}$ From this perspective, women's transnational peace movements from the past can be an inspiration for our times.

10 Ahmed (1992) concludes that mainstream Western, 'still-colonial,' feminism should be turned into 'a feminism that is vigilantly self-critical and aware of its historical and political situatedness' (Ahmed 1992: 247). Only then can feminism, rather than serving Western interests, contribute to a common human enterprise, by developing some criteria - out of its passionate commitment to the realization of societies that 'enable women to pursue without impediment the full development of their capacities and to contribute to their societies in all domains' (248). 


\section{Bibliography}

Abbeysbooks (n.d.). Personal blog, http://twilightirruption.blogspot.nl/?zx=efb905403548b8fb (last accessed, 21 September 2016).

—. 2013. 'Stephenie Meyer does not like Twilight.' http://www.crushable.com/2013/08/14/ entertainment/stephenie-meyer-does-not-like-twilight/ comment section (last accessed, 21 September 2016).

Abu-Lughod, Leila. 1986. Veiled Sentiments: Honor and Poetry in a Bedouin Society. Berkeley: University of California Press.

—. 2002. 'Do Muslim Women Really Need Saving? Anthropological Reflections on Cultural Relativism and Its Others.' American Anthropologist, 104:3, 783-790.

Afary, Janet and Kevin Anderson. 2005. Foucault and the Iranian Revolution. Chicago: Chicago University Press.

Ahmed, Leila. 1989. 'Feminism and Cross-Cultural Inquiry: The Terms of the Discourse in Islam.' In: E. Weed (ed.) Coming to Terms: Feminism, Theory, Politics. New York, London: Routledge, 143-151.

- 1992. Women and Gender in Islam: Historical Roots of a Modern Debate. New Haven: Yale University Press.

-.1999. A Border Passage:From Cairo to America:A Woman's Journey. New York: Penguin Books.

Akdeniz, Yaman. 2008. Internet Child Pornography and the Law. Aldershot: Ashgate.

Alcoff, Linda. 2006. Visible Identities: Race, Gender and the Self. New York: Oxford University Press.

Al-Hibri, Azizah. 2014. Islamic Worldview: Islamic Jurisprudence, An American Muslim Perspective, Vol. ı. Chicago: ABA Book Publishing.

Altman, Meryl. 2007. 'Beauvoir, Hegel, War.' Hypatia, 22:3, 66-91.

Amin, Qasim. 2000 [1899]. The Liberation of Women and The New Woman: Two Documents in the History of Egyptian Feminism. S. Peterson (trans.). Cairo: The American University in Cairo Press.

Amrane, Djamila. 1991. Les femmes algériennes dans la guerre. Paris: Plon.

Anderson, Benedict. 1983. Imagined Communities: Reflections on the Origin and Spread of Nationalism. London: Verso.

Anderson, Elizabeth. 2009. 'Toward a Non-Ideal, Relational Methodology for Political Philosophy: Comments on Schwartzman's Challenging Liberalism.' Hypatia, 24:4, 130-145.

Andreu, Nuria and Karen Vintges. 2013. Moroccan Women Today: New Perspectives. Documentary. https://www.youtube.com/watch?v=Fbj5-pTQ7aw ( last accessed, 21 September 2016). Subtitled in Dutch. https://www.youtube.com/watch?v=h4OoQlNDKkE (last accessed, 21 September 2016).

Anwar, Zainah and Rose Ismail. 2012. 'Amina Wadud and Sisters in Islam: A Journey towards Empowerment.' In: K. Ali, J. Hammer and L. Silvers (eds) A Jihad for Justice: Honoring the Work and Life of Amina Wadud, 63-72. Boston University Website. http://www.bu.edu/religion/ files/2010/03/A-Jihad-for-Justice-for-Amina-Wadud-2012-1.pdf(last accessed, 21 September 2016).

Appadurai, Arjun. 1990. Disjuncture and Difference in the Global Cultural Economy. Middlesbrough: Theory, Culture and Society.

-. 2012. 'Toward a Politics of Representation beyond Hegemonic Neoliberalism: The European Romani Movement Revisited.' Citizenship Studies, 16:2, 287-296.

Badinter, Elisabeth. 2011. 'Elisabeth Badinter: Un peu de kantisme dans notre societé serait bienvenu.' Le Monde. 28 September.

Badiou, Alain. 2004. 'Behind the Scarfed Law, there is Fear.' IslamOnline.net. 3 March. http://www.lacan.com/islbad.htm (last accessed, 21 September 2016). 
Badran, Margot. 2009. Feminism in Islam: Secular and Religious Convergences. Oxford: Oneworld Publications.

Bakare-Yusuf, Bibi. 2003. “'Yorubas Don't Do Gender”: A Critical Review of Oyeronke Oyewumi's The Invention of Women: Making an African Sense of Western Gender Discourses.' African Identities, 1:1, 121-142.

Bao, Ai-Min and Dick Swaab. 2011. 'Sexual Differentiation of the Human Brain: Relation to Gender Identity, Sexual Orientation and Neuropsychiatric Disorders.' Frontiers in Neuroendocrinology, 32:2, 214-226.

Barlas, Asma. 2002. 'Believing Women' in Islam: Unreading Patriarchal Interpretations of the Qur'an. Austin: University of Texas.

—. 2008a. 'Engaging Islamic Feminism: Provincializing Feminism as Master Narrative.' In: A. Kynsilehto (ed.) Islamic Feminism: Current Perspectives. Tampere: Tampere Peace Research Institute, $15^{-24}$.

- 2008b. Interview with Asma Barlas, by Laura Groeneveld. NL Next. http://www.maroc.nl/ forums/show thread.php?t=248172\&goto=firstpost (last accessed, 21 September 2016).

—.2016. 'Secular and Feminist Critiques of the Qur'an: Anti-hermeneutics as Liberation?' Journal of Feminist Studies in Religion. Vol. 32: 2, 111-121.

Baron-Cohen, Simon. 2003. The Essential Difference: Men, Women and the Extreme Male Brain. London: Allen Lane.

Bartky, Sandra Lee. 1988. 'Foucault, Femininity, and the Modernization of Patriarchal Power.' In: I. Diamond and L. Quinby (eds) Feminism and Foucault: Reflections on Resistance. Boston: Northeastern University Press, 63-64.

-1990. Femininity and Domination: Studies in the Phenomenology of Oppression. New York: Routledge.

Bascom, William. 1965. 'The Forms of Folklore: Prose Narratives.' The Journal of American Folklore, 78:307, 3-20.

Batliwala, Srilatha. 2007. 'Taking the Power out of Empowerment - An Experiential Account.' Development in Practice, 17:4\&5, 557-765.

Bauer, Nancy. 2001. Simone De Beauvoir, Philosophy and Feminism. New York: Columbia University Press.

—. 2015. How to Do Things with Pornography. Cambridge, London: Harvard University Press.

Beauvoir, Simone de. 1947. Pour une morale de l'ambiguité. Paris: Gallimard.

- 1948. The Ethics of Ambiguity. Frechtman, B. (trans.). New York: Philosophical Library.

-.1968a. Les Belles Images. O'Brian, P. (trans.) London: Collins.

- 1968b. Force of Circumstance. Harmondsworth: Penguin.

-. 1971. The Woman Destroyed. London: Fontana/Collins.

-.1988. All Said and Done. Harmondsworth: Penguin.

—.1999. America Day by Day. Berkeley: University of California Press.

-. 2005. The Mandarins. New York: Harpercollins Publishers.

-. 2010. The Second Sex. Borde, C., and S. Malovany-Chevallier (eds) New York: Alfred A. Knopf.

-. 2011. 'Misunderstanding in Moscou.' In: Simons, M. and M. Timmermann (eds). “The Useless Mouths," and Other Literary Writings. Urbana: University of Illinois Press, 219-274.

—. 2012. 'Must we Burn Sade?' In: Simons, M., M. Timmermann (eds) Simone de Beauvoir: Political Writings. Urbana, Chicago and Springfield: University of Illinois Press, 37-102.

- 2015a. 'A Review of Elementary Structures of Kinship by Claude Lévi-Strauss.' In: Simons, M., M. Timmermann (eds) Simone de Beauvoir: Feminist Writings. Urbana, Chicago and Springfield: University of Illinois Press, 58-66. 
—. 2015b. 'It's about Time Women Put a New Face on Love.' In: Simons, M., M. Timmermann (eds) Simone de Beauvoir: Feminist Writings. Urbana, Chicago and Springfield: University of Illinois Press, 76-80.

- 2015c. 'The Condition of Women.' In: Simons, M., Timmermann, M. (eds) Simone de Beauvoir: Feminist Writings. Urbana, Chicago and Springfield: University of Illinois Press, 88-96.

—.2015d. 'Brigitte Bardot and the Lolita Syndrome.' In: Simons, M., Timmermann, M. (eds) Simone de Beauvoir: Feminist Writings. Urbana, Chicago and Springfield: University of Illinois Press, 114-125.

- 2015e. 'Press Conference of the International Committee for Women's Rights.' In: Simons, M., M. Timmermann (eds) Simone de Beauvoir: Feminist Writings. Urbana, Chicago and Springfield: University of Illinois Press, 268-269.

Belil, Samira. 2003. Dans l'enfer des tournantes. Paris: Gallimard.

Bell, Britt. 2000. Betzy Akersloot-Berg: 1850-1922 Zeeschilderes. Franeker: Uitgeverij van Wijnen.

Benhabib, Seyla. 1987. 'The Generalized and the Concrete Other.' In: E. Kittay and D. Meyers (eds) Women and Moral Theory. Totowa: Rowman \& Littlefield, 154-177.

Benschop, Yvonne and Marieke van den Brink. 2012. 'Slaying the Seven-Headed Dragon: The Quest for Gender Change in Academia.' Gender, Work and Organization, 19:1, 71-92.

Bergoffen, Debra. 1997. The Philosophy of Simone de Beauvoir: Gendered Phenomenologies, Erotic Generosities. Albany: State University of New York.

Bettelheim, Bruno. 1976. The Uses of Enchantment: The Meaning and Importance of Fairy Tales. New York: Alfred A. Knopf.

Bilgrami, Akeel. 2014. Secularism, Identity, andEnchantment. Cambridge: Harvard University Press.

Bloem, Jeannette. 2004. 'The Shaping of a "Beautiful" Soul: The Critical Life of Anna Maria van Schurman.' In: D. Taylor and K. Vintges (eds) Feminism and the Final Foucault. Urbana: University of Illinois Press, 15-27.

- 2012. 'Anna Maria van Schurman.' In: C. Ceton, A. Halsema, I. van der Burg, K. Vintges and V. Vasterling (eds) Vrouwelijke filosofen: Een historisch overzicht. Amsterdam: Atlas, 195-201.

Boddy, Janice. 1989. Wombs and Alien Spirits: Women, Men, and the Zār Cult in Northern Sudan. Madison: University of Wisconsin Press.

Bonjour, Saskia and Doutje Lettinga. 2012. 'Political Debates on Islamic Headscarves and Civic Integration Abroad in France and the Netherlands: What Can Models Explain?' Journal of Immigrant \& Refugee Studies, 10:3, 260-278.

Borren, Marieke. 2013. 'Feminism as Revolutionary Practice: From Justice and the Politics of Recognition to Freedom.' Hypatia, 28:1, 197-214.

Boulé, Jean-Pierre and Ursula Tidd. 2012. 'Introduction.' In:J.P. Boulé and U. Tidd (eds) Existentialism and Contemporary Cinema:A Beauvoirian Perspective. New York, Oxford:Berghahn Books, 1-16.

Bovenkerk, Frans. 2014. Marokkaan in Europa, crimineel in Nederland. Een vergelijkende studie. Amsterdam: Boom Lemma Uitgevers.

Bowen, John. 2008. Why the French Don't Like Headscarves: Islam, the State, and Public Space. Princeton: Princeton University Press.

Bracke, Sarah. 2007. Women Resisting Secularisation in an Age of Globalisation. Four Case-studies within a European Context. PhD Thesis, Universiteit van Utrecht.

- 2011. 'Subjects of Debate: Secular and Sexual Exceptionalism, and Muslim Women in the Netherlands.' Feminist Review, 98:1, 28-46.

Braidotti, Rosi and Rick Dolphijn. 2015. 'Deleuze's Philosophy and the Art of Life or: What Does Pussy Riot Know?' In: R. Braidotti and R. Dolphijn(eds) This Deleuzian Century: Art, Activism, Life. Leiden: Brill, 13-36. 
Brouwer, Lenie and Edien Bartels. 2014. 'The Arab Spring in Morocco: Social Media and the 20 February Movement.' Afrika Focus, 27:2, 9-22.

Brown, Wendy. 2015. Undoing the Demos:Neoliberalism's Stealth Revolution. New York:Zone Books. Bucciferro, Claudia. 2013. The Twilight Saga: Exploring the Global Phenomenon. Lanham: Scarecrow Press.

Buitelaar, Marjo. 2006. "I am the Ultimate Challenge." Accounts of Intersectionality in the Life-Story of a Well-Known Daughter of Moroccan Migrant Workers in the Netherlands.' European Journal of Women's Studies, 13:3, 259-276.

—. 2014. 'Discovering a Different Me." Discursive Positioning in Life Story Telling Over Time.' Women's Studies International Forum, 43:3, 30-37.

Butler, Judith. 1990. Gender Trouble: Feminism and the Subversion of Identity. London, New York: Routledge.

—. 2000. Antigone's Claim:Kinship between Life and Death. New York: Columbia University Press.

Caputi, Mary. 2006. 'Acting on Behalf of the Other: Simone de Beauvoir and the Case of Djamila Boupacha.' In: P. Moynagh and L. Marso (eds) Simone de Beauvoir's Political Thinking. Urbana, Chicago and Springfield: The University of Illinois Press, 109-126.

Carrette, Jeremy. 200o. Foucault and Religion: Spiritual Corporality and Political Spirituality. London: Routledge.

Ceton, Carolien, Annemie Halsema, Ineke van der Burg, Karen Vintges and Veronica Vasterling (eds). 2012. Vrouwelijke filosofen: Een historisch overzicht. Amsterdam: Atlas.

Chakravarti, Uma. 1998. Rewriting History: The Life and Times of Pandita Ramabai. New Delhi: Zubaan.

Christman, John. 1988. 'Constructing the Inner Citadel: Recent Work on the Concept of Autonomy.' Ethics, 99:1, 109-124.

Coleman, Isobel. 2010. Paradise beneath Her Feet: How Women Are Transforming the Middle East. New York: Random House.

Collier, Stephen. 2009. 'Topologies of Power: Foucault's Analysis of Political Government Beyond “Governmentality."' Theory, Culture \& Society. 26: 6, 78-108.

Connell, Raewyn. 2009. Gender: In World Perspective. Cambridge, Malden: Polity Press.

Cooke, Miriam. 2001. Women Claim Islam: Creating Islamic Feminism through Literature. New York: Routledge.

Cooper, Anna Julia. 1892. A Voice from the South. Xenia, Ohio: The Aldine Printing Company.

Cornwall, Andrea, Jasmine Gideon and Kalpana Wilson. 2008. 'Introduction: Reclaiming Feminism: Gender and Neoliberalism.' IDS Bulletin, 39:6, 1-9.

Crenshaw, Kimberlé. 1991. 'Mapping the Margins: Intersectionality, Identity Politics, and Violence against Women of Color.' Stanford Law Review, 43:6, 1241-1299.

Crul, Maurice. 2008. The Second Generation in Europe: Three Questions about Integration. Keynote Lecture at the 13th International Metropolis Conference in Bonn, Germany. 30 October.

Dabashi, Hamid. 2012. The Arab Spring: The End of Postcolonialism. London: Zed Books.

Davidson, Arnold. 199o. 'Spiritual Exercises and Ancient Philosophy: An Introduction to Pierre Hadot.' Critical Inquiry, 16:3, 475-482.

—.1994. 'Ethics as Ascetics: Foucault, the History of Ethics and Ancient Thought,' In:J. Goldstein (ed.) Foucault and the Writing of History. Oxford, UK \& Cambridge, MA: Blackwell Publishers, $63-80$.

-.2005. 'Introduction.' In: F. Gros (ed.) Michel Foucault: The Hermeneutics of the Subject. Lectures at the Collège de France 1981-1982. New York: Picador, xix-xxx. 
Davis, Kathy. 1995. Reshaping the Female Body: The Dilemma of Cosmetic Surgery. New York: Routledge.

—. 2003. 'Surgical Surpassing: Or why Michael Jackson's Nose makes “us” Uneasy.' Feminist Theory, 4:1, 73-92.

De Jong, Jan Dirk. 2007. Kapot moeilijk: Een etnografisch onderzoek naar opvallend delinquent groepsgedrag van 'Marokkaanse' jongens. Amsterdam: Aksant.

De Rougemont, Denis. 1956. Love in the Western World. New York: Pantheon Books.

Dean, Mitchell. 2014. 'Michel Foucault's “Apology” for Neoliberalism.' Journal of Political Power, $7: 3,433-442$.

Descombes, Vincent. 1980. Modern French Philosophy. Cambridge: Cambridge University Press.

Diamond, Irene and Lee Quinby (eds). 1988. Feminism \& Foucault: Reflections on Resistance. Boston: Northeastern University Press.

Dix, Guus. 2014. 'Governing by Carrot and Stick: A Genealogy of the Incentive.' PhD Thesis, University of Amsterdam.

Donzelot, Jacques and Colin Gordon. 2008. 'Interview: Governing Liberal Societies - The Foucault Effect in the English-Speaking World.' Foucault Studies, 5, 48-62.

Dryzek, John, Bonnie Honig, and Anne Phillips. 2006. 'Introduction.' The Oxford Handbook of Political Theory. Oxford: Oxford University Press, 3-41.

Duby, Georges and Michelle Perrot (eds). 1992-1994. History of Women in the West (5 vols). Cambridge: Harvard University Press.

Duits, Linda and Liesbet Van Zoonen. 2006. 'Headscarves and Porno-Chic: Disciplining Girls' Bodies in the European Multicultural Society.' European Journal of Women's Studies, 13, 103-117.

Dwyer, Daisy. 1978. Images and Self-images: Male and Female in Morocco. New York: Columbia University Press.

Eddouada, Souad. 2008. 'Implementing Islamic Feminism: The Case of Moroccan Family Code Reform.' In: A. Kynsilehto (ed.) Islamic Feminism: Current Perspectives. Tampere: Tampere Peace Research Institute, 37-46.

Edwards, Kim. 2009. 'Good Looks and Sex Symbols: The Power of the Gaze and The Displacement of the Erotic in Twilight.' Screen Education, 53, 26-32.

Eisenstein, Hester. 2009. Feminism Seduced. How Global Elites Use Women's Labour and Ideas to Exploit the World. Boulder: Paradigm Publishers.

El-Guindi, Fadwa. 1999. Veil: Modesty, Privacy and Resistance. Oxford: Berg Publisher.

Eliot, Lise. 2009. Pink Brain, Blue Brain: How Small Differences Grow into Troublesome Gaps - And What We Can Do About it. Boston: Houghton Mifflin Harcourt.

Ember, Carol. 1978. 'Myths about Hunter-Gatherers.' Ethnology, 17:4, 439-448.

Ennaji, Moha and Fatima Sadiqi. 2006. 'The Feminization of Public Space: Women's Activism, the Family Law, and Social Change.' Journal of Middle East Women's Studies, 2: 2, 86-114.

Ennaji, Moha, Fatima Sadiqi, and Karen Vintges (eds). 2016. Moroccan Feminisms: New Perspectives. Trenton: Africa World Press.

Ferguson, Kathy. 2004. 'E.G.: Emma Goldman, For Example.' In: D. Taylor and K. Vintges (eds) Feminism and the Final Foucault. Urbana: University of Illinois Press, 28-40.

- 2011. Emma Goldman: Political Thinking in the Streets. Lanham: Rowman and Littlefield.

Fernea, Elizabeth Warnock. 1998. In Search of Islamic Feminism: One Woman's Global Journey. New York: Doubleday.

Foucault, Michel. 1970. The Order of Things: An Archaeology of the Human Sciences. London: Tavistock Publications. 
-.1972. The Archaeology of Knowledge and the Discourse on Language. New York: Pantheon Books.

-. 1979. Discipline and Punish: The Birth of the Prison. New York, Toronto: Vintage Books.

- 1986a. The Use of Pleasure. Harmondsworth: Penguin.

-. 1986b. The Care of the Self. Harmondsworth: Penguin.

-. 1988. 'Social Security.' In: L. Kritzman (ed.) Politics, Philosophy, Culture. Interviews and other writings 1977-1984. New York: Routledge, 159-177.

- 1989. 'An Aesthetics of Existence'. In: S. Lotringer (ed.) Foucault live: Collected Interviews 1961-1984. New York: Semiotext(e), 450-544.

-. 1997a. 'Sex, Power, and the Politics of Identity.' In: P. Rabinow and J. Faubion (eds) Ethics, Subjectivity and Truth: Essential Works of Foucault 1954-1984, Vol. ı. New York: The New Press, 163-174.

-.1997b. 'Technologies of the Self' In: P. Rabinow and J. Faubion (eds) Ethics, Subjectivity and Truth: Essential Works of Foucault 1954-1984, Vol. 1. New York: New Press, 223-251.

-.1997c. 'On the Genealogy of Ethics: An Overview of Work in Progress.' In: P. Rabinow and J. Faubion (eds) Ethics, Subjectivity and Truth:Essential Works of Foucault 1954-1984, Vol. 1. New York: The New Press, 253-280.

- 1997d. 'The Ethics of the Concern for Self as a Practice of Freedom.' In: P. Rabinow and J. Faubion (eds) Ethics, Subjectivity and Truth: Essential Works of Foucault 1954-1984, Vol. 1. New York: The New Press, 281-301.

-. 1997e. 'What is Enlightenment?' In: P. Rabinow and J. Faubion (eds) Ethics, Subjectivity and Truth: Essential Works of Foucault 1954-1984, Vol. 1. New York: The New Press, 303-319.

—. 1999. 'Michel Foucault and Zen: A Stay in a Zen Temple.' In: J. Carrette (ed.) Religion and Culture by Michel Foucault. Manchester: Manchester University Press, 110-114.

—. 2000. 'The Subject and Power.' In:J. Faubion (ed.) Power: Essential Works of Foucault 1954-1984, Vol. 3. New York: The New Press, 326-349.

-. 2001. Fearless Speech. J. Pearson (ed.). Los Angeles: Semiotext(e).

-. 2003. Society Must Be Defended. Lectures at the Collège de France 1975-76. M. Bertani and A. Fontana (eds) New York: Picador.

-. 2005a. Michel Foucault: The Hermeneutics of the Subject. Lectures at the Collège de France 1981-1982. F. Gros (ed.). New York: Picador.

- 2005b. 'What are the Iranians Dreaming About?' In:J. Afary and K. Anderson (eds) Foucault and the Iranian Revolution. Chicago: The University of Chicago Press, 203-209.

—. 2005c. 'Iran: The Spirit of a World without Spirit.' In:J. Afary and K. Anderson (eds) Foucault and the Iranian Revolution. Chicago: The University of Chicago Press, 250-26o.

-. 2005d. 'Is it Useless to Revolt?' In: J. Afary and K. Anderson (eds) Foucault and the Iranian Revolution. Chicago: The University of Chicago Press, 263-267.

-. 2006. The Will to Knowledge (vol. 1 ). London: Penguin.

- 2007a. Security, Territory, Population. Lectures at the Collège de France 1977-78. M. Senellart (ed.). New York: Palgrave, 87-114.

-. 2007b. 'Subjectivity and Truth.' In: S. Lotringer, L. Hochroth (eds) The Politics of Truth. Los Angeles: Semiotext(e), 147-167.

-. 2008. The Birth of Biopolitics. Lectures at the Collège de France 1978-1979. M. Senellart, F. Ewald and A. Fontana (eds). London, New York: Palgrave Macmillan.

-. 2011. The Courage of Truth: The Government of Self and Others II. Lectures at the Collège de France 1983-1984. Houndmills, Basingstoke, Hampshire: Palgrave Macmillan.

Fraser, Nancy. 2009. 'Feminism, Capitalism and the Cunning of History.' New Left Review 5 6, 98-117. 
Galster, Ingrid. 2004. Simone de Beauvoir: Le deuxième sexe. Le livre fondateur du féminisme moderne en situation. Paris: Éditions Champion.

Giere, Ronald. 2006. Scientific Perspectivism. Chicago: University of Chicago Press.

Gill, Rosalind. 2007. 'Critical Respect: The Difficulties and Dilemmas of Agency and "Choice” for Feminism: A Reply to Duits and Van Zoonen.' European Journal of Women's Studies, 14:1, 69-8o.

- 2008. 'Culture and Subjectivity in Neoliberal and Postfeminist Times.' Subjectivity, 25, $432-445$.

-. 2009. 'Breaking the Silence: The Hidden Injuries of Neo-Liberal Academia.' In: R. Flood and R. Gill (eds) Secrecy and Silence in the Research Process: Feminist Reflections. London: Routledge, 228-244.

Gill, Rosalind and Christina Scharff (eds). 2011. New Femininities: Postfeminism, Neoliberalism and Subjectivity. London: Palgrave Macmillan,

Gill, Rosalind and Ngaire Donaghue. 2016. 'Resilience, Apps and Reluctant Individualism: Technologies of Self in the Neoliberal Academy.' Women's Studies International Forum, Vol. 54, 91-99.

Gines, Kathryn. 2010. 'Sartre, Beauvoir, and the Race / Gender Analogy: A Case for Black Feminist Philosophy.' In: M. Del Guadalupe Davidson, K. Gines, and D. Marcano (eds) Convergences: BlackFeminism and Continental Philosophy. Albany: State University of New York Press, 35-52.

Goffman, Erving. 1976. Gender Advertisements. New York: Harper \& Row.

Göle, Nilüfer. 1996. The Forbidden Modern: Civilization and Veiling. Ann Arbor: University of Michigan.

Gordon, Lewis. 2008. An Introduction to Africana Philosophy. Cambridge: Cambridge University Press.

Gottlieb, Alma. 1990. 'Rethinking Female Pollution: The Beng Case.' In: P. Sanday and R. Goodenough (eds) Beyond the Second Sex: New Directions in the Anthropology of Gender. Philadelphia: University of Pennsylvania Press, 113-138.

Gray, Jonathan. 2015. 'Dutch student protests ignite movement against management of universities.' The Guardian. 17 March. http://www.theguardian.com/higher-education-network/2015/ mar/17/dutch-student-protests-ignite-movement-against-management-of-universities (last accessed, 21 September 2016).

Gros, Frédéric. 2005. 'Course Context.' In: F. Gros (ed.) Michel Foucault: The Hermeneutics of the Subject. Lectures at the Collège de France 1981-1982. New York: Picador, 507-550.

Hadot, Pierre. 1995. Philosophy as a Way of Life: Spiritual Exercises from Socrates to Foucault. Arnold Davidson (ed.). Malden, Oxford: Blackwell.

Hakim, Catherine. 2011. Erotic Capital: The Power of Attraction in the Boardroom and the Bedroom. New York: Basic Books.

Hall, Stuart. 1973. 'Encoding and Decoding in the Media Discourse', Stencilled Paper 7, Birmingham: CCCS.

Halsema, Annemie. 2015. 'Antigone's Act. Politicizing Love and Kinship'. Paper presented at the IAPH Seminar, 12 September, Amsterdam.

Harding, Sandra. 1991. Whose Science? Whose Knowledge? Thinking from Women's Lives. Ithaca: Cornell University Press.

Hardt, Michael and Antonio Negri. 200o. Empire. Cambridge: Harvard University Press.

Harris, Kimberley Ann. 2015. 'Studying Around: The Goals of Intersectionality,' Paper presented at the Hypatia Conference, Villanova University, 28-3o May.

Harvey, Laura and Rosalind Gill. 2011. 'Spicing it up: Sexual Entrepreneurs and The Sex Inspectors.' In: R. Gill and C. Scharff (eds) New Femininities: Postfeminism, Neoliberalism and Subjectivity. London: Palgrave Macmillan, 52-67. 
Haslanger, Sally. 2000. 'Gender and Race: (What) Are They? (What) Do We Want Them To Be?' Nous, 34:1, 31-55.

Hassan, Riffat. 1987. 'Equal before Allah? Woman-Man Equality in the Islamic Tradition.' Harvard Divinity Bulletin, 7:2, 26-29.

Havis, Devonya. 2014. '“Now, How You Sound”: Considering a Different Philosophical Praxis.' Hypatia, 29:1, 237-252.

Hegel, Georg Wilhelm Friedrich. 1977 [1807]. Phenomenology of Spirit. Oxford: Oxford University Press.

Heidegger, Martin. 1962 [1927]. Being and Time. New York: Harper.

Heinämaa, Sara. 1999. 'Simone de Beauvoir's Phenomenology of Sexual Difference.' Hypatia, 14:4, 114-132.

Hermans, Hubert. 2001. 'Mixing and Moving Cultures Require a Dialogical Self.' Human Development, 44:1, 24-28.

Hesp, Anneke. 2015. Walking with Simone de Beauvoir. Amstelveen: Totemboek.

Heyes, Cressida. 2002. 'Identity Politics.' In: E. Zalta (ed.) The Stanford Encyclopedia of Philosophy (Winter 2014 Edition). http://plato.stanford.edu/archives/win2014/entries/identity-politics/ (last accessed, 21 September 2016).

-. 2007. Self-Transformations: Foucault, Ethics, and Normalized Bodies. Oxford: Oxford University Press.

Hidayatullah, Aysha. 2014. Feminist Edges of the Qur'an. New York: Oxford University Press.

Honig, Bonnie. 2008. 'What Foucault Saw at the Revolution.' Political Theory, 36:2, 301-12.

hooks, bell. 1984. Feminist Theory from Margin to Center. Boston: South End.

Huppert, Caroline. 2014. Pour Djamila. Telefilm. https://www.youtube.com/watch?v=bZ93INw PPik (last accessed 21 September 2016).

Hurd, Elizabeth Shakman. 2008. The Politics of Secularism in International Relations. Princeton: Princeton University Press.

Ibn Qunfudh al-Qusţanținī, Abū l-'Abbās Aḥmad al-Khațīb. 1965. Uns al-Faqīr wa 'Izzu al- ḥaqīr. M. Fasi wa A. Faure (eds). Rabat: Manshurāt al-Markaz al-Jāmi'ī li al-Baḥth al-'Ilmī.

Jaggar, Alison. 1983. Feminist Politics and Human Nature. Totowa: Rowman and Allanheld. Jansen, Willy. 1998. 'Contested Identities: Women and Religion in Algeria and Jordan.' In: K. Ask and M. Tjomsland (eds) Women and Islamization: Contemporary Dimensions of Discourse on Gender Relations. Oxford: Berg, 73-102.

Jansen, Yolande. 2013. Secularism, Assimilation and the Crisis of Multiculturalism. Amsterdam: Amsterdam University Press.

Joppke, Christian. 2007. 'Beyond National Models: Civic Integration Policies for Immigrants in Western Europe.' West European Politics, 31:1, 1-22.

Jordan-Young, Rebecca. 2010. Brain Storm: The Flaws in the Science of Sex Differences. Cambridge: Harvard University Press.

Judaken, Jonathan. 2008. Race after Sartre:Antiracism, Africana Existentialism, Postcolonialism. Albany: State University of New York.

Kant, Immanuel. 1948 [1785]. Groundwork of the Metaphysic of Morals. New York: Harper \& Row. Kantola, Johanna and Judith Squires. 2012. 'From State Feminism to Market Feminism?' International Political Science Review, 33:4, 382-400.

Keefe, Terry. 2011. 'Introduction.' In: M. Simons and M. Timmermann (eds) Simone de Beauvoir: "The Useless Mouths," and Other Literary Writings, 213-218. 
Khanna, Ranjana. 2008. Algeria Cuts: Women and Representation, 1830 to the Present. Stanford: Stanford University Press.

Kleinherenbrink, Annelies. 2014. 'Mapping Plasticity: Sex / Gender and the Changing Brain.' Tijdschrift voor Genderstudies, 17:4, 305-326.

Kosambi, Meera. 2003. 'Returning the American Gaze: Situating Pandita Ramabai's American Encounter.' In: Pandita Ramabai's American Encounter: The Peoples of the United States (1889). Bloomington: Indiana University Press 1-46.

Kruks, Sonia. 199o. Situation and Human Existence: Freedom, Subjectivity, and Society. London: Unwin Hyman.

-. 2001. Retrieving Experience: Subjectivity and Recognition in Feminist Politics. Ithaca, New York: Cornell University Press.

—. 2006. 'Reading Beauvoir with and against Foucault.' In: L. Marso and P. Moynagh (eds) Simone de Beauvoir's Political Thinking. Champaign: Illinois University Press, 55-71.

- 2012. Simone de Beauvoir and the Politics of Ambiguity. New York: Oxford University Press.

Kugle, Scott Siraj al-Haqq. 2010. Homosexuality in Islam: Critical Reflection on Gay, Lesbian, and Transgender Muslims. Oxford: Oneworld.

Langer, Monika. 2003. 'Beauvoir and Merleau-Ponty on Ambiguity.' In: C. Card (ed.) The Cambridge Companion to Simone de Beauvoir. Cambridge: Cambridge University Press, 87-106.

Langer, Susanne. 196o. Philosophy in a New Key: A Study in the Symbolism of Reason, Rite, and Art. Cambridge: Harvard University Press.

Lemke, Thomas. 2001. "The Birth of Bio-politics": Michel Foucault's Lecture at the Collège de France on Neo-Liberal Governmentality.' Economy and Society, 30:2, 190-207.

Lépinard, Eléonore. 2011. 'Autonomy and the Crisis of the Feminist Subject: Revisiting Okin's Dilemma.' Constellations, 18:2, 205-221.

Lévi-Strauss, Claude. 1969. The Elementary Structures of Kinship. J. Von Sturmer, J. Bell, and R. Needham (eds) Boston: Beacon.

—. 1971. 'Interview with Claude Lévi-Strauss,' Diacritics, 1:1, 44-50.

Liking, Werewere. 1981. Orphée-dafric. Paris: L'Harmattan.

—.1983. Elle sera de jaspe et de corail. Paris: L'Harmattan.

Linsenbard, Gail. 1999. 'Beauvoir, Ontology, and Women's Human Rights.' Hypatia, 14:4, 145-162. Long, Imogen. 2013. Women Intellectuals in Post-68 France. London: Palgrave Macmillan.

Longman, Chia. 2007. "A woman of valour, who can find her? Far beyond pearls is her value...” Fundaments and Feminisms in Contemporary Orthodox Judaism.' In: I. Dubel and K. Vintges (eds) Women, Feminism and Fundamentalism. Amsterdam: SWP Publishers, 40-52.

Lorde, Audre. 1984. Sister Outsider: Essays and Speeches. Bel Air: The Crossing Press.

Lugones, María and Elizabeth Spelman. 1983. 'Have We Got a Theory for You! Feminist Theory, Cultural Imperialism and the Demand for “the Woman's Voice." Women's Studies International Forum, 6:6, 573-581.

Lundgren-Gothlin, Eva. 1996. Sex and Existence: Simone de Beauvoir's “The Second Sex.” Hanover: Wesleyan University Press.

Lutz, Helma, Herrera Teresa, and Linda Supik (eds). 2011. Framing Intersectionality: Debates on a Multi-Faceted Concept in Gender Studies. Farnham, Surrey: Ashgate.

Mackenzie, Catriona. 1998. 'A Certain Lack of Symmetry: Beauvoir on Autonomous Agency and Women's Embodiment.' In: R. Evans (ed.) Simone de Beauvoir's The Second Sex: New Interdisciplinary Essays. Manchester: Manchester University Press, 122-158. 
Mackenzie, Catriona. 2014. 'Three Dimensions of Autonomy.' In: M. Piper and A. Veltman (eds) Feminism and Autonomy. New York: Oxford University Press.

Mackenzie, Catriona and Natalie Stoljar (eds). 200o. Relational Autonomy: Feminist Perspectives on Autonomy, Agency, and the Social Self. New York: Oxford University Press.

Mahmood, Saba. 2001. 'Feminist Theory, Embodiment, and the Docile Agent:Some Reflections on the Egyptian Islamic Revival.' Cultural Anthropology, 16:2, 202-236.

-. 2005. Politics of Piety: The Islamic Revival and the Feminist Subject. Princeton: Princeton University Press.

—. 2007. Interview with Saba Mahmood: Islamism and Postcolonial Politics by Shaikh, Nermeen. In: The Present as History: Critical Perspectives on Contemporary Global Power. New York: Columbia University Press, 66-100.

- . 2008. 'Feminism, Democracy, and Empire.' In: J. Scott (ed.) Women's Studies on the Edge. Durham, London: Duke University Press, 81-114.

-.2012. 'Preface to the 2012 Edition.' In: S. Mahmood. Politics of Piety: The Islamic Revival and the Feminist Subject. Princeton: Princeton University Press, ix-xix.

Mann, Bonnie. 2009. 'Vampire Love: The Second Sex Negotiates the 21st Century.' In: R. Housel et al. (eds) Twilight and Philosophy: Vampires, Vegetarians, and the Pursuit of Immortality, Hoboken, NJ: John Wiley, 131-146.

Massoumi, Narzanin. 2015. "The Muslim woman activist": Solidarity across Difference in the Movement against the "War on Terror."' Ethnicities, 15:5, 715-741.

McLaren, Margaret. 2002. Feminism, Foucault, and Embodied Subjectivity. Albany: State University of New York.

-. 2004. 'Foucault and Feminism: Power, Resistance, Freedom.' In: D. Taylor and K. Vintges (eds) Feminism and the Final Foucault. Urbana: University of Illinois Press, 214-234.

McNay, Lois. 1992. Foucault and Feminism: Power, Gender, and the Self. Boston: Northeastern University Press.

McRobbie, Angela. 2004. 'Post-feminism and Popular Culture.' Feminist Media Studies, 4:3, 255-264.

—. 2011a. 'Preface.' In: R. Gill and C. Scharff(eds) New Femininities: Postfeminism, Neoliberalism and Subjectivity. London: Palgrave Macmillan, xi-xv.

—. 2011b. 'Beyond Post-feminism.' Public Policy Research, 18:3, 179-184.

-. 2015. 'Notes on the Perfect: Competitive Femininity in Neoliberal Times.' Australian Feminist Studies, 30:83, 3-20.

McWhorter, Ladelle. 2013. 'Post-liberation Feminism and Practices of Freedom.' Foucault Studies, $16,54-73$.

Mernissi, Fatima. 1977. 'Women, Saints and Sanctuaries.' Signs, 3:1, 101-112.

-.1991. The Veil and the Male Elite: A Feminist Interpretation of Women's Rights in Islam. Reading: Addison-Wesley Pub.

-.1994. The Harem Within: Tales of a Moroccan Girlhood. New York: Basic Books.

Meuzelaar, Andrea. 2014. Seeing through the Archival Prism: A History of the Representation of Muslims on Dutch Television. PhD Thesis, University of Amsterdam.

Meyer, Stephenie. 2015. 'Foreword.' In: S. Meyer. Life and Death: Twilight Reimagined. London: Little, Brown.

Mikkola, Mari. 2013. 'Review of Sally Haslanger's Resisting Reality'. Hypatia Reviews Online. http://hypatiaphilosophy.org/HRO/reviews/content/188 (last accessed, 21 September 2016).

Miller, Peter and Nikolas Rose. 2008. Governing the Present:Administering Economic, Social and Personal Life. Cambridge: Polity.

Ministry of Social Affairs and Employment. 2013. Agenda Integratie /19-02-2013. Den Haag: Ministerie van Sociale Zaken en Werkgelegenheid. 
Mir-Hosseini, Ziba. 1999. Islam and Gender: The Religious Debate in Contemporary Iran. Princeton: Princeton University Press.

-. 2004. 'The Quest for Gender Justice - Emerging Feminist Voices in Islam.' Islam, 21:36, 2-5.

-. 2010. Understanding Islamic Feminism: Interview With Ziba Mir-Hosseini. By Yoginder Sikand. Countercurrents. Org. 7 February. http://www.countercurrents.org/sikando70210. htm (last accessed, 21 September 2016).

Mir-Hosseini, Ziba and Kim Longinotto. 1997. Divorce Iranian Style. Documentary. https://www. youtube.com/watch? $\mathrm{v}=\mathrm{BBm} 8 \mathrm{GqMNwXU}$ (last accessed, 21 September 2016).

- 2008. Runaway. Documentary. https://www.youtube.com/watch?v=MbsVbyRGqL8 (last accessed, 21 September 2016).

Mir-Hosseini, Ziba, Mulki Al-Sharmani and Jana Rumminger (eds). 2015. Men in Charge? Rethinking Authority in Muslim Legal Tradition. London: Oneworld Publications.

Moghadam, Valentine. 2005. 'The "Feminization of Poverty" and Women's Human Rights.' SHS Papers in Women's Studies / Gender Research, 2, 1-39.

Mohanty, Chandra Talpade. 1991. 'Under Western Eyes: Feminist Scholarship and Colonial Discourses.' In: C. Mohanty, A. Russo, and L. Torres (eds) Third World Women and the Politics of Feminism. Bloomington: Indiana University Press.

Moorehead, Caroline. 1974. 'A Talk with Simone de Beauvoir.' New York Times Magazine. 2 June, 32. Moors, Annelies. 2013. Islamic Fashion and Anti-Fashion:New Perspectives from Europe and North America. London: Bloomsbury Academic.

Mulvey, Laura. 1999 [1973]. 'Visual Pleasure and Narrative Cinema.' In:L. Braudy and M. Cohen (eds) Film Theory and Criticism: Introductory Readings. New York: Oxford University Press, 833-844.

Murphy, Julien. 1995. 'Beauvoir and the Algerian war.' In: M. Simons (ed.) Feminist Interpretations of Simone de Beauvoir. University Park: Pennsylvania State University Press, 263-279.

Musawāh. 2010. http://www.musawah.org/ (last accessed, 21 September 2016).

Nader, Laura. 1969. 'Up the Anthropologist: Perspectives Gained from "Studying Up".' In: D. Hymes (ed.) Reinventing Anthropology. New York: Random House, 284-311.

—. 2008. 'Key note address.' Fifth Annual Public Anthropology Conference: Supporting Social Movements. American University, Washington.

Nadwī, Muhammad Akram. 2007. Al-Muhaddithāt: The Women Scholars in Islam. Oxford: Interface Publications.

Negra, Diane. 2009. What a Girl Wants? Fantasizing the Reclamation of Self in Postfeminism. London: Routledge.

Netherlands Institute for Social Research. 2012a. Closer Together? The Hague: The Netherlands Institute for Social Research.

-. 2012b. Muslims in the Netherlands. The Hague: The Netherlands Institute for Social Research.

Nietzsche, Friedrich. 2007. Beyond Good and Evil:Prelude to a Philosophy of the Future. Cambridge: Cambridge University Press.

Nussbaum, Martha. 2000. Women and Human Development: The Capabilities Approach. Cambridge: Cambridge University Press.

Okin, Susan. 1999. 'Is Multiculturalism Bad for Women?' In: J. Cohen, M. Howard, and M. Nussbaum (eds) Is Multiculturalism Bad for Women? Princeton: Princeton University Press. 7-24. Oksala, Johanna. 2013. 'Feminism and Neoliberal Governmentality.' Foucault Studies, 16, 32-53. Ong, Aihwa. 2006. Neoliberalism as Exception:Mutations in Citizenship and Sovereignty. Durham, London: Duke University Press. 
Oosterling, Henk. 2015. 'Mesopolitical Interests: Rotterdam Skillcity as Rhizomatic, Ecosophical, Reflective Event.' In: R. Braidotti and R. Dolphijn (eds) This Deleuzian Century:Art, Activism, Life. Leiden: Brill, 269-298.

Ortner, Sherry. 1974. 'Is Female to Male as Nature is to Culture?' In: M. Rosaldo and L. Lamphere (eds) Woman, Culture, and Society. Stanford: Stanford University Press, 68-87.

Ouguir, Aziza. 2013. Female Religious Agents in Morocco: Old Practices and New Perspectives. PhD Thesis, University of Amsterdam.

Oyewumi, Oyeronke. 1997. African Women and Feminism: Reflecting on the Politics of Sisterhood. Trenton: Africa World.

Pagès, Iréne. 1975. 'Beauvoir's “Les Belles Images”: Desubstantification' of Reality Through a Narrative.' Forum for Modern Language Studies, 11:2, 133-141.

Paglia, Camille. 1990. Sexual Personae. New Haven: Yale University Press.

-.1992. Sex, Art, and American Culture: Essays. New York: Vintage.

—.1994. Vamps \& Tramps: New Essays. New York: Vintage.

—.1995. 'Interview with Camille Paglia.' Playboy. May. http://maxxwolf.tripod.com/paglia_interview.html (last accessed, 21 September 2016).

-. 2012. 'Critic Camille Paglia Thinks "Revenge of the Sith” Is Our Generation's Greatest Work of Art.' In:Vice. 28 November. http://www.vice.com/read/camille-paglia-believes-that-revengeof-the-sith-is-our-generations-greatest-work-of-art (last accessed, 21 September 2016).

—. 2013. 'Rebel with a Cause.' In: ParisLike. February. http://www.parislike.com/EN/ happenings/39-Paglia.html (last accessed, 21 September 2016).

Pateman, Carole. 1988. The Sexual Contract. Stanford: Stanford University Press.

Pearlman, Julia. 2010. 'Happily (For)ever After: Constructing Conservative Youth Ideology in the Twilight Series.' BA Thesis submitted to the faculty of Wesleyan University, Middletown, Connecticut.

Pektas-Weber, Ceylan. 2007. 'Dutch Muslim Women and Fundamentalism: Experiences, Results and Strategies.' In: I. Dubel and K. Vintges (eds) Women, Feminism and Fundamentalism. Amsterdam: SWP Publishers, 12-24.

Pilardi, Jo-Ann. 1993. 'The Changing Critical Fortunes of “The Second Sex."' History and Theory: Studies in the Philosophy of History, 32:1, 51-73.

Power, Nina. 2009. One Dimensional Woman. Winchester, Washington: Zero Books.

Prado, C.G. 200o. Starting with Foucault: An Introduction to Genealogy. Boulder: Westview Press.

Prilleltensky, Isaac and Lev Gonick. 1996. 'Polities Change, Oppression Remains: On the Psychology and Politics of Oppression.' Political Psychology, 17:1, 127-148.

Ramabai, Pandita. 1888. The High-caste Hindu Woman. Philadelphia: Press of the J.B. Rodgers. Ramadan, Tariq. 2012. Islam and the Arab Awakening. New York: Oxford University Press.

Reynolds, Katherine and John Turner. 2010. 'The Story of Social Identity.' In: T. Postmes and N. Branscombe (eds) Rediscovering Social Identity: Key Readings. New York: Psychology Press, 13-32. Rhouni, Raja. 2010. Secular and Islamic Feminist Critiques in the Work ofFatima Mernissi. Leiden: Brill. Ringrose, Jessica. 2011. 'Are You Sexy, Flirty, Or A Slut? Exploring “Sexualization” and How Teen Girls Perform/Negotiate Digital Sexual Identity on Social Networking Sites.' In: R. Gill and C. Scharff (eds) New Femininities: Postfeminism, Neoliberalism and Subjectivity. London: Palgrave Macmillan, 99-116.

Rodgers, Catherine. 1995. 'Elisabeth Badinter and “The Second Sex”: An Interview.' Signs, 21:1, 147-162. Roggeband, Conny. 2010. 'The Victim-Agent Dilemma: How Migrant Women's Organizations in the Netherlands deal with a Contradictory Policy Frame.' Signs, 35:4, 943-967. 
Rose, Nikolas. 1990. Governing the Soul: The Shaping of the Private Self. London: Routledge.

Rose, Nikolas, Pat O'Malley and Mariana Valverde. 2006. 'Governmentality.' Annual Review of Law and Social Science, 2, 83-104.

Rössler, Beate. 2002. 'Problems with Autonomy.' Hypatia, 17:4, 143-162.

- 2013. 'Kantian Autonomy and its Social Preconditions: On Axel Honneth's Das Recht der Freiheit.' Krisis: Tijdschrift voor Actuele Filosofie, 1, 14-18.

Rottenberg, Catherine. 2013. 'The Rise of Neoliberal Feminism.' Cultural Studies, 28:3, 418-437. Rubin, Gayle. 1975. 'The Traffic in Women: Notes on the "Political Economy" of Sex.' In: R. Rayna (ed.) Toward an Anthropology of Women. London, New York: Monthly Review Press, 157-210.

Sadiqi, Fatima. 2006. 'Morocco's Veiled Feminists.' Project Syndicate. 25 May. http://www.projectsyndicate.org/commentary/morocco-s-veiled-feminists (last accessed, 21 September 2016).

-. 2012. Femmes et Médias dans la Région Méditerranéenne. Fez: Imprimerie Imagerie Pub Neon.

—.2013. Interview. In:N. Andreu and K.Vintges. Women and Islam:New Perspectives. Documentary.

—. 2014. Moroccan Feminist Discourses. New York: Palgrave Macmillan.

—. 2016. 'Centrality of Women's Movements in the Post-Revolution Dynamics in North Africa.' In: F. Sadiqi (ed.) Women's Movements in Post-“Arab Spring” North Africa. London: Palgrave Macmillan, 1-11.

Saharso, Sawitri. 2000. 'Female Autonomy and Cultural Imperative: Two Hearts Beating Together.' In: W. Kymlicka and W. Norman (eds) Citizenship in Diverse Societies. Oxford: Oxford University Press, 224-242.

Salime, Zakia. 2005. Between Islam and Feminism: New Political Transformations and Movements in Morocco. PhD Thesis, University of Illinois, Urbana-Champaign.

Salzman, Philip Carl. 1999. 'Is Inequality Universal?' Current Anthropology, 40:1, 31-61.

Sanday, Peggy Reeves and Ruth Goodenough (eds). 1990. Beyond The Second Sex: New Directions in the Anthropology of Gender. Philadelphia: Philadelphia University Press.

Sanday, Peggy Reeves. 1990. 'Introduction.' In: P. Sanday and R. Goodenough (eds) Beyond The Second Sex: New Directions in the Anthropology of Gender. Philadelphia: Philadelphia University Press, 1-21.

Sandberg, Sheryl. 2013. Lean In: Women, Work, and the Will to Lead. New York: Albert Knopf.

Sartre, Jean-Paul. 1995. Anti-Semite and Jew. New York: Schocken.

—. 2001 [1943]. Being and Nothingness: An Essay in Phenomenological Ontology. New York: Citadel Press.

Sawicki, Jana. 1991. Disciplining Foucault: Feminism, Power, and the Body. New York: Routledge. Schimmel, Annemarie. 1975. Mystical Dimensions of Islam. Chapel Hill: University of North Carolina Press.

Schinkel, Willem and Friso van Houdt. 2010. 'The Double Helix of Cultural Assimilationism and Neo-liberalism: Citizenship in Contemporary Governmentality.' The British Journal of Sociology, 61:4, 696-715.

Schlegel, Alice. 1977. 'Male and Female in Hopi Thought and Action.' In: A. Schlegel (ed.) Sexual Stratification. New York: Columbia University Press, 245-269.

Schwartzman, Lisa. 2006. Challenging Liberalism: Feminism as Political Critique. University Park: Pennsylvania State University Press.

Schwarzer, Alice. 1984. After "The Second Sex": Conversations with Simone de Beauvoir. New York: Pantheon Books.

Sciolino, Elaine. 1998. 'Lifting the Veil.' The New York Times. 22 March. http://www.nytimes.com/ books/98/o3/22/reviews/980322.22scolint.html (last accessed, 21 September 2016).

Scott, Joan. 2007. The Politics of the Veil. Princeton: Princeton University Press. 
Showalter, Elaine. 2001. Inventing Herself: Claiming a Feminist Intellectual Heritage. London: Picador. Simons, Margaret. 1999. Beauvoir and the Second Sex: Feminism, Race, and the Origins of Existentialism. Lanham: Rowman \& Littlefield.

- 2002. 'Beauvoir and the Problem of Racism.' In: J. Ward and T. Lott (eds) Philosophers on Race: Critical Essays. Oxford: Blackwell Publishers, 260-284.

Slaughter, Anne-Marie. 2012. 'Why Women Still Can't Have It All.' The Atlantic. July/August.

Slocum, Sally. 1975. 'Woman the Gatherer: Male Bias in Anthropology.' In: R. Rayna (ed.) Toward an Anthropology of Women. London, New York: Monthly Review Press, 36-5o.

Smith, Margareth. 1984 [1928]. Rabi'a the Mystic and her Fellow-Saints in Islam. Cambridge: Cambridge University Press.

Spelman, Elizabeth. 1988. Inessential Woman: Problems of Exclusion in Feminist Thought. London: Beacon Press.

Spivak, Gayatri Chakravorty. 1988. 'Can the Subaltern Speak?' In: C. Nelson and L. Grossberg (eds) Marxism and the Interpretation of Culture, Urbana: University of Illinois Press, 271-313.

Statistics Netherlands. 2008. Annual Report on Integration. The Hague, the Netherlands: CBS.

-. 2013. Annual Report on Integration. The Hague, the Netherlands: CBS.

Stevens, Christa. 2012. 'Werewere Liking.' In: C. Ceton, A. Halsema, I. van der Burg, K. Vintges, and V. Vasterling (eds) Vrouwelijke filosofen: een historisch overzicht. Amsterdam: Atlas, 486-492.

Stuurman, Siep. 2004a. 'How to Write a History of Equality?' Leidschrift. 19:3, 40-62.

- 2004b 'The Voice of Thersites: Reflections on the Origins of the Idea of Equality.' Journal of the History of Ideas, 65:2, 171-189.

- Forthcoming. The Invention of Humanity: Equality and Cultural Difference in World History. Cambridge: Harvard University Press.

Tatsuo, Inoue. 1999. 'Liberal Democracy and Asian Orientalism.' In: J. Bauer and D. Bell (eds) The East Asian Challenge for Human Rights. Cambridge: Cambridge University Press.

Taylor, Charles. 1989. Sources of the Self: The Making of the Modern Identity. Cambridge: Harvard University Press.

- 1994. 'The Politics of Recognition.' In: A. Gutmann (ed.). Multiculturalism: Examining the Politics of Recognition. Princeton: Princeton University Press, 25-73.

Taylor, Dianna. 2004. 'Foucault's Ethos: (Guide)post for Change.' In: D. Taylor and K. Vintges (eds) Feminism and the Final Foucault. Urbana: University of Illinois Press, 258-274.

Taylor, Dianna and Karen Vintges (eds). 2004. Feminism and the Final Foucault. Urbana: University of Illinois Press.

Thompson, Kevin. 2003. 'Forms of Resistance: Foucault on Tactical Reversal and Self-Formation.' Continental Philosophy Review, 36:2, 113-138.

Tidd, Ursula. 2004. Simone de Beauvoir. Routledge Critical Thinkers. New York, London: Routledge.

Tiqqun. 2010. Raw Materials for a Theory of the Young-Girl. Los Angeles: Semiotext(e).

Tully, James. 2009. 'The Crisis of Global Citizenship.' Radical Politics Today. July http://research. ncl.ac.uk/spaceofdemocracy/word\%2odocs\%2olinked\%2oto/Uploaded\%202009/Tully/ The_Crisis_of_Global_Citizenship_James_Tully.pdf (last accessed, 21 September 2016).

Van Baar, Huub. 2011. The European Roma: Minority Representation, Memory, and the Limits of Transnational Governmentality. Amsterdam: University of Amsterdam.

Van Beek, Mariëtte. 2002, 'Images of Lâlla cAwîsh, a Holy Woman from Marrakech.' In: M. Marín and R. Deguilhem (eds) Writing the Feminine. Women in Arab Sources. London: Tauris, 199-219.

Van Heelsum, Anja. 2008. 'Case Study on Diversity in Amsterdam, the Netherlands.' Dublin: Eurofound. 
Van Leeuwen, Bart and Karen Vintges. 2010. 'A Dream Dreamed by Reason... Hollow like All Dreams": French Existentialism and its Critique of Abstract Liberalism.' Hypatia, 25:3, 653-674.

Van Oers, Ricky. 2013. Deserving Citizenship: Citizenship Tests in Germany, the Netherlands and the United Kingdom. Leiden: Brill.

Van Oosten, Annemarie. 2015. Putting Things in Perspective. Young People's Susceptibility to the Effects of Sexual Media Content. PhD Thesis, University of Amsterdam.

Van Reybrouck, David. 2014. Congo: The Epic History of a People. Amsterdam: Harper Collins.

Van der Haak, Bregtje. 2008. Satellite Queens. Documentary.

Van der Valk, Ineke 2012. Islamophobia in the Netherlands. Amsterdam: Pallas Publications Amsterdam University Press.

Vargas Llosa, Mario. 1996. 'Simone de Beauvoir: Les Belles Images.' In: M. Vargas Llosa, Making Waves. New York: Farrar, Straus, and Giroux, 55-58.

Vasterling, Veronica. 2013. [Pseudo]Scientific Gender Claims, Embedded Embodied Cognition \& Feminist Phenomenology. Paper presented at The Future Directions in Feminist Phenomenology Conference, 24 May, Ontario.

Veyne, Paul. 1993. 'The Final Foucault and his Ethics.' Critical Inquiry, 20:1, 1-9.

Vintges, Karen. 1996. Philosophy as Passion: The Thinking of Simone de Beauvoir. Bloomington: Indiana University Press [or. 1992. Filosofie als Passie: het denken van Simone de Beauvoir. Amsterdam: Prometheus.]

—. 1998. 'Beauvoir's Philosophy as the Hidden Paradigm of Contemporary Feminism.' In: T. Akkerman and S. Stuurman (eds) Feminist Thought in European History: From the Middle Ages to the Present. London, New York: Routledge, 203-217.

-. 2001. "Must We Burn Foucault?" Ethics as Art of Living: Simone de Beauvoir and Michel Foucault.' Continental Philosophy Review, 34: 2, 165-181.

-.2004a. 'Endorsing Practices of Freedom. Feminism in a Global Perspective.' In: D. Taylor and K. Vintges (eds) Feminism and The Final Foucault. Urbana, Chicago: University of Illinois Press, 275-299.

-. 2004b. 'Beauvoir's Autobiography: "Auto-fiction" or Selftechnique?' In: Y. Raynova and S. Moser (eds) Simone de Beauvoir: 5oJahre nach dem 'Anderen Geschlecht'. Frankfurt am Main: Peter Lang GmbH, 203-211.

-. 2005. 'Some Hypes and Some Hope: Women and Islam in the Western Media.' Concilium: Islam and Enlightenment, 5, 41-48.

- 2007. 'The Life of Rabia al Adawiyya: Reflections on Feminism and Fundamentalism.' In: I. Dubel and K. Vintges (eds) Women, Feminism and Fundamentalism. Amsterdam: SWP Publishers, 53-60.

-. 2011. 'Freedom and Spirituality.' In: D. Taylor (ed.) Michel Foucault: Key Concepts. Durham: Acumen Press, 99-110.

-. 2012. 'Muslim Women in the Western Media: Foucault, Agency, Governmentality and Ethics.' European Journal of Women Studies, 19: 3, 283-298.

—. 2013. 'Erotic Capital?' Krisis: Tijdschrift voor Actuele Filosofie, 1, 131-134.

- . 2016. 'Women and Islam in the Western Media.' In: M. Ennaji (ed.) New Horizons of Muslim Diaspora in North America and Europe. New York: Palgrave Macmillan, 153-162.

—. Forthcoming. 'Misunderstanding in Paris.' In: N. Bauer and L. Hengehold (eds) The Blackwell Companion to Simone de Beauvoir. Hoboken: Wiley-Blackwell Publishers.

Wadud, Amina. 1999. Qur'an and Woman: Rereading the Sacred Text from a Woman's Perspective. New York: Oxford University Press.

-. 2006. Inside the Gender Jihad: Women's Reform in Islam. Oxford: Oneworld. 
Walters, William. 2012. Governmentality: Critical Encounters. London: Routledge.

Weber, Max. 1968 [1921]. Economy and Society. New York: Bedminster Press.

Westlund, Andrea. 2009. 'Rethinking Relational Autonomy.' Hypatia, 24:4, 26-49.

White, Stephen. 2000. Sustaining Affirmation: The Strengths of Weak Ontology in Political Theory.

Princeton: Princeton University Press.

Whyte, William. 1956. The Organization Man. New York: Simon and Schuster.

Wiedemann, Charlotte. 2014. The Last Gasp of Archaic Masculinity? 26 September, https://en.qantara.de/content/contrasting-images-of-islam-the-last-gasp-of-archaicmasculinity (last accessed, 21 September 2016).

Wilkinson, Maryn. 2014. 'The Makeover and the Malleable Body in 1980s American Teen Film.' International Journal of Cultural Studies, 18:3, 385-391.

Yafout, Merieme. 2013. Interview. In: N. Andreu and K. Vintges. Women and Islam: New Perspectives. Documentary.

—. 2015. 'Islamist Women and the Arab Spring: Discourse, Projects, and Conceptions.' Comparative Studies of South Asia, Africa and the Middle East. 35:3, 588-604.

Young, Brigitte. 2000. 'Disciplinary Neoliberalism in the European Union and Gender Politics.' New Political Economy, 5:1, 77-98.

Young, Iris Marion. 1990.Justice and the Politics of Difference. Princeton: Princeton University Press. Young, Robert. 2006. 'Sartre: The African Philosopher.' In: Jean-Paul Sartre. Colonialism and Neocolonialism. London, New York: Routledge, ix-xxviii.

Zabrodska, Katerina, Sheridan Linnell, Cath Laws, and Bronwyn Davies. 2011. 'Bullying as Intra-Active Process in Neoliberal Universities.' Qualitative Inquiry, 17:8, 709-719.

Zamora, D. and M. Behrent (eds) 2016. Foucault and Neoliberalism. Cambridge: Polity Press.

Zein Ed-Din, Nazirah. 1982. 'Removing the Veil and Veiling.' Women's Studies International Forum, 5:2, 221-226.

Zerelli, Linda. 2005. Feminism and the Abyss of Freedom. Chicago: University of Chicago Press. 


\section{Index}

Abbeysbooks 136, 147, 150-152

Abstract humanism 27, 49

Abstract morality 24, 28, 168

Abu-Lughod, Lila 59, 63

Academic philosophy 50, 69-70

Activation techniques 37, 116

Adawiyya, Rabia al 98, 102

Advertisements 85, 130

Aesthetics of existence 40, 48

African scholars 77

Agency 31, 36, 40, 46-47, 59, 63-64, 78, 95, 122, $134-135,138,145^{-14} 6,15^{0}, 15^{2-154}, 163,167$

Ahmed, Leila 78, 97, 99-100, 102-103, 109, 112, 121,174

Akersloot-Berg, Betzy 10, 78-79

Alcibiades 88

Algeria 85, 100-101, 123, 169-171

Al-Ghazali, Zaynab 97, 109

Al-Hibri, Azizah 107

Al Nisa -Dutch Muslim women's organization 124-125

Altman, Meryl 26

Ambiguity 15-16, 24-29, 48-50, 67, 71-72, 75-76

American mythology 148

Amin, Quasim 103

Amnesty International 85

Amrane, Djamila 170

Anderson, Benedict 88

Andreu, Nuria 126-127

Androcentric 71, 76, 102, 113

Antigone 82

Anthropological, anthropologist 62, 76, 8o, 148

Anti-fan 154-155

Antiquity, Western 38, 40, 45, 53

Appadurai, Arjun 147

Arab feminism 103

Arab spring 95

Arab world 17, 100, 103, 105

Arendt, Hannah 89

Argumentative discourses 167

Art 16, 20, 28-29, 42, 44-46, 48-49, 68-70, 86-89, $92,94,118,129,136,138,142,166-167,172$

Art of living, art of life 29, 44-46, 48, 68, 88-89

Ascesis, ascetic exercises 40-41, 43, 49, 53, 66, 94, 97, 100

Ascribed identities 89

Atomistic conception of the self 61,133

Authenticity 17

Autonomy 16-17, 27, 36, 43, 59-61, 63, 66-67, 71, $82,96,134,166$

Autonomous individuals 35

Baar, Huub van 9, 18, 37, 117

Badinter, Elisabeth 96,123

Badiou, Alain 137
Badran, Margot 107, 112

Bakare-Yusuf, Bibi 77-78

Ballah, Fatima 9, 119

Bardot, Brigitte 140-141, 145

Barlas, Asma 9, 103, 106-107, 109, 112-114, 121

Bartky, Sandra 78, 133-134

Bascom, William 148

Bauer, Nancy 9, 73, 76, 91, 134

Beauty 49, 132, 134, 136, 139-140, 148, 161-162

Beauvoir, Simone de 11-12, 15-19, 21-29, 47-51, 56-57, 67-68, 71-78, 80-83, 85-87, 91, 123,

$129-134,138-146,15^{0-155}, 159^{-160}, 163,165^{-173}$

Becker, Gary 33

Beguine movement 93

Behavioral techniques 172

Benschop, Yvonne 12

Bentham, Jeremy 31

Berber 101, 112

Bilgrami, Akeel 50

Bi-local residence 80

Bingen, Hildegard von 92

Biological, biology 30, 72, 74, 81, 86, 99, 139, 142

Biopolitics 32-33

Bios 45

Bloem, Jeannette 10, 53

Borren, Marieke 89

Boupacha, Djamila 123, 170-171

Bracke, Sarah 64, 115

Braidotti, Rosi 88, 167

Brink, Marieke van den 12

Brown, Wendy 46

Buddhism 77

Buitelaar, Marjo 9, 16, 122

Bureaucracy, Bureaucratization 22-23, 111, 120

Butler, Judith $63,82,90$

Capitalism 35, 173

Caputi, Mary 170

Care of the self $39-44,47,5^{2}, 65,88$

Career 21, 23-24, 132, 136, 154-155

Caring for others 41,47

Care work 14, 172

Caste system 93

Castration complex 82

Catholicism 92

Celebrities 126, 129, 146

Ceton, Carolien 52

Chakravarti, Uma 33, 94

Chicago School of Economics 33

Chinese culture 67

Christianity 43, 52, 66-67, 93-94, 97, 144

Christian woman 54

Cinderella 100, 140

Circe 140

Citizenship tests 120 
Class $61,77,90,118,148,170$

class struggle 77

Code-oriented moralities 39, 66

Coercion 36, 38, 47, 88-89, 138

Colonialism 13, 56, 77, 169

Communitarian, communitarianism 38, 50, 166

Community, communities 41-42, 44, 49-51, $53-54,65,68,92-94,110,115,159,160,173$

Competitive femininity 133

Complementarity 80

Compulsory sexual agency $135,146,15^{2}, 167$

Conduct of conduct 32, 34-36, 38, 137

Confucianism 67

Conservatism 88, 132

Constellation 13,167 power constellations 46

Consumerism 132

Contraceptives 75,144

Conversion (ethical) 25-27, 75

Core characteristics of freedom practices 90

Cooper, Anna Julia 56

Cooperative citizenship 173

Cosmetic surgery 44, 137, 149, 161-162

Courtly love $15^{1-152}$

Crenshaw, Kimberlé 90

Critical 9, 13, 15-18, 29, 41-42, 44-49, 51-52, 57-61, $67-68,70-71,78,87,89-92,94-95,112-113,121$, 130, 146, 161, 163, 166-168, 170, 174

Cross-cultural strategies $16,123,125,168,171$

Cross-cultural concept 16, 67, 70, 76, 90

Culturalization of citizenship 120

Cyber stalking 85

Cynics 45

Daraba 106

Davidson, Arnold 41, 43, 51

Davis, Kathy 161

Decolonizing feminism 13

Dean, Mitchell 35, 172-173

Deleuze, Gilles 88

Descartes 50, 54

Dieting 43-44, 133, 149, 161-162

Disciplining techniques $30-31,33,161$

Docile body 31, 46

Domination 41, 45, 47-49, 51, 9o, 100, 143, 168

Dream-narratives 166

Duits, Linda 145-46, 163

Eddouada, Souad 9, 169

Education 11, 14, 23, 31, 34, 56, 70, 75, 100-101, 103, $111,115-120,132,144,173$

Egalitarian effects 99, 126

Egypt 95, 100, 103, 107

Egyptian piety movement $63-64$

Empire 28, 59

Endemic feminism 102-103, 107, 112

Engaged freedom 25,72

Enlightenment, Western 45

Ennaji, Moha 9, 16, 122, 165, 169
Entrepreneurial self $34,51,117,137,165,172-173$

Equality 12, 14, 56, 60, 80-83, 97, 99, 102, 107-108, $113-114,125,165,169,172$ equality effects 99

Equity 102

Erotic capital 136-138, 144-145, 153

Ethical self 16, 21, 26, 29, 50-52, 67-68, 70-71, 9o, 166

Ethical self-creation 41, 49, 51, 54, 67

Ethical self-formation, ethical techniques of the self $39-41,43,46,48,54,56,62-64,66-67$, $97,112,120-121$

Ethics-oriented moralities 40

Ethico-political attitude 41

Ethnicity 61, 91

Ethos 40-42, 45, 47-48, 92

Euripides 45

European thought 17

Existentialist, existentialism 24, 49-50, 56, 72, $82,148,168$

Existential ethical perspective 49-5o, 72, 168

Exogamy 138

Expert knowledge 34-35

Fairy tales 69,148

Family Law 103, 169

Fan fiction 147

Fanon, Frantz 77, 171

Female gaze 152

Female sexual agent 131, 134, 138, 144-146, 154, 160,163

Feminism, colonial 174

Feminism, contested concept 13

Feminism in a new key 17, 92, 167-168, 173-174

Feminism, second wave 61,87

Feminism, transnational 170

Feminist freedom practices 89-92, 109, 160-161

Ferguson, Kathy 56

Film industry 160,167

FKA Twigs 161-162

FLN 169-170

Forms of life 28, 89

Foucault, Michel 10, 15-19, 29-52, 57, 63, 65-67, $70,78,88-89,92,97,135,137,153,162,165$, 172-173

Foundationalism 113, 131

Fraser, Nancy 83

Freedom practices 9o, 123, 129, 131, 146, 160-163, 166-168, 171, 173-174

Freud, Sigmund 81-82, 149

Friedman, Milton 33

Friendship 24, 26-27, 53, 75-76, 89, 118, 139, 148

Galster, Ingrid 81

Gaming industry 167

Game of Thrones 160

Gay movement 44, 46, 89

Gender 12-14, 16, 52, 54, 56, 60-61, 64, 77, 80-81, $83-84,90-92,94-98,100,102-104,106-107$, 
$109,111,113,129-130,132-134,144,147-148,150$, $15^{2}, 160-161,165,167-168,170,172$

Gender codes 130

Genealogical research 18

Giere, Ronald 19-20

Gill, Rosalind 17, 35, 85, 131, 133-134, 136, 138 , $145-146,163$

Gines, Kathryn 56, 74, 77

Goffman, Erving 130

Gogh, Vincent van 78

Goldman, Emma 56-57

Göle, Nilüfer 110

Gordon, Colin 39, 77

Governmentality 31-32, 35-38, 112, 117, 132-133, 165,172

Governmentality studies, governmentality school 22, 35-36, 39, 46, 111, 134

Governmentalization of the state 32

Grand theory 18-19, 77

Grassroots movements 62-63, 115, 173

Greek ethics 17, 42, 44, 52

Group membership 42, 88

Gros, Frédéric 38-39, 41-42, 44

Growth of capabilities 43,173

Guerroudj-Netter, Jacqueline 170

Haak, Bregtje van der 125

Hadot, Pierre 41-42, 50, 52, 64-65, 68, 92

Hagiography 100-101

Hakim, Catherine 136-137

Halimi, Gisèle 170

Hardwicke, Catherine $15^{2}$

Haslanger, Sally 91

Hassan, Riffat 107

Havis, Devonya 50, 68-69

Hayek, Friedrich von 33

Headscarf 96, 109, 120-123, 145

Health care system 117,119

Hegel 26-28, 48-50, 71-73, 76-78, 139, 168

Heidegger, Martin 50, 91

Hermeneutics 39, 42, 104, 113-114

Hetaera 53, 140

Heyes, Cressida 43-44, 88, 161-162, 173

Hierarchy between the sexes $86,98,139,165^{-166}$

Hinduism 93

Historical materialism 72

Hollywood 129-130, 140, 146, 153, 155-156, 160

Hollywood films 17, 140-141, 146, 149, 152-153

Hollywood hypes 130, 146, 166

Homo oeconomicus 33-34, 137

Homo politicus 46

Homosexuality 120

Honig, Bonnie 66

Hook-up culture 134

Houdt, Friso van 116-117, 120

Human capital 34, 137

Human sciences 30

Husserl, Edmund 50, 72

Hidayatullah, Aysha 113-114
Hobbes, Thomas 61, 144

Hybrid assemblages, hybrid entanglement 37

Hydra 13, 16-17, 86, 91, 129, 133, 165-168

Hypatia 53

Hypomnemata 41, 44, 57

Identity 39, 68, 77, 88-9o, 93-94, 111, 122, 136, 155,171

Identity politics $87-89,92$

ijtihād 113

Imperialism 17

Incest taboo 138

Informal care 84

Interdependent, interdependence 26, 67, 72

Intersectional, intersectionality 19, 56, 90, 122

Iran, Iranian Revolution 65-66, 107, 114, 121, 123, 125,171

Islam 9-10, 13, 16, 62-64, 66-67, 78, 92, 95-98, $100-115,117,121-122,125-126,165-166,168$

Islamic feminism 103, 107-112, 114, 125 International Congress on 125

Islamic history 78, 92, 96-97

Islamic State 95, 121

Islamic Women's Manifesto 125

Islamism 103

Islamophobia 115

Jansen, Willy 81, 122

Jansen, Yolande 96, 100

Jasmine revolution 95

Jew $77,168,170$

Jihadist movements 85,167

Kahlo, Frida 78

Kalam Nawaem 125

Kant, Kantian 27-28, 45, 6o-62, 67, 71, 96

Keys 16-17, 52, 70-71, 90, 92, 94, 129, 131, 161, 167-168

Kinship 80, 82

Kojève, Alexandre 77

Kruks, Sonia 51, 73, 88, 170

Labour 13-14, 34-35, 73, 76, 83, 85, 116, 137

Lacan, Jacques 153

Laicism 96

Langer, Monika 25, 28

Langer, Susanne 16, 69-7o, 86-87, 9o, 96-97, 129-130, 138, 146, 165-167

Lemke, Thomas 34-35, 47, 165

Leontion 53

Lévi-Strauss, Claude 80, 130, 138-139

Liberalism, liberal theory $32-33,59,62,88,96$, 117 liberalism as governmental regime $32-33$ Liberation 11, 29, 44-45, 51, 87, 103, 133, 169

Life-story 123

Liking, Werewere 50, 94

Lived experiences 74

Long, Imogen 123 
Love $26-27,75-76,82,98-99,107,111,132,141,143$,

$145^{-157}, 159-160,167$

Lugones, Maria 90, 171

Lundgren-Gothlin, Eva 71, 73, 76

Mahmood, Saba 59, 62-64, 114, 120, 122

Male dominance 11

Male gaze 141, $15^{2}$

Management of the population 32

Management techniques, micro-management $32,35,43,46$

Mann, Bonnie 150

Map making 19-20

Market shaped systems of action 34, 165

Martial arts 70

Marxist, Marxism 18, 35, 49-50, 71, 76-77, 82-83, $88,136-137$

Massoumi, Narzanin 115

Master-slave theory $72-75,77$

Materialist feminism 91

Maxims 24, 27-28, 32, 6o, 173

McLaren, Margaret 68, 71, 134

McRobbie, Angela 17, 35, 131-134, 137

McWhorter, Ladelle 71, 133

Mediascape 147

Media strategies 16, 123, 125-126, 168, 171

Mernissi, Fatima 101-102, 109

Method 11, 17, 33, 62

Microphysics of power 31-32

Migrant groups 116-117

Minimal freedom 36, 44, 46, 78

Minorities 88

Mir-Hosseini, Ziba 9, 107-109, 111-112, 125

Miller, Peter 22, 35-36, 47

Monistic approach 81-82

Moral agency 40, 63-64, 78

Moral codes, moral rules 39-40, 48, 50, 97, 150

Moral system 40, 122

Moralism 51, 100

Moroccan feminisms 16, 112

Moroccan female Sufi saints 101

Morocco 13, 95, 100-101, 107, 122, 127, 168-169

Multifactorialism 49, 54

Mulvey, Laura 146, 149, 152

Murphy, Julien 169-171

Murshidats 101

Musawāh 108, 112

Music 9, 68, 70, 85, 92, 94, 144, 151, 161

Muslim women, Muslim girls 13, 16, 19, 63-64, 94-97, 99-103, 105-107, 109, 111-115, 117, 119-127, $162,166,169,175,177,186,189$

Muslim women scholars 16, 102-103

Mysticism 76, 97

Mystics 92, 98, 100

Mythical tales 69, 86-87, 129-131, 138, 140-141, $146,148,166-167$

Mythology 13, 69, 129, 148, 151
Myths 17, 69-70, 74, 72, 86-87, 94, 129-131, 133, $135,137-147,149-151,153-155,157-163,166-167$, 172

Myth of Woman 86-87, 140-141, 144-146, 150, 155

Nader, Laura 19

Narcissism 41, 149

Nassef, Mala Hifni 103

Nationalism $56,88,175$

Nature $25-26,53,69,72-74,80,86-87,90$, $138-139,142-146,148-149,152,159,166-167$

Negra, Diane 149

Neo-Kantianism 96

Neoliberalism as exception 111

Neoliberal governmentality, neoliberalism as political regime $32-35,37,111,117,132-133,165$

Neoliberal economy 83

Neoliberal 'feminism' 133

Neoliberal models of self and society 35,44 , 51,173

Neoliberal woman 132, 134

Neuroscience 81

Nietzsche, Friedrich 50, 78, 144, 151

Nomadic life 89

Normalization 30-31, 40, 44, 88, 133, 162

Nussbaum, Martha 6o, 62

Oedipus complex $81-82$

Okin, Susan Moller 6o, 96

Oksala, Johanna 83, 133

Ong, Aihwa 37, 111-112

Ontological freedom 71

Oppression 69, 77-78, 82, 94-95, 120, 138, 168, 170

Organization Man, the man of success 21-23, 29, $33,51,132,165$

Organization Woman, the woman of success $23-24$

Ordo-liberalism, German 33

Othering 73-74, 77-78, 80, 122, 138

Other $25,29,73^{-7} 6,80,139,143,168$ absolute Other $74,77,86-87$

Ouguir, Aziza 16, 97, 99-102

Outlander 160

Overdetermination 49

Oyewumi, Oyeronke 77

Pagès, Irène 22

Paglia, Camille 17, 129-131, 136, 138, 141-146, $149-15^{0}, 15^{2}, 160,166-167$

Panopticon 31

Parrhesiastic, parrhesia 45-46, 48, 90

Pascal, Blaise 25

Pateman, Carol 84

Patchwork conception of society 37

Patriarchal power patterns $78,85,129$

Patriarchy 12-13, 16-19, 74, 82, 86, 91, 96, 102, 107, $111,125,162,165^{-166}, 168$

Patrilocal residence 80

Pearlman, Julia 148-149 
Peace movement 174

Perfect, the 132-133, 138

Personality tests 23

Philosophy as a way of life $41,50,52,64$

Philosophy in a new key 69-70, 167

Piety movement 62-64

Pilardi, Jo-Ann 71

Pious life 63

Plural feminism 15-16, 168, 171, 173

Political action 170, 173

Political Islam 103, 111

Polygamy 108, 110

Polytemporality 18

Popular culture 129-130, 163

Popular media 85, 130, 133, 144-146, 163, 166

Porete, Marguerite 93

Porno-chic fashion 145, 161, 163

Pornography 85,143

Postcolonial, postcolonialism 13, 17, 37, 50, 62, $78,88,96$

Postfeminist 131, 134-135, 145-146, 152, 163

Postmodern, postmodernism 49, 88, 131

Poststructuralism 49

Power, entanglement with knowledge 18-19

Power, dynamic relations 18,41

Power asymmetries between the sexes 11

Power, Nina 15, 137

Practices of freedom, Foucault's concept of 38 , $41,44-47,52,64-67,71,89,130$

Pregnancy 81, 142, 149-150

Presentational forms 16, 87, 130

Proletarian, Proletariat 29, 74, 168

Prostitution 12, 85

Psychoanalysis $18,30,72,81,86,153$

Public lynching 158

Qur'an's gender egalitarian message 102-108

Race $56,90,148$

Racism 56, 77, 169

Ramabai, Pandita 93-94

Ramadan, Tariq 95, 112

Rape 85, 170

Recognition $25,27,69,72-73,75-76,78,88,270$

Reconciliation 27, 49, 73, 75

Relational autonomy 61

Relationship of the self to the self 39

Relatively independent status of ancient ethics $40,43,48$

Religion 16, 20, 65, 67-69, 86, 93, 95-97, 103-104, $114-115,122,138$

Religious groups, religious communities $42,5^{2}$, $54,66,89,92$

Renaissance 52, 66

Resistance 31, 46, 56, 64, 95, 169

Responsibilization 117, 119

Rhouni, Raja 13, 113-114, 186

Rite 129

ritual exercises $64,97,121-122$
Rose, Nikolas 35-36, 47, 134

Rousseau, Jean Jacques 142

Rubin, Gayle 139

Sade, Marquis de 142-144

Sadism 143

Sadiqi, Fatima 17, 95, 112, 122, 165, 169

Sandberg, Sheryl 132

Sarkeesian, Anita 161

Sartre, Jean-Paul 24-26, 71, 73, 77, 154

Satellite Queens 125

Scott, Joan 120-121

Scharff, Christina 131, 133-134, 136, 138

Schinkel, Willem 116-117, 120

School system 117-119

Schurman, Anna Maria van 9, 53-55

Secular, secularism 59, 64, 96, 114, 130, 166, 168-169

Security 21-23, 32-33, 37, 47, 104, 118, 172-173

Second Sex, The 11-12, 15-17, 21, 28, 48, 57, 71-73, $76-78,80-82,86-87,91,134,138,140,143,151$, $165-167,172$

chapter on Myth 17, 86, 159

Self-care 47,149

Self-certainty $73,77,168$

Self-hatred 78

Self in action 88-89

Self-practices $40,43,48,66,112$

Self-techniques $35-36,38,40-44,47-49,51-52$, $54,56,63-64,67,70-71,100,121,137,173$

Sex industry 85

Sex workers 85

Sexual contract $84,132-133$

Sexual love $82,143,167$

Sexual personae 17, 129-131, 141, 146-147, 161, 166-167

Sexual violence 11, 84, 168

Sexuality $81-82,89,120,122,141,149,15^{\circ}$

Shaarawi, Huda 103

Shakman Hurd, Elisabeth 120

Sharia 111

Simons, Margaret 68, 73

Sisters in Islam 107-108, 111-112

Skinner, Quentin 144

Slavery $12,75,105$

Slaves $28,42,52-53,85,132$

Smith, Margareth 98

Social identity 77

Socio-political movements 44, 46, $5^{1}$

Social security 172-173

Socialist, socialism 23, 83, 172-173

Solipsism 41

Soul $35-36,53,65,88,104,134,139$

Sovereignty 37,173

Spelman, Elisabeth 9o, 171

Spirituality 20, 64-67, 70, 90

Spiritual exercises 41, 65

Spivak, Gayatri 19

State and market feminisms 14-15, 173 
Statism 172

Status hierarchy between the sexes 139, 166 Stevens, Christa 94

Stewart, Kristen 152-161

Strategy 44, 80, 88, 111, 155

Stromae 161

Studying upwards 18-19, 80-81, 85, 91, 163

Stuurman, Siep 99

Subjugated knowledges 19, 68

Success 11, 21-24, 34, 51, 53, 117, 119-120, 125 , $132-133,135,137,160,170-171$

Sufism 67, 97-100

Super Woman 21, 24

Taoism 92

Taylor, Charles 61, 78

Taylor, Dianna 15, 41, 71

Telos 40, 63-64, 97-98

Therapeutae 42, 65

Thompson, Kevin 36, 41, 44-46, 173

Tiqqun 132

Total theory 81, 91

all-encompassing theory 37,77

Trafficking in women and children $12,85,167$

Transition 26, 57, 138, 165

Transcendence $27-28,71^{-} 72,76$

Tristan and Isolde legend 151

Turban movement 109

Twilight fan base $147,156,160$

Twilight Saga 130, 146-152

Twilight hype 130-131, 146, 152, 16o
Universal Woman 90-91

Vargas Llosa, Mario 22

Valverde, Mariana 35

Veil 30-31, 33, 99, 102-103, 120-122, 134, 137, 141, 145

Venerators 101

Veyne, Paul 42-43

Vintges, Marga 119

Violence against women 84, 106, 108, 110

Visual forms $69,130,161,163$

Wadud, Amina 103-109, 111, 113

Walters, William 18-19, 32, 37-38

War on Terror 115

Waterbed 13,86

Weber, Max 22-23

Welfare state $47,117,172$

Wilkinson, Maryn $15^{\circ}$

Willing ourselves free $47,5^{1}$

Whyte, William 22-23, 33

Womanness 90-92, 109

Women Inc. 14

Women philosophers $52-53$

Wright, Richard 29, 68, 77

$\mathrm{Wu}$, Brianna 161

Yafout, Merieme 110, 169

Zamora, Daniel 172

Zerelli, Linda 89

Zoonen, Liesbeth van 145-146, 163 